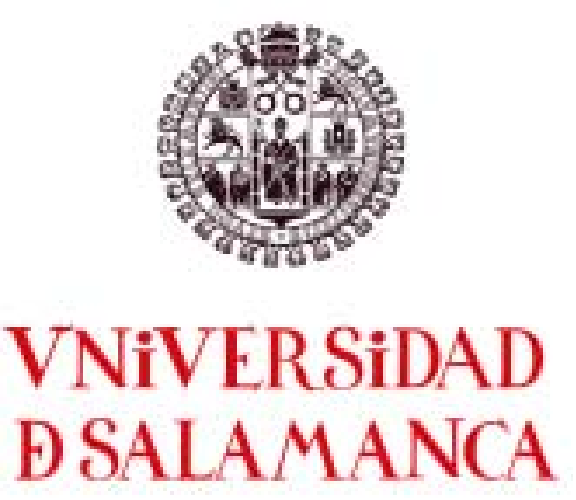

FACULTAD DE FILOSOFÍA

Departamento de Filosofía, Lógica y Estética

\title{
CAUSALIDAD Y RELEVANCIA EXPLICATIVA
}

\author{
Memoria para optar al grado de \\ Doctor en Lógica y Filosofía de la Ciencia \\ Presentada por
}

Roberto Ávila A.

Bajo la dirección del doctor

Sebastián Álvarez Toledo

Salamanca, 2016 

U no cree saber lo que busca, pero solo al final, auando lo encuentra, comprende realmente qué andaba buscando.

Y bien podría ser que lo que rige el destino del hombre no sea C risto ni Júpiter ni A lá ni M oloch sino Pachaćmac, el dios de los avanoes hacia ninguna parte, el dios de la sabiduría que llega un día después del fracaso*.

* O spina, William. E 1 país de la canela. Bogotá: Norma, 2008, p. 351. 

A Renata y D iego mis queridos amigos 



\section{Agradecimientos}

Sin el patrocinio de la Universidad Pedagógica y Tecnológica de Colombia la realización de este trabajo hubiera sido imposible y es por eso que espero seguir poniendo mi mayor esfuerzo por hacer de esta una institución más grande. También agradezco a la Universidad de Salamanca y a la misma ciudad de Salamanca que me acogieron durante los años importantes y felices de la realización del doctorado.

Q uedo en deuda, por su tiempo y por su paciencia, con el profesor Sebastián Álvarez Toledo, sin cuya ayuda indudablemente no se hubiera podido llegar a este punto. Agradezco también al profesor Carlos Arturo Londoño, por su lectura y comentarios. A ellos se deben los logros, que más que en el escrito quedaron en mi consciencia y en mi trabajo como profesor, aunque no se les pueden adjudicar los errores, que son sólo míos. 



\section{ÍNDICE}

\section{Página}

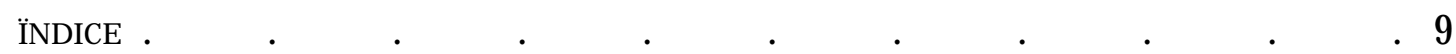

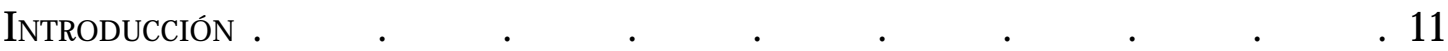

1. Nociones Preliminares sobre Causalidad y Explicación — . 17

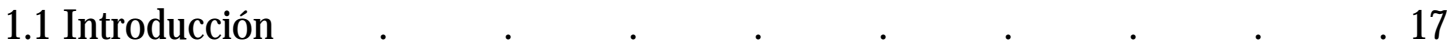

1.2 Precedentes: una lectura de las cuatro causas de A ristóteles _ . . . 19

1.3 El parcial escepticismo humeano . . . . . . . . . . . . . . 26

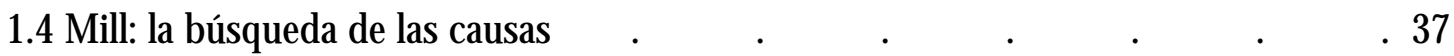

1.5 Russell: de la causa metafísica a las relaciones funcionales _ . . . . 41

1.6 D ucasse: una concepción singularista sobre causas y condiciones . . . . . 45

1.7 Suficiencia y necesidad en Mackie $\quad$. $\quad$. . . . . . . . . . 47

1.8 La teoría sobre la manipulación . . . . . . . . . . . . . 51

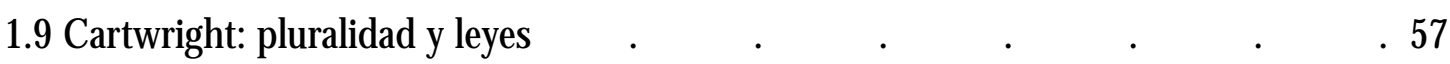

1.10 Salmon: de vuelta a la explicación causal $\quad . \quad$. . . . . . . $\quad$. 60

2. Los Variados Sentidos de la Pluralidad Causal . . . . . . 67

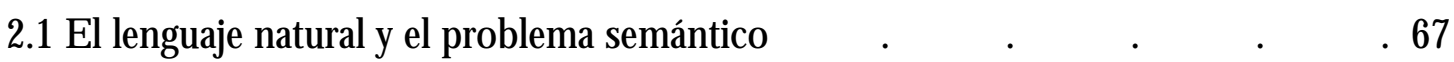

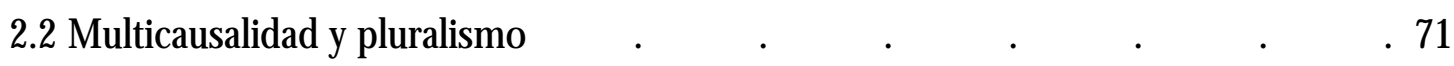

2.3 Singularismo y regularismo $\quad$. . . . . . . . . . . . . . 77

2.4 El debate entre reduccionismo y antirreduccionismo . . . . . $\quad$. 85

2.5 Monismo y pluralismo causal . . . . . . . . . . $\quad .92$

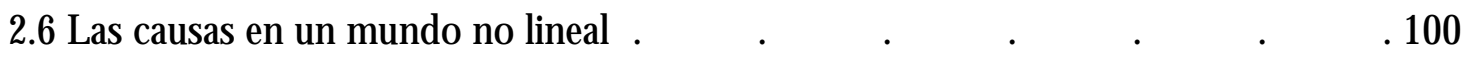

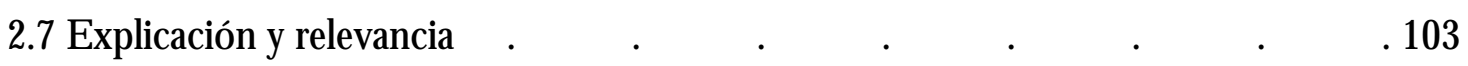




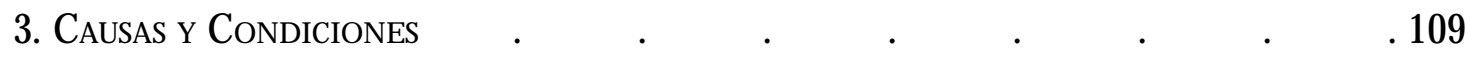

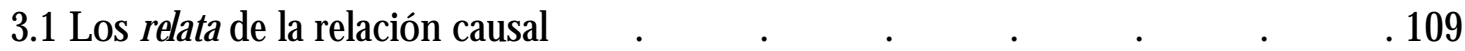

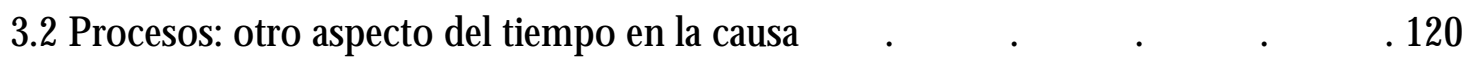

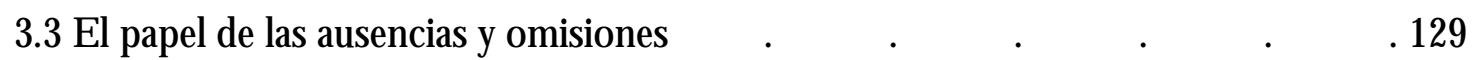

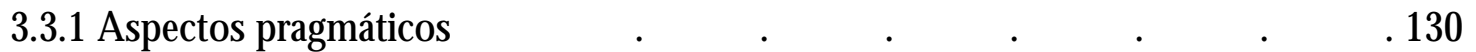

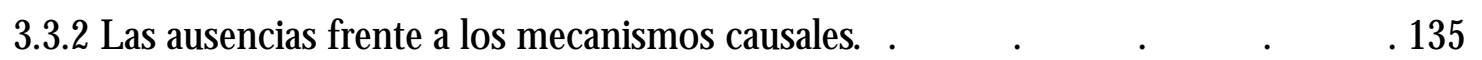

3.3.3 Ausencias y contrafácticos. $\quad$. . . . . . . . . . . . . . 141

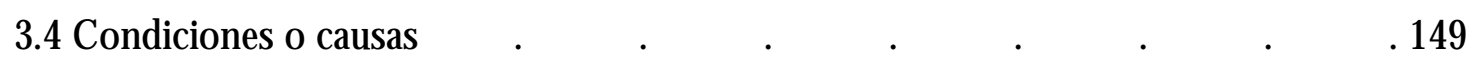

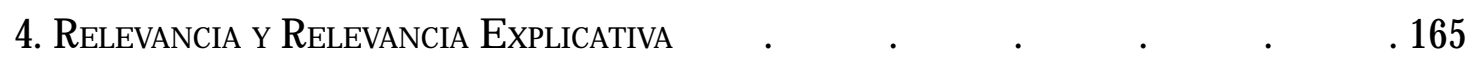

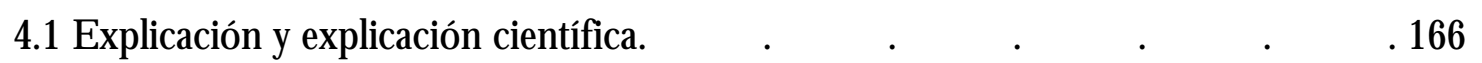

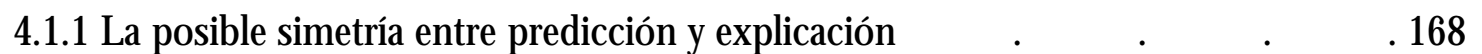

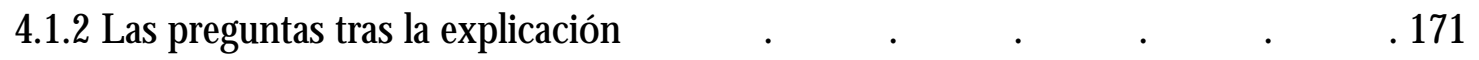

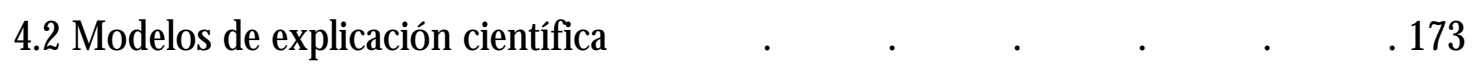

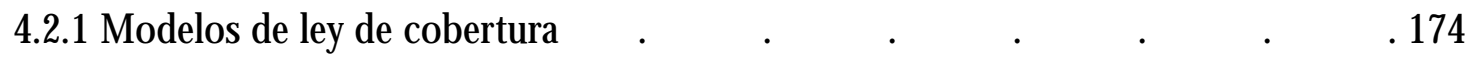

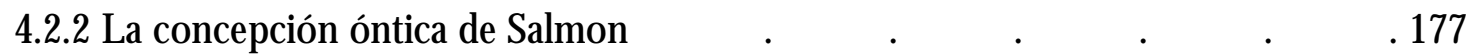

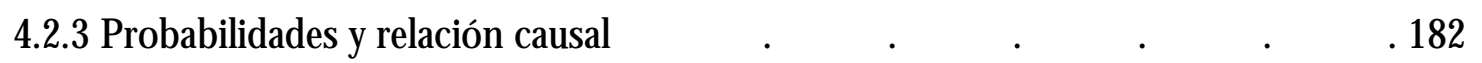

4.3 Las leyes y las relaciones causales .

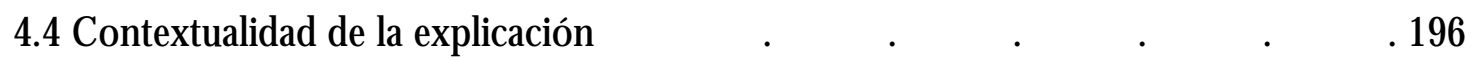

4.5 Relevancia en la historia causal y el contexto explicativo . . . . . 200

4.5.1 Los ámbitos de la explicación y de la causa $\quad . \quad$. . . . . 200

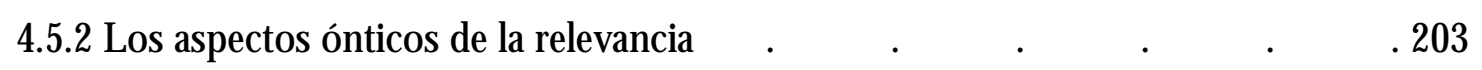

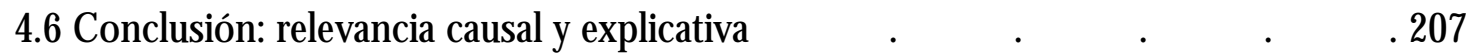

5. Conclusiones: La Pertinencia de la explicación Causal • • • . . . 215

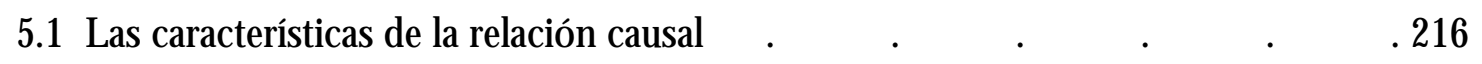

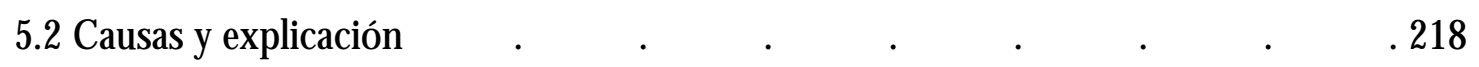

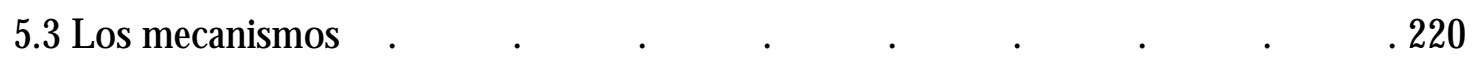

5.4 Coda $\quad . \quad$. $\quad . \quad$. . . . . . . . . . . . . 222

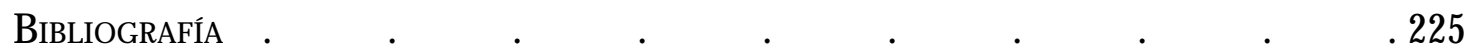




\section{INTRODUCCIÓN}

La causa es, sin duda, un elemento fundamental para comprender cómo se producen ciertas relaciones entre sucesos de la realidad: abundan los argumentos basados en relaciones causales que buscan dar cuenta de cómo y por qué ocurren muchos fenómenos. También existen estrategias de intervención en la naturaleza y tentativas de predicción que tienen esa misma base. Así que la causalidad tiene un importante papel en algunas formas de explicación, tanto en la búsqueda de evidencias sobre las razones por la que suceden algunos fenómenos concretos como en niveles más abstractos, en los que queremos encontrar los patrones que sigue el mundo en sus cambios. Sin embargo, desde algunas perspectivas científicas y filosóficas la causalidad ha sido vista con recelo por la dificultad de encontrar una definición que genere consenso y por el acento metafísico que conlleva. Este acento metafísico ha llevado a intentar excluir la noción de causa del campo de la ciencia, pero hoy se ha avanzado en la comprensión de su papel en la experimentación y en las regularidades de los acontecimientos en el mundo, motivo que alienta estudios que buscan precisar su papel en cierto tipo de relaciones entre eventos.

En alguna medida el presente trabajo fue la consecuencia inevitable de haber elaborado algunas exploraciones previas sobre el determinismo y sobre historia de la ciencia. Lo primero porque la noción de determinismo, asociada con la causalidad en la época del mecanicismo, ha ido dando paso a concepciones de la realidad que admiten que las causas operan de forma mucho menos lineal: por una parte, en la microfísica se acepta que existen fenómenos en los que interviene el azar y por la otra, la aplicación de leyes deterministas no excluye la posibilidad de secuencias de sucesos con caminos variados o poco predecibles. Y, en segundo lugar, la historia de la ciencia nos da a conocer un panorama en que los descubrimientos científicos y la experimentación revelan la importancia de la búsqueda de las causas, pese a que tal propósito pueda aparecer con frecuencia de manera tácita: la ciencia, pese a lo que se ha sostenido, tampoco prescinde por 
completo de la búsqueda de causas, aunque lo que revela su evolución ha sido un camino progresivo pero más intrincado de lo que puede imaginarse.

Tanto en un estudio inicial como en uno de mayor calado se hace necesaria la reflexión sobre los términos con los cuales se pretende trabajar. Inicialmente nos podemos guiar por el significado y uso de un término en el lenguaje común para luego acudir a las instancias en las que se da un tratamiento especializado, teniendo en cuenta que puede haber una enorme distancia entre la manera en que una noción es comúnmente intuida y lo que pueda considerarse una definición correcta para un espacio más específico. Esta es la inquietud inicial que surge al indagar por la noción de causa: que dicho término tiene muchos sentidos y se usa en contextos muy diferentes, lo que dificulta la elaboración de una definición aceptable de modo general, que abarque múltiples fenómenos compuestos por diversos factores que operan por vías diversas. Pero es evidente que el problema no se agota en la definición, de modo que es necesario indagar si esencialmente corresponde a un solo tipo de fenómeno y, dado el caso, si tiene elementos a los cuales pueda reducirse. Un breve recorrido por la bibliografía sobre el tema nos pone al corriente de que el problema ha sido abordado desde multitud de ópticas, que mantienen relaciones intrincadas con diversos problemas fundamentales. El abordaje de tal panorama es demasiado extenso, razón por la cual en el presente escrito se optó por iniciar con un recorrido por las fuentes de las concepciones principales, que pretendían sustentar las bases de la presente investigación. D e esta manera, el primer capítulo tiene el objetivo de hacer un recuento de antecedentes: las fuentes pertinentes para estructurar la concepción que subyace al presente trabajo. Se inició con los autores que se consideran los referentes clásicos, pues dieron forma a las principales ideas y preguntas que aún hoy gravitan sobre cualquier visión que pretenda resolver alguno de los aspectos que conforman la variedad de inquietudes que tenemos al respecto. Y se culminó con el autor que ha posibilitado en mayor medida la estructura del presente escrito, Wesley Salmon, por sus estudios sobre causalidad y sobre explicación científica y, fundamentalmente, porque su desarrollo de una concepción óntica de la causa y de la explicación que reivindica el papel de las historias causales como una vía adecuada para ofrecer explicaciones genuinas a partir de la diversidad de manifestaciones que ofrecen las cadenas causales de acontecimientos.

El recuento por las teorías de la causalidad aclara que las concepciones al respecto van desde la completa negación del papel de la causa en la ciencia hasta la indagación por sus relaciones con las leyes de la naturaleza y con lo que entendemos como la estructura de los cambios, pasando 
por toda la variedad de teorías que intentan delimitar qué es propiamente la causa y cómo puede operar, teorías que han desarrollado el importante trabajo de indagar acerca de la posible o de las posibles tipologías bajo las cuales se manifiesta aquello que recogemos bajo el término causa. Así que la pregunta que se intentó solucionar en el segundo capítulo es el de la posibilidad de una teoría causal única. Tal problema se relaciona con las primeras reflexiones acerca de lo que podemos llamar las características primarias de las teorías de la causalidad y de qué forma es factible la búsqueda de una teoría común frente a sus diferentes manifestaciones. El problema es determinar en qué medida estas pueden ser consideradas como producto del uso de un término insuficientemente definido o si puede considerarse como una expresión de un mundo complejo e irregular. Un aspecto importante en este sentido es el que tiene que ver con las características más evidentes de la relación causal: el hecho de que frecuentemente se presenta como un fenómeno complejo, en el que confluyen diversidad de factores, tanto en los objetos que causan y sufren la transformación como en las condiciones dentro de las que se encuentran. Y no solo eso sino que las transformaciones que ocurren lo hacen por medio de multitud de vías de influencia, de modo que son notorias las diferencias entre los mecanismos físicos, químicos, biológicos y los que producen cambios en los acontecimientos del comportamiento humano, para poner unos pocos casos. D e esta forma el problema que se va esbozando es el de si los fenómenos causales pueden ser reducidos a sus elementos o si puede existir algún hecho o idea común a la diversidad de manifestaciones de la causa.

En el tercer capítulo se desarrolla la parte más descriptiva del tipo de causalidad de la que se está hablando, por eso se examina cuáles pueden ser los relata causales, el papel del tiempo y de las omisiones y el problema de si pueden diferenciarse las condiciones de la causa. Este último punto es fundamental, en la medida en que se partió de la idea intuitiva de que hay una preponderancia de la causa eficiente sobre las causas estructurales; idea de la que se deriva que las condiciones pueden diferenciarse de las causas propiamente dichas, pero esto sería equivalente a encontrar el elemento privilegiado de la causa, o a una definición objetiva y, puesto que no se ha logrado una definición satisfactoria, se presume que tampoco haya una respuesta completa a tal problema. Así que en este aparte se indaga acerca de cómo opera la causa, su relación esencial con el cambio, entre qué tipo de entidades ocurre y cómo es posible que las ausencias tengan un papel en secuencias causales. Y en este punto nos encontramos con uno de los aspectos de la influencia causal que ha sido más difícil de solucionar en diversas teorías, pues si hablamos de que la causa es una transmisión de alguna influencia, surge el problema de cómo es posible que 
la ausencia de uno de los eslabones en la cadena de influencia causal pueda producir algún efecto. El panorama sobre esta cuestión es rico en posibilidades, pues implica el examen del conjunto de factores capaz de cambiar el curso de los acontecimientos, así como los límites de una definición de los objetos de la relación causal. Por tales razones este análisis es central en el tercer capítulo pues permitió hacer un examen detallado con el que se dio forma a una concepción singularista de la causa, al igual que posibilitó una toma de posición con respecto a la discusión sobre la posible distinción entre la eficiencia y las condiciones de trasfondo causal, y de la relación del análisis causal con el problema de la explicación.

Las intersecciones entre causa y explicación constituyen una cuestión tan amplia que su solución ha requerido y requiere de la contribución de múltiples pensadores. El aporte que se busca hacer con el presente trabajo es presentar las posibles vías que parecen más fructíferas para continuar con el desarrollo y definición de las herramientas que permitan construir el conocimiento de un mundo que es complejo, pero que a la vez muestra ventanas de orden que nos permiten vislumbrar formas de adelantar en su comprensión, lo que equivale a elaborar esquemas conceptuales más ricos y más adecuados a la búsqueda de explicaciones de una variedad más amplia de fenómenos. El papel de la causa en la ciencia se fundamenta, entre otras razones, en la necesidad de hallar explicaciones. La idea de la causa, su concepto y uso, está ligada al progreso de los esquemas conceptuales y los modelos científicos, en la medida en que crece la necesidad de encontrar mejores explicaciones que permitan predecir cómo han de suceder las cosas. Sin embargo, no puede negarse que existe una tensión entre los modelos y las descripciones detalladas de lo real: este es un problema fundamental del conocimiento, que sigue siendo un incentivo para seguir indagando por la posibilidad de tejer "redes cada vez más finas" que permitan describiry entender con mayor detalle los fenómenos. En esta vía, la indagación por las causas, es decir, el rastreo de las huellas que dejan, es un medio adecuado para la búsqueda de los mecanismos que producen los cambios. Puede verse que no es posible deslindar tajantemente entre el campo óntico y el epistémico, que se involucran en la cuestión, pero también es cierto que se debe profundizar en su delimitación: de forma paralela se indaga por las causas de las cosas y se buscan explicaciones que den cuenta de la realidad. Sin embargo, esto no implica que se pueda reducir la causa a la explicación ni lo contrario, pues no todas las explicaciones son causales y no todos los fenómenos de los cuales conocemos la causa están completamente explicados. 
D e esta manera se llega a la cuestión central planteada en este trabajo de tesis doctoral: el de la relación entre la causalidad y la relevancia explicativa. La idea que se intentó seguir es que la causalidad es esencialmente una relación que existe en los hechos, pero que está vinculada con los enunciados que hacemos sobre ellos y con su finalidad explicativa. En esta dirección se sostiene que la indagación causal es compatible con la investigación científica, así como con otros ámbitos de nuestra relación con la realidad. Esta posición permite también relacionar los aspectos ontológicos de la causación con los aspectos epistémicos, en razón a que la explicación causal ofrece un campo muy amplio para dar cuenta de múltiples formas de relación entre eventos reales.

Dado que el objetivo del trabajo no es todo el problema de la explicación sino la explicación causal, se entendió que era necesario aceptar que los eventos suelen ser complejos, de modo que se hizo el ejercicio de la búsqueda de indicios de influencia causal, fin con el cual se elabora una propuesta que sigue la de Salmon, en cuanto la explicación causal da respuesta a una amplia variedad de cambios en la naturaleza. En el cuarto capítulo se desarrolla la propuesta sobre la explicación causal y se proponen las alternativas pertinentes para la delimitación de los problemas ónticos y epistémicos al respecto. La cuestión consiste en indagar cómo la explicación permite solucionar algunos de los problemas de nuestras concepciones sobre la causa, fin para el que fue necesario comparar diferentes ideas de lo que se entiende por relevancia, para esbozar procedimientos para el manejo de situaciones en las que es usual la presencia de multitud de causas, a la vez que permite identificar que algunos de los problemas relativos al análisis causal han ofrecido arduas dificultades en su solución por el hecho de que los planos óntico y epistémico no han sido correctamente delimitados: el campo epistémico depende del óntico, pues las causas ocurren entre eventos, que son parte de la realidad, mientras que las explicaciones son muy sensibles al contexto de indagación.

Como decíamos, en el mundo lo usual no es que se presente un factor único operando para producir un único efecto, sino más bien una red intrincada de influencias con mayor o menor relevancia en la producción del efecto. Solemos representar la causa como una flecha que une $\mathrm{E}$ $\mathrm{yC}$, cuando lo usual es que nos encontremos con multitud de factores con más o menos relevancia causal, es decir factores cuya presencia va a ser más o menos determinante en la producción de un efecto, y una cosa es determinar si el factor en cuestión es relevante en los hechos y otra si es relevante para la elaboración de explicaciones, pues en ellas siempre hay un interés en absolver 
cierta pregunta previa que marca el rumbo de la indagación. Lo que parece suceder es que no hay una coincidencia plena entre lo que sea relevante a nivel causal en los hechos concretos y lo que es relevante para la explicación; y que tener en cuenta esta diferencia nos permite elaborar mejores explicaciones causales y comprender un campo más amplio de relaciones causales. En última instancia lo que se encontró fue un conjunto de herramientas para detectar indicios causales que manifiestan las posibles relaciones que ocurren entre los diversos factores que conforman los eventos implicados pero, y tal vez más importante, que permiten construir explicaciones acerca de algunas de las formas en las que suceden los cambios en las cosas.

Ahora, lo que se intentó defender en la tesis es una idea de la causalidad con ciertas características: se defiende que la causa ocurre entre eventos, que tiene pluralidad de manifestaciones, que la transitividad es restringida, y que los procesos son graduales. En esas condiciones adquiere su importancia el problema de la relevancia, pues no es usual que nos encontremos con una relación directa de causa a efecto sino con un panorama más complejo en el cual es necesario contar con el grado de influencia que puede tener cierto factor en la producción de un efecto. D e modo que el asunto de las causas seguirá sin una solución completa, pero se propone indagar por ellas por sus indicios y tratarlas desde una perspectiva más rica. 


\section{NOCIONES PRELIMINARES SOBRE CAUSALIDAD Y EXPLICACIÓN}

\subsection{Introducción}

El problema de la causalidad tiene una extensa historia en la filosofía por la amplitud de sus repercusiones ontológicas y epistémicas. Por tal razón, su estudio requiere de una delimitación muy específica de objetivos con el fin de que no sea necesaria una revisión de toda su historia, sino apenas de los aspectos que permitan fundamentar una concepción coherente destinada a estructurar respuestas sobre los aspectos pertinentes. Lo que se presentará a continuación es un recuento de las teorías y de las ideas que han sido fuente del presente trabajo, las referencias conceptuales en torno a las que girará la exposición de los capítulos posteriores, así como los vacíos que no han podido ser llenados con respecto a la compleja relación entre la búsqueda de las causas y ciertas concepciones de la explicación. Por tal razón, no se pretende hacer aquí un recorrido detallado por las especulaciones que ha hecho la filosofía al respecto ni tampoco se hará un análisis exhaustivo de los autores principales, de los cuales ya hay una extensa bibliografía crítica. Necesariamente un tema tan extenso implica dejar de lado muchos autores y aspectos de la problemática causal, pero la única vía para desarrollar una concepción propia implica una labor de selección de las ideas más compatibles dentro de una estructura de conceptos capaz de dar respuestas coherentes, un intento de rastrear los aportes teóricos sobre la causalidad que ofrezca información no solo sobre los aspectos acerca de los cuales hay puntos de acuerdo sino, lo que es seguramente más importante en un estudio de este tipo, acerca de los desacuerdos, que puedan sugerir vías de investigación futuras sobre el tema.

En esta indagación sobre el problema de la causalidad hay que remontarse brevemente al origen de los elementos principales que han sido utilizados para intentar entender sus alcances y las 
dificultades que se erigen desde las diferentes perspectivas que se han empleado en su formulación. Desde el comienzo llama de la atención que existe una gran cantidad de matices, y más aún, profundas diferencias conceptuales, entre quienes han indagado sobre el tema a lo largo de la historia. Este primer capítulo no pretende aún sugerir soluciones o compromisos teóricos sino más bien presentar los aportes que aún pueden ser fructíferos en la indagación sobre las causas y su relación con la explicación, como un medio para reconstruir el camino que nos llevará hasta la formulación de una propuesta de delimitación de los espacios propios de la indagación causal, así como de ciertas vías metodológicas para su manejo.

En el recorrido propuesto se seleccionaron los autores que proveen los elementos necesarios para entender la noción de causa, así como los clásicos que siguen siendo puntos de referencia imprescindibles del tema, entre ellos, Aristóteles y Hume, quienes, pese a la multitud de lecturas de que han sido objeto, siguen ofreciendo sugerencias importantes acerca de cómo entendemos el problema de las causas. En tiempos más recientes, los aportes del empirismo y la crítica a las herramientas inductivas del conocimiento ha llevado a la exploración del problema de la causa como la suma de factores capaces de originar un evento: la tensión entre las visiones pluralistas y singularistas ha dado lugar a una interesante discusión acerca de si hay posibilidad o no de privilegiar un factor como causal, o sobre si se puede delimitar con cierta precisión la posible necesidad o suficiencia de una característica de la realidad previa al efecto. Tales elementos de análisis señalan un cierto giro epistémico de la cuestión, que, de todas formas, no acaba con las vías de análisis ontológico. Desde otra perspectiva, la del escepticismo causal, el problema ha girado en torno a diversas posiciones, desde la posible negación de la necesidad causal hasta la misma negación del concepto como parte de los problemas pertinentes de la investigación científica, discusiones que hoy se remiten al diseño de herramientas que permitan tener una idea más fundamentada acerca de cómo ocurre en la realidad la transmisión de influencia causal, esto es, cómo es posible que una serie de factores se junte y que esa unión confluya para permitir la existencia de cambios en la realidad, propuesta fundamental para entender el papel de la explicación científica como elemento imprescindible de análisis. Tal es el recorrido que se busca hacer en el presente capítulo, como una forma de poner sobre la mesa los elementos que originan y permiten fundamentar las propuestas de los siguientes capítulos. 


\section{2 Precedentes: una lectura de las cuatro causas de Aristóteles}

Lo que se entiende por causa tiene múltiples significados, como corresponde a un mundo diverso en el que la razón busca dar cuenta del origen mediato e inmediato de los fenómenos, pues estos son de diferentes tipos y se relacionan de formas muy diversas. Por ejemplo, cuando interpretamos los actos de un congénere, nos preguntamos por las razones que lo hacen actuar de una u otra forma, es decir, por la causa de que haya hecho algún acto. De la misma forma, frente a la realidad natural nos preguntamos cuál es la causa de que cierto evento se haya presentado, en especial cuando tales eventos no eran previstos, pues una parte del conocimiento de la naturaleza es satisfecho al encontrar regularidades que permitan comprender cómo se relacionan los diversos acontecimientos. Así, las preguntas tipo ¿por qué... ? están vinculadas a la necesidad de entendery prever lo que ocurre en un mundo que es externo a nuestra mente y que se resiste en mayor 0 menor medida a su reducción a unos pocos principios comprensibles. Cuando los acontecimientos o los actos humanos se acercan más a lo habitual no suelen ser tan frecuente preguntarse por el porqué ni buscar las causas, con lo cual intuimos que, por lo menos en los usos comunes, el concepto de causa está relacionado con el de cambio (natural) y con el de acción, por una parte, y por la otra, con la capacidad de la mente de escindir una secuencia de acontecimientos entre aquellos que obran como precedentes y los que obran como efectos.

En cualquier situación, salvo las muy simples y directas, es usual que nos encontremos con que en el punto en que inicia un efecto concurren un número más o menos grande de circunstancias, de la cuales no es evidente cuál o cuáles son las responsables de la ocurrencia del fenómeno: puede ocurrir que confluyan simultáneamente y por eso no podamos diferenciar la causa; puede haber una causa aparente que oculta otra genuina, o incluso puede que existan procesos sin causa, pues obedecen a desarrollos naturales o automáticos que no precisan de injerencia externa. En diferentes textos, Aristóteles (Física, 194b-195b; también en Metafísica A.3, $\Delta .2$ y A nalíticos Segundos 94a20ss.) expone su concepción sobre la causa, encontrando cuatro sentidos en los cuales se entiende el actuar de la causa, conocidas comúnmente como material, formal, eficiente y final; en principio una muestra de que las vías por la cuales se puede establecer una relación entre causa y efecto son múltiples, aunque también se ha interpretado esta clasificación como cuatro clases de causas o cuatros formas de explicar un hecho. Así que no son solamente sentidos posibles del término; más que esto, lo que implica es que en cada evento concurren diferentes elementos que nos permiten entender las razones por las cuales ha llegado algo a su estado 
actual: un cambio es inducido en la propia naturaleza del objeto por medio de un agente que funge como factor determinante (el principio eficiente de la transformación y del movimiento) y cuya acción busca cumplir una finalidad. También implica que un mismo cambio tiene varias causas, como se aprecia en el ejemplo propuesto por el autor: una escultura es efecto tanto de su escultor como del material del que está hecha, lo cual implica que actúan como causa de forma diferente, de modo que la materia impone ciertas características y limitaciones y sobre ellas el escultor ejerce su acción. En tal situación hay una materia, la receptora pasiva de una influencia externa, un factor eficiente o fuerza motriz con capacidad de actuar; una causa formal, que le da su esencia o cualidad al objeto que recibe la influencia, y la causa final, que consiste en el cumplimiento de una finalidad o de una tendencia. Este conjunto de posibilidades puede ser interpretado como un medio de buscar las posibles explicaciones, en tanto se requiere de causas que den cuenta del porqué - pregunta que el autor identifica con la obtención de conocimiento, es decir de la razón por la que ocurre las transformaciones de la realidad.

Estamos habituados a la idea de que la causa es una acción sobre una materia (que es receptora pasiva de la acción), aceptamos un cierto énfasis del factor eficiente, que es el que desencadena el cambio, así como entendemos que intervenimos en la realidad en la búsqueda de un objetivo. La causa eficiente es el principio que transforma la materia para producir el efecto, pero actúa en conjunción con multitud de factores; hoy podríamos decir que es un cambio previo al efecto, con la capacidad de transmitir la influencia causal. Sin embargo, pese a que hablar de acción sugiera la intervención de un agente, no es necesario entenderlo como externo o consciente, pues los procesos de desarrollo vegetativo, por ejemplo, no cumplen esas condiciones: algunas plantas dan semillas porque esa es su forma de reproducirse y perpetuarse pero, para llegar a este punto, necesitan que sus flores hayan sido polinizadas y que la planta haya recibido unos componentes materiales (agua, luz, fertilizantes) y que se encuentre en un estado de madurez y en la época adecuada para que este proceso suceda.

La idea de eficiencia ha tomado ciertas características a partir de la modernidad: estas se refieren a objetos 0 a eventos mientras que Aristóteles hablaba de sustancias y de las cualidades esenciales de las cosas. Cada aition (el término que tradicionalmente se ha traducido como causa) puede ser considerado como una respuesta a un porqué, es decir, se busca una explicación, más que una causa propiamente dicha, como lo plantea Cohen (2015). Los nombres que se suelen dar a las "cuatro causas" no son de Aristóteles; se refieren a los sentidos en que puede ser aplicado el 
término: causa material es aquello de lo que viene el objeto, por ejemplo el bronce de la estatua. La causa formal, se refiere a la forma, al patrón, o más exactamente a lo que define la esencia del objeto. La causa eficiente, se identifica con la fuente de cambio o estabilidad. Y la causa final, es aquello para lo cual se hace el objeto o la acción, aquello para lo cual se cumple una finalidad. Sin embargo, se puede discutir acerca de si esta clasificación se puede entender como un catálogo de causas o una forma de decir que cada cosa tiene esas cuatro causas. El problema está en la ambigüedad del término, aunque podemos entender que corresponden con cuatro posibles preguntas sobre un objeto: de qué está hecho, qué es, que lo produce, para qué es. Con uno de los ejemplos de Aristóteles, podríamos responder: la mesa está hecha de madera, lo que tiene cuatro patas y una superficie plana es una mesa; la hace un carpintero, y su función es la que cumple tal artefacto.

En otro ejemplo se puede responder a la pregunta acerca de cuál es la explicación o la causa de que una planta produzca semillas: su necesidad de reproducirse - la causa final- , que su flores fueron fecundadas - causa eficiente- , que contó con los elementos sobre los cuales el proceso se produce - causa material- y que estaba en la fase del desarrollo en que le era posible reproducirse - causa formal- , pues en un estado inmaduro o fuera de la época determinada por su naturaleza el proceso no hubiera culminado. Todas son causas que confluyen en la producción del mismo efecto y por eso todas pueden ser alegadas como respuestas posibles a la pregunta de por qué una planta da sus semillas: porque esos elementos hacen parte de la manera en que ocurre el desarrollo natural de las plantas. En la naturaleza la causa final es interna, no es un propósito sino es estado final de desarrollo, de manera que las causas eficiente y final confluyen con la causa formal: la esencia y el fin son lo mismo y a ello se dirige el principio del movimiento (Aristóteles, Física, 198a25); de modo que, en esta perspectiva, entender qué es algo implica entender por qué es como es. La causa de ser una sustancia es la forma o esencia que es predicada de la materia, por ejemplo los ladrillos o las piedras con respecto a la casa. La materia y la forma nos proveen las herramientas para un análisis estático de las cosas, paro el cambio consiste en cómo se toma o se pierde la forma, que se expresan en la causa eficiente y en la final.

Para Aristóteles el conocimiento de la causa era equivalente a tener una explicación, vía que preserva una parte de la causa aristotélica: cada explicación necesita de las cuatro causas, que hoy podemos leer como diferentes aproximaciones al mismo suceso, o como cuatro respuestas adecuadas a preguntas que indagan por cuál puede ser la causa en dependencia de un cierto 
contexto (Clatterbaugh, 2012, p. 55), muestra de que el problema de la causa se traslapa con el de la explicación. Para Aristóteles el conocimiento se basa en la capacidad de elaborar una demostración con base en premisas verdaderas y necesarias que den cuenta del vínculo causal y que no se limiten a características accidentales, pese a que sean regulares: frente a las explicaciones que se centran en los accidentes, ofrecen una mayor seguridad aquellas que se basan en las características esenciales o en las relaciones causales, que parecen más adecuadas como vehículo en la transmisión de influencia. En el caso de los rumiantes y su pezuña hendida (el ejemplo de relación accidental que utilizaba Aristóteles) se asume que no hay un vínculo causal entre el hecho de ser rumiante y que la pezuña del animal esté hendida, relación diferente a la que puede establecerse entre la carencia de incisivos superiores con respecto a los hábitos alimenticios y fisiología del animal. La visión aristotélica es plenamente congruente con un mundo de esencias, sustancias y capacidades; más exactamente, obedece a la necesidad de entender qué relaciones operan entre las diversas entidades que forman el mundo y cómo ocurren los cambios. Las cosas se originan y se destruyen, lo cual lleva a la insatisfecha curiosidad humana a buscar los principios por los cuales tales eventos suceden.

Aristóteles acentúa el peso de la causa final pues su concepción de orden del mundo lo conduce a concluir que lo más importante de una secuencia causal es la finalidad con la que esta se produce, finalidad que no se limita, como se mencionó, a la participación deliberada de un agente que persigue un fin, sino a la idea de que en el mundo existe cierto orden, que conduce a los acontecimientos hacia un estado de armonía en el que los procesos operen con un sentido, tal como ocurre con las piedras que caen buscando su lugar natural en la superficie de la tierra. Pero aceptar que la búsqueda de una finalidad es lo que explica todo el proceso nos produciría una determinación causal inversa a las secuencias causales usuales y a la dirección del tiempo: así, la necesidad de reproducción haría posible que las plantas produzcan semillas, para lo cual necesitan que sus flores sean fecundadas y que hayan tenido las condiciones para que se desarrollen hasta el grado de madurez necesario. Visto así, parece como si la causa ocupara un tiempo posterior al que ocupan tanto sus efectos como los medios para alcanzarla, es decir, como si hubiera una determinación inversa a la dirección temporal, razón que hace sospechoso el finalismo para la ciencia moderna: esa dirección inversa a las secuencias causales y temporales impide 0, por lo menos oculta, los medios por los cuales se puede propagar la influencia causal, que son los que privilegia la ciencia moderna. 
La crítica del siglo XVII al teleologismo aristotélico obedece a que la ciencia no encuentra los mecanismos ni las evidencias directas de que la naturaleza esté orientada a fines o de que exista una tendencia natural a la armonía. La ciencia moderna enfatiza que si algo merece el estatus de causa debe ser eficiente, vía por la cual se llega al determinismo laplaciano (Norton, 2007, p.16): la concepción de que la realidad puede ser entendida como el conjunto de interacciones mecánicas reguladas por las leyes físicas o, en lenguaje causal, como la suma de los factores que producen efectos. Hay que anotar que, pese a las fundadas críticas al finalismo, no toda la ciencia se adscribe de forma exclusiva a las causas eficientes: una cierta forma de finalismo pervive en relación con procesos funcionales de los seres vivos, en los que sus secuencias de desarrollo se dirigen hacia el cumplimiento de metas, no como una determinación causal inversa al tiempo, sino como una forma de explicación más sintética de cómo las funciones seleccionan algunas de las vías posibles de influencia causal. Así, a las descripciones de los mecanismos directos de propagación de la influencia causal se suma una forma de explicación finalista que haga más comprensibles algunos fenómenos biológicos, de manera tal que una explicación más sintética consiste en entender los mecanismos de autoregulación biológica como si operaran buscando fines.

La ciencia no se ocupa de las esencias, en el sentido en que busque las definiciones últimas de los términos con los que trata, lo cual parecía ser el objetivo de la causa formal aristotélica, pero algo de esto pervive en cierta medida en la búsqueda de la posible estructura causal de los acontecimientos; esto implica tener en cuenta que las explicaciones puedan enmarcarse dentro de uniformidades generales que funcionen como principios explicativos 0 , más exactamente, como las leyes que utiliza la ciencia para dar cuenta de los comportamientos de la naturaleza. Por otra parte, la causa material puede servir para dar cuenta de procesos internos y capacidades: ya ha sido superada la idea de que la materia es completamente pasiva - como lo concebía el mecanicismo (Chaparro \& Ávila, 2005, p. 59) - , pues la concepción actual entiende que materia y energía son manifestaciones de las mismas realidades y que los procesos de transformación requieren de disposiciones y capacidades que hacen parte de las características de los cuerpos materiales. A ristóteles menciona la causa eficiente, que es externa, pero también causas internas al sistema como las materiales y formales (Álvarez, 2014, p. 140): para que una causa opere sobre cierto objeto es necesario que en él existan algunas características susceptibles de ser modificadas por la acción. Un cristal se quiebra con un golpe porque sus moléculas tienen cierta estructura periódica, un vidrio porque es un sólido amorfo con cierta inestabilidad; tales características de su estructura interna permiten entender por qué un cuerpo tiene una u otra respuesta ante el 
contacto con su entorno, lo cual implica que la estructura material provee datos indispensables en el análisis causal. Sin embargo, adjudicar las causas solamente a disposiciones internas implicaría corren el riesgo de circularidad (por ejemplo, si pretendemos explicar el hecho de que la sal se disuelva porque es soluble), riesgo del cual sólo escapamos aportando información adicional acerca de las razones por las cuales la materia implicada se transforma de la forma en que lo hace.

Vemos que Aristóteles señala algunos problemas útiles para indagar acerca de la relación entre causas y explicación. El primero, que la clasificación de las causas puede ser vista como un problema de la relevancia que una explicación pueda tener sobre otras en un determinado contexto, 0, en otras palabras, como la capacidad que tenga un enunciado para dar respuesta a cierta pregunta. Podemos entender la causa como un conjunto de posibilidades de explicación de un proceso, pero de esta forma constatamos que no existe una forma única de entender lo que sería la causa de un fenómeno, pues depende del sentido de la posible pregunta que indague por su origen. Una causa final puede tener mayor relevancia si preguntamos por el propósito del comportamiento de un agente o por algunas secuencias de eventos naturales en las que los recursos de seres vivos son puestos al servicio de una meta: de esta manera apelar a la causa final no implicaría una inversión de la secuencia causal y temporal pues es la explicación la que se remonta en el tiempo para reconstruir una historia; una explicación finalista puede ser válida como elipsis de toda la historia causal, a pesar de que en la realidad la secuencia causal siga el desarrollo del tiempo, cuyas consecuencias, en principio, son impredecibles. Así, para volver a uno de los casos mencionados, la evolución de los seres vivos no busca el logro de ciertas finalidades, sino el uso de los recursos disponibles; sin embargo, manejar este proceso como si obedeciese a una búsqueda de finalidades nos permite entenderlo. D e igual manera, si se pregunta por las vías de influencia mecánica o material que forman una secuencia causal, se encontrarán los factores que pueden ser los determinantes en este o en otro tipo de eventos, es decir, los factores desencadenantes, o la causa eficiente del suceso. Aristóteles ve la multitud de factores previos a un efecto y entiende que la causa depende del punto de vista que se elija, es decir, de la categoría de solución que estemos indagando, pues en cada una de ellas hay factores cuya relevancia es mayor para explicar un efecto.

De todas formas no hay que perder de vista que el análisis de las causas de Aristóteles conlleva las dificultades de interpretación inherentes a la distancia histórica que nos separa del autor. Por tal razón, hoy, autores (como el previamente citado Cohen) se apartan de la traducción de aition 
como causa, en la medida en que hoy asociamos este término a la noción de eficiencia. Hoccutt insiste en que debería hablarse no de causas sino de porqués (because), pues caben en el contexto de las explicaciones y demostraciones a las que se refiere Aristóteles y, en efecto, son tentativas de respuesta a preguntas que indagan acerca de por qué (W hy?) ocurren las cosas. Así, afirma:

The main argument for translating the term [aition] as 'because' is that it would make sense of much that must otherwise remain incoherent. Aristotle explicitly presents causes as answers to the question 'Why?', a question which is normally answered by saying 'Because'. If the question is ¿Why is the statue heavy'? an answer might be 'Because it is made of bronze'. This answer mentions the statue's matter. If the question is 'Why is the angle a right angle?' one answer is 'Because it is half of two right angles', an answer which invokes the form of the triangle. If the question is 'Why does a man walk?' the answer is 'Because he wants to be healthy', which refers to the purpose served, albeit in a referentially opaque way. In none of the cases is there any hint of 'productive agency' or 'necessary conditions for production' (Hocutt, 1974, p. 387).

En los textos de Aristóteles se usan ejemplos similares que apuntan hacia la explicación, pero donde es más evidente es en los Segundos A nalítioos, donde queda claro que las causas o explicaciones son usadas como término medio en la construcción de los silogismos que demuestran enunciados científicos, en los cuales también se utiliza una regla general. Indagar por explicaciones implica cierta imprecisión, pues la pregunta alude a diferentes sentidos de qué puede ser una explicación válida: en unos casos se preguntará por características materiales, por los atributos esenciales, por los factores desencadenantes o por la finalidad, aunque la explicación completa debe dar cuenta de todas las posibilidades que nos permitan entender un fenómeno. Es cierto que en ciencias como la geometría la explicación de la forma es la principal, y que subsisten los problemas relativos a la causa final, pues en ella el efecto aparece como anterior a la causa, como en el caso de pasear para obtener salud (es decir, para mejorar los procesos digestivos).

La indagación aristotélica sobre las causas nos muestra la importancia del contexto en la relación causal y en las preguntas que indagan por ella: pese a que esta división de las causas no dé las respuestas que hoy necesitamos, es importante contemplarla como una de las fuentes primeras que nos abre el camino a las complejas relaciones entre causa y explicación, pues en ella se ve la insuficiencia de una concepción unitaria sobre las causas y, de la misma manera, la insuficiencia de una explicación única sobre un fenómeno. Pese a la crítica moderna, la causa no se limita a la eficiencia, pues esto implicaría dejar de lado las condiciones materiales, el trasfondo causal, que es tan importante como aquella para entender un fenómeno; en cierta forma también la causa 
formal alude a las regularidades que serán tan necesarias para la búsqueda de un conocimiento fiable sobre un mundo que esperamos sea previsible. E igual se puede decir sobre las explicaciones: separar los elementos que intervienen en la relación causal es también una forma de elaborar las diferentes explicaciones que pueden ser aceptables para un fenómeno, dependiendo del contexto en que hagamos la indagación, pues es diferente hacer una pregunta acerca de los materiales implicados que sobre los factores que identificamos como desencadenantes. Que uno sea más determinante que otro depende de la explicación que necesitemos, algo que intentaremos desarrollar en el aparte correspondiente.

\subsection{El parcial escepticismo humeano}

Las concepciones de la modernidad, en comparación con el mundo aristotélico de las esencias, son más afines a la funcionalidad mecánica, razón por la cual la idea moderna de causalidad se dirige a la indagación por los mecanismos que rigen los acontecimientos, es decir, por el conjunto de fuerzas o influencias capaces de transformar en mayor o menor medida un objeto. En diferentes autores se hace más notoria la inclinación a dar prioridad a los datos de los sentidos, por buscar los vínculos que producen los fenómenos en sus manifestaciones, es decir, en aquello que pueda ser corroborado por la experiencia, ya que la alternativa de aceptar que la naturaleza obedezca a principios metafísicos 0 a seres sobrenaturales no es compatible con la búsqueda de explicaciones científicas ni con una visión racionalista de la filosofía. De la misma forma también se insta a considerar que la lógica da cuenta de las relaciones entre las ideas, pero no es necesariamente el camino para indagar por la verdad de los hechos.

La reflexión de Hume es producto de una época en la que se había hecho más aceptable la causalidad mecánica en la medida en que se estaba consolidado una visión del mundo más inclinada a encontrar en la naturaleza nuevas formas de orden y de transformaciones eficientes. En el mundo moderno se acepta que el punto de partida más adecuado para crear una representación comprensible de la realidad son los datos de los sentidos, datos que pueden ser dudosos o incompletos, pero son susceptibles de exámenes más concluyentes que los de los principios metafísicos. Por esta vía se hace más fuerte la idea de que la causalidad solamente pueda ser aceptable a partir de los elementos constatables mediante la percepción directa, idea que, en perspectiva, es congruente con la posición privilegiada que da la ciencia moderna a la causa eficiente. D e este modo, cuando Hume examina la diversidad de situaciones que ponemos bajo 
el término causa, encuentra que no es evidente si existen o no características similares que vinculen las causas a sus efectos, dadas sus diversas manifestaciones; en principio, lo único que parecen tener en común estas relaciones es que unen pares de objetos en el tiempo y en el espacio.

Hume se pregunta sobre el origen de un conocimiento cierto y no lo encuentra fuera de lo que puede ser percibido y de las relaciones que la mente puede establecer entre ideas. En el caso de la causalidad, la relación es entre objetos, pero ninguna cualidad conocida de estos corresponde a la necesidad que parece existir en la relación causal, que justifique ese vínculo que establecemos entre las cosas (Hume, 1896, p. 45). La idea de causalidad alude a la existencia de una relación y la primera característica que se percibe en esa relación es la de la contigüidad espacial entre cierto par de objetos (0, más exactamente, entre eventos), a la que se suma la precedencia temporal de la causa; pero en estos elementos no se agota lo que entendemos por causalidad. Fuera lo que captan los sentidos, no hay seguridad acerca de qué otro elemento pueda tener una relación para que la entendamos como causal. A hora bien, el mismo Hume encuentra ejemplos de casos en los que se da una sucesión de hechos conectados espaciotemporalmente y esto no implica que entre ellos haya una relación de causa a efecto, como ocurre con la sucesión del día y la noche. Cuando observamos dos péndulos sincronizados, al percibir que se mueven a la par la mente imagina que entre ellos puede haber una relación causal, aunque sean realmente independientes. Sin embargo, no parece haber una diferencia perceptible entre una secuencia causal y una sucesión que no lo sea; Hume lo ejemplifica con el caso de las bolas de billar: fuera del movimiento y del choque de las bolas, no se encuentra nada más, alguna especie de vínculo o conexión entre los objetos que llamamos causa y efecto que nos permita identificar si esta es una relación causal genuina y no un accidente. D e tal modo, la relación causal va más allá de lo perceptible por los sentidos; Hume no encuentra (fuera de la mente) la necesidad, y no parece haberla en la naturaleza:

The idea of necessity arises from some impression. There is no impression convey'd by our senses, which can give rise to that idea. It must, therefore, be deriv'd from some internal impression, or impression of reflexion. There is no internal impression, which has any relation to the present business, but that propensity, which custom produces, to pass from an object to the idea of its usual attendant. This therefore is the essence of necessity. Upon the whole, necessity is something, that exists in the mind, not in objects; nor is it possible for us ever to form the most distant idea of it, consider'd as a quality in bodies. Either we have no idea of necessity, or necessity is nothing but that determination of the thought to pass from causes to effects and from effects to causes, according to their experienc'd union (Hume, 1896, p. 91). 
Ante tal falta de una impresión de que la causa sea un vínculo necesario que se pueda constatar por medio de los sentidos, Hume acude a construir el vínculo causal a partir de experiencias anteriores. Ante la precariedad de nuestra percepción para dar cuenta de en qué consiste la relación entre causa y efecto se buscan relaciones similares que testifiquen que entre ellas haya un vínculo causal genuino, algún elemento que justifique que a la presencia de un objeto siga la presencia de su efecto; esa es la base del regularismo humeano, que apoya la relación causal en experiencias previas similares, en otras palabras en su conjunción constante:

The only connexion or relation of objects, which can lead us beyond the immediate impressions of our memory and senses, is that of cause and effect; and that because 'tis the only one, on which we can found a just inference from one object to another. The idea of cause and effect is deriv'd from experience, which informs us, that such particular objects, in all past instances, have been constantly conjoin'd with each other: And as an object similar to one of these is suppos'd to be immediately present in its impression, we thence presume on the existence of one similar to its usual attendant (Hume, 1896, p. 52).

Así, Hume entiende que nuestras experiencias previas sobre ciertas relaciones nos llevan a asumir que existe una relación causal en la medida en que en nuestra experiencia siempre se han manifestado conjuntas. Pero el autor se pregunta por qué consideramos necesario que algo que inicia tenga una causa, por qué es necesario que unas causas particulares tengan efectos particulares, y en qué consiste la inferencia de causas a efectos. Que todo lo que tiene un comienzo tiene una causa, lo asumimos como una máxima, sin embargo, al examinar la idea Hume no encuentra tras ella ninguna certeza, ni por semejanza ni por otras relaciones de ideas. Solo encuentra que las ideas de causa y de efecto son diferentes y que no existe una demostración concluyente de que la causa sea necesaria. En una relación causal particular no es perceptible nada más que la secuencia temporal y la adyacencia en el espacio de dos objetos; estos son los claros elementos irreductibles que se presentan a los sentidos en las relaciones que denominamos como causales, pero parece haber algo más que la sucesión, muy común en la naturaleza, que no implica por sí sola la existencia de un vínculo capaz de servir de origen a una posible transformación de un objeto. Sin embargo, el programa empirista de Hume le impide dar un paso más allá del dominio de los sentidos. La mente concibe una relación que permita ligar las causas con los efectos, más allá de las impresiones inmediatas, elaborando una inferencia que nos lleva de un objeto a otro; y en eso consiste la búsqueda de la conexión necesaria. 
Hume desconfía de los mecanismos inductivos que construyen regularidades generales a partir de una serie de casos coincidentes, pues las evidencias empíricas que lo sostienen son controvertibles, en la medida en que se puedan encontrar excepciones a la regla, capaces de refutar el enunciado inductivo. Popper (1995, p. 120) señala que aquí hay dos problemas diferentes: cómo justificar un enunciado partiendo de los casos en los que se cumple y por qué aceptar la asimilación de nuevos casos desconocidos a los ya conocidos. Eso sucede con nuestro conocimiento del poder causal: inferimos - a partir de la observación de una o más secuenciasy postulamos una regla general de lo que pueda ocurrir en casos similares; cuando vemos que esa secuencia se repite empezamos a denominar al precedente como causa y al consecuente como efecto, suponiendo que hay una conexión o algún poder que actúe; pero esto es apenas un hábito de la mente, que tiende a ordenar objetos similares en un conjunto, agrupando los antecedentes temporales en el conjunto de las causas y los consecuentes en el de los efectos.

D e tal manera, la limitación de la inducción nos lleva también a la imposibilidad de hacer inferencias válidas desde lo conocido empíricamente hacia lo no conocido, impidiendo que tengamos una idea cierta de aquello que no ha ocurrido. En otras palabras, el hecho de que hayamos podido ser testigos directos de la multitud de ocasiones en las que se produjo una cierta secuencia de eventos $A-B$, no nos ofrece ninguna certeza de que en la próxima oportunidad en que estemos frente a la ocurrencia de A necesariamente el evento B lo suceda, pues lo único que percibimos son las secuencias ya ocurridas, pero de ello no podemos inducir que necesariamente el tipo de evento A sea seguido por el tipo de evento B. Puede ser una conjunción constante y de ella inferimos que la siguiente oportunidad va a seguir siendo igual: se pasa de la impresión a la idea y se asume como necesario algo que puede ser contingente (así sea altamente probable, como se diría en lenguaje más actual). Nuestra convicción de que la naturaleza obedece a un principio causal nos conduce a la idea de que existe una conexión necesaria:

Reason can never shew us the connexion of one object with another, tho' aided by experience, and the observation of their constant conjunction in all past instances. When the mind, therefore, passes from the idea or impression of one object to the idea or belief of another, it is not determin'd by reason, but by certain principles, which associate together the ideas of these objects, and unite them in the imagination (Hume, 1896, p. 54) .

No se percibe ese, como se ha denominado, pegamento que une las causas a los efectos; solamente existe una conjunción, que se ha mostrado constante entre ciertos eventos, obedeciendo a un principio asociador que las une en la mente, pero de ella no podemos concluir que la conexión 
sea constante ni necesaria, es decir, no tenemos certeza de que el objeto que asociamos a la causa posea alguna propiedad que permita el origen o producción de un efecto, pues no podemos percibir la naturaleza de la conexión entre ellos, dado que solamente es una relación entre ideas producida por el hábito:

Let men be once fully perswaded of these two principles, That there is nothing in any object, consider'd in itself, which can afford us a reason for drawing a conclusion beyond it; and, That even after the observation of the frequent or constant conjunction of objects, we have no reason to draw any inference concerning any object beyond those of which we have had experience [... ] (Hume, 1896, pp. 77-78).

Así, pese a la frecuencia que pueda tener la conjunción entre los objetos que consideramos como causas y los objetos que consideramos como efectos, no por eso podemos declarar con certeza que entre ellos exista una relación causal, pues la constatación empírica no nos da más información acerca de si hay otro tipo de vínculo entre ellos. La ausencia de percepción completa de los elementos de la causa, junto con la precariedad de la regularidad, deja a la razón sin ningún medio para demostrar que la conexión causal es necesaria 0 , al menos, para entender en qué consiste este tipo de relación.

Si no tenemos una idea clara de lo que son las causas, menos posibilidad hay de hablar de tipos de causa: si algo es una causa, dice Hume, esta debería ser eficiente, pues cuando no hay causa eficiente, simplemente no hay causa, de modo que hay que entenderla como cierta sucesión:

We may define a cause to be 'An object precedent and contiguous to another, and where all the objects resembling the former are plac'd in like relations of precedency and contiguity to those objects, that resemble the latter.' [... ] 'A cause is an object precedent and contiguous to another, and so united with it, that the idea of the one determines the mind to form the idea of the other, and the impression of the one to form a more lively idea of the other' (Hume, 1896, p. 93).

Si se habla de la causa en los objetos concretos se deben tener en cuenta reglas como la contigüidad espaciotemporal y la conjunción constante, es decir, la igualdad de causas para los mismos efectos, observaciones que no apelan ni a la demostración ni a la intuición; son datos de la experiencia, dentro de la cual no hay lugar para la necesidad. La causa y el efecto están unidos "en la imaginación" de forma tal que la causa genera la idea del efecto, pero, anota Hume (1896, p. 94), esa influencia sobre la mente es excepcional e incomprensible; su realidad depende apenas de lo que pueda ser experimentado, de modo que algo de la causa queda oculto tras lo perceptible. 
Los objetos existen para la experiencia en la medida en que podamos percibirlos y constatar sus relaciones, de ahí que la experiencia no podría captar más noción de la causalidad que las cualidades del vínculo humeano: así, no se podría asegurar definitivamente que un objeto sea causa de otro o que no lo sea, más allá de que hayamos percibido la constancia de su conjunción en eventos previos del mismo tipo, de manera análoga al convencimiento que tenemos de que el Sol saldrá mañana porque siempre hemos experimentado que tras la noche llega el día. Entendemos la causa como una conexión entre objetos, pero no sabemos si es necesaria pues si estamos limitados a percibir la contigüidad, no podemos intuir o demostrar propiamente lo que sean las causas con la certeza que nos puede dar una deducción de la lógica.

Y en esto consiste el problema principal que plantea Hume sobre la causalidad: la falta de una certeza empírica que dé cuenta de la presunta necesidad causal que opera en el mundo. Lo cual nos lleva al problema de cómo diferenciar secuencias de objetos que obedecen a conjunciones accidentales de las que están unidas por un vínculo causal, esto es, de eventos en que el objeto precedente tenga la capacidad de producir el consecuente. Para la idea de causa en Hume es fundamental la conjunción constante, que es el indicio más confiable de que existe una conexión necesaria, pero esta conjunción constante es lo que falta en las secuencias accidentales. Sin embargo, de ello no puede concluirse que la posición de Hume sea escéptica: su intención no niega propiamente las causas sino que el vínculo causal sea parte de la experiencia directa, o que exista una justificación a priori de la inferencia causal (en la expresión de Mackie, 1999, p. 229).

Lo que se ha entendido como causa, dice Hume, se asocia a la sustancia, a la forma, a los accidentes 0 a facultades, pero ninguna de estas explicaciones es sólida y fundamentada; lo que hacemos es inferir un objeto a partir de otro, pero eso no implica que conozcamos los poderes y cualidades capaces de producirlo (Hume, 1896, p. 59) en un caso concreto que estemos observando: es la conjunción constante lo que nos hace creer que hay un vínculo necesario; en esa idea basamos la acción de las causas. Añadir casos semejantes no enriquece la idea original pues sigue siendo la misma que la originada en cada una de las impresiones; así, la idea de necesidad no existe en los objetos, sino solo para la mente: de los objetos que consideramos causas inferimos sus supuestos efectos, por costumbre, pero no porque podamos verificar que en la naturaleza exista un poder causal. Para llegar a este punto, Hume en la Investigación reitera lo enunciado en el Tratado, en torno a que la mente no percibe en la realidad nada más que la secuencia de dos objetos, uno tras de otro, sin que se pueda decir qué los une o si existe alguna suerte de poder o de cualidad que 
haga capaz al primero de ejercer una fuerza o influencia sobre el segundo. Pero, ante el hecho de que la conjunción constante no dé apropiada cuenta de qué sea la relación causal, agrega: Or in other words, where, if the first object had not been, the second never had ex isted" (Hume, 2004, p. 181)7. Hume define la causa como un objeto precedente y contiguo a otro, o también como el objeto que está en la misma relación con otros objetos semejantes en las mismas condiciones, determinando en la mente la idea del efecto. Ello implica que hay una noción para los objetos y otra para la relación entre ideas. Mucho se ha discutido en torno a que esta última línea que añade Hume a la definición de causa en la Investigación, no es tanto una aclaración sino otra definición, diferente en la medida en que desplaza el problema del campo de los objetos al del conocimiento. En esta segunda definición se propone una idea que va más allá de la asociación de precedencia y contigüidad, se compara un mundo con la presencia de la causa en cuestión con un mundo en el que ella no exista. En esta perspectiva, no conocemos nada que pueda llamarse un poder causal, ni tampoco podemos derivar o deducir - a partir de la observación de una secuencia constante- que esa secuencia sea parte de una regla aplicable a casos similares. Por esto Hume intenta precisar el sentido buscado en su definición inicial de causa introduciendo una idea muy diferente, la de la dependencia del efecto a partir de la causa: si el objeto inicial no hubiera existido tampoco se hubiese producido el efecto, apoyando la idea de necesidad en la de dependencia contrafáctica. La mente, confrontada con la experiencia, asocia la idea de causa con la de necesidad; de la uniformidad de la naturaleza deriva la adjudicación de los mismos efectos a las mismas causas. Y es que los hábitos de la mente hacen que ante un conjunto de situaciones del mismo tipo se adelante por vía inductiva que una nueva situación va a presentarse de forma similar: se asume como una previsión fiable un resultado semejante a los anteriores; la mente anticipa un resultado consecuente. Se pasa así de una definición a otra: se empieza hablando de la causa como conjunción de eventos y luego de la relación de los objetos en el pensamiento, sin decir qué es específicamente la causa, pues no tenemos noción de esa conexión, más allá de esperar que de un evento A sigue otro $B$, sin ninguna seguridad lógica ni ninguna certeza empírica de si A es la causa de B.

Ahora, el problema es indagar si existe de hecho una conexión entre esos objetos que estamos acostumbrados a denominar como causa y efecto. Si nos atenemos a las secuencias temporales que se dan en la naturaleza, vemos que muchas de ellas pueden ser constantes pero eso no indica que entre ellas se dé tal relación. El día sigue a la noche o la primavera sigue al invierno sin que se pueda decir que uno depende causalmente del otro: no hay relación causal pues son secuencias 
recursivas. Las causas cumplen las reglas del vínculo humeano y si los efectos son diversos es debido a una diferencia en alguna propiedad del evento inicial, lo cual implica que esa cualidad debe ser propiamente considerada la causa; una causa no puede producir espontáneamente un efecto sin la intervención de algún principio capaz de introducir un cambio. Así, los razonamientos sobre causas y efectos se deben, más que a las observaciones, a la costumbre, de manera que el posible escepticismo de Hume no es tajante, pues no niega las causas sino que constata los límites de la razón más allá de la experiencia, en particular que pueda ser percibida la necesidad del vínculo causal.

Es útil la diferenciación que hace Mackie (1999, p. 12) con respecto a los sentidos que puede tener la noción de necesidad en Hume, en tanto es imprescindible diferenciar una necesidad de hecho de una necesidad lógica: la llamada neœsidad ${ }_{1}$ permite diferenciar las secuencias causales de las que no lo son y la neosidad ${ }_{2}$ garantiza la inferencia causal a priori. Esta última implicaría una conexión lógicamente necesaria, que garantice que una vez que ocurra $A$, se produzca $B$ a continuación. La observación no nos revela la necesidad de una inferencia a priori; nuestra idea de causa incluye la de conexión necesaria, pero esa conexión necesaria es algo que tampoco puede ser observado. Las herramientas de examen lógico empleadas en la verificación de razonamientos ofrecen una confiabilidad que se basa en la corrección formal, aunque su contenido, por depender del comportamiento de la realidad, ofrece una confiabilidad más limitada que depende de la contrastación con los hechos. Hume buscaba esa necesidad de que un efecto sea determinado por la causa, pero como no la percibimos, juntamos las experiencias previas para formar la creencia de que a todo A sigue B y que si A no se ha presentado, entonces B no puede ocurrir; una causa necesaria de este tipo haría seguro el conocimiento de la realidad, pero Hume no la encuentra.

Por vía inductiva el sentido común objetiviza impropiamente la regularidad de las secuencias causales como si esta constituyese la necesidad causal, pero si no conocemos el funcionamiento del proceso que nos puede dar a conocer con certeza que el evento B deba seguir al A , estaríamos tomando un enunciado apoyado en la inducción como si fuese una verdad objetiva. Pero es evidente que las reglas de razonamiento están sometidas a principios abstractos, que operan con conceptos con estas mismas características, mientras que la realidad se caracteriza por estar completamente llena de contingencias, lo que constituye una fuente, si no de completa incertidumbre, por lo menos de inseguridad, en tanto es necesario tomar en cuenta que las 
múltiples circunstancias pueden alterar o impedir una secuencia causal. De ahí que hoy apenas nos sintamos inclinados a decir que una conjunción constante es un indicio de que los eventos $\mathrm{A}$ y B están probablemente asociados, mientras no podamos probar que es así por medio de la reconstrucción de sus mecanismos de influencia.

D el planteamiento de Hume se deriva una forma de determinismo que buscaría obtener siempre un resultado $\mathrm{E}$ a partir de un objeto $\mathrm{C}$, que excluya la duda sobre la existencia de un vínculo real entre esos objetos. La pregunta sigue siendo en qué basamos nuestra creencia de que el efecto se siga necesariamente de cierta causa. Hay evidentemente un problema en nuestro conocimiento pues no tenemos plena certeza de la necesidad con la que habría de producirse el efecto, cuestión que deja a la razón en estado de incertidumbre: percibimos la conjunción, pero no la conexión, no percibimos la necesidad que permita determinar un efecto, es decir, no conocemos ni percibimos qué poder ni cómo actúa para que se produzca un acto o un efecto. Además, para Hume no existe azar, pues este consiste simplemente en el desconocimiento de las causas reales, y si no podemos predecir siempre su comportamiento es porque podemos desconocer las causas. Hume es, como lo anota Vicente Sanfélix "determinista en lo ontológico y probabilista en lo epistemológico" (Hume, 2004, p. 146 y nota 2, p. 367): todo evento está determinado por unas causas, independientemente de que las conozcamos; así, nuestro conocimiento causal es apenas probable: no tenemos seguridad de que iguales secuencias obedezcan a los mismos mecanismos, lo cual es constatable en la dificultad de hacer predicciones precisas. Frente a la ausencia de intuiciones o demostraciones fiables, es usual que la mente recurra a principios ocultos pues, insiste Hume, ni siquiera en lo más habitual se conoce por completo en qué consiste el mecanismo causal, más allá de la experiencia de la conjunción de objetos, lo que explica por qué se ha recurrido tanto al D eus ex machina, al dios que tiene que intervenir para causarlo todo.

Al parecer la interpretación de Hume como escéptico se debe a Kant; tal escepticismo se remite al tratamiento que hace sobre la inducción y sobre la necesidad causal, pero hoy se acepta más la idea de que su intención es la de constatar la insuficiencia de la razón en demostrar la uniformidad de la naturaleza (de Pierris \& Friedman, 2013, nota 7). Los autores consideran la causa como un problema que no se puede resolver por vía analítica, como afirmaban los racionalistas: no hay entre causa y efecto ninguna razón que haga que de una pueda derivarse deductivamente la otra ni tampoco necesidad que ponga a depender una sustancia de la otra. Sin embargo, los autores difieren de la causa a priori de Kant en la medida en que niegan que la causa sea un concepto que 
podamos derivar de la experiencia y que la necesidad se reduzca a la costumbre. D e modo que, ante la imposibilidad de una experiencia causal o de una percepción de la causa, se pueden conocer las relaciones posibles entre objetos constituyendo principios que posibilitan la experiencia, en la misma categoría que la permanencia de la sustancia o la simultaneidad: principios de determinación de la existencia a la vez que reglas del entendimiento; son los que permiten que ciertos datos de la experiencia sean objetivos. D e esta forma la causalidad es una categoría del entendimiento. La experiencia ofrece ejemplos de regularidad, dice K ant (1982, p. 77), pero esto no justifica su objetividad, salvo que se fundamente a priori en el entendimiento, pues ninguna otra cosa puede justificar su consideración como acontecimiento necesario, su obediencia a una regla universal que determina que la causa conduzca al efecto.

Kant también asume una diferencia fundamental con respecto a Hume en lo que tiene que ver con el tiempo. Para Hume el tiempo está dado y lo apreciamos en la secuencia de impresiones, mientras que para Kant (1982, p. 121) esa percepción es subjetiva, no tiene un estatus similar al conocimiento de un fenómeno; es el concepto de causalidad el que cumple la función de transformar en objetiva una secuencia temporal, pero esto no se puede hacer como producto de experiencias congruentes de sucesos sino por los reglas a priori del entendimiento. Esto implica pasar de la conexión constante a una ley universal. Sin embargo se está hablando de dos principios: que todo efecto tiene una causa (lo que se entiende como ley de causalidad) y que todo efecto obedece a la misma causa (uniformidad causal) (de Pierris \& Friedman, 2013), con respecto a los cuales Hume erige sus reservas, mientras que Kant defiende solo el primero. Es evidente que el pensamiento de los dos autores diverge con respecto a las leyes de la naturaleza, pues para Hume las leyes no tienen necesidad objetiva, mientras que para Kant la naturaleza obedece a leyes universalmente válidas y necesarias. La discusión abierta consiste en si se puede hablar de leyes universales objetivas y necesarias: Hume señala que esto está más allá de lo que podemos percibir. Mientras tanto hoy la ciencia trabaja, es decir, explica y predice, con base en la regularidad que encuentra en los hechos de la naturaleza, de modo que la idea que tenemos de cierta causa obedece a una generalización empírica (Dicker, 2001, p. 145). El hecho de que los efectos no siempre se produzcan, aún en presencia de la causa que solemos adjudicarle, nos muestra que las secuencias de eventos son contingentes, no como K ant pensaba: el problema de la noción kantiana es que asocia la causalidad con el determinismo (Suppes, 1970, p. 6). Lo que encontramos son similitudes entre tipos de secuencias, pero en principio no es claro qué es lo que tengan de similares dos secuencias para considerarlas del mismo tipo, es decir, qué factores son los 
causalmente relevantes para que las situaciones se puedan considerar como similares o en qué nos basamos para distinguir las secuencias legítimamente causales de las que son apenas accidentales. El argumento de Kant consiste en que el principio de causalidad es presupuesto en la percepción de los eventos y no que se deriva de ella.

Pero aún hay otras interpretaciones sobre Hume: Carnap (1995, p. 190), por ejemplo, afirma que el autor no rechaza por completo la idea de causa, sino que su intento estaba más bien encaminado a depurarlo del tipo de necesidad que se asume como consustancial a la causa, dado que los enunciados sobre una relación causal son condicionales y dependen de las regularidades observadas en la naturaleza; lo que plantea es sólo que nuestra experiencia es insuficiente para dar cuenta de ellas. Sin embargo, esa idea se ha venido revisando en el sentido en que ya no se considera que sea reductivista ni eliminativista de la idea de necesidad, sino que su posición es de realismo escéptico: acepta las causas en la naturaleza, esto es, que existen conexiones objetivas entre los eventos naturales, pero es escéptico acerca de nuestro entendimiento y conocimiento de ellas, pues entiende que la necesidad no está en las cosas sino en la mente, aunque sus dos definiciones de causalidad sugieren que no quería dar cuenta solamente del razonamiento causal sino de la naturaleza de la causa. Hoy algunos autores interpretan a Hume como un realista causal, pero otros lo ven como un proyectivista (Beebee, 2007, p. 73), esto es, que acepta el hecho de que la mente nos lleva de la causa a su efecto, o que la conjunción constante se proyecta como si fuera una cualidad del objeto, a pesar de que no pertenezca a la estructura metafísica del universo. Los matices plasmados en sus escritos todavía darán lugar a muchas interpretaciones posibles, algunas de las cuales se han mencionado como muestra de las diferentes vías que pueden ser exploradas en el análisis causal.

Podemos concluir este aparte afirmando que es razonable pensar que, en general, no podemos percibir el poder que causa el efecto, dado que la conexión necesaria - ese tipo de conexión implícita en nuestra idea de causa- no es observable y consiste más que todo en la expectativa de que cierto evento se produzca, de que se cumplan ciertas leyes. Pero tampoco se puede ir tan lejos como para negar tajantemente la percepción de todo vínculo causal; en efecto existen vínculos de los que no conocemos los mecanismos pero que presumimos como causales por la constancia de su conjunción o por la identificación parcial de algunos de los factores implicados. A pesar de que desconocemos muchos mecanismos causales, en la medida en que la ciencia avanza devela más mecanismos capaces de transmitir influencia causal; se espera que la ciencia 
provea cada vez más y mejores descripciones y explicaciones que nos permitan entender cómo ocurren los cambios en la naturaleza.

\subsection{Mill: la búsqueda de las causas}

Mill defiende que la idea de causa debe derivarse de la experiencia, en la cual no existe nada que podamos reducir a una percepción de necesidad causal. Parte de que los fenómenos naturales pueden ser simultáneos o sucesivos, y que los sucesivos se rigen por la ley de causalidad: "[... ] That is, the universal law of successive phenomena is the law that every consequent has an invariable antecedent" (Mill, 1973, p. 326). Señala, además, que la tal noción de causa hace referencia a los fenómenos, no a alguna causa última, dado que las causas son físicas, nada parecido al ningún poder o vínculo oculto. La sucesión regular e invariable entre una causa y su efecto es la sucesión que se puede conocer por experiencia; y si la sucesión es invariable lo descubriremos por la observación, independientemente de que conozcamos el modo de producción del fenómeno. Es común que singularicemos un único antecedente como si fuese la causa propiamente dicha, aunque el efecto se produzca como resultado de la participación, "el ensamblaje", de un conjunto de antecedentes. Así, dice Mill, "The real Cause is the whole of these antecedents; and we have, philosophically speaking, no right to give the name cause to one of them exclusively of the others". Y agrega que lo que oculta la incorrección de señalar una sola de las condiciones como si fuera la causa es debido a cierta característica: "[... ] that the various conditions [... ] were not events (that is, instantaneous changes) but states possessing more or less of permanency [... ]" (Mill, 1973, p. 328).

De modo que cada efecto requiere de cierta combinación de circunstancias, un ensamblaje de estados permanentes que se combinan con eventos, ensamblaje cuya concurrencia es siempre seguida por el efecto; lo raro, si es que existe, es que sea un solo antecedente. A posteriori vemos que si alguna de estas condiciones no se hubiera producido, el efecto tampoco se habría presentado, de modo que seleccionamos una de ellas como la causa y a las otras les dejamos el nombre de condiciones; pero esta es una forma de simplificar la situación, pues la causa es el conjunto de los antecedentes: a todas las condiciones por igual se debe que el efecto ocurra.

Entonces, en la perspectiva de Mill, la causa consiste en el orden de sucesión de dos fenómenos, correspondiente a la uniformidad de la naturaleza; así, la universalidad de la ley de causalidad consiste 
en que cada consecuente está ligado a una serie de antecedentes: "For every event there exists some combination of objects or events, some given concurrence of circumstances, positive and negative, the occurrence of which 'is always' followed by that phenomenon" (Mill, 1973, p. 327).

El uso habitual del término causa restringe los factores a un número manejable, tal como se hace en experimentación, controlando unas cuantas variables y replicando el experimento para comprobar su relevancia pero no puede adjudicarse a un único antecedente el papel de causa. A diferencia de Hume, Mill reconoce de forma explícita que los efectos se producen por una multitud de antecedentes, elemento importante para el análisis causal, dado que permite entender cómo ciertas propiedades entran en acción en determinadas condiciones. Mill llama la atención sobre un hecho fundamental como es el de que accedemos a una noción de regularidad por medio de la apreciación de situaciones diferentes, con lo cual necesitamos de leyes estadísticas que nos permitan manejarlas. Sin embargo, lo que hay que indagar es si los casos de causalidad involucran regularidades o si la causalidad consiste en ellas. Sin embargo, no siempre se puede hablar de conjunción regular, dado que el efecto puede ser único o accidental y eso no lo hace acausal, como, por ejemplo, sucede en el caso de un terremoto: pese a que hayamos sido testigos de este fenómeno una sola vez, esto no implica que carezca de causas. Puesto que un efecto es el resultado de la presencia de cierto conjunto de condiciones, se espera que algunas de estas tengan un papel más activo (por eso habla de circunstancias negativas, que son las que inhiben el efecto); pero, como se mencionó, el autor no acepta que exista propiamente una diferencia entre causas y condiciones: se suele llamar causa a la última condición que existe antes del efecto, lo cual es una forma conveniente pero limitada de describir una sucesión causal.

En alguna medida el método que plantea Mill se dirige a buscar qué hay de diferente en una situación en la que se produce un cambio; pues si se descubre que una causa particular es efectiva es porque existe una ley. Tal procedimiento de búsqueda de causas de Mill está emparentado con las viejas críticas a los procedimientos inductivos de Aristóteles: la generalización a partir de unos pocos casos semejantes provee resultados sobre los cuales no tenemos plena certeza; es más útil e informativo comparar casos distintos en los que se presenten factores causales diferentes o consecuencias diferentes. La idea básica sigue siendo muy útil: si los cambios son acompañados por factores que permanecen, una explicación debe detectar cuáles son los factores que influyen en la modificación de las propiedades en cuestión, es decir, qué factores son capaces de propiciar un cambio similar en circunstancias similares. Se comparan situaciones en las que se produce un 
efecto con el fin de detectar si existe un factor en común en todas ellas y, de ser así, se concluye que dicho factor es probablemente una condición suficiente para la aparición del efecto. $\mathrm{Si}$ comparamos un conjunto de situaciones en las que se pueda establecer una relación entre cierto factor de la situación causal y la producción de un efecto, comparadas con otras en que el factor y el efecto no se presentan, podemos concluir que probablemente el factor sea condición necesaria para el efecto. En este procedimiento podemos apreciar que la búsqueda de las causas está emparentada con la búsqueda de explicación y de predicción. Algunos cambios estarán determinados por la relación física entre cierto factor y las propiedades del objeto sobre el cual recae el efecto, pero otros dependerán de una conjunción de factores que tienen una relevancia limitada en las condiciones específicas de la situación. Por eso el M étodo de acuerdo y diferencias que desarrolla Mill en el capítulo VIII de A System of L ogic es de particular importancia: porque permite diseñar experimentos en los cuales se puede llegar al factor determinante dentro de las circunstancias, es decir, el factor que es capaz de conjugarse con el conjunto de los demás factores para la producción de un efecto. De esta forma una causa, pese a ser particular, no excluye las leyes regulares que describen parcialmente los comportamientos de diversos factores.

La ciencia suele poner a prueba el alcance que tiene una regularidad, pues el conocimiento de las condiciones es siempre insuficiente. Sostener que existe una tendencia que favorece un efecto es asociar ese efecto a la presencia de ciertas condiciones y de una ley que las acoge, lo cual no implica aceptar un determinismo fuerte que excluya las leyes estadísticas: estas generan una aproximación válida a las regularidades naturales. Mill afirma que no hay causas incondicionales: lo que aceptamos como causas son los ensamblajes de condiciones; el problema es que ciertas regularidades se aceptan como causales y otras no, aunque esto parece revelar una cierta indefinición sobre los procesos que no son necesariamente causales, una muestra más de los obstáculos que se encuentran en los intentos de reducir la causalidad a la regularidad.

Más adelante volveremos sobre Mill, pero por ahora valoramos el intento de sistematizar la búsqueda de los factores causales. Pese a que constituye un indudable avance, el problema de su análisis parece continuar enfrentándonos a extremos: 0 bien de reducir tanto los factores como para que podamos visualizar que apenas uno de ellos es el determinante, o bien de considerar la causa como el conjunto completo de las condiciones antecedentes. La primera opción simplifica en exceso, pero la segunda no es práctica, dado que existen una enorme cantidad de factores previos a cada suceso y muchos de ellos pueden ser poco relevantes. Al parecer es mejor una 
opción intermedia en que se acepte que la naturaleza no es completamente uniforme o que lo sean sus principios causales: seguramente un evento siempre obedezca a una suma de factores (y de vías de acción causal), pues de otra forma la realidad no sería tan compleja

\subsection{Russell: de la causa metafísica a las relaciones funcionales}

El problema del examen de causas y condiciones nos lleva a Russell y su escepticismo causal formulado en su conocida cita:

All philosophers, of every school, imagine that causation is one of the fundamental axioms or postulates of science, yet, oddly enough, in advanced sciences such as gravitational astronomy, the word "cause" never occurs [... ] the reason why physics has ceased to look for causes is that, in fact, there are no such things. The law of causality, I believe, like much that passes muster among philosophers, is a relic of a bygone age, surviving, like the monarchy, only because it is erroneously supposed to do no harm (Russell, 1953, p. 387).

D esde esta perspectiva la ley de causalidad es más un problema de la vieja filosofía que, en la medida en que la ciencia progrese, se superará, pues las leyes funcionales son las que dan cuenta de cómo opera la naturaleza. Russell, en las críticas de su primera etapa - su posición posterior es más cercana al análisis causal- apunta hacia varios problemas, tales como el de la precedencia y unidad de la causa. El problema de la precedencia consiste en que las leyes funcionales de la naturaleza son simétricas con respecto al tiempo, mientras que la causa nunca parece ir en dirección contraria; mientras que el problema de la unidad radica en que, si aceptamos el principio de que a la misma causa sigue el mismo efecto, la delimitación exacta de las condiciones del primer evento lo hace único y tan complejo que no puede ocurrir más que una vez (Hitchcock, 2007, p. 48). Si tomamos el argumento de Russell desde una perspectiva más amplia, considerando que todo está encadenado causalmente con todo, no habría causalidad local, pues al utilizar el Universo como modelo no hay variación posible, pues cada relación causal particular dependería del comportamiento del conjunto. Dicho argumento implica que necesariamente hay que acudir a alguna forma de limitar el alcance de la relación causal, pues las descripciones físicas, aún incompletas, son las mejores aproximaciones a la descripción adecuada de la realidad.

Russell afirma que la ciencia encuentra regularidades que luego se disuelven ante la cantidad de antecedentes relevantes y que, por ejemplo, las regularidades de los movimientos newtonianos no son causales sino que obedecen a relaciones expresables mediante ecuaciones; para el autor 
una ciencia madura tiene leyes funcionales, mientras que el uso de conceptos causales revela que esta se encuentra aún en sus comienzos. La propuesta de Russell de reemplazar la causalidad por dependencia funcional es compartida por Mach (que concibe la causa apenas como una abstracción) y por el Círculo de Viena, que la reduce a un determinismo mecánico: en efecto, se esperaría que, una vez que cada ciencia se consolide y desarrolle, sea capaz de dar cuenta de las leyes que regulan el comportamiento de sus objetos de estudio.

Pese al escepticismo del primer Russell, el tema de la causalidad sigue siendo tan importante en la ciencia como en la filosofía contemporánea, en particular con respecto a los problemas de la verificación, la predicción y la explicación. D esde el un punto de vista que se adopta en el presente escrito, creemos que tras las leyes funcionales siguen existiendo leyes causales. Las leyes funcionales no acaban con la utilidad y necesidad de contar con causas que nos permitan relacionar y entender los fenómenos de la realidad: la dependencia funcional no da cuenta de la conexión que origina un proceso, relacionando cualidades que pueden coexistir sin esa conexión, pues la dependencia funcional es apenas una de las posibles formas de la regularidad causal.

Pero también es cierto que algunas de las objeciones propuestas por Russell sobre la causalidad siguen sin una solución definitiva, por ejemplo, la de la asimetría temporal de la causa. Es posible que las opciones no sean tan extremas como el rechazo o la aceptación de la causalidad y que a Russell se le escaparan posiciones intermedias: Price y Corry (2007, p. 2), siguiendo con las alusiones monárquicas de la famosa cita, hablan de una opción republicana que, como en el caso de la política, no se atenga exclusivamente al origen divino de la autoridad. Se puede ser crítico con respecto a la concepción de la causalidad como ley - la noción de causalidad que asimila Russell a la monarquía - , sin dejar de reconocer la posibilidad de una concepción construida, pues eliminar la causalidad implicaría caer en una especie de anarquía. D e todas formas es necesario determinar en qué medida el problema atañe a la ciencia o a qué área de la filosofía concierne apropiadamente.

Al respecto de si puede concebirse la causalidad como un problema científico son diversas las posiciones, en lo cual seguimos la exposición de Norton (2007, p. 15): por una parte existe un fundamentalismo causal que defiende la idea de que la causalidad está en la naturaleza y la gobierna, con lo cual el objeto de las ciencias es encontrar sus expresiones. Sin embargo, para quienes defienden esta concepción el problema es cómo definir un concepto de causa científicamente aplicable o encontrar el contenido y los límites de un concepto tan elusivo como este. La 
preeminencia que el mecanicismo otorga a la causa eficiente conduce a que se reduzca la causalidad al determinismo, expresada en la mente universal del demonio de Laplace. Sin embargo, también la física de Newton, que es tomada como su base, alberga espacios de impredecibilidad, pues no siempre es posible conocer de manera exacta y exhaustiva las condiciones iniciales que darán paso a una situación futura. D owe y Salmon, por su parte, intentan sustentar el papel de la causa en la ciencia por medio de la teoría de la cantidad conservada. Por otra vía, Nagel ve la causalidad como una máx ima orientadora, más que un enunciado con contenido, de lo cual Norton deduce que no hay una naturaleza causal y que la utilidad de la idea no se deriva de los hechos sino de nuestra propia psicología (Norton, 2007, p. 20), de esta forma no se niega la causa, no se considera arbitraria sino que se entiende como un concepto general que subsiste bajo algunas nociones de la ciencia y que nos permite entender ciertos aspectos de la realidad.

Recapitulando, el escepticismo de Hume se remitía al hecho de que fuera de la conjunción constante no percibimos nada que fundamente que la causa sea una conexión necesaria. Entretanto, Russell ataca la noción de causa como obsoleta e imprecisa y en razón a que no se emplea de forma explícita en la ciencia, pues esta se dedica a establecer relaciones funcionales entre eventos particulares, sin recurrir a ninguna categoría metafísica. Cada ciencia en sus inicios puede trabajar con generalizaciones imprecisas, pero no se podría consolidar dependiendo de regularidades invariables. Russell no comparte que la causalidad se acepte como una idea a priori (atacando así la idea kantiana de la causalidad como condición necesaria de conocimiento). Posteriormente Russell mostrará que la noción de causa no es tan perjudicial como sostuvo y que nuestras percepciones sobre el mundo hacen referencia a relaciones causales sobre las que podemos declarar su verdad o falsedad; del eliminacionismo tajante de 1912 pasa en 1948 (Russell, 2009, p. 270) a aceptar que necesitamos leyes causales que nos permitan hacer predicciones e inferencias sobre el mundo; esto es, que la ciencia no se limita a establecer relaciones funcionales entre sucesos. La ciencia identifica relaciones entre eventos agrupados bajo leyes pues necesita prever los acontecimientos del mundo, así como los resultados de nuestras intervenciones en la naturaleza.

En su segunda versión Russell plantea que existen líneas causales, secuencias de acontecimientos en que hay una persistencia sin cambios súbitos, pero niega la causa, si se entiende que esta es una conjunción constante invariable. La necesidad y la universalidad son cuestionables: en la medida en que sea más precisa la situación de un evento es menos replicable. El autor señala que este tipo de causa necesaria es una incursión de la metafísica en la ciencia, dado que implica un conflicto entre la causa y los mecanismos funcionales, de modo que tendríamos que optar por 
una opción fisicalista de las relaciones funcionales o por la opción metafísica de los mecanismos causales, pero no pueden actuar causas y relaciones funcionales en el mismo plano. Sin embargo, aun aceptando que la causa en general no es un asunto estrictamente científico, sigue siendo importante en filosofía y ciencia, pues se la usa como guía de la investigación: esa causa abstracta sigue siendo un problema de la filosofía, no de la ciencia. Parece más comprensible un mundo con causas que den cuenta de cómo se producen los cambios: la presencia de cierto factor, alguna propiedad de un objeto, repercute sobre la transformación de las propiedades de otros objetos: es dependencia funcional - es decir, una relación funcional entre estados de uno o más sistemas- , pero también se puede denominar causa si utilizamos una noción más abstracta, como corresponde a una noción ontológica o a un principio unificador, de manera tal que no se superponen sino que responden a dos principios diferentes de análisis.

Woodward (2007, p. 69) también señala la diferencia entre la noción de causa usada por la ciencia y la del sentido común, y afirma que la noción de causa en física se sustituye por una más precisa, pero esto no indica que no se use. Adam Elga (2007, p. 107), por su parte, afirma que Russell intenta descartar el modelo de sentido común de la causalidad, idea que es apenas aproximadamente correcta en algunos dominios, de forma análoga a como la física de Newton es un caso de aplicación limitada frente a la relatividad, que también da cuenta de los fenómenos en condiciones de mayor velocidad y mayor atracción gravitacional. La idea común de causalidad es útil pues trata a los objetos como si estuvieran aislados, lo que permite hallar y entender las interacciones causales; en cambio, Russell prefiere las leyes de la dinámica como un objetivo más preciso de la ciencia, pues ellas trabajan con relaciones aisladas de objetos regidas por leyes funcionales. Sin embargo, el hecho de que la idea general de causalidad no sea un concepto con la exactitud buscada por la funcionalidad operativa de la ciencia, no permite descartar por completo su utilidad. Además parece ser inevitable, dado que las nociones filosóficas y las nociones comunes necesitan de un principio que permita unificar las relaciones que existen entre objetos que cambian. Pueda que la causación no aparezca explícitamente en los enunciados de la ciencia, pero esto no indica que deje de ser un principio tácito tanto en la reconstrucción del origen de un evento determinado como en la necesidad de predicción de la realidad futura. Conocer las causas de un evento equivale a poder dar cuenta de su origen y eventualmente de determinar su futuro.

Russell considera que el concepto de causa no puede ser reducido a la física sin problemas, aceptando que las relaciones físicas entre estados son más fundamentales que la causalidad, pero 
al costo de trivializar este concepto y de confrontarlo con nuestras intuiciones, según lo afirma Eagle (2007, p. 173). Plantea Russell que si intentamos definir el concepto o precisar sus características nos daremos cuenta de que podemos prescindir de su consideración como una idea a priori, y ese es un matiz acertado de su crítica de la causalidad pues las implicaciones metafísicas y su imprecisión dificultan su manejo científico. Si no hay reducción, el concepto es autónomo y no juega ningún papel en la física, pues terminaría sobredeterminando los efectos, dando otra descripción en otro plano, con lo cual tendríamos dos niveles de descripción: las físicas (más complicadas y precisas) y las causales; de esta forma nos encontramos con explicaciones que se excluyen pero coexisten. Al respecto, Eagle es muy claro:

Though causal accounts may be rendered inessential by fundamental physics, they are not thereby robbed of their distinctive contribution to understanding. Rather than focusing on causal descriptions of the phenomena, we should attend to causal ex planations, which seem to play a quite different role than purely descriptive accounts. While it may well be true that the physical description of the situation is optimal with respect to the desiderata governing a good description of how some event came about, the same physical description needn't provide scientific understanding of why that event came about (Eagle, 2007, p. 176).

De modo que no es necesario asumir que las relaciones funcionales de la ciencia excluyan las explicaciones causales, entre otras razones porque en la explicación también se intenta reconstruir la historia causal de un evento, como también lo sostiene Lewis (1986, p. 217), ya que conocer un hecho no se limita a describir sino que también abarca la explicación. Además, no hay que olvidar que la explicación causal también tiene un cariz pragmático, en tanto permite la continuidad entre nuestras intuiciones y la ciencia, apoyando nuestra idea de actuar como agentes y de predecir los cambios en el mundo.

No existe una causa a priori, esto es, no hay algo común en las diversas relaciones que llamamos causales pero, reiteramos, si la hubiera no sería objeto de estudio de la ciencia; lo que esta estudia es la relación entre eventos. El conocimiento se encuentra entre dos extremos: si generalizamos se hace a costa de simplificar, si no generalizamos, los eventos son irrepetibles. Russell tiene razón en que la ciencia no se puede guiar por nuestra intuición común de lo que sea causa, pues en ciencia se usan términos más precisos y específicos del tipo de relación analizada. De todas formas la causa no es solamente mecánica ni física: en un hecho puede haber múltiples factores con más o menos relevancia, puede haber diferentes mecanismos de propagación de la influencia causal y diferentes velocidades en la acción; hay cambios graduales, otros que se acumulan, rupturas, 
etc., y no siempre hay proporcionalidad, pues es posible que una causa pequeña produzca un gran efecto o que se den efectos prolongados luego de una causa puntual. Tampoco se puede olvidar la existencia de aleatoriedad, otra razón más a tener en cuenta para afirmar que la causa no implica una determinación estricta, como se cree en el sentido común. El asunto es que la causa no excluye la explicación por mecanismos - la dependencia funcional- sólo que ambas formas de entender los fenómenos pueden apuntar hacia planos diferentes del mismo problema, lo cual también nos sugiere que el problema tiene que ver con la explicación.

\subsection{D ucasse: una concepción singularista sobre causas y condiciones}

Algunas razones que hacen atractiva las referencias a Curt D ucasse para el presente trabajo son sus intentos de dar cuenta de un análisis causal en los hechos desde una perspectiva singularista, junto con su concepción sobre las condiciones. El autor considera que la causa consiste en un cambio que ocurre en el entorno inmediato y con anterioridad al efecto, es decir, que si restamos condiciones, lo que puede considerarse en estricto sentido como la causa es la última condición con la cual el evento aún ocurre, de modo que la causa no tiene como elemento definitorio a la conjunción constante; esta no sería más que una característica adicional pues, si la causa está definida adecuadamente, la relación es observable. Las causas y los efectos solo ocurren entre eventos: "[... ] an event can be defined as either a change or an absence of change in the relation of an object to either an intensive or an extensive standard of reference, during a specified time interval" (D ucasse, 1968, p. 2, nota 2).

Las causas no ocurren entre objetos por sí mismos, pues esos son agentes o pacientes de los cambios, de modo que la relación causal ocurre entre eventos, relación que tiene una cierta duración en el tiempo, de modo que tal cambio constituye un proceso. Así, hay causa en los cambios o en su ausencia, que ocurren a objetos inmersos en su entorno, pero la causa no depende tanto de una eventual relación invariable sino del cambio singular que preceda al efecto, que puede ser observable, mientras que la repetición de secuencias causales puede inclusive no existir o ser desconocida. El uso común del término causa, más que a tipos de eventos, se asocia a sucesos concretos que podemos percibir, idea que en principio parece adecuada, salvo que nuestra percepción no suele estar tan desnuda, pues lo usual es que cargue con un gran bagaje de preconceptos: es difícil imaginar cómo se pueda prescindir de las relaciones causales previamente conocidas cuando identificamos las relaciones que estamos experimentando. 
Lo que se entiende por conexión causal es definido por Ducasse (1924, p. 122-3) en razón a la suficiencia y la necesidad, por medio de cuatro términos: causa, efecto, condición y resultante. Todos ellos son estados o cambios que se suceden y se relacionan de cuatro formas posibles: la causa se define por ser suficiente para el efecto, y este, a su vez, se define en razón a que fue necsario, una vez que ocurrió la causa; la condición es el estado o cambio neesario para el efecto y es resultante si es contingente con respecto al estado o cambio inicial. Ducasse (1924, p. 122-3) no es tajante con respecto a que los estados sean siempre condiciones y que los cambios sean causas y efectos, solo afirma que se entiende que es más frecuente que sea así. Toma tres términos en consideración: el entorno de un objeto, un cambio en ese entorno y el cambio resultante en el objeto. Y, puesto que acepta la observabilidad de la causa, descarta poderes ocultos tras ella, así como rechaza la explicación del efecto con base en la regularidad o en la ley, ya que su definición de causa hace referencia a un evento singular; si hay recurrencia esto es una ley causal, pero no es causal como resultado de que sea general (como sí lo aceptaba Hume). Una relación causal es esencialmente entre eventos concretos y si se elabora una ley es porque existen otros casos similares; a la cual se llega por vías estadísticas (D ucasse, 1968, p. 6).

El autor entiende la causa como el cambio que antecede al efecto, independientemente de si es una instancia de una relación invariable; sin embargo, cuando el efecto es precedido por varios cambios simultáneos, no podríamos distinguir cuál de ellos es el relevante, de manera tal que el autor apela a contrafácticos o a leyes, es decir, a la comparación con otros casos. D esde tal punto de vista hay una diferencia notable entre causas y condiciones; el autor señala que causas y efectos son cambios, mientras que las condiciones tienden a ser más estados, es decir, situaciones en las que no ocurren cambios súbitos previos al efecto. Ahora, la cuestión es cómo aceptar en este marco que la ausencia de cambio también pueda constituir un evento causal, pues una ausencia es un estado, de modo que aceptar que un evento también pueda ser la ausencia de cambio en un objeto es difícil de compatibilizar con la noción de causa como "el único cambio previo al efecto".

Como puede esperarse, tanto en la experimentación como en la experiencia cotidiana, lo usual es que existan cambios paralelos a aquel al que se adjudica un papel causal, y en el tratamiento de D ucasse no se hace explícito que hay muchos factores irrelevantes ni cómo podemos diferenciarlos. La definición de Ducasse de causa como el único cambio en el entorno del efecto no explica del todo en qué consiste la suficiencia de ese cambio: si entendemos que la causa es el último de los 
factores que restamos antes de que se impida el efecto, tal factor sería suficiente, pero el orden en que restemos los factores comporta cierta subjetividad o configuraría un estado de cosas diferente del original. No siempre se puede identificar cuál es el cambio que tiene el papel causal en un conjunto de cambios simultáneos, cuál de ellos es suficiente para la ocurrencia del evento, y por esa vía quedamos inmersos en un razonamiento contrafáctico y dependiendo de una inferencia que el autor explícitamente rechaza.

El riesgo que comporta el singularismo es el de debilitar el papel de las leyes, lo cual se compatibiliza con mucha dificultad con el quehacer científico. Por otra parte, el singularismo estricto que se centra en las relaciones entre eventos concretos no permite diferenciar las relaciones causales de las no causales, pues en unos y otros casos ocurren secuencias de cambios, secuencias únicas, en cuanto están situadas en condiciones irrepetibles. Al parecer hemos de indagar más en torno a la relevancia causal, pues no se pueden tomar en consideración los cambios que ocurren simultáneamente con la causa, solo los que pueden tener una influencia significativa. D e D ucasse también es destacable su idea de que los cambios son procesos, es decir, que no son instantáneos sino divisibles, pues en el mundo a nuestra escala las cantidades cambian de forma gradual, sin saltos. El instante y la superficie de contacto entre cambios constituye el límite, pero la delimitación general del proceso depende de su descripción: por ejemplo, no son evidentes los límites entre las fases de una metamorfosis, lo cual nos devuelve a la dificultad de separar la búsqueda de causas de nuestros propósitos explicativos.

\subsection{Suficiencia y necesidad en Mackie}

Visto está que la necesidad causal carece de sustentación plena, lo que nos conduce a la búsqueda de un análisis más preciso de cómo puede operar una relación causal, y al examen de las condiciones que pueden dar origen a un efecto. Se entiende que un evento es la causa de otro si el primero es la condición sin la cual no se presenta el segundo, siempre y cuando hablemos de eventos independientes. Mackie (1999, p.31) acepta que la causa es la condición necesaria y suficiente para que se presente su efecto, aclarando que esto implica la dificultad de diferenciar las condiciones de las causas, o el papel causal de cada uno de los factores previos al evento: "What we call a cause typically is, and is recognized as being, only a partial cause; it is what makes the difference in relation to some assumed background or causal field" (Mackie, 1999, p. xi). 
El análisis causal puede ser de objetos o epistémico: necesitamos saber cómo suceden las causas en la realidad y cómo las conocemos, pero si el problema de la causa está en los objetos, esto implica que no existe la necesidad lógica. Un evento causa otro si es la condición sin la cual no se presenta, así que el evento existe dentro de un estado de cosas, dentro de un campo causal; la dificultad consiste en hacer una diferenciación entre condiciones y causas, distinción que puede ser manejada en el lenguaje común, pero una vez examinada en detalle no se encuentran reglas que permitan una diferenciación al margen de la duda, más allá de que se suele asociar la causa a los factores que emergen fuera de lo considerado como usual. Cuando nos preguntemos acerca de las razones por las que ocurre algún evento, estamos indagando por aquel de los factores que se escapa de la norma; de ahí que se considere, por ejemplo, como causa de un incendio a la chispa y no a la calidad de inflamable del material incendiado (Mackie, 1999, p. 34), lo que nos permite ver el contraste de la posición de Mackie con respecto a Hume, para quien es precisamente el curso normal de la conjunción constante el que la mente acepta como causal. Aceptamos como normal la presencia de oxígeno, que es permanente en las circunstancias en las que vivimos, pero rascar un fósforo o la aparición de un cortocircuito son hechos (no permanentes) que podemos más fácilmente producir o prevenir, mientras que, por ejemplo, sacar el oxígeno de la casa en la que ocurrió el incendio, es muy inusual, y en tal situación ese factor cumpliría un papel imprescindible para explicar el fenómeno. De ahí que el factor que en el lenguaje común se denomina como la causa dependa del contexto, pues es evidente que lo que se considere como habitual en una situación es muy diferente a lo aceptado en otras condiciones: producir fuego en un laboratorio tendrá condiciones determinadas previamente que pueden distar mucho de las que ocurren en un incendio accidental.

El efecto no ocurre como un evento aislado sino dentro de un estado de cosas, y si este cambia, cambiarán las relaciones causales del evento, dado que cualquier efecto se enmarca dentro de un conjunto de condiciones que ejercen influencia causal. En alguna medida las cuatro causas de Aristóteles apuntan hacia la dirección entre las causas estructurales que predisponen y las eficientes que desencadenan un evento, cuya suma es lo que explica la ocurrencia del efecto. También la aplicación del método de diferencias de Mill (muy útil en experimentación) apunta hacia la misma dirección: cambiar un solo factor cada vez permite detectar si alguno de ellos tiene influencia causal. 
La suficiencia de la condición es definida por Mackie como la dependencia del efecto con respecto a la causa: siempre que se dé la condición estará presente el efecto ya que la definición de causa hace referencia al conjunto de factores que lo preceden. Existen conjuntos de factores capaces de producir un efecto, usualmente no uno solo, dado que las circunstancias que llevan al efecto pueden variar: en el caso del incendio se necesita oxígeno, material inflamable y un cortocircuito; en otros casos, oxígeno, material inflamable y un rayo, así que no existe un único conjunto de condiciones con la capacidad de producir el incendio. Podremos agregar que el conjunto de todos los conjuntos de condiciones es el único a la vez suficiente y necesario para producir el incendio, pues los conjuntos parciales constituyen apenas una condición suficiente pero no necesaria para la producción del efecto. El conjunto de oxígeno, material inflamable y cortocircuito constituye la mínima condición suficiente que puede producir el efecto. Cada factor A (es decir, cada factor que hace parte del conjunto mínimo) no es suficiente ni necesario para producir $\mathrm{P}$, el efecto; sin embargo, A con respecto a P es: "[... ] an insufficient but non-redundant part of an unnecessary but sufficient condition" (Mackie, 1999, p. 62). Tal es la condición Inus: si una serie de eventos (no exclusiva) ocurre, causando un efecto, implica que esa es la serie mínima que configura la condición suficiente; si no se da completa, el efecto no ocurre, lo cual muestra que cada factor no es redundante. En esta definición, reiteramos, se aprecia que el autor entiende como causa el conjunto de factores que tienen que darse para que ocurra un efecto pues, aun cuando nos esforcemos en declarar una causa única, lo habitual es que haya multitud de ellas: cada conjunto completo de factores es suficiente para producir el efecto, pero individualmente no es necesario, pues otra conjunción de factores puede ser suficiente para producir el efecto. En eso consiste la condición Inus, un factor causal es solo una parte del conjunto de factores suficiente para producir el efecto, no la totalidad de la causa. D e modo que el cortocircuito, la presencia de oxígeno o el material inflamable son, cada una, condiciones Inus para que se produzca el incendio, pero este conjunto de condiciones no es necesario, pues el incendio puede ser causado por un pirómano 0 por un rayo. La concepción de Mackie también es regularista, pues considera que las causas tienen patrones: se necesitan leyes para poder comprobar que estamos hablando propiamente de causa y no de un accidente: la necesidad y la suficiencia sólo se pueden entender con respecto a otros enunciados generales con los cuales puedan ser contrastados, dado que no es factible asociar ineluctablemente los casos, pues la naturaleza no es del todo homogénea. Esta situación nos deja un espacio compatible con la complejidad de las relaciones causales: un evento es el resultado de los papeles variables que cumplen multitud de factores en el origen de cierto efecto. 
Mackie define la necesidad con respecto a un enunciado contrafáctico: si la condición no se da, tampoco el efecto; y es suficiente si el efecto ocurre siempre que se dé la causa. Si una serie de factores causa un efecto es porque reúne las condiciones mínimas para que este ocurra; si está incompleta el efecto no ocurre (pese a que lo usual es hacer una elipsis que enfatiza una sola de las condiciones). Si nos referimos a un factor $A$, decir que $A$ causa $B$, equivale a afirmar que $A$ es necesario, pero no suficiente; sin embargo, la noción general de causa implica que algo es necesario y suficiente en las circunstancias para producir un efecto, pero si aquellas ocurren no se requiere que la causa deba ser suficiente en el sentido contrafáctico fuerte, esto es, que la garantía de que el evento ocurra no es completa, dada la contingencia del comportamiento de la naturaleza. De todas maneras se requiere más la necesidad que la suficiencia, sobre todo a posteriori (Mackie, 1999, p. 58); en otras palabras, cuando estamos analizando una secuencia causal queremos saber si hubo un determinado factor necesario para la ocurrencia del efecto, pues en cierta medida de esto depende la solidez de algunas explicaciones.

Como ejemplo de lo anterior podemos utilizar el tipo de disposición con que se trabaja en un experimento: una situación artificialmente aislada con el fin de que la naturaleza opere de acuerdo con sus leyes; se manipulan los factores que intervienen con el fin de determinar cuál o cuáles pueden tener relevancia causal sobre el efecto. Así, el factor que se descubre como desencadenante es necesario pero no suficiente para producir el efecto; un posible campo causal completo es lo que podría ser considerado como suficiente (aunque no necesario, pues un mismo efecto puede ser producido en diferentes circunstancias). D ado que en ocasiones describir exhaustivamente el campo total es o muy dispendioso o francamente imposible, se suele privilegiar un único factor como causal. Por eso la experimentación se esfuerza por limitar la cantidad de factores presentes y se centra en mantenerlos constantes para que cierto factor pueda operar sin interferencias. La consideración sobre lo normal y lo anómalo no parece aclarar el panorama de las relaciones causales pues sería otro factor adicional a definir en razón a que depende del contexto de indagación. La presencia de factores anómalos parece más asociada a la agencia humana pues la actividad humana suele ser un factor relevante de cambio en el entorno; es similar a decir: ¿qué habría pasado en la naturaleza sin la intervención humana? A hora, que si identificamos la causa con lo anómalo, nos quedamos sin respuestas para los acontecimientos que tienen un comportamiento regular. 
Mackie examina por medio del ejemplo del incendio que existen unos factores con más peso que otros en la ocurrencia de un evento: cada conjunto de factores puede ser suficiente; así como cada condición Inus lo es tanto como otra. Sin embargo, la eliminación de algún factor puede hacer el resultado más probable que la eliminación de otro. Se preguntará en últimas cuál es el factor cuya presencia es suficiente para que el evento ocurra o qué es lo común a la causa de un tipo de eventos, pero Mackie afirma que el factor es insuficiente sin las condiciones que lo acompañan. Se trabaja con el factor que tenga una mayor capacidad de dar cuenta del efecto en las circunstancias, esto es con la característica causalmente relevante, dado que en una situación existen factores que no tienen incidencia en el efecto; la suma de estas es un reporte causal mínimamente completo (minimally complete causal account), que es un recuento ideal de las causas relevantes para la ocurrencia del efecto, aunque, agrega: "[... ] but if the account is causal rather than probabilistic we can assume that each relevant feature was necessary in the circumstances for that event" (Mackie, 1999, p. 260).

Lo cual implica aceptar que la teoría está limitada a situaciones en que podamos hablar de eventos definidos de forma general, dejando fuera el problema de cómo tratar con fenómenos aleatorios. Además, como afirma Kim (1993, p. 72), el objetivo principal de Mackie es analizar enunciados causales singulares, pero la necesidad y suficiencia se basa en enunciados generales. Podríamos agregar que es posible que la solución consista en buscar la causa que mejor explique, teniendo en cuenta que en ocasiones no podemos dar cuenta del factor con mayor relevancia causal. Como veremos en el cuarto capítulo esta tensión entre relevancia causal y relevancia explicativa da pie a una indefinición que dificulta el análisis causal.

\subsection{Las teonías sobre la manipulación}

Las concepciones sobre la causa como manipulación se basan en la idea de que nuestras acciones se orientan a las intervenciones en la naturaleza, intervenciones que tienen sentido en cuanto a que son capaces de producir efectos: sabemos que para lograr cambios manipulamos la causa, y no ocurre lo contrario, es decir, que actuemos sobre el efecto para influir en la causa. Tal idea es muy útil para entender el origen de la noción de causa, dado que, como afirma Gasking (1955, p. 486), la noción primitiva de causa hace referencia a los medios que ponemos en juego para lograr un resultado. Sin embargo, una noción de este tipo conlleva una gran imprecisión pues da cabida 
a formas causales que no todos los autores aceptan como genuinas, tales como la prevención 0 ciertas secuencias no causales: por ejemplo un cuerpo en caída libre se acelera uniformemente si no se lo perturba, de modo que podemos producir un resultado previsible por las leyes de Newton, pero nuestra intervención se limitaría a dar comienzo al proceso y sus posibles fases o momentos posteriores no son más que el desarrollo de un proceso causado por leyes naturales. En los casos de experimentación el agente interviene creando condiciones de aislamiento artificial que tienen un papel causal, aunque la secuencia de cambios en los objetos que intervienen obedezca a la dinámicas naturales. En un experimento sobre fertilizantes, por ejemplo, el agente procura suministrar o impedir el acceso de alguna planta a cierto elemento químico, con el fin de ver cómo se modifica el crecimiento de la planta en comparación con otra que le sirve de control. Por eso sabemos que la planta crece más con el suministro de ciertos elementos y que su crecimiento se ve limitado cuando los mismos le faltan. La intervención del agente es la que pone las condiciones del experimento, pero es la naturaleza y sus procesos las que producen el resultado, permitiendo identificar los factores que inciden en la producción de un efecto buscado. Collingwood (1940, p. 296) afirma que preguntar por la causa equivale a preguntar cómo podemos producir o prevenir un evento: se actúa sobre lo contingente para obtener fines prácticos, de modo que al privilegiar una condición dándole el nombre de causa lo que hacemos es darle una mayor importancia a la condición sobre la que podemos intervenir. De este modo la causa se refiere a la relación entre medios y fines, es decir que la idea de causa implica un medio por el cual algo hace que otra cosa pase.

En la perspectiva de von Wright (1971, p. 66), es conveniente distinguir entre hacer y producir (bring about): al hacer una cosa podemos producir otra (abriendo una ventana producimos una corriente de aire, enfriamos la habitación, resfriamos a alguien), que es causar ciertos efectos, pero, desde esta concepción el resultado es parte de la acción, y es errado entenderla como causa del resultado, y aunque la distinción entre resultado y consecuencia es relativa, a nuestras intervenciones debemos algunos elementos que nos permiten entender la causa:

The idea that causal connections are necessary connections in nature is rooted in the idea that there are agents who can interfere with the natural course of events. The concept of causation under investigation is therefore secondary to the concept of a human action. And this implies, as I shall try to show, that the idea of causal determinism, associated with this idea of causation, can claim validity only for limited portions of the world, and not for the world as totality (von Wright, 1974, p. 1-2). 
Así, es por medio de la acción que podemos conocer la causa, pues cuando produzco algo es porque realicé una acción previa, como se puede apreciar en los experimentos: se ponen en movimiento sistemas que producen sus estados iniciales y se observa qué pasa dentro del sistema. Por lo tanto, el autor afirma que no es exacto decir que un estado cause otro, más adecuado es decir que la eficacia de una causa puede depender de que se presenten ciertos estados. Si se identifica la causa como manipulación, su espacio propio sería la ciencia natural experimental (y no las ciencias humanas), pero puede ser que en las ciencias humanas existan otros tipos de causación.

Para von Wright en cada efecto hay una multitud de cosas que cambian y otras que no, unas son relevantes para el efecto y otras no, pero no hay una frontera que delimite qué es lo relevante. Por causa entiende una condición suficiente que relaciona factores lógicamente independientes (pues no es una relación entre conceptos o entre enunciados). D e manera que, según el autor, la agencia es la forma básica y primaria de la causa: el agente no es la causa de la causa, sino que la causa es el resultado de su acción (von Wright, 1974, p. 49) pero, agrega, también existe en los eventos naturales. Algunas regularidades naturales son nómicas y otras accidentales, pero son las nómicas la base válida de aserciones condicionales contrafácticas. Sin embargo, no hay forma de comprobar definitivamente un enunciado contrafáctico; solo podemos hacer una analogía: si pudiéramos producir cierto estado, se seguiría el efecto, de lo que se sigue la relación que el autor establece entre el concepto de conexión causal y el de acción.

El planteamiento de Woodward sobre causalidad y explicación también apunta hacia el papel de la manipulación en el uso y elucidación de los factores causales que inciden en la ocurrencia de un suceso. Para Woodward la causa estáligada a los factores que al ser alterados producen cambios con respecto al resultado esperado; por eso para el autor la explicación tiene que responder a la pregunta: ¿qué pasaría si las cosas hubieran sido diferentes? (Woodward, 2003, p. 11); es decir, si se interviene (real o hipotéticamente) sobre cierto antecedente de un hecho, la posible alteración del efecto puede revelarnos el papel que tiene el factor intervenido en la obtención del resultado. Con este tipo de explicación se puede dar cuenta de la diferencia entre las generalizaciones causales y las que son apenas accidentales (Woodward, 2003, p. 16). De tal modo se define la causa en razón a una intervención posible: si cambia solo el valor x de manera que cambie el valor de y o su distribución, entonces x causa y. Si x es una causa de y, tal que interviniendo sobre x se alterará el valor de y, x es necesario para y. 
El atractivo del planteamiento de Woodward está en el hecho de que entiende la manipulación no solo como la posibilidad de intervención real del agente sino que contempla también situaciones hipotéticas acerca del resultado posible de la alteración de algún factor, como ocurre en un experimento ideal, incluso si la intervención es impracticable. En el ejemplo del incendio, aceptamos que el cortocircuito es la causa pues sin él no se produciría, pero se necesitan otras condiciones: si pudiésemos prescindir del oxígeno, tampoco se produce el incendio, razón que lo convierte en necesario. Así, incluso un factor ausente constituye una causa que contribuye a que cierto resultado ocurra: en el caso de un médico que no prescribe los antibióticos al paciente que tiene una infección bacteriana (Woodward, 2003, p. 89), la inacción del médico es causa del deceso del paciente, aunque sean las bacterias las que producen directamente el efecto. Sin embargo, aceptar las ausencias como causas implica correr el riesgo de tener en cuenta una enorme cantidad de información y lo que parece pertinente es limitar los factores a los que puedan ser causalmente relevantes. Para Woodward, las teorías causales deben aceptar casos en que las omisiones son buenas explicaciones, lo cual parece ir en contra de la separación entre causa y explicación, uno de los factores que se considera importante en el presente trabajo: no hay una coincidencia necesaria entre la relevancia de un factor para la causa y la relevancia de un factor parala explicación; pueden no coincidir y si coinciden no es por las mismas razones.

Woodward aplica su razonamiento contrafáctico a tipos de casos, contando con el papel que cumplen las leyes tanto en la causalidad como en la explicación. La concepción heredada aceptaba la validez de una explicación en la medida en que pudiera ponerse en relación con leyes de las cuales el enunciado que describe el evento pueda ser deducido. Sin embargo, la ley no puede entenderse como un enunciado general carente de excepciones y su ámbito de aplicación está limitado a casos previamente definidos: no siempre es evidente la diferencia entre una ley y las generalizaciones de casos accidentales. D e este modo, el hecho de que exista una ley no es garantía absoluta de que cierto factor causal se relacione con su consecuente, pues suele suceder que la ley explique ciertas correlaciones generales, pero no necesariamente dé cuenta de los casos individuales: un insecticida tiene una determinada probabilidad de matar cierto tipo de insectos, pero aún si la probabilidad fuera baja las muertes que cause son su legítimo efecto. Y también es cierto que hay relaciones causales que existen fuera de la ley, dado que una causa completamente fortuita, es decir, que no obedece a alguna regularidad prescrita, no por eso deja de producir su efecto. 
De todas maneras Woodward necesita de un concepto de mayor alcance al de ley y por eso considera que el mejor criterio es que ante intervenciones y otros cambios se conserve una cantidad invariante, dado que las relaciones que nos dan una referencia adecuada de cómo $\mathrm{C}$ altera $\mathrm{E}$ son invariantes, lo cual es más factible. Ante la imposibilidad de encontrar leyes cuya aplicación no esté limitada por rangos y condiciones, Woodward propone que la noción se extienda a toda generalización, incluyendo las de ámbito local y las leyes ceteris paribus. A firma el autor que lo causal se mezcla con la invariancia: la relación causal da cuenta de los resultados experimentales hipotéticos, por lo que alguna medida de constancia (invarianœ) frente a las intervenciones es necesaria para que una relación sea causal: si un enunciado predice qué pasa bajo variaciones del tipo apropiado es una ley causal (Woodward, 2003, p. 16). Sin embargo, no siempre puede prescindirse de las posibles interpretaciones que se hagan sobre qué factores son invariantes en una situación causal: las causas tienen múltiples formas de operar y las descripciones de los eventos pueden ser hechas de múltiples formas. Al respecto es interesante el ejemplo que cita Woodward (2003, p. 230) sobre las posibles causas de un accidente de tránsito: el ingeniero de carreteras se preocupa por el peralte de la curva, la policía de si se habían sobrepasado los límites de velocidad o de alcohol, el constructor sobre las características del vehículo. Aquí se ve que un suceso unitario puede tener muy diversas descripciones y explicaciones, dependientes del punto de vista que sea relevante como respuesta. Así que no hay posibilidad de establecer una causa única aceptable, por lo cual la investigación tiene la función de sopesar cuál es la relevancia de cada factor.

El análisis contrafáctico de la causalidad se enfrenta con el problema de aquellos casos en los que interviene el azar, caracterizados por inestabilidad y sensibilidad a las condiciones iniciales, de modo que variaciones infinitesimales en las condiciones iniciales de dos secuencias de eventos puedan llevarlas a resultados muy diferentes. Por otra parte, existen procesos en los que puede conocerse el mecanismo sin que se sepa cómo operan las causas, como en el caso de un cuerpo en caída libre: la descripción de movimiento se conoce perfectamente, pero todavía su mecanismo causal no ha sido aclarado por completo. Así, podemos hacer manipulaciones de los factores desencadenantes como la altura de la caída, el volumen, el peso y la fricción para predecir cómo variará el resultado y, sin embargo, el mecanismo todavía sigue medianamente oculto. De todas maneras el planteamiento del autor parece seguir muy ligado a la causalidad lineal, lo cual puede deducirse de los ejemplos utilizados y de su análisis: si hay proporcionalidad entre las causas y los efectos, y los procesos son lineales, será más previsible el resultado de la manipulación, pero en 
procesos no lineales se pueden producir cambios que obedecen al comportamiento de sistemas con equilibrios inestables. Los casos de correlaciones estadísticas también pueden constituirse en un obstáculo para la aplicación de las intervenciones.

En resumen, Woodward maneja las causas como estrategias de intervención; sin embargo, las causas así definidas necesitan una definición previa acerca de qué intervenciones son efectivas. De ahí que tal definición sea un tanto circular, en razón a que intenta determinar cuál es el factor que, una vez intervenido, sea capaz de producir una alteración en su efecto, sin precisar cómo 0 por qué es capaz de actuar; además una intervención puede no actuar directamente sino por medio de una cadena causal que conduzca al efecto. En otras palabras la cuestión es que podemos hallar un factor que tenga una correlación con el efecto pero no necesariamente esa correlación es la clave de su producción. Además los contrafácticos dependen de una situación general previamente conocida y no funcionan cuando hay sobredeterminación, ya que si el efecto tiene más de una causa, es posible que este se produzca pese a que una de las causas falle. El autor habla de causas totales o contributivas (Woodward, 2003, p. 60), en razón a un condicional contrafáctico: para probar que una causa tiene incidencia sobre un efecto dependemos de que los demás factores estén fijos, ya que si hay más variaciones no podríamos saber cuál tiene un papel causal determinante. Pero estas causas contributivas se parecen mucho a lo que otros denominan condiciones: los estados que constituyen factores necesarios para que las causas emergentes operen.

El problema para la teoría de Woodward es el mismo que para todas las que usan condicionales contrafácticos, una cierta precariedad ontológica: la comparación con un infinito número de mundos posibles, que no nos ofrece seguridad acerca de si en efecto con la manipulación se produciría el resultado previsto. Las teorías contrafácticas dan cuenta de casos que no solucionan otras teorías, como los casos de doble prevención y también de casos en los que no hay transferencia de energía o de otra cantidad conservada, como los efectos por omisión. $Y$ en esto consiste su fortaleza y utilidad, pues es un procedimiento valioso como medio para indagar acerca de las posibles causas y factores que inciden en la presencia de un efecto. De igual manera, las intervenciones y los razonamientos contrafácticos parecen un medio muy útil para la formulación de explicaciones causales, dado que el procedimiento puede ser el adecuado para determinar la relevancia causal de factores entre causas múltiples. 


\subsection{Cartwright: pluralidad y leyes}

Nancy Cartwright da especial importancia a la explicación causal, pues en esta el poder explicativo es a la vez garantía de verdad: no podemos inferir la verdad de una hipótesis solo por el hecho de que esta sea capaz de dar más explicaciones; en lugar de aceptar como verdaderos los enunciados que permiten construir explicaciones o salvar los fenómenos, se debe buscar la causa más probable (Cartwright, 1991, p. 6). Para nuestro conocimiento son muy importantes las leyes causales, en la medida en que son ellas las que nos permiten diferenciar las estrategias efectivas para conseguir un fin, de aquellas que no lo logran; a su vez, una importante forma de la explicación consiste en determinar las causas y encontrar el marco en que cada hecho se relaciona con patrones más generales o teorías más amplias: debe haber acuerdo entre el contenido de las leyes y su capacidad explicativa (Cartwright, 1991, p. 72). Prescindir de las causas implicaría que no pudiésemos utilizar estrategias efectivas para incidir sobre los acontecimientos y, dado que la técnica es un conjunto de muestras de capacidades efectivas de intervención en la naturaleza, hemos de deducir que las causas son reales. Cartwright llama la atención acerca de que el empirismo confíe más en las leyes que en las causas, y es cierto que las leyes y las causas parecen, desde cierto punto de vista, sustentarse sobre la regularidad: un caso ilustrativo es el de las réplicas experimentales, que incrementan la confiabilidad de las inferencias causales; pese a que entre cada experimento y el siguiente no haya conexión física sino una analogía, es un procedimiento completamente válido para corroborar leyes e inferencias causales.

Ahora bien, así como existen muchas vías en las que se puede influir en una situación para procurarse un resultado, existen también muchas formas de acción causal, pues la naturaleza no es homogénea: hay pluralismo causal pues la causa es un concepto muy amplio que abarca relaciones de tipos diferentes. El problema es que, pese a esta consideración, se pretende usar un concepto unitario, cuando lo más adecuado sería aceptar que o es un racimo de conceptos o un término no específico: si no conocemos exactamente cómo se produjo el evento o por medio de qué mecanismos, el lenguaje causal es el más adecuado. Los mecanismos son la preocupación del conocimiento científico, mientras que el análisis causal general es objeto de la especulación filosófica y un problema de la intuición, de manera que, a falta de información más precisa, habremos de esperar que no haya una teoría única, sino solo variados intentos de relacionar el concepto de causa con el de explicación y el de ley natural. 
Para Cartwright las leyes no son suficientes para una buena explicación, leyes que, desde su perspectiva, deben atender primordialmente a la descripción de fenómenos más que a dar cuenta de entidades teóricas; esto hace que sean más adecuadas para los modelos que para el comportamiento real de los fenómenos. Afirma que las leyes son pocas, pues lo usual es que sean generalizaciones que operan bajo condiciones acotadas: leyes limitadas a las situaciones correctas, con lo que se reitera la enorme distancia entre modelos y realidad, y si las ecuaciones son verdaderas para los modelos, es una prueba de que las leyes no gobiernan la realidad (Cartwright, 1991, p. 162). Se puede agregar a lo que plantea la autora el hecho de que las leyes físicas más comunes están diseñadas para describir y modelar procesos lineales, y que dejan por fuera muchos de los fenómenos de la naturaleza: en estos casos las leyes apenas apuntan hacia las características más gruesas del comportamiento de un sistema sin que puedan hacer predicciones precisas. Una opción ante este problema es acudir a herramientas estadísticas, pero la autora no cree que allí esté la solución dado que tales herramientas no se ocupan de los casos excepcionales o aún de los que tienen una baja probabilidad. Sin embargo, la autora no parece tener en cuenta que también puede cuantificarse la relevancia negativa, es decir, el peso relativo que algunos factores pueden tener para bajar la probabilidad de que ocurra un evento y que en los casos cuya probabilidad es baja también es posible que puedan encontrarse otros patrones bajo estudios más detallados.

Ahora, difícilmente es aceptable una afirmación tan tajante como la que hace la autora con respecto a que las leyes no gobiernan la realidad sino solo los modelos, pues tendríamos que olvidar que los modelos se hacen para abstraer el comportamiento de la naturaleza en ausencia de interferencias, lo cual los acerca a la forma de las estructuras matemáticas (que carecen de contenido) y los aleja de la causación fáctica. Si prescindimos de los modelos tendremos dificultades para contrastar enunciados, pues careceríamos de una estructura ideal con la cual comparar las variaciones reales y para formular leyes, que necesitan de regularidad. De todas formas no se puede prescindir de las leyes, pese a sus limitaciones: con ellas se especifican los factores que son relevantes para una explicación; son ellas las que permiten diferenciar qué modelos son admisibles y cuáles no, pese a que la causa sea la que da la clave para saber qué propiedades de los modelos corresponden al comportamiento real.

El propósito de esta reflexión no es el de devolvernos a un regularismo que ponga a depender la causa de una relación con otras secuencias causales: esto implicaría que la causa no estuviera en los hechos y que una secuencia individual se reputara como causal apenas por depender de otras 
similares. Frente a esta posición es mejor defender una posición singularista como la de Anscombe y Cartwright (2000, p. 47): una causa singular no lo es por ser similar a otras, no necesita ser confirmada, ya que puede haber ocurrido una sola vez y pese a eso ser causal. Las regularidades y la estadística nos ofrecen datos en la búsqueda de causas, pero no siempre: es otro caso más en que la ciencia sufre la tensión entre la descripción detallada (en extremo inabordable o muy compleja) o la modelización (simplificadora y por tanto inexacta). Es aquí cuando el estudio sistemático de un solo caso - como el del estudio de la digestión por Beaumont (Harré, 1986, pp. 32-41) - puede ser una forma de indagación capaz de ofrecer una visión muy completa de la historia causal de un evento, cuya generalización se hace a posteriori.

D esde Hume se ha indagado acerca de en qué puedan consistir las posibles fuerzas que permitan unificar las distintas relaciones causales, sin que se haya podido hallar una respuesta que abarque la pluralidad de los casos. Los eventos a que dan lugar las causas obedecen a un conjunto de condiciones que se suman, de las cuales se suele privilegiar como causales aquellas que cumple la función de detonante siempre que las condiciones necesarias ocurran: las capacidades o disposiciones podrían ocupar este papel, lo cual es muy útil en ciertos casos como los relativos a la búsqueda de estrategias de intervención o para determinar la responsabilidad derivada de los actos, 0 incluso cuando tratamos de reconstruir la historia causal que precede a un efecto. La causa en Cartwright está asociada a las capacidades de los objetos, como en el caso de la reacción de elementos químicos: tienen cierta capacidad que pierden o se transforma en virtud de la reacción con otros. Sin embargo, tales capacidades pueden más bien entenderse como parte de las condiciones necesarias para que las causas operen: un vidrio es frágil ante la piedra, pero resistente frente a la lluvia. En ambos casos la condición del material es la misma, pero en el primer caso hay un factor cuya potencia es superior a la resistencia del vidrio.

En síntesis, aparte de la pluralidad causal, de la autora hay algunas ideas que sirvieron como germen de la que aquí se pretende sustentar: postular regularidades como lo hace la ciencia al formular leyes de la naturaleza revela la necesidad de construir una visión ordenada sobre los hechos de la realidad que se contrapone a la complejidad de lo natural. Aceptamos que la realidad es plural, en dos sentidos: como riqueza de mecanismos por medio de los cuales se propaga la influencia causal y como la multitud de factores que confluyen en la ocurrencia de un efecto. La ciencia elabora modelos de comportamiento más o menos idealizados que permiten comprender de qué forma operan los diversos fenómenos, pero no se desentiende de los mecanismos por los 
cuales se propaga la influencia causal, lo cual es un ejemplo en los hechos de cómo la necesidad de explicaciones comprensibles nos lleva a dejar de lado las diferencias de lo concreto, pero es de esperar que la ciencia continúe con su camino en la elaboración de explicaciones más específicas que también den cuenta de la diferencia.

\subsection{Salmon: de vuelta a la explicación causal}

Salmon entiende que la explicación consiste en la búsqueda de los mecanismos causales, de modo que las relaciones causales son un requisito de las explicaciones; así que estas consisten en encontrar cómo los eventos se enmarcan dentro de la estructura causal del mundo y, por tanto, no se limitan a la elaboración de un argumento deductivo. Para llegar a este punto, el autor define que los mecanismos causales consisten en procesos que interactúan; propone que en las situaciones causales existen cantidades que se conservan, mientras que se transforman algunas propiedades de los objetos involucrados. La noción de proceso de la que parte se aleja un tanto de la noción común: en un proceso típico, por ejemplo, una bola de billar impulsada sobre una mesa, esta conserva ciertas cantidades como su masa y velocidad, capaces de interactuar con otros procesos, como otra bola con la cual choca. Con ello vemos que lo que se entiende Salmon por proceso causal (derivado de la noción russelliana de línea causal) consiste en cierta entidad que conserva su estructura, de modo tal que sea capaz de transmitir una marca, es decir, una modificación de alguna característica particular de su estructura. En cambio, existen líneas de sucesos que semejan ser procesos, pero en las cuales el cambio aparente no deja una marca, no es capaz de una transformación. Así sucede, por ejemplo, en el paso de la sombra de un objeto que se mueve, proyectada sobre un fondo irregular: es un pseudoproceso, en la medida en que sobre el fondo en el que se proyecta la luz no hay ninguna marca que se haya producido por el paso de la sombra, sin transmitir su estructura ni las modificaciones en su estructura. El autor defiende una postura óntica de la explicación y de la causa, en contraste con la concepción epistémica que se basa en las regularidades; en su concepción los procesos cumplen el papel de mecanismos capaces de transmitir influencia causal, participando en líneas de secuencias que ocurren en el mundo, capaces de transmitir una marca y de interactuar con otros procesos: si un proceso tiene una característica que se modifica después de la intersección con otro estamos hablando de una interacción causal; la explicación válida es la que da cuenta de los mecanismos causales. Salmon intenta responder a la búsqueda de una idea de causa ligada al comportamiento de los objetos, es decir, aquellos procesos o líneas de mundo que muestran ciertas constantes en el tiempo, que 
mantienen cantidades en ausencia de interacciones con otros procesos, por tanto, capaces de portar una marca, que es una característica que permite diferenciarlos de los pseudoprocesos. Ahora bien, la interacción entre los procesos definidos en tales términos es lo que propiamente puede ser llamado interacción causal: una marca - una modificación de cierta característica - es conservada por un proceso y transmitida por medio de una conjunción interactiva entre procesos (Salmon, 1984, p. 179).

El modelo de transmisión de marca de Salmon está principalmente ligado a las causas mecánicas, en la medida en que la noción de proceso causal depende de modificaciones de estructura que tengan alguna permanencia. Además, la transmisión de marca no siempre da cuenta de la causa, pues existen marcas irrelevantes con respecto a las interacciones causales: una marca de tiza en una bola de billar, por ejemplo, se conserva como parte del proceso, pero no es relevante con respecto a un choque, mientras que las características del movimiento son relevantes para la interacción con otras bolas. Así, el criterio de transmisión de marca permite excluir los pseudoprocesos pero no las características irrelevantes para las interacciones causales. Hay dificultades para aplicar el modelo a casos como el de la gravedad, pues aún no se han identificado si existen ondas o partículas capaces de propagarla $;$ y mucho más sucede en los casos en los que no se presenta transferencia de energía, como sucede habitualmente en psicología o en economía. En este último campo, por ejemplo, el precio de un bien escaso sube como resultado de multitud de transacciones, cada una de las cuales implica un intercambio físico de objetos, pero no es el proceso físico el que nos permite entender la alteración del precio del bien. También los eventos complejos se escapan a los presupuestos del modelo, pues en casos como los de la explicación molecular de la temperatura o de la presión de un gas, son más adecuados los manejos estadísticos, dado que es físicamente imposible medir individualmente cada intercambio de energía. Así que la teoría de transmisión es un intento de solucionar la conexión oculta de la causalidad humeana, pero es adecuada primordialmente a procesos físicos más bien idealizados, porque es usual que las cantidades, por ejemplo, de energía, disminuyan por fricción o disipación. Además, no parece compatible con omisiones y ausencias, que nos proveen buenas explicaciones, pese a tener el aspecto de cadenas causales disyuntas.

\footnotetext{
${ }^{4}$ Según lo último que sabemos son ondas, pero todavía no conocemos sus mecanismos.
} 
D e todas maneras el estudio de Salmon es fundamental, no solamente en referencia a su propuesta de manejo de las causas sino también en lo que tiene que ver con la explicación, como se verá en detalle en el capítulo 4. Para el autor el mundo tiene una estructura causal, compuesta de procesos e interacciones, a partir de las cuales se construyen las explicaciones. No lo ven así Hempel y O ppenheim, (1948, p. 141), quienes creen que la explicación no tiene que ser necesariamente causal, esta es apenas un tipo particular de explicación más (inadecuada para la física y la química) y expresamente limitan la explicación causal al estudio del comportamiento humano, en la medida en que en este intervienen propósitos. Frente a este punto parece más adecuada la posición de Salmon, pues es fundamental tener en cuenta que las causas permiten entender, esto es, construir explicaciones e historias causales de eventos concretos, dando cuenta de por qué ocurren cambios en la realidad.

Se suele entender por explicación, entre otros sentidos posibles, dar un significado o describir cómo ocurre un fenómeno; pero la importancia de la explicación causal radica en la amplitud de fenómenos a los cuales se aplica, además de que, en principio, parece adecuarse a la necesidad de dar cuenta de los sucesos individuales. La explicación puede obedecer a necesidades pragmáticas; pero aun así, tanto la explicación como la causalidad necesitan basarse en un plano objetivo. No puede negarse que las explicaciones son epistémicamente relativas, pues dependen del contexto de la pregunta y de lo que se conozca previamente, razón por la cual solemos aceptar lo que nos es más conocido, pero habría que ir muy lejos para negar que en la realidad existen mecanismos que permiten la transferencia de influencia causal entre eventos. El asunto es que las explicaciones pueden ser más o menos válidas en cada contexto, pues un factor adquiere mayor relevancia, por ejemplo, dependiendo de la escala en la que se describa y analice el proceso; así, no es lo mismo el magnetismo a escala atómica que en un plano macroscópico y menos aún la temperatura, que en la escala microscópica es solamente movimiento.

La idea de que la causa es el cemento del Universo obedece a la necesidad de contar con un principio que dé cuenta de la regularidad causal, pero, dado que en las situaciones concretas no se repite exactamente la misma relación causal, es necesario determinar cuáles son los factores relevantes que permiten encontrar similitudes entre dos situaciones causales: sin ellos tal idea carece de contenido (Kutach, 2007, p. 329). Salmon plantea que incluso cotidianamente existen patrones de razonamiento que permiten la búsqueda de causas: por ejemplo, cuando hay una coincidencia improbable buscamos una causa común, como cuando surge una enfermedad en 
un grupo de personas; en esto consiste una horquilla conjuntiva (esta idea y el nombre vienen de Reichenbach (Salmon, 1984, p. 158), aunque éste las entendía como frecuencias o propensiones, mientras que Salmon las entiende como frecuencias). Las horquillas conjuntivas están abiertas hacia el pasado, no hacia el futuro (es decir las coincidencias es explican en términos de causas comunes, no de efectos comunes). Sin embargo, Salmon concluye que no siempre es claro que haya una causa común identificable pues los efectos pueden ser secundarios a una causa previa, así que lo que hay que hacer es buscar los mecanismos causales que transmiten la influencia, con lo cual la causa común es apenas un indicio que habría que comprobar. La necesidad de regularidad ha conducido a intentos de reducir la causa a probabilidad, pero esta vía tiene algunas conocidas limitaciones y por ello Salmon abandona parcialmente la tesis de que todos los factores causales pueden ser explicados en términos de relevancia estadística (Salmon, 1984, p. 44-46), pues no siempre una correlación estadística es un indicio correcto de que exista una relación causal. Menciona Salmon que en la búsqueda de la causa de ciertas patologías, se pueden confundir correlaciones con causas, como en el caso de un estudio que relacionaba el consumo de café con las enfermedades cardiacas, luego refutado por haber ignorado que la correlación se daba con respecto a que los pacientes fumaban tabaco con el café, de modo que una correlación estadística positiva simulaba ser una confirmación de lo que no era más que una causa indirecta. Por razones como esa, Salmon insiste en la necesidad de que conozcamos las relaciones causales, pues una alta probabilidad no siempre es una demostración de que exista una relación directa entre cierto factor y su presunto efecto. Se requiere de una relevancia positiva, es decir que el factor causal se pueda asociar a un incremento en el efecto, lo que Salmon considera un ingrediente necesario de la causalidad. También hay que tener en cuenta los factores que bajan la probabilidad del efecto, pues el conjunto de factores que elevan la probabilidad como los que la disminuyen son los que nos permiten reconstruir la historia causal del evento. Lo que hay que discutir es si ese factor es suficiente como prueba de la causa o si es apenas un indicio de la existencia de una relación causal, elemento que no parece haber sido desarrollado a cabalidad. En esta vía de la construcción de la historia causal del evento, Salmon enfatiza la importancia de los factores relevantes para las explicaciones:

Inference, whether inductive or deductive, demands a requirement of total evidence-a requirement that all relevant evidence be mentioned in the premises. This requirement, which has substantive importance for inductive inferences, is automatically satisfied for deductive inferences. Explanation, in contrast, seems to demand a further requirementnamely, that only considerations relevant to the explanandum be contained in the explanans. This, it seems to me, constitutes a deep difference between explantions and arguments (Salmon, 1984, p. 94). 
Así, las herramientas estadísticas pueden ser una vía para acceder a las relaciones causales a partir de la búsqueda de constantes o por lo menos de altas probabilidades, vía por la cual se podrían conciliar las particularidades de los eventos reales con la necesidad de regularidades nomológicas que los expliquen. Sin embargo, lo que privilegia Salmon con su teoría de los procesos no se dirige a buscar el incremento de la probabilidad como indicio de la causa sino la continuidad de los procesos causales y las interacciones entre eventos (D owe, 2000, p. 148). La cuestión que se quiere responder es cómo pueden explicarse los casos en los cuales se produce un efecto pese a su baja probabilidad. El hecho es que en cada situación hay numerosas condiciones presentes, algunas interfieren, otras no y no tenemos un criterio suficientemente claro que nos permita delimitar ex ante cuáles de ellos son relevantes: en el caso del defoliante que no acaba con todas las plantas, no sabemos cuáles sobrevivirán ni por qué.

Salmon sustenta su visión en el papel que cumple la explicación causal. El autor busca mostrar cómo los eventos se enmarcan dentro de la estructura causal del mundo: la única explicación posible no es la que se deriva deductivamente de las leyes, sino que también es factible explicar a partir de los factores relevantes para la ocurrencia de un hecho. Así, afirma:

To provide an adequate explanation of any given fact, we need to provide information that is relevant to the occurrence of that fact-information that makes a differenoe to its occurrence. It is not sufficient simply to subsume an occurrence under a general law; it is necessary to show that it has some special characteristics that account for the features we seek to explain. As we shall see, this notion of explanatory relevance plays a key role in the development of theories of statistical explanation (Salmon, 2006, p. 45).

De manera que se ha de buscar aquel factor significativo para elaborar una buena explicación, cuestión a la cual las leyes no siempre dan respuesta: pueden cubrir un cierto rango de casos, pero pueden dejar una porción sin cobertura, como puede verse en el método inductivo-estadístico propuesto por el autor: la probabilidad más alta se asocia con la causa, pero existen correlaciones accidentales y también otras que obedecen a una causa común; además de que no tiene en cuenta la relevancia negativa que ejercen los factores que dificultan o impiden el efecto. Salmon inicialmente rechaza que las explicaciones científicas deban ser argumentos, pero luego acepta que algunas lo son; en el mundo existen diferentes formas de interacción entre eventos, pero nuestra observación rara vez revela el mecanismo causal, de ahí que se requiera un esfuerzo para descubrir las relaciones y las explicaciones causales, pues la explicación puede ir más allá del conocimiento descriptivo de lo observable. 
Las explicaciones buscan develar los mecanismos, causales o de otro tipo, como los que pueden operar en la evolución de las especies o en las relaciones de equilibrio o co existencia, en que unos factores alteran otros dentro del sistema, y que pueden implicar interacciones reversibles o cíclicas. En cambio, para que haya causa debe haber transformación de una propiedad por la acción externa de otra, capaz, junto con los demás factores que hacen parte de la situación causal, de producir los hechos que se intenta explicar. La concepción óntica de Salmon explica por medio de hechos y relaciones objetivos: lo que explica un evento es lo que lo produce, a pesar de que los mecanismos estén ocultos. La concepción óntica entiende la explicación como la búsqueda de los mecanismos subyacentes que producen los fenómenos. D e esta forma, la relación causal no depende de otros hechos con los cuales se compara: cada hecho tiene sus propias y únicas causas, a cuyo conocimiento podemos llegar por diferentes vías, incluidas muchas de las que utiliza el regularismo, como pueden ser los índices de correlaciones estadísticas entre factores y efectos.

La perspectiva de Salmon tiene un acento más realista que pragmático, en la medida en que la explicación suele responder a porqués, pero no está estrictamente limitada al contexto; dado que la búsqueda de causas hace referencia a los hechos reales, no se conforma con explicaciones que salven los hechos. El contexto puede determinar qué explicaciones son más pertinentes, pero eso no altera que las causas hayan ocurrido de cierta forma, de modo que la explicación pragmática entra en conflicto con las relaciones de relevancia objetiva que hacen a una explicación científicamente correcta, aunque el pragmatismo puede determinar qué aspectos son los más prominentes en un determinado contexto (Salmon, 2006, p. 185). La pertinencia se da en razón a nuestros intereses, que pueden ser los de prevención, acción o simple curiosidad intelectual, de modo que la posición pragmatista, si bien no da respuesta a naturaleza de la causa, da cuenta de por qué pueden coexistir explicaciones diversas.

En su defensa del modelo de relevancia estadística, Salmon creía que las relaciones causales podían ser explicadas por medio de conceptos estadísticos, pero luego reconoce que las relaciones de relevancia estadística no tienen fuerza explicativa por sí solas, sino que su valor depende de la medida en que provean evidencia de las relaciones causales (Salmon, 2006, p. 166); de modo que la explicación causal debe apelar a mecanismos como los de propagación o la trasmisión de una cantidad conservada, que no se explican en términos estadísticos. La relevancia estadística es una fuente de indicios causales, muy útil porque permite encontrar patrones de comportamiento que 
pueden expresarse como leyes o por lo menos como tendencias: la relevancia estadística apunta a las correlaciones de factores entre causa y efecto, es indicio de las causas, pero la relevancia causal está en los hechos y en las posibles vías y mecanismos de influencia causal.

En resumen, vemos una amplia variedad de teorías que intentan dar cuenta de en qué consiste propiamente que algo pueda considerarse como una causa, más allá de una consideración muy amplia, que abarca múltiples manifestaciones y modos de relación, como puede verse en la reflexión de Nancy Cartwright:

Causes make their effects happen. That is more than, and different from, mere association. But it need not be one single different thing. O ne factor can contribute to the production or prevention of another in a great variety of ways. There are standing conditions, auxiliary conditions, precipitating conditions, agents, interventions, contraventions, modifications, contributory factors, enhancements, inhibitions, factors that raise the number of effects, factors that only raise the level, etc. (Cartwright, 1999, p. 119).

No se ha demostrado que pueda plantearse una teoría capaz de unificar las diferentes concepciones, pues hay distancias insalvables entre los dominios puramente mecánicos y materiales, con respecto a las concepciones epistémicas que ponen el acento en la forma en la cual damos cuenta de las secuencias de eventos; parece por ahora imposible cerrar la brecha entre las concepciones que entienden el problema de la causa como una relación ontológica frente a quienes defiende que este es un problema epistemológico, por lo cual un objetivo sensato seńa el de intentar delimitar de forma más precisa cuáles son los aspectos correspondientes a cada campo, procedimiento que, si bien no nos dará todas las respuestas, por lo menos nos aclarará los métodos más adecuados para su abordaje. 


\section{LOS VARIADOS SENTIDOS DE LA PLURALIDAD CAUSAL}

E 1 mundo no es una hilera de fichas de dominó

S. Pinker

Ante la diversidad de análisis posibles sobre el problema de la causa, algunos de los cuales fueron presentados en el capítulo anterior, es necesario entrar a considerar si nos encontramos frente a una relación que ofrece múltiples manifestaciones o si la diversidad podría estar más bien en las teorías que abordan de diferentes formas un solo fenómeno, problema que recorre desde el lenguaje común hasta los usos del término en ámbitos especializados. Fuera de la cuestión semántica, se puede observar que una parte del problema se deriva del hecho de que las situaciones causales suelen ser complejas, de modo que lo habitual es que los efectos obedezcan a la conjunción de una multitud de factores y que existan diferentes mecanismos por medio de los cuales opera la transmisión de influencia causal. A demás, en el plano teórico se debe examinar si existe alguna posibilidad real de entender la causa por medio de sus posibles elementos o de términos más básicos, un punto importante para saber si puede esperarse que se formule una teoría única o si debemos conformarnos con múltiples teorías que den cuenta apenas parcial de los fenómenos agrupados bajo el término causa. Una vía interesante de exploración del problema nos lleva a considerar de nuevo que el problema de la causa está emparentado con el de la búsqueda de cierto tipo de explicaciones, vía que permite manejar algunas de las inquietudes planteadas a lo largo del capítulo.

\subsection{El lenguaje natural y el problema semántico}

Los intentos de encontrar una definición operativa y general sobre el concepto causa no han dado hasta ahora los frutos esperados, pues ni en el lenguaje común ni en los especializados parece 
haber un acuerdo sobre los límites y alcances de lo que denominamos con dicho término. Por tal razón conviene empezar por intentar una exploración general de los ámbitos en los que se suelen utilizar las diversas referencias al término, ya que no sólo se utiliza en la filosofía sino que su uso común es amplio, unas veces de forma explícita y otras implícito en muchos términos que expresan ciertas relaciones. De ahí que sea conveniente hacer algunas consideraciones sobre los usos del término en lenguajes no especializados, con el fin de aproximarnos a una delimitación del concepto. No hay que olvidar que la economía de los lenguajes naturales hace que, en estricto sentido, no haya sinónimos - cada palabra justifica su existencia siendo la expresión de un cierto matiz- , razón por la cual determinar los significados de las palabras suele hacerse comparándolos con otros términos o descomponiéndolos en otros más simples, procedimiento que suele ser problemático, como sucede en los casos de conceptos tan comunes y complejos como: onocer, ex plicar, bueno. El lenguaje filosófico aspira a un grado de precisión mayor, que aprehenda el significado adecuado a nuestro concepto esencial sobre lo que sea propiamente la relación causal.

En el lenguaje común entendemos por causar hacer que algo suceda; con ello se alude a la razón, al principio, a la acción que conduce a que un cierto resultado se logre; pero este significado presenta una notoria vaguedad. Lo equiparamos con verbos como generar, producir, hacer, provocar, determinar; aunque también con otros de carga negativa como evitar, parar o prevenir. En este conjunto no es evidente un vínculo que nos dé indicios acerca de cuáles han de ser las características que comparten dichos verbos para ser sinónimos, ni se hace evidente una característica común que deba tener aquello que se denomine causa: el término es lo suficientemente amplio como para que no sepamos si se hace referencia a un objeto, a una acción o a una relación. Además, tampoco es evidente cómo diferenciar una causa de aquello que se le asemeja. En resumen, el término no nos da información de su pertenencia a un género mayor ni de la especie que permita diferenciarlo de otros afines.

D e todas maneras los lenguajes naturales no son sistemas cerrados cuyos significados tengan una correspondencia unívoca con los conceptos a los cuales sirven de vehículo y no sobra hacer alguna exploración acerca de su uso. Las palabras sufren de una alta dependencia con respecto al contexto, hecho que no implica necesariamente la existencia de una multiplicidad de significados, como lo afirma Pinker (2007, p. 164), sino que es una muestra de que la mente no utiliza el significado como una unidad indisoluble sino como el resultado de agregar fragmentos útiles para cierto contexto, con el fin de evitar la multiplicación de las palabras en cantidades inmanejables 
por la memoria humana; por ello se acude al uso de giros y matices, así como a términos más específicos que permitan comunicar la información precisa: el contexto permite determinar la función gramatical que cumplen ciertos términos y el alcance que tienen frente a los hechos efectivamente referidos. Además, tanto el significado de las palabras como el alcance de los conceptos varían con el paso del tiempo, con lo cual no podemos esperar que palabras con una larga historia, como la que ahora nos compete, carezcan de ambigüedades.

El determinismo lingüístico sostiene que la lengua hablada es la del pensamiento o por lo menos lo estructura (Pinker, 2007, p. 176), pero el lenguaje no puede impedir que efectivamente se pueda pensar de una u otra manera, en tanto sirve de medio, más o menos eficiente, para la elaboración y expresión de conceptos. Por eso en ocasiones se lamenta que la lengua marque 0 limite el conocimiento, pero lo cierto es que no hay lenguas privilegiadas que permitan un mayor desarrollo de algunas áreas del conocimiento; es más, todo lenguaje es limitado en tanto medio expresivo de la razón, pero también da apoyo al razonamiento al permitir comunicar aspectos abstractos de la realidad tales como el espacio, el tiempo, la causalidad, entre otros, términos que han venido enriqueciéndose y haciéndose más precisos a lo largo de su historia. D e todas maneras sigue persistiendo un margen apreciable que distancia las palabras de los conceptos que intentamos expresar por intermedio de ellas.

Como ya veíamos, el término aitia, uno de cuyos sentidos originales alude a las causas, se relacionaba con la búsqueda de la culpabilidad o responsabilidad por la comisión de un acto, para luego abarcar la idea de motivo (Broadie, 2012, p. 21; también en Collingwood, 1940, p. 291), con lo cual revela el matiz inicial que se refería principalmente a los actos humanos y a la agencia asociada a la causa, sentido compatible con la causa como forma de acción que se ejerce sobre un objeto o situación pasiva. En la historia también ha sido frecuente la asociación del término causa con el de explicación, con lo cual no puede diferenciarse inicialmente si el sentido pertinente se inclina más hacia la descripción de las cosas en sí mismas, hacia las formas de relación de estados de cosas sucesivos en la realidad o hacia el problema de cómo y qué conocemos de tales estados de cosas, esto es, que en principio no se puede percibir si la preocupación por el término causa se debe buscar en la realidad de las cosas o en las representaciones que nos hacemos de ellas. Sin entrar aun en el problema de la explicación, la búsqueda de respuesta a las preguntas del tipo ¿por qué... ? se asocia desde los inicios de la reflexión causal con la necesidad de dar cuenta de los factores que permiten la existencia de un determinado estado de cosas por cuyo origen indaga 
este tipo de preguntas: se empieza a disociar (sin claridad suficiente, claro está) el papel que cumple la mecánica de la relación entre determinados factores, de lo que podría considerarse una causa última o el motivo de un acto.

Al parecer, así como sucede en el lenguaje científico - en el cual el término causa se suele reemplazar por otros más específicos, con mayor precisión descriptiva - en los lenguajes naturales suelen usarse verbos de acción más adecuados a la diversidad de situaciones con las que nos enfrentamos a diario, pues permiten comunicar de manera más efectiva el tipo de hecho que se sucede. Es plenamente posible hacer una descripción adecuada de una acción real prescindiendo de la palabra "causa"; podemos dar cuenta de sus antecedentes, de los factores necesarios y de las circunstancias suficientes para que un cambio en un estado de cosas tenga lugar, es decir, se puede describir la historia de los mecanismos sin necesidad de acudir explícitamente a un concepto abstracto como el de causa. Lo cual sugiere que una de las dificultades relativas a la definición del término está en su grado de generalidad con relación a los verbos particulares utilizados para describir ciertas acciones. En general, los verbos de uso más cotidiano suelen expresar descripciones más bien concretas, en las que se encuentran implícitos componentes elementales, entendiendo que nociones causales, así como sucede con contado y movimiento, funcionan como parte de los significados de los verbos (Pinker, 2007, p. 134), lo que sugiere la posibilidad de que tales nociones sean componentes básicos de las herramientas cognitivas. De esta forma, en los casos generales operan los vocablos propios del campo abstracto, mientras que en los particulares se requiere de términos que den una mejor cuenta de los mecanismos o de las características propias de una situación concreta, de forma análoga a lo que sucede con los términos bueno o malo en ética, que pueden ser remplazados por otros más precisos, que describen de forma más adecuada el tipo de actos que se quieren calificar. La noción de causa se usa en referencia a acciones o relaciones básicas para nuestra comprensión y manejo de secuencias de hechos; está implícita en muchas acciones que se describen en el lenguaje: se entiende que "cortar un pan" es causar que el pan esté dividido, sin necesidad de describir que el hecho de que una persona haya pasado un cuchillo por el pan fue la causa de que los trozos estén separados; de modo que el término se comporta como uno de los elementos básicos que nos permiten elaborar significados más complejos, ya que el lenguaje común no obliga a emplear las descripciones causales explícitas de las situaciones en las que el contacto, el movimiento o cierta acción sean los mecanismos de relación efectiva. 
El uso de la palabra causalidad es, en cambio, más especializado, pues se dirige a la relación entre causa y efecto, a su principio o cualidad, ya un tanto alejada de sus aspectos prácticos. Con ese término se suele entender el enunciado general ontológico que nos dice que todo tiene una causa, que existe una ley vinculante entre las causas y los efectos. D ado que esta afirmación ha generado ya bastantes debates, algunos autores, para evitar los posibles sesgos y la restricción de marco conceptual derivada, usan el término inglés causation, que algunos trasponen en español por causación, en referencia al hecho de que algo cause un efecto, en un plano más abstracto que el uso común, pero más concreto que el de causalidad, útil para entender el tipo de acciones o de relaciones sobre las cuales se intenta dilucidar el problema de la causa. Por tal razón y pese a no ser un término aún reconocido utilizaremos ocasionalmente causación con el fin de diferenciar el concepto de la ley de causalidad y de la causa concreta.

Ahora, el asunto es que ya han sido desarrolladas muchas concepciones sobre la causalidad, que podrían caber entre los extremos de entender lo causal como un elemento del conocimiento o aceptarlo como una parte necesaria y real del mundo. Y, puesto que no hay acuerdo sobre cuál ha de ser la posible naturaleza única de la causa, también existen concepciones que defienden su pluralidad: sea porque el concepto usual involucre dos sentidos o más o porque haya un concepto aplicado con diferentes criterios. Ya se ha dicho que el término causa es muy general y por esto su uso se traslapa con el de términos más específicos que describen cómo operan las secuencias de eventos particulares. Lo que se pregunta es si esa confusión reside en la realidad o en los conceptos: en principio hay una indefinición de los conceptos, pero en cuanto nos referimos a la realidad tampoco es muy claro qué pueda ser en ella la causa. Así, en lugar de dos, hay tres instancias (G odfrey-Smith, 2012, p. 328): el uso del término, el curso del mundo y la relación entre las dos anteriores; de manera que debe aclararse si nuestro problema está en la imprecisión de nuestro lenguaje, un problema más propio de un estudio sobre la semántica que, por dicha razón, no se desarrollará en este trabajo. A hora bien, puesto que asumimos que el problema está en la realidad y no solo en las palabras, nos es preciso indagar cómo opera y cuáles serían sus características, por lo pronto en lo que respecta a algunos aspectos referidos a la pluralidad de teorías, la multitud de relaciones causales posibles y las posibilidades de reducción.

\subsection{Multicausalidad y pluralismo}


Es necesario aclarar un aspecto de la causalidad que conviene tener en cuenta: en las situaciones concretas lo usual no es encontrar un único factor que tenga el poder de modificar por sí solo una situación para producir un efecto; lo usual es que existan una multitud de factores con más o menos relevancia causal, más o menos influencia dentro de la situación; en estos casos se habla de multicausalidad, pues no puede identificarse en definitiva un factor único capaz de producir un efecto, a diferencia de lo que podría suceder en secuencias causales controladas y sencillas. Para hacer más compleja la situación, también es usual que los factores causales operen por medio de diferentes mecanismos, es decir, por medio de diferentes vías de influencia, ya que no es igual, por ejemplo, el papel que cumple el Sol en el caso de la fotosíntesis de las plantas que su papel en las mareas. Razones como estas también tienen incidencia en el problema de si es posible establecer un concepto monolítico de la causa o si hemos de conformarnos con la idea de que la causa es el término común bajo el que ponemos un conjunto plural de teorías causales; a tal situación se le llama pluralismo causal. Son dos cuestiones naturalmente diferentes, pero en este aparte se desarrollará el vínculo entre los dos problemas.

Conviene mencionar ciertos ejemplos en los que se hacen evidentes algunas de las complejidades del problema de la pluralidad de causas operantes, es decir, de la multicausalidad, ya que en la naturaleza un suceso suele obedecer a la conjunción de un conjunto plural de factores entrelazados capaces de dar origen a esa nueva situación. En el ejemplo de Mackie (1993, p. 34) sobre el cortocircuito que causa un incendio, como ya veíamos en el capítulo anterior, aquel es una parte insuficiente, es decir incompleta, de las causas, pues se necesitan otros factores; pero el fuego puede deberse a otro conjunto de causas, conjunto en el que, a su vez, se congregan una serie de factores causales necesarios para la producción del efecto. Mackie señala como campo causal al conjunto de factores que se presentan en una situación; sin embargo, frente a determinadas preguntas sobre la causa algunos de esos factores pueden ser más o menos relevantes. Es diferente, por ejemplo, preguntar por qué alguien padece de cáncer y otra diferente la serie de preguntas subsidiarias sobre el órgano afectado, la persona que lo padece, el momento en que se presenta 0 la incidencia dentro de la población de la que hace parte el individuo (Mackie, 1993, p. 40). Lo interesante es que estas preguntas indagan sobre ciertos aspectos de la relación causal, es decir, sobre los diversos factores y los diversos mecanismos que apuntan a la obtención de los vínculos que puedan ser más relevantes desde alguna perspectiva particular. Y tal relevancia, por lo menos en principio, está relacionada con la búsqueda de explicaciones concretas. 
Además de múltiples, las causas también pueden entrar en relaciones que les permiten producir resultados diversos: en la dirección de la causa hacia el efecto puede haber disyunciones que se traduzcan en la producción de más de un efecto 0, en la dirección contraria, que cuando se quiere dar explicación causal a un evento podemos encontrar que es producto de más de una causa. De aquí se derivan situaciones que implican algunas formas especiales de relación causal como la sobredeterminación, en que un efecto está producido por más de una causa, ya sea que actúen de forma simultánea o alterna. Actúan simultáneamente, por ejemplo, una fisura en una columna y la sobrecarga en un edificio, de modo que los dos factores hacen que el edificio colapse. Actúan de manera alterna una manada de predadores que persiguen a su presa de forma tal que si el primero no le da alcance, lo hará otro de los individuos. La sobredeterminación causal puede ser regular y satisfacer el criterio de transmisión de energía, pero en los ejemplos se aprecia que cada una de las causas no constituye la condición necesaria para la producción del efecto. Un efecto puede ser producto de un único factor que determine algún cambio en su naturaleza o en su magnitud, pero también puede ser producto de causas redundantes en el caso en que cada una de las cadenas causales que llega a la disyunción es suficiente para producirlo. Así que, tenemos por lo menos indicios de que la multicausalidad puede ser parte de una situación en la que existan horquillas causales que vinculen múltiples causas o múltiples efectos, dado lo cual la búsqueda de los factores relevantes debe complementarse con la indagación por las vías de influencia causal.

El problema con la enumeración de los factores que den respuesta a una pregunta particular sobre la causa es que en los casos complejos debería incluirse toda la historia y la totalidad de factores que puedan ofrecer un relato causal definitivo que, con tal alcance, se puede hacer imposible: si necesitáramos una precisión extrema, habría que incluir todo el pasado del efecto y además, si esto fuese posible, se tendría que narrar la historia de todo como el único medio para dilucidar definitivamente las causas, aunque así se excluye la posibilidad de ninguna repetición y por lo tanto de la comparación entre sucesos similares, elemento que suele ser muy útil en la indagación sobre las causas. Así que lo habitual es restringir los factores a aquellos que se consideran más relevantes en el caso, sea por su necesidad, como la presencia de oxígeno y de material inflamable en el incendio, sea porque constituyen un factor desencadenante, como el cortocircuito, o por constituir parte de las acciones humanas, como los sistemas automáticos de corte de energía. La cuestión es que de esta forma tampoco podemos definir con precisión los límites de la causa, pues se traslada el problema de la necesidad al de la relevancia, que en principio, parece muy dependiente del contexto. De todas maneras, la complejidad de la realidad no siempre es un 
obstáculo insalvable para la ciencia o para lo cotidiano: en ambos campos se resume la historia causal a lo que se cree relevante para la ocurrencia de un evento, ya sea porque son los factores cuya alteración se refleja de forma más clara en la existencia del efecto o porque tenemos el conocimiento suficiente que nos indica que este caso es similar a otro o porque se rige por una ley conocida o incluso porque sea el factor sobre el que podamos intervenir. En síntesis, la cuestión es que la constatación de que la multicausalidad es una característica pertinaz parece favorecer un pluralismo causal frente a las visiones monolíticas de la causa: es un indicio de que posiblemente se necesite de un conjunto de teorías causales, cada una capaz de dar cuenta de ciertas formas de relación causal.

En situaciones multicausales son útiles los procedimientos de Mill, herederos de los análisis lógicos de la búsqueda de causas en la confluencia de pluralidad de factores: se busca el factor común en varios casos en que el efecto ocurre, o cuál es el factor ausente cuando el efecto no ocurre. Cuando se desconoce cuáles son las vías de influencia causal que operan dentro de una determinada relación se puede apuntar a la búsqueda de correlaciones que permitan determinar cuál es el factor cuya presencia hace más probable un determinado efecto. En estos análisis no se llega siempre a una causa necesaria o determinante, dado que existen factores que incrementan la probabilidad del efecto (pero no necesariamente lo producen) o también puede presentarse la situación de que un factor opera solamente en presencia de otro, como en el caso de los catalizadores de ciertas reacciones químicas. Sin embargo, lo que tenemos que ver es hasta dónde una correlación es la respuesta adecuada para resolver una relación causal. Es el caso de los diagnósticos médicos: dados ciertos síntomas es más o menos probable que la enfermedad obedezca a cierta patología, pero esto no implica que haya certeza (Williamson, 2012, p. 193), y sin embargo la frecuencia usual de ciertas asociaciones suele inducir a que se declaren como causas reales meras correlaciones que incluso pueden obedecer a factores adicionales, pues no puede descartarse una suma de hechos que confluyan hacia el mismo fin. Es, por ejemplo, el caso que se presenta al analizar la longevidad de los vegetarianos, pues al parecer la causa del fenómeno no está tanto en la privación de proteínas de origen animal como en su estilo de vida saludable que los lleva a abstenerse del tabaco, del alcohol y de comidas procesadas y a controlar el consumo de calorías. La probabilidad de una correlación es muy útil como principio investigativo, pero dificulta la solución de casos como los de eventos que obedecen a una causa común; en efecto, cuando dos eventos obedecen a una sola causa la probabilidad de uno varía en el mismo sentido que la probabilidad del segundo, sin que entre ellos medie una relación de causa a efecto. 
También está el caso de correlaciones no mecánicas como las que se presentan entre componentes de un organismo, alentadas por factores químicos, cuyas interacciones se resisten a ser explicadas por medio de eventos físicos, en el sentido de trasmisiones efectivas de masa o de energía. Por eso, se ha dicho que la causación probabilista, un buen mecanismo para dar respuesta a la multicausalidad, se contrapone a la influencia física, pero sería más adecuado afirmar que estas no son dos formas de acción causal sino dos formas de tratar con la causa que dependen de nuestro conocimiento sobre los mecanismos, reforzando también la idea de que no hay una única reecta que describa las causas.

A la multiplicidad de las causas hay que añadir el problema de si operan o no de maneras similares: la historia de la causalidad muestra variedad de concepciones acerca de lo que puedan ser las causas y las relaciones causales, cuestión que por el momento constituye un indicio de las diversas formas de operación de las causas, diversidad confluente con las múltiples aproximaciones teóricas al respecto. Entre otras formas de entender la causa, se habla de líneas causales, de transmisión de marca, de conservación de cantidad, de transferencia, de persistencia (D owe, 2008); se habla de causación mental, de causas históricas o sociales, de causas físicas; por otra parte se alude a la causa como hecho general o como hecho individual, o como condición contrafáctica, regularidad, incremento de la probabilidad, etc. Pueden verse así algunos de los problemas que se derivan del uso del mismo término para tipos de relación cuyas características parecen operar de formas diferentes. Fuera de la abundante argumentación escrita al respecto, en la literatura sobre el tema encontramos una gran cantidad de ejemplos que se ha venido utilizando como prueba de que las causas se comportan de determinada manera. Sin embargo, suelen ser buenos ejemplos y no tanto pruebas concluyentes a favor de una concepción, aunque pueden refutar algunas definiciones que los excluyen. Mientras no haya un acuerdo decisivo al respecto da la impresión de que tendremos que aceptar que la forma usual de la causa es la confluencia múltiple de factores y que también es múltiple la forma en que las causas operan en la realidad (Cartwright, 2007, p. 11).

Así que a las dificultades de hallar una causa única o principal hay que sumar la de encontrar si la causación obedece a una naturaleza única, cuestión que tampoco parece tener una respuesta positiva, en vista de las diversas formas en que parecen relacionarse las diversas causas con sus efectos. Por ejemplo, la causa puede entenderse como producción, cuando interactúan entidades reales mediante un mecanismo de acción local, tal como la transferencia de una propiedad o de una cantidad física de la causa al efecto, modificando las características de los objetos involucrados. 
En otros casos, como los de equilibrio mecánico, aparentemente las causas y los efectos son simultáneos (como en los extremos de un balancín); mientras que en otros las relaciones causales involucran la variación gradual de alguna cantidad que puede ser medida en los periodos de tiempo en que se realice la acumulación. Vemos que cada descripción en esta corta lista es adecuada para ciertas formas de relación causal, pero no parece útil para todo tipo de sucesión. Y continuamos, pues aparte de que la causa pueda entenderse como producción, también puede entenderse como dependencia, que puede ser nomológica, contrafáctica o probabilista (Psillos, 2008, p. 8). D e todas formas los conceptos de producción y dependencia están relacionados con distintas intuiciones sobre la causa: la primera, con la relación intrínseca que se da entre hechos, mientras que la dependencia se relaciona con la intuición de que es una relación extrínseca entre eventos (una de cuyas manifestaciones es la regularidad). En la producción la conexión causal se refiere al lazo que existe entre una causa y un efecto concretos, un vínculo que no se necesita en la dependencia. Los dos conceptos, producción y dependencia, pueden tomarse como aspectos diferentes de la causa, y si es así, se puede concordar con Psillos siendo escéptico frente a lo que llama la "camisa de fuerza" del monismo causal: si es el caso que la causación tiene una doble naturaleza, no podría de hecho existir una teoría única sino que tendríamos que elaborar dos teorías causales para explicar las diferentes manifestaciones que esta asume y quedaría por definir si ambos conceptos son causación y cuál sería su ámbito de aplicación, lo cual no parece dar una respuesta definitiva al asunto, entre otras cosas porque no hay acuerdo en esta naturaleza dual, sino que parece haber aún más respuestas.

O tra opción a considerar con respecto a las relaciones entre multicausalidad y pluralidad causal es el hecho de que no siempre existe una relación estrictamente determinista entre causa y efecto: sabemos que, en principio, existe tal determinación y que por eso podemos esperar que el mundo sea previsible en el corto plazo, pero en plazos mayores y cuando operan múltiples factores la determinación empieza a ser dudosa. Existen casos en que la presencia de cierto factor no implica necesariamente que siga el efecto esperado; en estos casos lo que conocemos de la sucesión es cierta relación de dependencia entre la presencia de cierto factor y la ocurrencia de un efecto: la presencia de tal factor eleva la probabilidad de que el efecto suceda o condiciona en un plazo más largo su presencia o ausencia.

Nuestro uso de la causalidad para elaborar razonamientos explicativos suele confundir el ámbito dentro del cual se debe responder al tipo de relación: así sucede con la dificultad de diferenciar la 
causa de las implicaciones lógica, matemática o semántica, en las cuales la probabilidad del supuesto efecto es muy alta pero por razones lógicas y no estrictamente causales; como también ocurre en los casos en que la relación obedece a leyes físicas no causales (Williamson, 2012, p. 200). Es el caso, por ejemplo, de las relaciones entre la temperatura y la presión de un gas, proporcionales entre sí, pero no por ello puede decirse que una sea la causa de la otra, sino que son manifestaciones del movimiento de las partículas que lo componen y ese hecho se traduce en que los tres factores, presión, temperatura y movimiento, varín de forma proporcional.

Los eventos son el resultado de una suma de influencias y factores combinados, aunque también puede ocurrir que un solo factor tenga efectos diferentes si se presenta aislado o combinado con otros factores; son conocidas las dificultades de aislar factores, tanto en situaciones complejas como las de las ciencias sociales como en las condiciones controladas de un laboratorio. Si la multitud de causas es tan usual como la diversidad de mecanismos causales, es de esperarse que, mientras no se halle un concepto unitario de la causa tendremos que manejar un grupo de nociones que reúna lo que en el lenguaje se entiende como tal, aunque es necesario recalcar que no se limita a la cuestión semántica, sino que se extiende a los conceptos involucrados y al uso que se les da como descripción de hechos reales. Hemos visto que en la filosofía se ha creído en la idea de que la causalidad es o debía ser un "concepto monolítico", una idea de aplicación universal para las múltiples y muy diversas situaciones que recogemos bajo el término genérico de causa, problema sobre el que volveremos más adelante en este capítulo; sin embargo, reiteramos, esta idea tropieza con dos situaciones: la primera, la de la multicausalidad, el hecho de que existen múltiples factores que condicionan o producen un efecto, sin que haya acuerdo en torno a si pueden diferenciarse lo que es causa de las condiciones, y la segunda, que esas múltiples causas tampoco parecen operar bajo una norma común e incluso que tampoco hay acuerdo en torno a si en efecto la causa sea una característica de la realidad o un medio en que nuestro pensamiento imponga orden a sus representaciones: de esta forma las teorías parecen confinadas a ser parciales. Es necesario, entonces, entrar a considerar si, a pesar de que la multicausalidad parece dificultar una noción aplicable a diversos factores que pueden actuar de formas diversas, puede encontrarse alguna característica común que nos permita tener una noción con un grado de aplicación amplio.

\subsection{Singularismo y regularismo}


En términos comunes la causa se asocia a aquellos factores capaces de producir una diferencia en una secuencia de eventos, o al factor que se concibe como necesario para producir el efecto, una muestra de que se suele hacer más referencia a eventos individuales, como es evidente en la particularidad con la que el lenguaje registra las acciones causales. Pese a esto, la mente asocia ciertos eventos a otros en las secuencias que se consideran causales, de modo que la regularidad de las secuencias de nuestra experiencia es un indicio importante para identificar la causa, o al menos para suponer que una secuencia puede ser causal. En efecto, en ocasiones no tenemos más elementos de juicio para presumir que existe una relación causal que su regularidad, que no implica el conocimiento de los mecanismos: los objetos caen regularmente, ya sea porque existe una fuerza de atracción o porque la gravedad deforma el espacio. No conocemos del todo los mecanismos, pero asumimos una relación causal como consecuencia del comportamiento regular. El regularismo afirma que el hecho de que una secuencia de eventos c y e sea causal depende de que los eventos del tipo correspondiente al primero de la serie sean seguidos por eventos como el segundo; poniendo a descansar el peso de la prueba en la existencia de repeticiones regulares de secuencias de eventos. Un argumento a favor de la concepción regularista es que apunta en la misma dirección que la ciencia, pues tales regularidades de la naturaleza le permiten a la ciencia formular leyes (aunque las leyes no siempre sean causales).

El argumento más común que se erige contra la concepción regularista es que la repetición de secuencias no es base suficiente para determinar una causa, como el mismo Hume advierte en su resistencia a las vías inductivas, pues no por comunes las secuencias regulares construyen una necesidad: el día sigue regularmente a la noche sin que medie una relación causal entre los dos eventos. También es cierto que el ejemplo se refiere a un caso cotidiano, definido en términos de los lenguajes naturales, en los que no se precisan los límites y características de los dos eventos: no tienen límite ni duración precisos, pero, lo que es más importante, uno no es la causa del otro sino que son producto de una causa común, de la rotación de la Tierra sobre su eje.

Así que hemos de partir de un punto básico y es que para poder constatar que existe cierta regularidad hemos de determinar qué casos son pertinentes y hasta dónde pueden ser toleradas sus diferencias. Hemos de definir las características pertinentes para que podamos considerar si un nuevo caso nos sirve para comparar con el caso por el que indagamos. Pero, como punto de partida, podemos presumir que se requiere de un cierto grado de abstracción, ya que cada caso presenta sus particularidades; es la mente humana la que tiene que determinar cuáles son las 
características indispensables para declarar que dos situaciones son afines, problema con el cual se enfrentan las teorías regularistas; habría que definir dentro de qué límites y cuáles son las excepciones a tomar en cuenta, pues de no ser así todas las secuencias serían únicas. Es evidente que los sucesos reales divergen, empezando por su situación espaciotemporal, y que no siempre es posible identificar sin duda si dos secuencias de sucesos corresponden al mismo tipo, de manera que puedan ser considerados muestras de una misma relación causal. El problema es que las teorías regularistas no parecen haber solucionado cómo puede darse este tránsito de lo particular a lo general, en qué medida las características comunes de dos secuencias de eventos concretos son más importante que sus diferencias como para considerar que pueden ser subsumidas bajo cierta tipología. Entre tanto el singularismo entiende que la causa es una relación localizada y específica que existe con independencia de universalidades o leyes (García-Encinas, 2011, p. 36). En su crítica al regularismo, Russell pregunta qué tan grandes pueden ser las diferencias entre las situaciones que abarcamos bajo el comportamiento regular: partimos de cierta similitud, y en la medida en que indagamos si los casos pueden ser comparables nos encontramos con que tenemos que incluir más variables, dado que cada caso tiene sus características propias. A hora bien, en la medida en que incluimos más información, es más improbable que se repita el caso.

Enunciados tales como los ejemplos de Kim (1993, p. 73): "la muerte de Sócrates" o "el hundimiento del Titanic", se refieren a eventos individuales en los que se describe un objeto particular que presenta una propiedad en un momento determinado; la cuestión es que, incluso con esas descripciones tan sucintas, podemos presumir que tras de cada una de ellas se esconden múltiples propiedades de las que no sabemos si tienen o no un papel causal, esto es, que no nos dan una guía de cómo diferenciar el conjunto de factores que reunidos producen el efecto y tampoco nos indican cómo un evento o serie de eventos causales puede ser relacionado con otros similares. Pese a que los enunciados aluden a eventos únicos o accidentales, no por eso prescindimos de la búsqueda de sus causas, así fuese apenas para prevenir que ocurran sucesos similares. D e ahí que el estudio ontológico de la causalidad nos lleva más allá de la consideración del carácter único de las sucesiones causales, hacia la búsqueda de sus características generales, pues es por medio de la comparación con otras secuencias como podemos llegar a tener alguna noción sobre necesidad y suficiencia. Puesto que no hay dos casos reales que sean completamente exactos, podemos presumir que cada efecto es precedido por un estado de cosas particular; de ahí que incluso las situaciones experimentales sean aproximadas y sea necesario replicarlas para tener seguridad sobre si se ha identificado la causa genuina. Sin embargo, limitar el mundo a la 
serie de eventos frágiles que ocurren una única vez, nos deja en una posición epistemológica muy débil: la mente no podría hacer nada más que constatar que cada evento ha sucedido sin pretender un conocimiento mayor. Nuestro conocimiento ha progresado estableciendo regularidades útiles para conocer tipos de objetos y para prever el comportamiento de la naturalezay, si nos limitamos a señalar que los eventos son únicos, reducimos los alcances de la mente humana a los de un espectador pasivo que señala las cosas que pasan sin poder relacionarlas. Lo que sucede con nuestro conocimiento causal muestra otro procedimiento y es que, en efecto, comparamos tipos de secuencias para indagar por las causas, para elaborar hipótesis de cómo opera la realidad, para explicarla y prever su comportamiento, además de planear nuestras intervenciones.

Las concepciones regularistas tampoco dan suficientes elementos de juicio para distinguir las secuencias causales de las regularidades no causales. Es cierto que en muchas ocasiones no tenemos a mano o definitivamente no se conoce una descripción detallada de cómo se producen efectos habituales que se consideran vinculados causalmente. El choque entre un bola de billar luego de moverse hacia otra estática produce en esta última un movimiento y un sonido, pero la respuesta a por qué se producen estos efectos es mucho más compleja que esta descripción e involucra conocimientos sobre elasticidad, acción y reacción, en lo que tiene que ver con el movimiento resultante, y con las ondas de presión, en el caso del sonido. Tenemos una acumulación de experiencias con respecto a cómo varían los movimientos en función de la velocidad con la que ocurre el choque, lo cual apoya la visión regularista, pero esto nos lleva a conocidos problemas, tales como que ponemos a depender la causa de otros sucesos con los cuales no hay ningún contacto o cercanía, como la misma concepción lo requiere, dejando la repetición apenas en calidad de un indicio de la causa, como si estuviéramos en el punto de partida: entre causa y efecto hay una conjunción contante pero no una conexión necesaria.

En casos más complejos los problemas se incrementan: cuando existen efectos colaterales 0 secundarios el regularismo no ofrece ningún medio de distinguirlos, ya que si un factor es seguido por cierto evento y este por otro, no podemos diferenciar si esta secuencia es una cadena de causas o si el primer factor causó ambos eventos. Ambas situaciones pueden ocurrir: que el primer evento sea la causa del segundo y este del tercero, una típica cadena causal, o que el primero sea la causa de los otros dos, pero de manera sucesiva, de forma que el segundo sea causado inmediatamente y el tercero de forma retardada, es decir, como un efecto secundario. Puede ser, por ejemplo, el caso de un insecticida que se aplique sobre una planta, de manera que inicialmente el efecto sea la muerte de los insectos y que el efecto posterior sea la caída de las 
hojas. Si nos atenemos a la conjunción constante, no tendríamos cómo distinguir una cadena causal de los efectos sucesivos de una sola causa: podríamos creer (o podría suceder) que la muerte de los insectos causó la caída de las hojas.

Hay otro argumento más fuerte contra el regularismo: en una secuencia que contemplamos 0 que ocurre solo una vez no tendríamos elementos de juicio para saber si estamos ante una verdadera causa 0 ante una conjunción accidental. Existen relaciones causales que han ocurrido una sola vez: si se indaga por el origen de la Luna, el caso es tan específico que posiblemente no sea asimilable a las situaciones en las que otros planetas han adquirido sus satélites. Un planeta de cierto tamaño puede atrapar gravitacionalmente algunos cuerpos, pero este no parece ser el caso de nuestra Luna y, de ser así, las características particulares del evento que le dio origen quedarían por fuera de lo que entendemos por una relación causal regular. La necesidad de encontrar una explicación causal subsiste, pero el regularismo parece renunciar a dar cuenta de este tipo de eventos: serían producto de un accidente o de una coincidencia y apenas los podríamos declarar como causales en el caso en que hubiera una serie de secuencias comparables. Así que, como lo plantea García-Encinas (1998, p. 130), en este punto existe un conflicto entre singularismo y regularismo que gira alrededor del papel de los patrones universales que fundamentan la explicación causal. En alguna medida es la tensión entre la necesidad de explicación de los eventos singulares frente a la necesidad de patrones regulares que nos permitan ordenar los datos de los sentidos y establecer cuál de los factores que componen un evento puede modificar a otro, pero también es una muestra de que en la perspectiva ontológica los eventos son únicos, mientras que nuestra necesidad de entenderlos apela a compararlos.

La pluralidad de manifestaciones de la relación causal y las diversas limitaciones de las teorías causales nos devuelven al problema de definir cuál es el papel de la regularidad en la causación, pues las secuencias causales se nos presentan de forma individual, como sucede con toda experiencia. Ahora, el asunto es que la experiencia primaria no nos es muy útil si no la podemos generalizar y abstraer, es decir, establecer relaciones que nos permitan hacer predicciones, previsiones y en últimas ejercer algún grado de control sobre la realidad. De ahí la necesidad de encontrar el papel de la regularidad causal, y de la posible o posibles leyes causales, pues es el medio que utilizamos para incrementar nuestro conocimiento y nuestra capacidad de explicar las relaciones entre eventos, así como nuestra capacidad de intervenir efectivamente en cadenas causales. Esto no implica que se hable de poderes ocultos ni de conexiones necesarias per se: la 
multiplicidad de manifestaciones ha de dejar paso a la búsqueda de características comunes que nos permitan identificar los factores más relevantes. Las regularidades que hay tras la causación son complejas, pues lo más común es que un efecto obedezca a múltiples causas: el conjunto es necesario, pero no cada uno de sus elementos, tal como Mackie hace explícito. La condición Inus de Mackie (1999, p 62) da cuenta de las excepciones: si se presenta tal condición no necesariamente implica la producción causal pues se necesitan otras condiciones para que el efecto ocurra. Sin embargo, no es claro cómo puedan distinguirse las causas genuinas de los efectos de una causa común; así sucede cuando se dice que el sonido del silbato es la causa de que los obreros de un fábrica salgan, o que la bajada en la lectura de un barómetro sea la causa de una tormenta (Psillos, 2012, p. 152): son factores que están regularmente asociados al efecto y que suceden en su inmediación espaciotemporal y sin embargo no cumplen otros requisitos para producir el efecto, no son condiciones necesarias sino factores que obedecen a una causa anterior.

D esde la perspectiva del empirismo lógico se ha discutido si la búsqueda de una teoría capaz de unificar nuestros conceptos de la causa se deriva del hecho de que el término tenga cierta unidad de uso. Frente a esta idea Anscombe (1993, p. 92) observa que la palabra causa es muy general y abarca una multitud de fenómenos, pero lo que percibimos son sucesos particulares, no la constancia de las conjunciones de las que pueden ser instancias y, por lo menos en algunos casos particulares, podemos observar la eficacia de la acción. Nuestra noción de causa se asocia a verbos específicos de acción, lo que equivale a decir que el lenguaje causal unifica aquellas situaciones en que no disponemos de un lenguaje más específico - un argumento que puede apoyar el singularismo - . La causa resume las condiciones que existen en cierta región del lenguaje, pero no por eso implica una naturaleza subyacente o regular del concepto. Este argumento, en principio, apunta a la reducción de los diversos planos de la problemática causal a la cuestión semántica del uso de un término, pero también se refiere a la naturaleza de los hechos: si el concepto no fuera tan importante y de tan amplio uso en la heurística de la explicación, no generaría tanta preocupación la búsqueda de las características comunes que revelen su papel en las relaciones entre eventos.

El lenguaje nos provee de un indicio de que puede haber diferentes formas de relación causal, manifiesta en los casos y palabras concretas. En esta perspectiva nos encontramos de nuevo con la cuestión de si la causación puede concebirse como una relación particular, dado que quizá la mayoría de ejemplos en la literatura sobre el tema elaboran análisis de enunciados causales 
singulares, en los que se expresan relaciones entre objetos particulares o sus características. En esta vía, D ucasse defiende el singularismo causal, entendiendo la relación causal como un suceso singular entre dos eventos, aunque reconoce parcialmente la razón que le asiste a Hume al afirmar que la conexión causal no puede ser asociada a ninguna percepción sensorial específica. Lo que percibimos es una relación entre eventos concretos, es decir, un cambio que sucede en el entorno de otro (D ucasse, 1968, p. 9), de manera que los casos que observamos son particulares, pues lo que se observa no son secuencias múltiples de eventos; las sucesiones observadas no son afectadas por lo que haya ocurrido u ocurrirá en otras ocasiones, por semejantes que sean. Aun si no volviera a darse una situación similar la relación causal observada seguiría siéndolo, de modo que el autor concibe la causa como una relación que no depende más que de los sucesos involucrados, es decir, de las propiedades y relaciones presentes: cuando se busca una causa no siempre se espera encontrar la relación invariable correspondiente a tal tipo de eventos sino que se quiere saber cuál es la diferencia particular entre las circunstancias presentes que conlleva la ocurrencia del efecto determinado. La causa es una alteración singular de las circunstancias en las inmediaciones del efecto y si el evento corresponde a una relación regular es un indicio que puede reforzar nuestras razones para que constatemos una relación causal o para encontrar una ley al respecto, pero estas serían consideraciones adicionales. D ucasse considera que la causa se define sin apelar a ninguna ley de uniformidad pues el uso concreto del término alude a un solo caso (D ucasse, 1924, p. 89); no niega la regularidad que vincula tipos de eventos, pero la rebaja a un corolario de la causalidad, ya que una relación es causal no en razón a la conjunción constante sino que, más bien, esta consiste en la síntesis de un conjunto de eventos singulares.

Con las regularidades y leyes podemos construir argumentos que se apoyan en las tipologías de las relaciones que se producen entre ciertas causas y ciertos efectos: la causa particular puede verse como una instancia de una regularidad que está explicada por el cambio en una propiedad de los objetos inmersos en la relación, de forma similar a como lo entiende Kim (1993, p. 73), para quien los eventos son ejemplificaciones de propiedades que poseen objetos singulares en un cierto tiempo, concepción que tiene la ventaja de aclarar la eficacia causal de las propiedades: por ejemplo, un objeto x rompe en un instante t a otro objeto en que se apoya, debido a una propiedad $\mathrm{P}$, su peso. Bajo estas consideraciones el riesgo consiste en reducir las causas a las disposiciones, factores con poderes causales que explican las relaciones causales, pero como bien lo señala G arcía-E ncinas (2011, p. 44), hay muchos problemas insolubles por esta vía, entre ellos el de que la causalidad dejaría de ser una relación asimétrica, pues las disposiciones son recíprocas, de 
modo que un poder actúa sobre otro que recibe la acción, mientras que la causas siguen una dirección de influencia que ocurre en la misma dirección que el paso del tiempo.

De tal forma, las causas, pese a manifestarse por medio de situaciones singulares, pueden ser instancias de una regularidad o de una ley. La cuestión es que las versiones regularistas de la causalidad, al debilitar la idea de que la relación causal existe en los casos particulares (afirmando que son instancias de la regularidad), tendrían que aceptar que una secuencia causal particular dependería de cosas que pasan en otro lugar. Lo más adecuado parece ser abandonar las posiciones extremas, pues si los particulares son instancias de esa regularidad es porque presentan características comunes a los demás objetos en que se manifiesta y la utilidad que tienen las leyes está basada en que nos permiten entender tipos de hechos y prever formas de comportamiento. A su vez, el riesgo de la opción singularista es que se llegue a olvidar que las causas ocurren de acuerdo con regularidades de la naturaleza; puede que no sepamos cuáles leyes estén implicadas, o cómo operan o cómo se combinan, pero nuestra necesidad de conocer la naturaleza nos lleva a la búsqueda de patrones en los cambios.

D ucasse admite que podemos describir una causa de dos formas diferentes: por la referencia al evento concreto y también como una elipsis que alude a relaciones similares. Afirma, por ejemplo, que se percibe - no que se infiere- que una rama de un árbol se inclina a causa de que un pájaro se posa en ella. La percepción no se limita solamente a los objetos y a los sucesos en que se involucran, sino que también son perceptibles sus relaciones, que se expresan por medio de diversos verbos causales, en clara diferencia con la posición de Hume (Ducasse, 1968, p. 26). Para D ucasse la causación es una relación triádica entre un estado de cosas $\mathrm{S}$ en que ocurre un cambio C seguido de un cambio E . Esta triada no es un signo de la causa sino la causa misma, que es percibida directamente por el observador. La causa se percibe en cada una de las instancias en las que esta sucede y si es una sola, no por eso implica que deje de existir una relación causal. Además, el observador es capaz de distinguirla de una secuencia accidental, signo claro de que se tiene una idea útil de lo que es la causa.

La visión regularista responde que la única manera de que una relación sea causal es que este hecho se pueda repetir regularmente, lo cual funciona como signo fiable de que se habla de una causa real y no de un accidente. En la concepción de D ucasse las leyes causales existen pero no son las que explican la causa sino que son generalizaciones de los hechos particulares, los únicos 
existentes en la realidad; de forma que las leyes no constituyen hechos causales, como lo afirman los regularistas. D ucasse parte de entender una causa como la diferencia o alteración que ocurre en un estado de cosas inicial, a la que sucede otra diferencia, que es su efecto. Acertadamente Psillos (2012, p. 147) dice que no son claras las características que tendría que tener tal diferencia, dado que tal definición no lo declara expresamente, ni cuáles cambios son relevantes para el efecto, puesto que lo usual es que constantemente ocurran cambios en la realidad y la búsqueda de una definición de la causa es necesaria precisamente para diferenciar los cambios causales de los cambios coincidenciales o accidentales.

Como conclusión del recorrido anterior podemos sugerir que los argumentos para defender el singularismo causal se apoyan en la apreciación de las secuencias causales concretas que, en efecto, presentan características particulares en tanto son sucesos que ocurren dentro de unas coordenadas espaciotemporales que los hacen únicos, lo cual corresponde a la unidad ontológica de la realidad. Sin embargo, el argumento regularista apela a otro aspecto fundamental, como el de comparar el cambio en cuestión con otros de su tipo, permitiéndole estudiar qué es lo que cambia y qué se conserva. Este argumento tiene más peso y funcionalidad dentro del aspecto epistémico de las causas, pues es la vía por la cual accedemos a un tipo de análisis que nos permite encontrar la relación entre la causalidad y las leyes que gobiernan la naturaleza. D e aquí también podemos concluir que la causación singular, aún si aceptamos su observabilidad, no implica necesariamente que el singularismo sea la respuesta más adecuada para dar cuenta de la relación causal, dado que la observación puede ser compatible con diferentes posiciones sobre la causalidad y no resuelve necesariamente el problema de la identificación de las causas. Así que tendremos que contar con que, en los hechos, las sucesiones de causa a efecto son únicas, pero que necesitamos estudiar las relaciones entre tipos de secuencias como un indicio fiable para encontrar la eficiencia de esas formas de relación causal: una forma de decir que la opción que parece más viable es ser singularistas en el campo ontológico y regularistas en el epistémico.

\subsection{El debate entre reduccionismo y antirreduccionismo}

Hay que considerar la posibilidad de que la causa corresponda a un tipo de evento elemental 0 que, por el contrario, sea un nombre general que puede ser analizado en elementos más básicos, en otras palabras, examinar si la causa se entiende como un concepto primitivo irreductible o si se puede traducir a otras nociones, que serían los posibles componentes elementales de la causa. 
En el primer caso se asume que lo causal es una herramienta cognitiva básica, pero en el segundo hay que examinar qué elementos más básicos pueden ser parte de la causa, es decir, si existe algún elemento con el que pueda comprenderse en qué consiste su acción. Se ha contemplado que ese elemento común sea, por ejemplo, la regularidad o algún elemento común a las formas de relación causal, esto es, que exista un elemento sobreviniente en toda situación causal, o que ese elemento común sea la dependencia contrafáctica, que compara la situación causal con mundos posibles que pueden o no ocurrir; o las relaciones probabilistas, tan útiles en el rastreo de vínculos causales. $\mathrm{O}$ que el factor común se encuentre en los elementos materiales que ocurren entre la causa y el efecto, tales como la transferencia de magnitudes o de perturbaciones mecánicas; 0 que sea la suma de los factores humeanos de contigüidad espaciotemporal y conjunción constante. Hay que empezar por hacer una reflexión sobre las generalidades al respecto.

En lo que nos atañe en este momento el problema de la reducción consiste en si el concepto de causa puede ser descompuesto en otros más simples ya que varios intentos de definición parecen terminar creando círculos viciosos en los que se remplaza un término por otro con similares dificultades en su definición. Así, no se soluciona el problema cambiando el término causar por producir, originar, motivar, ocasionar, influir, etc., ya que la sustitución altera en alguna medida el significado de la expresión. Las tentativas se han resistido al éxito, pues requieren una comprensión previa, al igual que ocurre con otros conceptos como los de ley, explicación, probabilidad, etc., que se resisten a su análisis en términos más simples. Por el contrario, lo que se busca en una buena definición es remplazar un término por otro más básico o más comprensible que no dependa del que se busca definir, y que evite el riesgo de las referencias entrecruzadas que comporta la sustitución de un concepto por sinónimos. En los lenguajes naturales, un concepto como el de causa se refiere a los vínculos de influencia efectiva o al elemento cognitivo que nos permite expresar de forma abstracta la transformación de un estado de cosas en otro. Ante este panorama hay que indagar acerca de los alcances del concepto, de ahí que sea necesario entrar a considerar algunas de las dificultades que se erigen frente a las concepciones de la causa como entidad (más bien, relación) que pueda ser descompuesta en elementos más básicos, o explorar qué posibilidades podría tener la vía reductiva.

El reduccionismo busca la posible existencia de elementos más simples o primitivos que permitan descomponer o hacer comprensible la causa, de modo que sea posible identificar los hechos causales a partir de sus elementos, que deben encontrarse en toda sucesión causal. Frente a esta 
posición se erige el antirreduccionismo que afirma que la causación no puede ser descompuesta en términos más elementales, lo cual implica la imposibilidad de describir una causa utilizando términos que no sean estrictamente causales, pero también niega que la causación pueda sobrevenir a factores no causales, es decir, como el resultado de cierta conjunción de elementos. Así, esta última perspectiva acepta que el concepto de causa es más bien primitivo (que puede ser innato o similar a la necesidad humeana), lo que parece confirmarse en el hecho de que la búsqueda de significados solo nos deja por resultado unos cuantos sinónimos que solamente se diferencian por ser más específicos, mientras que el de causa es genérico. Sin embargo, asumir la causa como un concepto primitivo es renunciar a la posibilidad de elaborar una definición que nos dé luces sobre cómo operan las causas en los hechos reales y sobre cómo se relaciona este concepto 0 herramienta con ellos, es decir, sobre cómo podemos reconocer las causas.

En el reduccionismo hay matices: por ejemplo hay quienes aceptan que la reducción puede consistir en la posibilidad de dar cuenta de la causación en los niveles más básicos de la realidad, específicamente al nivel de la física fundamental (Carroll, 2012, p. 280), posición que en realidad pretende la eliminación del término para sustituirlo por las leyes de las interacciones físicas. Sin embargo, las leyes físicas no parecen sufrir de la asimetría temporal de la causa: el movimiento aleatorio de las moléculas de un gas confinado en un recipiente pareceróa ser idéntico en el sentido habitual del tiempo que en el sentido contrario. En cambio, la relación de causa a efecto tiene - descontando las secuencias en que el efecto podría ser simultáneo con la causa - una tendencia a seguir el paso del tiempo: el golpe es seguido por la rotura del vidrio y nunca observamos que esta ocurra primero que aquel. Nuestras posibilidades de intervención son efectivas y nuestra comprensión de cómo ocurren los cambios en el mundo llegan a ser acertadas en razón a que operan dentro de una secuencia temporal que se trastocaría de no ser así. Por otra parte tampoco han sido del todo exitosas las tentativas de explicar un nivel de la realidad a partir del nivel inferior, tal como se ha pretendido al decir que, por ejemplo, los eventos biológicos logren ser explicados del todo por la química. En otras palabras, apelar a las leyes físicas implica un reduccionismo causal en el que las causas subsistan pero en un nivel inferior, lo que no aporta mucho a dilucidar el problema de la causa, más allá de trasladarlo a niveles de operación diferentes. Al decir de Schaffer (2000, p 83), si las propiedades físicas son lo básico, D ios no habría necesitado más que crear lo físico, todo lo demás, por ejemplo lo mental o lo moral, serían la consecuencia de este plano básico, y de la misma forma lo serían las causas y las leyes, que quedarían reducidas a patrones que elabora la mente a partir de la experiencia, pero que no tienen lugar en la realidad. 
O tro de los intentos reductivos entiende las secuencias causales como transferencias de cantidades conservadas, pero tiene el problema de que el ámbito de aplicación se limita a procesos en que hay una interacción física y esto excluye una multitud de formas de relación aceptadas como causales, e incluso procesos de corta duración entre partículas subatómicas, tal como lo plantea D owe (2008); pero, además, la hipótesis depende de que en los procesos causales no se presente más que la interacción causal involucrada en el efecto, cuando lo habitual es que haya múltiples factores que intervienen simultáneamente. La teoría de la transmisión de marca no permite diferenciar siempre qué interacciones son las que afectan los procesos en los que se produce el efecto: algunas de ellas son irrelevantes, pero son simultáneas a aquellas a las que atribuimos el papel causal; adicionalmente, en cada objeto que interviene en la relación existen múltiples cantidades conservadas, pero no todas ellas intervienen como causas de la modificación que produce el efecto. En un choque entre dos objetos uno puede transmitir cierta cantidad de movimiento y también una carga eléctrica, pero la carga eléctrica no incide habitualmente sobre el movimiento del que estamos indagando la causa. Además tampoco se logran excluir todos los pseudoprocesos ni las omisiones y ausencias en la consecución de algunos efectos, pese a que la teoría ofrece una buena explicación de una gama amplia de procesos físicos, y aún más importante, el asunto es que de esta forma se niegan elementos fundamentales de la causa, o incluso la causa misma, pues se desconoce su localidad y asimetría: sería apenas un apéndice de las leyes de conservación (García-Encinas, 2011, p. 44).

O tra de las alternativas de reducción consiste en considerar la causa como una situación en la que el efecto se presenta si cierto condicional contrafáctico ocurre. Pero hay situaciones que no se solucionan; por ejemplo, al analizar la causa en términos de enunciados contrafácticos, si ocurre que $c_{1} 0 c_{2}$ causa e, la formulación del enunciado contrafáctico que, dado e, adjudica, digamos, a c $c_{1}$ la causa, no es necesariamente correcta, dado que el efecto puede haber venido de $c_{2}$. Así, la opción hipotética de "si no hubiera ocurrido $c_{1}$ no se habría dado e" no resuelve la cuestión de cuál es la verdadera causa. D e todas maneras al argumento va dirigido más hacia la búsqueda de causas en el pasado, en tanto ya no puede variar, mientras que hacia el futuro se muestra más incierto, lo cual también dificulta la elaboración de estrategias para producir efectos.

Sin embargo, el argumento contrafáctico es útil en el caso de las ausencias, otra de las formas problemáticas de la relación causal, que consiste en que la producción de un efecto depende de 
que falte cierto factor. Resulta muy difícil dar respuesta a las ausencias dentro de visiones como las mecánicas, sea de transferencia de cantidad o de transmisión de marca, ya que no puede afirmarse que un factor inexistente pueda llevar a cabo un efecto mecánico. En este caso la condición contrafáctica tiene la capacidad de dar cuenta de este tipo de causación: la ausencia puede ser el criterio diferencial sin el cual el efecto no se produce, pero se termina construyendo una doble negación en la que no hay factor actuante ni resultado, lo que nos dirige al indicio de que en los casos reales son otros factores los que actúan*.

Hay una forma de singularismo, defendido por Schaffer (2000, p. 82), que sostiene que las causas consisten solamente en - o que se reducen a - las historias particulares de los hechos concretos, es decir, que en la secuencia causal no hay nada más allá de la configuración particular de factores que dan origen al efecto, de modo que lo que entendemos por causas y leyes no es más que los patrones de los eventos. Según el autor existe una reducción teorética, que pretende la unificación del concepto, pero una más importante de carácter ontológico, independiente de cómo teorizamos las entidades, pues estas son independientes de la mente, y en este plano es innegable que la causa consiste en sus manifestaciones concretas. A sí como una película de cine está basada en (o existe en función de) los fotogramas que la componen, la causa y las leyes están basadas en las historias particulares, que son las que las componen. De tal forma la causa y las leyes no hacen referencia a conexiones necesarias entre eventos sino al aspecto modal de nuestro conocimiento, lo que creemos que debe ser. La máxima concesión que hace el autor al antirreduccionismo es que la causación se reduce a la historia junto con las leyes, es decir, que para dar cuenta de un hecho acudimos a las condiciones necesarias y suficientes para producirlo, junto con las leyes pertinentes al caso. El ejemplo que cita viene al caso: si cada uno de los magos Merlín y Morgana hacen un encantamiento (con 50\% de efectividad) para convertir el príncipe en sapo, ¿qué diferencia hay en que el hechizo proceda de Merlín, de Morgana o de su conjunción? Para Schaffer no hay diferencia causal debido a que hay una sola historia, aunque narrada en tres formas diferentes, sin que constituyan situaciones ontológicamente diferentes. Pretender que hay diferencia es hacer una concesión a nuestra intuición, al costo de pagar un alto precio metafísico al crear artificialmente situaciones diversas.

\footnotetext{
* Este problema se analizará en detalle en el capítulo siguiente.
} 
Desde la posición que se ha sostenido en el presente escrito hay una parte del argumento de Schaffer que puede ser adoptado, en lo que respecta a que las leyes son sistematizaciones inductivas que parten de los hechos, en otras palabras, que se comportan como patrones del comportamiento natural en situaciones ideales y que sacarlas de ese marco implica una forma de reificación. Sin embargo la reducción que propone es inaceptable en la medida en que termina siendo una forma de eliminativismo, similar al del primer Russell, con todas las consecuencias que comporta, entre ellas depender de una narración exhaustiva como medio de dar cuenta de la causa, que puede llegar a ser irrealizable. Si volvemos al caso de la sobredeterminación, no podemos compartir que haya una sola historia porque el efecto sea el mismo: en este caso existen dos o más relaciones causales que se suman o que contribuyen en diferente medida a la producción de un efecto y es necesario determinar la contribución de factores no solo porque intuyamos la diferencia sino porque esto nos permite contar con una explicación más satisfactoria, con la cual podemos mejorar nuestras predicciones y planear el efecto de nuestras acciones sobre los fenómenos.

De esta manera hay que abordar las posiciones contrarias al reduccionismo. Si partimos de que autores tan importantes como Hume y Mill no lograron por completo hacer una reducción satisfactoria, es decir, un análisis no causal de la causa, nos encontramos con que no se ha superado del todo el uso de sinónimos, que nos exigen, a su vez, nuevas definiciones, procedimiento mediante el cual no podríamos explicar la noción a alguien que la desconociera. Ante esta situación es necesario entrar a considerar una posición antirreduccionista, que defiende que la causa es simple e inanalizable, que no se deriva de ningún otro concepto. La cuestión es si la imposibilidad de reducir el concepto a sus elementos nos permite elaborar una noción única y básica de la causa, que no sea susceptible de más análisis, lo cual lo convierte en una noción primitiva. Sin embargo esta idea tiene obstáculos difíciles de superar, entre ellas el riesgo de elaborar una definición circular, pero hay que tener en cuenta que, ya que la causalidad tiene una presencia tan permanente es porque parece ser un elemento constitutivo de los cambios de los fenómenos y por lo menos un signo de que hay cierta regularidad en el mundo.

El argumento de Hume sobre imperceptibilidad de la conexión causal necesaria es precisamente un argumento fuerte en contra de la noción primitivista, pues no podría entenderse cómo una noción básica deba ser inferida. Sin embargo, esta idea sugiere algunas reflexiones: en la actualidad no podemos limitar la percepción a la capacidad de captar sensorialmente lo que sucede ante nosotros. Primordialmemte porque no podemos hablar de una percepción directa que pueda 
prescindir completamente de la serie de herramientas cognitivas que utilizamos para conocer la realidad. Sin ellas, los sucesos quedarían convertidos en una sucesión de hechos sin ningún significado, ante los cuales la mente solo se limitaría a constatar su existencia sin ninguna comprensión del posible entrelazamiento que puede haber entre sucesos. Si bien es cierto que la percepción directa no posibilita tener seguridad sobre si alguno de los múltiples factores que anteceden la existencia de un objeto es necesariamente la causa, no es lo mismo constatar que la rama de un árbol se dobla porque un pájaro se posa en ella, que demostrar que la luz se aparta de su trayectoria rectilínea por la acción de un campo gravitacional de una magnitud considerable. En el primer caso no requerimos de instrumentos de medición (aunque ese no es el problema principal), la diferencia más notoria es que en el segundo requerimos de herramientas conceptuales de mucha mayor complejidad, incluido un cuerpo teórico capaz de interpretar la geometría del espacio, así como contar con fenómenos cuya observación directa es imposible. Entonces, puesta la causa como concepto primitivo o como sujeto de impresión directa es insuficiente para dar cuenta satisfactoria del concepto; de esa forma tendría más el papel de una intuición, una idea que emana de nuestras experiencia aunque sin la formalización racional que puede ofrecer un enunciado científico.

Un argumento que se esgrime contra el antirreduccionismo es que no aporta información a lo que podemos entender como causa pues, en cambio, la reducción lo aventajaría al permitir una mayor comprensión sobre las relaciones de lo causal con otros sucesos del mundo (Carroll, 2012, p. 290), aunque como ya se ha mencionado subsiste la dificultad de llegar a un acuerdo sobre cuál es el elemento que permite soportar la reducción de la causa. El antirreduccionismo en alguna medida cae en las consecuencias de nuestra tendencia a reificar, a crear cosas con conceptos. Si entendemos que la causación hace referencia a los hechos concretos y a sus relaciones, y aceptáramos que las causas son una especie de entidades, nos encontramos trasladando el problema de la definición a otro nivel, pero no solucionándolo, pues aparte de multiplicar inútilmente los entes, seguiríamos con la necesidad de definir en qué consiste su naturaleza y cómo opera, por lo tanto no debemos acudir a una ontología causal fuera de los hechos involucrados (Carroll, 2012, p. 294). Además la causalidad no se comporta como un tipo de entidad sino que su papel es el de una relación o un tipo de relaciones que se establece entre objetos o estados de cosas.

Para resumir, parece que los argumentos presentados se inclinan en contra de la posibilidad de reducir la concepción de lo causal a sus elementos, ya que no siempre son los mismos en diversas 
situaciones, pero, más que eso, porque no se ha encontrado un buen candidato que sea capaz de dar cuenta de lo que sea la causa en términos más elementales; sin desconocer que los intentos reductivos son valiosos como instrumento para identificar algunas de las posibilidades de entender tipos particulares de acción causal: la transferencia, por ejemplo, no da cuenta de todas las formas de la causa, pero permite entender un rango de ellas, así como los análisis probabilísticos son una herramienta fundamental para identificar otro tipo de relaciones. Igual se podría decir de la dependencia contrafáctica o de la transferencia: son otras de las formas que asume la causalidad, otra muestra de que en los hechos concretos las causas adoptan múltiples formas y por eso acentúan características que tienen una mayor o menor relevancia según el caso. No siempre se puede apreciar en las secuencias de causa a efecto una estricta precedencia temporal, por ejemplo, o la contigüidad espacial. Esas razones son suficientes para dar pie a un singularismo ontológico, que no es un obstáculo para continuar en la búsqueda de los elementos comunes que fundamenten la búsqueda de leyes causales, estas sí en el ámbito epistémico.

\subsection{Monismo y pluralismo causal}

Si se intenta elaborar una definición es porque se asume que hay un sentido primario de la causalidad, pero tal afirmación puede objetarse si el término abarca una multiplicidad de sentidos, correspondientes a los tipos de relación que se pueden establecer entre diferentes causas con sus respectivos efectos. Como ya se mencionó, Psillos califica la búsqueda de una definición unitaria de la causa como la camisa de fuerza del monismo (Psillos, 2008, p. 1), que consiste en que las teorías causales han intentado encontrar un único concepto que abarque todas las relaciones que se recogen bajo la expresión "c causa e", pretendiendo que su versión cubra todos los casos y que excluya como no causales todas las sucesiones de eventos que no cumplan las condiciones que se pretendan bajo la posible definición. Tales concepciones sostienen que el conjunto de hechos relativos a la causa puede ser reducido a una teoría única, capaz de dar cuenta de si la relación es singular o general, extrínseca o intrínseca, irreductible o reductible a hechos no causales. Sin embargo, la revisión de las diversas teorías monistas muestra que sistemáticamente se encuentran situaciones que se escapan de las condiciones puestas en cada una de las definiciones propuestas, lo cual lleva a sus defensores a adicionar cláusulas que vuelven las nociones más complejas de lo que pretendían, con el objeto de incluir fenómenos no contemplados previamente. Ante la ausencia de la teoría total, Psillos aduce que no tiene tanto sentido seguir criticando las diversas opciones como intentar descartar la camisa de fuerza del monismo. Así que hay que considerar la posibilidad 
de que los elementos asociados a la causa, tales como la regularidad, la dependencia contrafáctica, la transferencia y demás, no sean tanto definiciones como características particulares de ciertas relaciones causales, pues las múltiples formas que adopta no deja alternativa al intento de unificar la causa por esos posibles síntomas (como también lo sostiene Anscombe). Ninguno de los elementos mencionados parece poder dar cuenta de todo lo que entendemos por causa ni puede escapar de excepciones, por eso las teorías suelen ser complementadas con lo que se podría llamar hipótesis ad hoc para ajustar los argumentos a la intuición o para cubrir las excepciones de los casos contemplados. Esa sería una buena razón para explicar por qué no siempre se hable en términos causales - como lo hace la ciencia al acudir a términos funcionales- , pero esto no implica que el término deba o pueda ser abandonado, pues sigue siendo útil cuando hablamos en términos más abstractos. Psillos (2008, p. 4) comenta que quizás no haya un hecho metafísico o una naturaleza más profunda de la causa: no necesariamente esto implica defender el carácter oculto de la necesidad, ni la presunta carencia de contenido de la causalidad, sino la imposibilidad de encontrar un principio causal único.

Por su parte, Hitchcock (2003, p. 4) también afirma que no hay un único referente cuando se habla de la relación causal, esto es, que cuando empleamos el término causa y sus relativos podemos en realidad estar entendiendo no una sola entidad sino una variedad de relaciones: así, se han identificado algunas de las características propias de la causa, pero esto no significa que alguno de esos elementos nos permita identificar siempre cuándo la relación es netamente causal y no accidental, por ejemplo. El asunto es que el uso del término causa puede estar haciendo referencia no solo a la noción general sino a los elementos que la caracterizan o la acompañan. Pero, puesto que no parece haber una forma única de analizar una relación causal, el análisis debe identificar qué tipo de relación se presenta en cada caso particular de causación, así como cuáles son los elementos que se presentan en el caso. El problema es que no hay acuerdo en admitir solo una de las múltiples posibilidades causales, o en aceptar que no hay un único concepto privilegiado, como se ve en la posición de Hitchcock: una especie de igualitarismo causal que no privilegia como más adecuada o verdadera alguna de las posibles relaciones causales.

Vista la variedad de opciones que se han dado sobre lo que sea la causa, no parece sostenible la idea de que exista una única relación objetiva que sea causal (lo que Hitchcock llama la "tesis del vínculo humeano" en 2003, p. 4) lo cual se pone de manifiesto cuando exploramos algunas de las objeciones que se erigen contra las principales teorías unitarias. El autor afirma que los vínculos 
entre causa y efecto están relacionados con la distinción que se puede hacer entre estrategias efectivas y no efectivas, pero además, añadimos, pueden ser de otras múltiples variedades: la causa puede ser uno de los eventos de una secuencia que conduce a la aparición de un efecto, puede causar un solo efecto o puede causar algún efecto secundario; estar vinculada a una ley física, o estar vinculada al efecto en la medida en que haya algún dominio de variación, es decir, que el efecto se produzca en la medida en que la causa opere por una modificación gradual de un factor que, rebasando un cierto límite, posibilite el efecto. Además no hay que olvidar que también nuestro papel como agentes implica que tenemos la capacidad de crear múltiples formas de relación causal.

Cartwright cree que la idea del "concepto monolítico" de la causa de Hume y K ant es errada, en tanto no existe una única ley causal sino que el mundo está lleno de ellas y no se ha encontrado una formulación suficientemente amplia y precisa como para que pueda unificarlas. También la autora reitera que la noción general de causa en las descripciones específicas se reemplaza por verbos más precisos, de la misma manera que en otros campos los términos abstractos se pueden reemplazar por otros que describen de forma concreta en qué consisten los hechos calificados. Las causas no son completamente misteriosas y la ciencia ya sabe cómo operan relaciones específicas, pero lo que falta por definir es si la causa se puede caracterizar siempre de forma similar. La variedad de concepciones causales parece un buen indicio de que el contexto de aplicabilidad de cada una de ellas es muy particular. Como lo afirma Cartwright (2007, p. 23), las organizaciones causales del mundo son múltiples, porque el mundo es variado y, así, son muchos los tipos de relaciones y estructuras que adoptan los sucesos del mundo como para creer que todas se puedan reducir a una única forma de operación causal.

La ciencia puede utilizar el término causa como una guía de la investigación y de la búsqueda de explicaciones, pero es evidente que se suele preferir descripciones formalizadas y leyes. La cuestión se mueve en medio del difícil equilibrio entre simplicidad y precisión: simplicidad porque la única forma de entender los sucesos de la naturaleza es por medio de procedimientos capaces de traducir la complejidad externa a esquemas que permitan establecer semejanzas entre tipos de hechos; precisión porque necesitamos hacer predicciones que nos permitan manejar el mundo y prever cómo ha de comportarse. Pero ese equilibrio está condenado a ser en alguna medida insatisfactorio, pues mientras mayor es la exactitud de nuestras descripciones de la naturaleza, menor es su simplicidad y capacidad de cobertura: la ciencia en su etapa moderna aspiraba a 
leyes universales, que hoy sabemos son de alcance limitado a ciertas regiones y dentro de determinadas condiciones. D e todas formas hoy la ciencia sigue necesitando leyes que le permitan diferenciar y manipular los factores relevantes para explicar o para predecir el comportamiento natural. Pero aislar los factores relevantes tiene algo de solución de compromiso: las leyes siempre tienen algún grado de provisionalidad mientras se formulan otras más precisas, que a su vez tendrán algún grado de provisionalidad, de imprecisión y de limitación en su uso. Pero no por esto podemos llegar al extremo de creer que la naturaleza está tan bien regulada y que hay una ley para cada caso, pues de tal manera nuestra representación del mundo sería tan compleja como el mundo mismo, ni podemos creer que se puede contar con la descripción y explicación última de algún fenómeno.

Sin entrar en el problema del significado de las leyes naturales, la concepción de Cartwright asume que las leyes son necesariamente limitadas pues en su formulación general tienen un rango de aplicación que cubre ciertos casos especiales. D esde su punto de vista la limitación œeteris paribus hace que estas no sean verdaderas leyes, aunque conserven su papel explicativo: siempre están delimitadas por restricciones, pero eso no impide que nos permitan ordenar algunas relaciones entre eventos; son muestra de que existen en la naturaleza regularidades, pero son regularidades parciales, en claro paralelo con las parciales explicaciones causales. Lo que nos compete en este momento es que el hecho de que las leyes estén limitadas a situaciones acotadas revela que en efecto pueden existir y existen múltiples formas de relación causal, lo que se hace evidente, por lo menos, en las explicaciones. Por ejemplo, en casos en que un efecto no sea plenamente seguro, como en la aplicación del insecticida, Suppes y Salmon dicen que el uso de mejores herramientas estadísticas permite determinar los factores que entran en la explicación, pero Cartwright (1991, p. 53) no lo cree por la existencia de casos que quedan sin explicar: la supervivencia de individuos de la plaga que se intenta exterminar. Es claro que el agente químico es el responsable de que un cierto número de individuos de una plaga desaparezca, pero Cartwright afirma acertadamente que no se puede acudir al agente como la causa de que algunos individuos de la plaga continúen con vida.

Este ejemplo permite acercarnos al pluralismo causal: la diversidad de teorías actual sugiere que no parece haber posibilidad de hallar un único concepto capaz de abarcar esa multitud de formas en que se presentan las relaciones causales, no solo por sus múltiples formas de acción sino porque cada una de las teorías se enfrenta con una o más dificultades insalvables. Además, parece 
también muy difícil unificar los diversos dominios de aplicación a los que suelen remitirse las teorías causales: en algunos casos la inferencia a partir de leyes naturales es suficiente para adjudicar las causas, como ocurre con ciertos casos del comportamiento subatómico, mientras que algunos de los fenómenos de nuestra escala responden con éxito al criterio de transmisión de energíay de momento. Esto indica que en principio la causalidad no se deja reducir a una condición única con una naturaleza determinada, ni tampoco que haya una visión metafísica única. De estas dificultades en la indagación de su naturaleza ontológica no podemos concluir que nuestras necesidades epistemológicas tengan el mismo final de incertidumbre, ya que sigue siendo perentorio explorar qué podemos conocer de la mecánica causal y de su relación con otros conceptos, en particular el de explicación, en la medida en que en este espacio la noción de causa ofrece respuestas importantes. En este sentido, el trabajo de exploración hecho hasta hoy ha ampliado las posibilidades que abarcan las relaciones causales, contribuyendo a la comprensión que tenemos sobre fenómenos diversos y también a los usos que hacemos de nuestros conceptos. Pese a su crítica general a las leyes de la ciencia, Nancy Cartwright (2004, p 814) defiende la variedad de las leyes causales y por tanto, la diversidad en la forma en que estas operan, diversidad que se refleja en la inespecificidad del término causa, una especie de etiqueta que se aplicada a relaciones diferentes.

Ahora bien, que existan diferentes evidencias sobre un hecho causal no implica de por sí una confirmación de pluralidad causal, en el sentido en que no hay necesariamente varios conceptos de causa derivados de los diferentes hechos. Como ejemplo, Casini cita el del cáncer que, pese a tener un solo nombre, no corresponde a una sola dolencia que opere de la misma manera en sus diferentes manifestaciones. El caso es que, o el concepto de causa no es específico, lo cual parece cierto dado que alude a diferentes tipos de relaciones, o estamos definitivamente hablando de un racimo de conceptos (duster conœpt) (Casini, 2012, p. 208). Frente a esta consideración, Casini hace referencia a dos opciones: en primer lugar, asumir que el problema no está en las cosas sino en los términos, pues el hecho de que una relación haya sido denominada como causal es un problema histórico y no filosófico; la otra opción es que exista un hecho o vínculo real, de modo que si existen coincidencias se justifican por referirse a una relación del mismo tipo, es decir, cierto tipo de inferencias. Entonces, la dificultad en la definición del concepto se produce ya sea porque es más bien un conjunto de conceptos agrupados bajo un solo término o porque representa un conjunto de nociones diversas que no permite determinar cuál es el sentido particular en que se usa. D e nuevo, podemos ver que la cuestión no se limita al problema semántico: es también el 
problema epistémico de saber en qué consiste el fenómeno con el cual nos enfrentamos y el problema ontológico de la entidad y operatividad de un tipo de relación que sucede entre hechos reales. Hay un aspecto del problema semántico que es llamativo y es que pese a la dificultad de concertar una definición, el término tiene la fortaleza de servir para comunicar de forma amplia el tipo de relación aludida, si tenemos en cuenta que al hablar de causa lo usual es que esta se entienda como contrapuesta a relaciones de otro tipo, como la correlación de probabilidades, la secuencia temporal o las correlaciones accidentales.

Sin embargo, como veíamos en el aparte anterior, adoptar el pluralismo no es precisamente la solución final del problema, dado que hay que responder a las inquietudes de cómo se utiliza el término y cómo adoptamos un solo concepto para aludir a lo que es múltiple; no es suficiente asumir que cada par de eventos se comporta de manera única y que nuestro objeto se agota en describir esa relación y sus mecanismos, pues a partir de este punto necesitamos encontrar las regularidades necesarias para conocer de forma más completa la realidad, para predecir su comportamiento y para poder intervenir en ella. Pero seguimos necesitando dar respuesta a la razón de por qué existe un único término para abarcar cosas que aparentan ser tan diferentes: sin esa respuesta no podremos conocer del todo los fenómenos implicados ni predecir cómo han de comportarse. La pluralidad no nos libra de la necesidad de buscar una unificación de la causa como una función o característica de cierto tipo de relaciones, que debe ser tan clara como para que podamos oponerla a otro tipo de relaciones que no tienen esa función de producción y de explicación. Esa cierta unidad de uso del término y del concepto es un indicio de que existen elementos comunes en sus múltiples manifestaciones, a la vez que sugiere diferencias con otros tipos de secuencias. Como lo plantea Psillos (2008, p. 19), existe una propiedad sustantiva, pero de ello no se sigue que haya una entidad metafísica que subyazca (y haga verdaderas) a todas las verdades causales. Negar que exista una única característica común subyacente no es negar la causa sino su tratamiento unitario, es decir, que se la considere como un único tipo de entidad cuyas manifestaciones puedan presentar siempre las mismas características. Una posible vía de salida de este problema es concebir la causalidad desde una visión modularista: esto es, que cada mecanismo que conduce al efecto es descrito por su ley específica, y que ese mecanismo puede operar de otra forma con respecto a otro efecto, de acuerdo con determinados parámetros. Hay varias opciones, entre las que se puede mencionar que la causa sea identificable, pese a que obedezca a formas de operación diferentes, o que la pluralidad dependa de los modos en que 
operan los factores causales. Cartwright $(2007$, p.16) concluye que no se debe descartar la modularidad, sino que no se puede considerar como la base de un concepto unívoco.

Por tales razones, incluso el pluralismo vuelve a la búsqueda de la característica común: se suele aceptar que una relación causal ha de ser necesaria, repetible, explicable, espaciotemporalmente continua y anterior al efecto (Losee, 2011, p. 192), y el vínculo se intenta unificar por medio de la ley que relaciona la causa con el efecto, la dependencia contrafáctica, el incremento de probabilidad, algún proceso causal o mecanismo, algo que se transfiera de la causa al efecto o una característica tan general como para dar cuenta de múltiples casos. Como dichas características no siempre se presentan juntas, la consecuencia es que existen muchas formas de identificar un hecho causal; pese a esto, suele haber acuerdo sobre cuál de los factores antecedentes es considerado la causa de un efecto y si no existe tal acuerdo se buscan los indicios de la insuficiencia de los factores conocidos. Pese a ese mediano acuerdo práctico, son notorios los desacuerdos en la filosofía de la causalidad, y esto no deja de ser llamativo pues parece más viable señalar la posible causa que la razón por la cual aceptamos que ese factor sea propiamente causal.

El hecho de que una situación concreta pueda ser comprendida bajo diversas caracterizaciones puede entenderse como la evidencia de que estamos hablando de la acción simultánea de relaciones diferentes, o de que esas características deben ser tomadas, en los términos mencionados de Psillos (2008, p. 11), como síntomas causales que se presentan en mayor o menor medida en cada uno de los casos. El autor denomina esta posición como una especie de agnosticismo causal, diferente del atéísmo causal de los negacionistas. La ventaja de este agnosticismo causal es su consistencia con la naturaleza metafísica de la causa: no la niega, sino que asume que no hay una sola naturaleza o que esta no es radicalmente definible; mientras tanto, el ateísmo causal es más radical, en tanto que declara que el uso común de cierto lenguaje causal no implica la existencia de una naturaleza común, es decir, que la existencia de un único término no implica una naturaleza única. En esta especie de ateísmo causal no se afirma la naturaleza plural de la causa, es más, no se acepta que exista alguna cualidad singular, sino que aquello que sea la variedad de la causa es simplemente la manifestación de sus múltiples síntomas.

Entonces, una de las tensiones de la discusión está en si se da más o menos énfasis al sustento ontológico de la causa: el hecho de que haya unidad en el término no implica que necesariamente esté aparejada con una unidad metafísica. Puede ser que la multitud de inferencias que pueden 
hacerse a partir de los hechos concretos implique muchos conceptos de causa, o que el proceso de abstracción del conocimiento elabore diferentes nociones ordenadas en tipologías correspondientes a tipos de casos basados en evidencias diversas. 0 tra opción diferente está en que la unidad no esté en el campo de las manifestaciones externas ni en el espacio ontológico, sino fuera de estos campos, en la búsqueda de explicaciones y de algunos enunciados pragmáticos, lo que nos pone de nuevo en una cierta forma de monismo causal, unificado no por la causa en sí misma sino por sus aplicaciones. Casini (2012, p. 213), quien defiende un concepto unitario de la causalidad, utiliza un argumento sobre la eficacia de la comunicación: consiste en que si dos comunidades utilizan la misma palabra con diferente significado, sucede que o su comunicación no es exitosa o no concuerdan en las reglas de aplicación del término; por otra parte, si el desacuerdo es evidente hay que examinar la opción del diferente significado, pero si la comunicación continúa esto implica que hay coincidencias en los alcances y uso del término. Dado que se ha venido utilizado el término causa de manera más o menos efectiva en la comunicación, esto ha de implicar que es un solo concepto o que puede haber diversidad de conceptos pero con características comunes. En alguna medida es un problema usual dela tensión entre los conceptos abstractos y sus manifestaciones particulares; en efecto, esta es una muestra del problema de las definiciones: el concepto está siempre en un punto intermedio entre la especificidad y la generalidad extremas, la primera es nociva porque termina señalando más que definiendo, mientras que la segunda está plena de vaguedades.

Recapitulando, el problema del pluralismo es que no da cuenta de la razón por la cual deba usarse un solo término para abarcar tipos de relaciones que son muy diferentes, pues de todas formas ese hecho es por lo menos un indicio de que puede existir un concepto unitario. Y, de todas formas, el pluralismo ofrece un aspecto insatisfactorio en tanto la mente busca la economía óntica, semántica y lingüística por fundadas razones: no es la mejor idea la de contar con un abanico de manifestaciones diferentes en remplazo de una definición clara que precise los alcances del término. Por la vía semántica, de la búsqueda del significado de la expresión lingüística, el inferencialismo propone que se defina o que se maneje el concepto en términos de las relaciones de inferencia que pueden establecerse entre unas circunstancias dadas y sus consecuencias. De tal manera, conocemos el significado de las expresiones no por su función referencial sino por la forma en que se usan en el lenguaje y, de forma análoga, las sentencias derivan su significado no de los valores de verdad sino del papel que cumplan dentro de un razonamiento. A sí, en lugar de elaborar una definición de trascendencia ontológica, se opta por la vía pragmática del uso de la 
expresión, en que las premisas son las circunstancias de aplicación apropiada (experimentos, observaciones, pruebas aleatorias) y las conclusiones son las explicaciones, predicciones e intervenciones (Casini, 2012, p. 206), de manera que el significado de los enunciados causales está constituido por las relaciones inferenciales entre evidencias y consecuencias. Sin embargo, por esta vía no se solucionan la mayoría de los problemas de los espacios ónticos: la definición de la causa tiene particularidades que dificultan su solución, pues no solo involucra el tipo de relaciones, de alguna forma observables, que se producen entre eventos concretos sino que también alude a cuestiones de una generalidad mayor, que involucra cierta relación entre entidades así como los procedimientos mediante los cuales la mente elabora razonamientos. La mente posee mecanismos para establecer si las relaciones entre determinados eventos corresponde al tipo de transformación de la realidad que presenta las características de asimetría temporal y de contigüidad espaciotemporal y que sirve también como base a lo que se acepta como parte de una explicación sobre el origen de las cosas o de sus cambios, pero no hay que olvidar que las causas se encuentran en los hechos, mientras que las inferencias se hacen entre enunciados.

\subsection{Las causas en un mundo no lineal}

En este momento es útil entrar a considerar una de las razones que parece hacer inevitable la pluralidad causal. Nuestro conocimiento del mundo y la formulación de leyes nos permiten tener la convicción de que siempre que existan dos conjuntos de condiciones iguales, esperaremos iguales resultados. Sin embargo, lo usual es que sea difícil encontrar dos conjuntos de situaciones exactas, elemento a tener en cuenta cuando se buscan las causas y que no parecen considerar la mayor parte de teorías causales. Que el mundo sea o no determinista es otro problema, pues cualquiera de estas concepciones puede ser compatible con que los acontecimientos del mundo puedan ser predichos de forma limitada, pues lo usual es que no conozcamos todos los datos necesarios para hacer predicciones exactas. Hay que tener en cuenta que existen fenómenos que pueden ser modelados con ecuaciones lineales, pero otros requieren una matemática más compleja: así, los modelos lineales formulan predicciones precisas para sistemas aislados con condiciones conocidas y determinadas, mientras que los no lineales modelan los comportamientos dentro de ciertos parámetros, teniendo en cuenta que, debido a la particular naturaleza de los sucesos de los que se ocupan, ofrecen una aproximación cada vez menos precisa en la medida en que las predicciones se alejen del momento presente, aunque ofrecen más información sobre lo pasado (Bertuglia \& Vaio, 2005, p. 45). 
Existe una gran variedad de fenómenos que se resisten a encajar dentro de modelos lineales con secuencias causales deterministas, de los cuales veremos a continuación algunos ejemplos. Cuando se debate sobre la posibilidad de formular leyes históricas, ocurre que no son muy estrictas, presentan muchas restricciones o se acotan a condiciones muy particulares, lo que hace discutible que sean leyes en sentido estricto. En contra de las leyes históricas se esgrime que los acontecimientos humanos son únicos, y así el objetivo de la explicación en historia más que encontrar las regularidades que nos permitan construir argumentos deductivos, es el de la comprensión (verstehen) (G onzález, 2003, p. 33), que no deja de lado la noción de causa. En este ámbito de la ciencia se acepta la noción de explicación teleológica (en principio considerada inadmisible en las ciencias de la naturaleza), ya que los acontecimientos humanos están mediados por finalidades: el efecto posterior es la guía para la acción previa, cuestión similar a lo que ocurre con las explicaciones funcionales en biología. Ahora, no es necesario invertir la dirección causal, pues los efectos siguen siendo posteriores en el tiempo: pese a que prefiguren un camino para lograrlos, la intención es previa y el resultado incierto. Sin embargo, esto no descarta la aplicabilidad de la explicación funcional en biología, que permite entender cómo la naturaleza ha llegado a soluciones convergentes para suplir una misma función o necesidad. Por eso Riedl (1983, p. 238) prefiere el término teleonomía, que no excluye el análisis de la finalidad en los seres vivos, pero tampoco contempla propiedades sobrenaturales. En las ciencias sociales la complejidad dificulta aún más (o incluso impide) la formulación de leyes; en algunos casos es claro que los actos se modelan porque se planean para cumplir una finalidad, pero hay otra fuente de complejidad que es la realimentación: las causas producen efectos que a su vez son causas. A tales dificultades se añade la interferencia de la consciencia humana ya que la previsión modela el comportamiento con la intención de que el efecto se pueda propiciar o prevenir: muestra de ello son las profecías autocumplidas y los fenómenos virales. También hay que contar con otro plano añadido y es si el comportamiento colectivo se puede resolver o no (o reducir) por medio de los comportamientos individuales, además del problema de si las entidades colectivas con las que se trabaja en ciencias sociales - muchas son constructos teóricos- son capaces de establecer interacciones causales (Kincaid, 2012, p. 730). No nos detendremos en esto, es solo una muestra de las dificultades de implementar una noción causal en espacios diferentes de aquel en que sus respuestas parecen encajar mejor, que es el de la física clásica. 
Hemos insistido en que las causas son eventos singulares en el sentido en que el cambio que producen es único por su situación espaciotemporal en el universo, pero accedemos a la comprensión de los eventos de la naturaleza por medio de regularidades que nos proveen de las explicaciones correspondientes; estas pueden ser múltiples, pese a que versen sobre un solo evento, y es que el mundo es complejo y no es tan predecible como quisiéramos: la razón sufre del sesgo de confirmación que nos hace regularizar lo heterogéneo e intentar linealizar los comportamientos complejos de la naturaleza, pues nos es más manejable un mundo en el que una causa sea seguida por su mismo efecto y en el que podamos reconstruir una historia causal pese a que tenga muchos eslabones. Quizás de ahí derivamos una cierta confianza en que las causas sean transitivas, como en la conocida historia (Cohen, 2010, p. 158) de que por un clavo se perdió una herradura, por la herradura se perdió un caballo, por el caballo se perdió un jinete, por el jinete se perdió una batalla y por la batalla se perdió la guerra, todo por un clavo: retrospectivamente se puede reconstruir la historia, pero eso no implica que pueda hacerse una predicción fiable cuando los vínculos entre los eslabones de la cadena causal sean tan débiles. Sobre este ejemplo O wens (1992, p. 16) dice que los eventos de la cadena no tienen una explicación común: la ocurrencia de la cadena causal es coincidencial, de modo que el primer elemento de la cadena difícilmente puede explicar el último, pues se requiere de ciertas condiciones en cada una de las etapas de la cadena. Esa es la cuestión: la debilidad de las cadenas causales está vinculada al hecho de que la predicción es más fiable mientras más cercana sea en el tiempo; mientras haya más pasos intermedios la predicción es menos fiable y por tanto se debilita la capacidad explicativa de la cadena causal. Igual sucede con todo sistema carente de aislamiento, de forma tal que lo normal es que haya numerosos factores causales que intervienen en las fases del proceso; es posible que podamos elaborar una explicación transitiva, pero las secuencias causales son más débiles: mientras más eslabones, mayor la inseguridad de la predicción. No hay que olvidar que el azar puede ser entendido como una limitación del conocimiento pero también como una característica de algunos eventos reales y que la confluencia de factores va creando condiciones que hacen impredecibles los acontecimientos fuera de las condiciones de aislamiento de laboratorio, es decir, suprimiendo perturbaciones y acortando los plazos. Ni siquiera los movimientos de las bolas de billar serían predecibles si pudiéramos prescindir de la fricción, pues en un plazo más largo los múltiples choques harían el sistema completamente impredecible. Ni tampoco el sistema solar, relativamente aislado, escapa a comportamientos caóticos en el largo plazo. D os conclusiones provisionales quedan hasta este momento: la primera es que, pese a las leyes, el mundo no es tan previsible como una hilera de fichas de dominó, lo cual nos reserva un espacio muy intrigante de investigación acerca de cómo se ensamblan los diversos factores que confluyen en la producción 
de un efecto. La segunda es que, en las mismas condiciones, hay mayor factibilidad en la elaboración de una explicación satisfactoria de un evento ya ocurrido que de hacer una predicción sobre uno que eventualmente ocurra, que no es un enunciado tan trivial como se podría imaginar, dado que nos habla del contraste entre las líneas causales que llegan del pasado hasta hoy, enfrentadas contra las múltiples ramas de los caminos que se despliegan hacia el futuro.

Son otras muestras de que los campos epistémico y ontológico no son separables del todo, pero debe intentarse una delimitación, pues desde la perspectiva ontológica las causas son singulares y los eventos frágiles, pero desde la perspectiva epistémica tenemos que trabajar con leyes, probabilidades y tipologías de mecanismos. Esto nos va configurando el panorama que nos permite delimitar los problemas y conocer cuáles son las vías de exploración: la historia del clavo nos revela que los acontecimientos del mundo están encadenados de formas impredecibles, de forma que podemos elaborar una explicación que recoja la transitividad de las causas, pero la probabilidad de que volviese a ocurrir tal secuencia es tan baja que no podemos contar con ella, una muestra de que el universo se enfrenta a múltiples futuros posibles. Entonces, esto nos lleva a la definición de un panorama más complejo en el que hay que examinar las causas no solamente como objetos determinados por medio de relaciones lineales, sino como parte de situaciones compuestas de factores diversos y condiciones que se entrelazan para que ocurra un efecto, teniendo en cuenta, además, que el vínculo entre causa y efecto opera de formas diversas.

\subsection{Explicación y relevancia}

Tras el recorrido que se ha hecho a lo largo del capítulo lo que podemos apreciar es que la noción de causa abarca una variedad de posibilidades que no han permitido aún consolidar una única concepción. Pero podemos adelantar alguna toma de partido frente a la cuestión. En primer lugar, el hecho de que se utilice un solo término para hablar de la causa no indica que esta ofrezca una naturaleza única, pues a la vista se encuentra toda la variedad de fenómenos que se han intentado cobijar bajo un solo concepto. Sin embargo, no podemos ver este hecho como una consecuencia de las limitaciones de los lenguajes ordinarios. En el campo de la filosofía se sigue discutiendo en torno a si puede hablarse o no de una naturaleza común, pero hasta el momento lo que parece más sensato es aceptar que el término causa es un término abstracto que aspira a abarcar las secuencias en las que se producen los cambios, aunque la misma noción de cambio es problemática, pues hay varios ejemplos conocidos en los que se indaga por la causa de un cierto 
estado de cosas en equilibrio. Sin embargo, lo que se ha visto es que en la medida en que se intente acotar más el término es más probable que empiecen a quedar fuera fenómenos en los cuales intuimos influencia causal, entendida como la posibilidad de que la presencia de una cierta situación altere una o más características de las que componen un evento. Así que, tal como ocurre con todo conocimiento, construimos las causas con base en nuestra experiencia de ciertas regularidades naturales en las que operan diferentes mecanismos de transmisión de influencia: desde los casos más evidentes de intercambio de energía hasta los casos más complejos de cadenas causales con factores aleatorios en los cuales las líneas de influencia pueden ser rastreadas solamente a posteriori. Sin olvidar que otro de los síntomas importantes es el de los enunciados contrafácticos, que tienen múltiples aplicaciones en la indagación causal: nos proveen de medios para identificar los factores que pudieron haber tenido una acción causal.

Una de las dificultades principales en la búsqueda de una concepción unificada de la causa es que no parece haber puntos en común entre fenómenos tan diversos como, por ejemplo, las emociones humanas, la simbiosis entre especies animales o los choques de las bolas de billar. Es evidente que, a pesar de que podamos utilizar el término causa en los tres casos, estamos hablando de factores muy diferentes que operan por medio de vías tan diversas que podría ser aceptable el rechazo de la noción de causa en alguno de los casos. Y, pese a que defendemos que la causa está en los hechos, es decir en los casos particulares en los que aceptamos la capacidad de transmitir influencia causal, no podemos desconocer el trabajo que se ha hecho en la identificación de lo que se ha llamado síntomas causales. Es también una forma de aceptar y entender que la causa tiene que entenderse como un fenómeno múltiple. Sin embargo, y volviendo a los síntomas, no se puede desconocer que las visiones regularistas han ofrecido un medio para reconocer las causas que no puede ser desdeñado, aunque no lo consideramos aceptable como medio de explicar o reducir la causa; quede claro que esta también es una forma de decir que no creemos en la posibilidad de reducir la causa a términos más elementales.

Así que consideramos que la causa se manifiesta de forma plural, en el sentido en que no se acomoda a una única manera de transmitir su influencia sobre los efectos, pero que puede ser reconocida por uno o más de sus signos o síntomas. Parece claro que la cantidad de acercamientos a la causa tenían la intención de domeñarla, ya fuera por reducción o eliminación, o por lo menos haciendo una definición que no dejara dudas sobre sus características, pero también habrá que admitir una cierta derrota hasta el momento. Lo que podría ocurrir en adelante es que se sigan 
explorando vías independientes que den cuenta de cómo operan las causas en tipologías de casos, que es lo que ha venido haciendo la ciencia, al igual que desde la filosofía se debe seguir intentando dar cuenta de cómo las causas nos permiten entender muchos fenómenos. Por tales razones, lo que se está proponiendo en el presente trabajo es explorar la relación entre causa y explicación, que tampoco pretende ser una concepción causal completa sino una de las vías que nos ofrecen respuestas, así como también una de las posibles formas de identificar el papel causal que pueden presentar ciertos factores en una sucesión de eventos, datos a partir de los que construimos explicaciones.

Aceptando que las causas obedecen a una conjunción de múltiples factores que operan de diversas formas, es claro que no podemos reconstruir de forma completa y exhaustiva la secuencia de eslabonamientos causales que da origen a un evento y es por eso que para entender cómo se producen las relaciones entre causas y efectos necesitamos aislar los sistemas en estudio, de manera que se pueda elaborar un cuadro más o menos sucinto y comprensible, de los factores que han confluido en la producción de un evento. Sin embargo, dicho procedimiento implica correr permanentemente el riesgo de que la reducción de factores desvirtúe nuestra comprensión, pero es la única manera en que podemos hacer frente a la complejidad de la información que nos ofrece la realidad. El diseño experimental y la búsqueda de explicaciones hace necesario perseguir que los objetos y su comportamiento se asemejen en la mayor medida posible a modelos ideales. De todas maneras, el aislamiento nunca es perfecto; siempre existen factores que no se logran conocer o controlar por completo, siempre se tiene que asumir que algún porcentaje del conocimiento que tengamos del proceso es conjetural y que nuevas investigaciones revelen nuevas causas o un papel determinante que había sido ignorado en secuencias conocidas: en la investigación se espera que ningún factor con capacidad de ejercer alguna influencia causal sea dejado por fuera del diseño del experimento o del argumento explicativo, pero la naturaleza siempre nos guarda sorpresas.

Entonces, lo que nos es más útil es conocer la serie de acontecimientos cuya sucesión está vinculada directamente con la producción del efecto, esto es, su cadena causal; la dificultad radica en determinar cuáles son precisamente los factores que tienen la capacidad de producir una alteración en la secuencia de eventos, pues es evidente que del conjunto completo de factores antecedentes, una mayoría carece de la capacidad para que su incidencia produzca una alteración en el resultado. La cuestión es que determinar cuáles son los factores relevantes puede ser evidente en casos 
extremos, pero lo usual es que dependa del tipo de explicación o de descripción que estemos buscando, ya que la concurrencia de factores no permite en principio delimitar lo que sean propiamente las condiciones necesarias de lo que sean causas desde otra óptica, como veremos en el capítulo siguiente.

Las visiones regularistas dependen de las secuencias de eventos similares, es decir de la que se considera una situación habitual o normal, aunque definirla no siempre es factible; para lo que es pertinente en este aparte, el análisis de una causa concreta depende de lo que conozcamos sobre otros casos semejantes, lo cual nos obliga a seguir contando con el análisis regularista de la causa, así como con la comparación contrafáctica con situaciones hipotéticas. Una causa es la situación previa a un efecto, pero determinar cuáles de sus elementos sean los relevantes para el efecto no siempre es evidente, para lo cual es necesario compararlos con otros, ascender hacia los tipos de eventos, con el fin de indagar qué cambia y qué se conserva en la situación (Psillos, 2012, p. 147): si bien puede ser observable que en ciertos casos un factor determina la ocurrencia de un efecto, es más usual que los casos sean tan complejos que impliquen la concurrencia de más de un cambio, simultáneamente con el que se podría denominar como propiamente causal; de ahí que la determinación de la relevancia solo se puede hacer contrastando con otros casos o con leyes conocidas que den cuenta de eventos similares, pues en esto consiste la búsqueda de explicaciones sobre los fenómenos cuyas causas desconocemos. Sin embargo subsiste el problema de que no hay una manera clara para distinguir las leyes causales de lo que puede ser simplemente regularidades accidentales o generalizaciones parciales.

Puesto que las leyes no son del todo universales, una opción es la de entender que existe un mecanismo específico, una ley causal, para la producción de tipologías de efectos, como ocurre con las leyes naturales, en correspondencia con la necesidad de relacionar las causas, unificarlas o clasificarlas, por lo menos al nivel de nuestro conocimiento. Sin embargo, el papel descriptivo de la ley es mucho más específico que el de la causa pues se espera de aquella que no ofrezca ambigüedad y que sea capaz de hacer predicciones fiables cuando la magnitud de los antecedentes sufre variaciones. Esta opción consiste en concebir las leyes causales bajo una visión modularista, es decir, capaz de hacer predicciones en un rango de variaciones de algún factor: si un enunciado predice qué pasa bajo variaciones del tipo apropiado es una ley causal (Cartwright, 2007, p. 16). D e esta manera podríamos dar respuesta a la disputa de las visiones singularistas con las regularistas: las causas se manifiestan en los hechos concretos, que son singulares, por medios particulares de 
acción, pero pueden ser ordenadas y entendidas por medio de una clasificación de tipos causales que operan dentro de los límites que impone la naturaleza de los hechos entre los que sucede tal relación de producción. En otras palabras que la causa es un aspecto de la realidad, mientras que nuestras estrategias de conocimiento y de intervención se encuentra en un plano epistémico en el que intentamos solucionar los problemas habituales de las causas y de sus manifestaciones. Un mismo hecho puede obedecer a conjunciones que, pese a ser unitarios en la realidad, son conocidos de maneras diversas en dependencia de si se hace un análisis de sus aspectos físicos, químicos o biológicos, por poner el caso.

Lo que puede observarse cuando se estudia la evolución del término causar es que de todas maneras no es un término tan específico como quisiéramos: hoy no nos satisface entenderlo simplemente como un término primitivo indefinible, y sin embargo nos sirve por su papel en la evaluación de las condiciones necesarias y suficientes para que un determinado evento pueda llegar a ocurrir y además nos es muy útil en la comprensión de las explicaciones de los cambios del mundo. En el caso de la causa, uno de los elementos que ofrece más consenso es que se dirige a la búsqueda de cierto tipo de explicaciones. Así, se podría decir que la causa tiene un solo sentido, ligado a la búsqueda de comprensión de las sucesiones de eventos en las que se producen cambios, así que su ámbito de aplicación no es específico, y no puede ser de otra manera, pues corresponde a la necesidad de proveer explicaciones de situaciones muy diversas.

En síntesis, las relaciones que existen entre la causa y la explicación están mediadas por el hecho de que el concepto de lo causal está vinculado a dos instancias de suma importancia: la búsqueda de respuestas a preguntas del tipo ¿por qué... ? y la necesidad de crear estrategias efectivas de modificación de la realidad. En el primer caso, tal tipo de preguntas está fuertemente vinculado al contexto material de los hechos en que la situación se produce, en la medida en que un solo hecho puede ser analizado desde diferentes perspectivas según los aspectos que puedan ser relevantes en el momento, pero también a las necesidades de búsqueda de explicaciones satisfactorias de los fenómenos, pues sobre un mismo hecho pueden plantearse múltiples preguntas de acuerdo con los intereses que estén en juego, tanto en la ciencia como en la vida cotidiana. En el segundo caso, nuestra necesidad de producir efectos sobre la realidad nos lleva a buscar el tipo de actos que posibiliten la producción de unos resultados previsibles, también mediada por un contexto pragmático. 



\section{CAUSAS Y CONDICIONES}

En el análisis de la causalidad hay diferentes instancias, pero el término mismo alude a los problemas más generales, relativos a si existe o no una ley de causalidad y en qué términos puede ser definida. Para el presente capítulo se intentarán analizar algunos aspectos de la operación concreta de las relaciones causales, es decir cómo las causas relacionan ciertas propiedades de los eventos. Para cumplir tal finalidad se tratará acerca de cuáles pueden ser los elementos implicados en la relación causal, es decir, qué tipo de entidades pueden ser las apropiadas para ocupar el lugar de causas y efectos. También se explorará la noción de proceso, que permite entender la gradualidad de los cambios. En el desarrollo de la investigación sobre el papel de las condiciones o el trasfondo causal, se encontró el problema de cómo determinar el papel de las ausencias y omisiones, una de las dificultades que ha ofrecido más resistencia a diferentes teorías sobre la causa, pero que, a nuestro parecer, ofrece indicios importantes sobre cómo opera el análisis de las causas. Dicho problema ha sido fundamental para comprender en qué medida se podía solucionar la cuestión del papel del trasfondo causal y, por esa vía, indagar en qué medida esta indagación se relaciona con la búsqueda de explicaciones.

\subsection{Los relata de la relación causal}

Pese a la pluralidad de definiciones y de usos para el término causa, es necesario ocuparse de sus posibles características comunes, otra forma de aproximarnos a una comprensión del esquivo concepto. Existen varias formas de abordar el problema de determinar el espacio apropiado para la indagación causal; por ejemplo, Mackie (1999, Prefacio, p. ix) plantea que el análisis puede ser factual, conceptual o epistémico: el primero se refiere a aquello que ocurre en la realidad, esto es, independiente de nuestro pensamiento, el segundo tipo de análisis indaga si el problema se limita a los conceptos que manejamos y el tercero se refiere a qué es aquello que conocemos acerca de 
la causalidad en los objetos y cómo accedemos a tal conocimiento. En esta perspectiva, nos ocuparemos preferentemente de lo factual, en la medida en que sea posible mantener este espacio separado. En la Investigación sobre el entendimiento humano, Hume (2004, p. 181), como veíamos en el capítulo 1, elabora dos definiciones de la causa: una que pone el peso en los objetos que se relacionan por medio del vínculo causal y otra que lo pone más en los enunciados contrafácticos, en la medida en que la mente elabora un razonamiento en que si se suprime el antecedente ya no ocurrirá la consecuencia. O tros autores posteriormente examinan posibilidades, tales como que la causa relacione tropos, universales o enunciados; sin embargo, las referencias a las causas o a los efectos son con frecuencia identificadas con eventos concretos. Así que es necesario ocuparse de dilucidar qué respuesta puede darse al problema de cuáles son los relata de la relación causal.

Una intuición básica nos indica que la causa ocurre entre entidades particulares, dentro de unas circunstancias únicas adscritas a un tiempo y a un lugar específico, así que no puede olvidarse que cada manifestación de una relación causal tiene esa particularidad, como punto de partida, y que las demás circunstancias pueden ofrecer características que no siempre son susceptibles de generalización. Esto no indica que su acción no pueda ser puesta en relación con otras similares, o que para entender el problema de la causa no debamos remitirnos a lo general. La causa relaciona dos entidades, una de ellas cumple el papel de causa y la otra el de efecto. Sin embargo, de inmediato surgen dudas acerca de cómo pueda producirse tal relación, dado que esta idea común no lleva implícita la idea de una acción, de una dinámica o de una fuerza o impulso que posibilitela transición entre un objeto y el otro; para ponerlo en términos humeanos: no percibimos la conexión. A pesar de que Hume utilice el término objeto para causa y efecto, es justo decir que en realidad parece referirse más a eventos, en la medida en que entiende que los objetos por sí solos no constituyen las causas, sino que lo hacen en virtud de ciertas propiedades que poseen y de ciertas condiciones en las que se encuentran: de tal modo, entendemos que la causa y el efecto son cambios que les ocurren a objetos individuales o a conjuntos de objetos. Una causa no puede consistir de un objeto inerte (o pasivo) seguido de otro en su misma condición, pues esta es una idea muy incompleta de lo que sea una causa: un objeto mantiene su estado de pasividad a no ser que algo lo saque de ese estado o que una fuerza externa sea capaz de transformar el objeto inicial en el objeto que nos encontramos en el segundo lugar. De ahí que debamos considerar la idea de causa indisociablemente ligada a la idea de cambio, ya que los estados, salvo posibles excepciones (o una definición más amplia de estado), no requieren de una causa para persistir. 
En un sentido general la causación se da entre objetos ya que la realidad se compone de ellos: las causas y los efectos consisten en los cambios que les ocurren a los objetos implicados. Pero, en lo que concierne a las relaciones causales, se necesita de algo que dé cuenta de cómo y por qué pueda existir tal relación, como se ve en uno de los ejemplos típicos: si estamos ante la rotura de un vaso por un martillo, la relación causal no consta solamente de los dos objetos, sino que implica una relación dinámica entre ellos; no es el martillo el que rompe el vaso sino que es el golpe del martillo lo que constituye la causa de la rotura, es decir, una acción que se hace con él, un movimiento con ciertas características, un cambio en un objeto que está vinculado al cambio en otro objeto. Así, en cuanto hablamos de causa estamos aludiendo - en referencia a los fenómenos perceptibles directamente por los sentidos- a objetos inmersos en un cambio, esto es, que los objetos son los que sufren las modificaciones producidas por la causa, son los pacientes que experimentan alguna forma de cambio, acción, influencia o transmisión puesto que, sin cambio, el objeto seguiría siendo lo que es. A hora, el hecho de que los objetos y los eventos sean observables no indica que sus relaciones lo sean: podemos observar la secuencia de sucesos, pero no necesariamente esto implica que observemos la causa. La observación no es tan simple 0 tan directa como se puede imaginar; existe una observación primigenia, la percepción sensorial, que podría limitarse a la constatación de las cosas frente a nosotros, pero para que esa observación sea vehículo de conocimiento, es necesario ponerla en relación con otras percepciones. De esa forma podemos decir que para hacer una observación útil de una causa, al igual que ocurre con cualquier fenómeno, debe hacerse alguna inferencia a partir de las percepciones concretas.

Ducasse se pregunta si los objetos constituyen el dominio al que se refieren las expresiones causales (D ucasse, 1924, p. 120), pues para él son ciertos atributos y relaciones de los objetos, no los objetos mismos, los que en estricto sentido presentan cambios y estados de sus propiedades: son estas propiedades las que cambian y sufren los efectos, lo cual implica que ellas son la primera manifestación de la causa. Una enfermedad, dice, no es causada por un microbio sino por su presencia en un organismo y por su comportamiento dentro de él: las cosas son agentes y pacientes, y son las interacciones de sus propiedades las que operan como causas y efectos. Desde esta perspectiva se incluyen como causas los estados de las cosas, que permiten explicar ciertas formas de relación causal; por ejemplo, podemos entender que se adjudique la causa de la caída de un objeto puesto en equilibrio precario a su energía potencial, pero esto al costo de dar más peso a las disposiciones y poderes de los objetos que a las situaciones en las que se hallan puestos. Particularmente no compartimos que los estados de cosas de por sí sean aceptables como parte 
de los relata causales, pues si bien van más allá del objeto pasivo al incluir ciertas propiedades que se relacionan con otros objetos, tampoco permiten entender del todo qué se necesita para que ocurra una relación causal. Por otra parte los estados se definen precisamente por su tendencia a conservarse, no a cambiar, así que no parecen ir por la dirección de la indagación causal y hacen ver como causales situaciones de equilibrio.

En el habla común habitualmente se denomina a los objetos como causas o efectos, pero esto ocurre más por economía del lenguaje, pues suelen ser identificables en los extremos de la relación causal, o como los sujetos del cambio; ahora bien, si aceptamos que la causa se asocia o que se refiere a cambios, no son las cosas de por sí las que constituyen las causas, sino que sería más apropiado hablar de eventos - entendidos como el conjunto de propiedades que se modifica en cierta situación - localizados en el espacio y el tiempo. Por ejemplo, lo que hace caer a una manzana del árbol no es la gravedad por sí misma sino un cambio en la rama que la sostenía. Se puede decir que la manzana se encuentra en un estado de reposo y que ese estado tiende a mantenerse, pero si describimos ese estado como un equilibrio dinámico, la situación cambia: la manzana tiene una energía potencial que ha ido creciendo en la medida en que el árbol ha fijado agua y nutrientes dentro de ella de manera que su peso se ha incrementado semana tras semana; el proceso de maduración hace que se debilite progresivamente la unión entre el pedúnculo y la rama, con el resultado final de que la tensión entre la gravedad - el peso de la manzana - y las fuerzas que unen las cadenas de moléculas que la sostienen llega al punto en que el cambio gradual acumulado hace que la gravedad venza la resistencia de la rama, momento en el cual la manzana cae. El objeto en la relación es pasivo, mas lo que podemos entender como causa y efecto es el conjunto de sus propiedades dinámicas y las relaciones que se establecen entre ellas, es decir que, para dar una imagen más completa de la noción de causa, a los objetos hay que sumarles el conjunto dinámico de propiedades del que hacen parte.

Si el mundo se limitara a las interacciones mecánicas newtonianas, habría que aceptar su clausura física: no habría ninguna fuente de modificación de la situación que escapara a las leyes de la física; cualquier violación de ese estado de cosas sería un milagro. Sin embargo, la realidad tiene otros planos de interacción posibles: uno de ellos es el que se desprende de la actividad microfísica, aunque su práctico aislamiento lo pone fuera del alcance de la mayoría de interacciones macroscópicas, pero otros planos más cercanos a nuestra escala nos darán pistas seguras sobre otras interacciones reales, tales como la actividad electromagnética de la materia, los enlaces 
químicos y la capacidad de acción autónoma de los organismos. Si fuera posible reducir el mundo al quehacer de las causas mecánicas nos encontraríamos con una realidad mucho más limitada que la actual, seguramente sin ningún testigo que pudiera dar cuenta de ella. Pero no es el caso: lo que ha sucedido en los largos plazos que nos han precedido es que la materia ha tenido la ocasión de hacerse más compleja hasta el punto de adquirir conciencia de su propia existencia y la de la realidad exterior.

El mecanicismo acogía una concepción de la causa eficiente como una acción que ejerce su influencia desde el exterior del sistema modificado y que, una vez cesa, también lo hace su efecto. La causa interna (que planteaban Leibniz y Spinoza) se ha defendido pese a que hoy no se suele aceptar, pues ampliaría el concepto de causa hasta abarcar todo tipo de determinación; lo que se asocia a la causa interna hace referencia a hechos evolutivos, al desarrollo de ciertas dinámicas (crecimiento, por ejemplo) o a la degradación de la materia. Afirma Bunge (1961, p. 188) que el determinismo causal moderno es más restrictivo y realista que el aristotélico - que aceptaba dos causas intrínsecas, la material y la formal- , pero ese peso que se le otorga a la causa eficiente, implica un menosprecio de las peculiaridades de la actividad de la naturaleza vivay de la existencia de hechos relativamente incausados, tales como el movimiento inercial o la propagación de ondas, sucesos naturales que persisten aún si su fuente se apaga. O tros procesos que se mantienen son los que ocurren en reacciones químicas y nucleares: la causa puede desencadenar un proceso interno, un efecto mucho mayor que la causa (violando el principio mecanicista de que a igual causa igual efecto), cuyo efecto puede ser de larga duración.

Consideraciones como las anteriores nos llevan a afirmar que reducir la causa a la eficiencia mecánica es dejar incompleta la historia causal del evento, olvidando que hay dinámicas en las cosas, que aun cuando la causa sea exterior, desencadenan procesos internos; así, dice Bunge (1961, p. 209), ocurre en el arco que impulsa la flecha: liberar la cuerda es el desencadenante, pero se requiere que se haya acumulado una tensión previa; de manera que la causa no se limita a la acción externa de un factor sobre un objeto pasivo, sino que existe una síntesis de determinación interna y externa, en tanto el cambio del objeto que experimenta el efecto requiere, por decirlo así, de un reacomodo de sus elementos. El cambio que ocurre en la flecha consiste, en resumidas cuentas, en una transformación de energía potencial en cinética, la energía se conserva, de acuerdo con el principio, pero esto no impide que existan cambios; se pasa de potencia a acto por influjo de la causa eficiente, con lo cual el efecto está de alguna forma contenido en la causa (Bunge, 
1961, p. 220). La visión mecanicista no admite la novedad pues asume las relaciones entre causas y efectos como manifestaciones de acciones y reacciones mecánicas, de por sí reversibles, a la manera de los movimientos de las moléculas de un gas en un recipiente estanco. La naturaleza, como ya se dijo, pese a estar compuesta por partículas físicas, no reduce su comportamiento a las interacciones mecánicas, pues también está sujeta a las influencias electromagnéticas y de ahí en más, cada nivel de estructuración de la materia tiene sus propias formas de interacción causal: no es explicable la biología solo por la química o la química por la física. En la realidad las novedades son cambios graduales que resultan de procesos que actúan so bre ciertas propiedades y en alguna medida lo que se espera es encontrar las causas de lo que ocurre en cada nivel o en un nivel adyacente.

Los cambios en la naturaleza se caracterizan por cierta invariancia, pues la materia no se crea o se destruye; además los cambios no son instantáneos porque hay una velocidad límite y las estructuras tienden a conservarse. Una aparente desaparición de materia o energía no es más que una transformación o una cesión a otro sistema, pues la naturaleza es conservadora y resiste al cambio en la medida en alcanza puntos de estabilidad; así que el cambio es más probable en sistemas inestables. Si se sostiene que algún objeto o sustancia pueda ser una causa, persiste el problema de cómo y cuándo empieza a actuar, dado que para ser objeto o sustancia se requiere de cierta permanencia: entender la realidad como una suma de objetos inertes nos impediría crear una concepción adecuada de las relaciones causales. No parecen abundar (si es que existen) los procesos autogenerados en la realidad: lo usual es ver interacciones de líneas causales que tienen un desarrollo independiente, que producen el cambio cuando interactúan. Los fenómenos biológicos serían, en cierta medida, una excepción: la vida se caracteriza principalmente por su capacidad de transformar formas de energía en estructuras materiales, de apropiarse del entorno inerte; son capaces de desarrollo autónomo y de evolución, que son procesos acausales, si ponemos como requisito la exterioridad de la causa. Tales fenómenos parecen ir en contra de la degradación espontánea de la materia: se asume que son el resultado de una materia pasiva sobre la que actuaron fuerzas de diverso tipo, capaces de originar estructuras químicas cada vez más complejas; en la Tierra hay energía disponible en formas diversas, pero además se dieron las raras condiciones para que la materia adquiriera formas más complejas. El incremento de complejidad es el resultado de la acción autónoma de la materia, si entendemos que esta también se manifiesta como energía, o podemos considerar que la materia fue pasiva ante la acción de las fuerzas impulsadas por diversas manifestaciones de energía. La vida tiene la propiedad de utilizar la energía disponible 
para crear moléculas complejas, para formar células, para crecer y para agruparse en organismos. Desde la distancia se ve un proceso autoorganizativo o autopoyético, pero cada uno de los eslabones del proceso es el resultado casual de la rara reunión de condiciones que se han presentado en nuestro planeta.

En principio las causas están separadas de los efectos, de forma que un objeto no actúa sobre sí mismo; además, si entendemos que las causas son relaciones entre eventos, esto es, cambios que ocurren a objetos, lo usual es que la influencia causal sea ejercida desde el exterior, de manera tal que se conserve la uniformidad de la naturaleza, que no haya saltos incausados; muchas veces lo que puede verse como proceso interno es una influencia causal sin identificar o la acción de una parte de los factores sobre otros dentro del mismo sistema. Ahora bien, la cuestión es que existen procesos que no parecen requerir de influencia externa como, por ejemplo, la degradación atómica o molecular. Los átomos pesados decaen en otros más livianos sin intervención ajena, posibles influencias que apenas acelerarían o retrasarían el proceso. Un átomo solo no requiere más que de su actividad interna para decaer, pero esto puede verse como la dispersión de energía al entorno que impide al átomo en mención conservar la cohesión de su núcleo, es decir, que la ruptura se produce porque la energía se reduce hasta un punto en el que no es suficiente para superar la repulsión de las cargas del mismo signo que alberga su núcleo. En la concepción de Lewis (1986, p. 261) no todos los eventos implican la existencia de cambios, ya que concibe la historia del mundo como la historia de los eventos, razón por la cual incluye lo que no cambia, de modo que en el caso de una partícula que decae espontáneamente, este cambio sigue a una cadena de permanencias. El autor, de esta forma extiende el alcance del término evento a situaciones sin cambio, lo que en nuestro parecer conlleva una cierta confusión entre los eventos y los estados de cosas, que asumimos más simples, en tanto se refieren a objetos que conservan propiedades durante un periodo de tiempo (Armstrong, 1993, p. 429). En todo caso, un mundo de objetos pasivos o un mundo de hechos en equilibrio, no tendría posibilidades de cambiar sin la acción de agentes externos, sin mecanismos capaces de producir situaciones diferentes a una tendencia mortal hacia el equilibrio mecánico y térmico: sus choques y atracciones no pueden producir nada diferente a la dispersión progresiva de la energía y por esta vía al agotamiento de sus formas utilizables, de los diferenciales energéticos que permiten producir trabajo.

Volviendo a la cuestión de los relata de la relación causal, hay que entender que la realidad no se reduce simplemente a los objetos, como si se hiciera un corte instantáneo en su secuencia temporal, 
sino que también comprende las relaciones que ocurren entre tales objetos. Sería más adecuado declarar que el mundo no se limita a la disposición de los objetos en el espacio, sino que se desenvuelve en el tiempo conformando estados de cosas: el mundo no es solo lo que existe sino también lo que sucede; en otras palabras, que si fuese posible tomar la fotografía instantánea del Universo tal como es, no nos enteraríamos de cómo opera, pues su dinámica es lo que permiten explicar su evolución. Por eso, retomando el conjunto de ejemplos de las páginas anteriores, entendemos a los objetos como tradicionalmente se ha hecho: como los sustratos de un conjunto de propiedades, pero desde la perspectiva causal la base está en los eventos, entendidos como los sucesos temporales y contingentes que le ocurren a los objetos del mundo y consisten en el cambio de una o más propiedades o características de los objetos en un cierto tiempo, como los define D owe (2000, p. 169). De ahí que se pueda considerar la causa como una relación entre eventos particulares y que, dada cierta regularidad de las relaciones naturales, podamos considerarla como instancia de una ley. Existe una conexión causal en la medida en que ocurra un vínculo entre los cambios en las propiedades de uno o más objetos: las causas y los efectos, por ejemplo, pueden involucrar la posesión y el cambio de valor de una cantidad conservada pero, dado que nuestra necesidad de dar cuenta de las causas va más allá de la causalidad mecánica, debemos incluir características que den cuenta de cambios no materiales como los que se dan en las interacciones químicas o biológicas o en las relaciones humanas; por ejemplo, cuando una persona recibe una orden que la lleva a realizar un acto no existe ninguna transferencia de materia o de energía sino un cambio interno de disposición que lleva a esta persona a cumplir la orden, que puede ser considerada como la causa en la medida en que induce al cambio en el estado anímico de quien la obedece.

Hay que ser precavido con una confusión común y es que accedemos al conocimiento de la realidad por medio de sus verbalizaciones, lo cual suele conducir a que se confundan los eventos con sus descripciones. La causa puede entenderse como cierta relación entre eventos particulares que expresamos mediante enunciados; sin embargo, es prioritaria la perspectiva ontológica del problema. La mente humana se ocupa del conocimiento de la realidad y con este fin elabora estructuras de conceptos; pero son niveles diferentes que hay que intentar mantener separados en la medida de lo posible: en las estructuras de conceptos funciona la lógica, pero la realidad opera con regularidades externas a la mente y al conocimiento. D esde esa perspectiva hay que empezar por dilucidar el papel de la causación como relación entre los eventos, así como sus características y requisitos, lo cual no excluye que su conocimiento pueda ser posteriormente 
ordenado de acuerdo con reglas de razonamiento y jerarquías de enunciados. Mackie (1999, p. 248-9) se pregunta si las causas son eventos o hechos (facts) y sobre si los enunciados causales son extensionales; Menzies (2012, p. 344), sobre este punto, entiende la causación como una relación extensional que conecta aconteceres reales del mundo, mientras que la explicación es una relación intensional que conecta hechos o verdades, y esto es en alguna medida debido a que la causación no depende de la mente mientras que la explicación sí. Adoptando una perspectiva ontológica es necesario limitar el alcance de las circunstancias y de las condiciones causales a las propiedades cuya influencia pueda ser eficaz para la producción de un resultado, pues de otra forma todo sería aleatorio e indescriptible; de nuevo nos encontramos con la tensión entre los fenómenos concretos, llenos de características variadas y complejas y la necesidad de dar cuenta de ellos. La dificultad efectivamente se encuentra en que la causa ocurre entre fenómenos concretos, localizados espaciotemporalmente, pero nuestro conocimiento de la causa depende, por lo menos en alguna medida, de comparaciones con otros sucesos, en las que es necesario dar prioridad a aquellas características significativas para el efecto. Por ejemplo, las visiones regularistas y el proceso de elaboración de leyes requieren que las causas sean puestas en enunciados que permitan establecer relaciones entre diferentes manifestaciones de las causas concretas, pero pueden existir muchos desacuerdos entre las descripciones utilizadas y, así se refieran al mismo hecho, esto no implica que las características empleadas en la descripción sean las relevantes para que la explicación sea válida: en el ejemplo de Mackie (1999, p. 249), no es lo mismo decir que el discurso del hombre con la nariz más grande ha conmovido a Francia, que hacer referencia a de Gaulle; que fuera presidente de Francia era relevante para las consecuencias del discurso, no el tamaño de su nariz.

Tampoco hay pleno acuerdo sobre la definición de evento, al igual que ocurre con cualquier noción primitiva. Lewis entiende que cada evento es un hecho contingente localizado en una región particular del espaciotiempo (Lewis, 1986, p. 243); consiste en lo que ocurre, pero su definición no deja muy claro cómo delimitar lo ocurrido ni el lugar en que ocurre; por ejemplo, menciona que una muerte ocurre si su parte final ocurre en la región del evento, pero el evento inicia con el comienzo de la muerte. A diferencia de los estados de cosas, un evento se desenvuelve en el tiempo necesario para que un objeto experimente un cambio en alguna de sus propiedades (Menzies, 1989, p. 61). Así, el evento incluye tanto las condiciones necesarias como las suficientes para que ocurra, añadiendo vaguedad a la definición, ya que las causas pueden ser muy remotas y el evento de muy corta duración, con lo cual podríamos estar desconociendo muchos de sus 
elementos. Ducasse acude al "postulado de la no interferencia de la naturaleza" para separar aquellas características que se conservan luego de la acción causal, pero Psillos lo ve como una aceptación de la derrota (Psillos, 2002, p. 70), como un argumento ad hoc que funciona solo si conocemos previamente la diferencia entre lo causalmente relevante y lo que no lo es. El asunto es que al precisar la definición el evento se haría frágil de manera que cualquier cosa que cambie lo destruye 0 altera, pero la manera en la que hablamos de las causas es más robusta: los eventos se unen por relaciones de relevancia, es decir, que lo que hace parte de los eventos que participan como causa y como efecto deben delimitarse en la medida en que sus características y condiciones tengan la posibilidad de ejercer alguna influencia causal en las circunstancias.

En esta concepción de Lewis el evento se compone de la causa y el efecto, que ocurren necesariamente en la misma región, el problema es que los eventos que ocurren en la misma región pero que son diferentes, quedarían incluidos en la delimitación, lo cual implica la inclusión de múltiples factores que pueden no ser relevantes. Lewis (1986, p. 255) dice que si se describe un evento de dos formas no indica que haya dos eventos, pero la calificación que se puede dar en alguna descripción puede diferir causalmente. Más allá de lo que plantea el autor, este no es un problema menor, pues si bien un evento puede dividirse en subconjuntos, lo es por razones que pueden ser muy diferentes; una es la que tiene que ver con sus manifestaciones o con el ámbito de acción de sus principales influencias causales: podemos, por ejemplo, hablar del sistema solar como un todo, y también del sistema Sol-Tierra-Luna; entre esos dos conjuntos existe una diferencia dependiendo de la perspectiva que se adopte, en unos casos podrá ser impuesta por las circunstancias que permiten manejar un sistema de forma más o menos aislada. No siempre esto es posible, una prueba más de que no hay ni puede haber definiciones tajantes al respecto, pues nuestras descripciones de los eventos no llega a ser tan objetiva como deseamos; lo usual es que nuestras descripciones dependan de la explicación que busquemos, del campo de atributos con los que estemos trabajando, de modo tal que los límites del evento tienen que ponerse en razón a su significado causal.

La descripción de un evento depende por lo menos en alguna medida de la explicación más relevante para la indagación en curso ya que la infinidad de sus características impide que exista una única forma de describirlo y por eso se toman en cuenta o se omiten elementos que se consideran más o menos importantes para entender por qué ocurre. Los eventos no están claramente delimitados en la realidad: es un conjunto de objetos y sus propiedades enlazados por 
relaciones dinámicas, de la misma forma en que los sistemas tienen mecanismos mediante los cuales se enlazan con otros, y esto nos lleva a aceptar que en principio existe una cierta limitación impuesta por la relevancia en la clasificación y separación de eventos, lo cual pone un límite a nuestro conocimiento de causas y efectos. Cuando se indaga por las causas se busca información sobre la historia del evento, elemento a tener en cuenta en la descripción que de ellos se hace, pues con frecuencia se corre el riesgo de adjudicar causas objetivas a cuestiones que dependen más bien de relaciones lógicas entre enunciados, como en algunos de los ejemplos tratados por O wens (1992, p. 46): queX se convierta en tío a causa de que su hermana tuvo un hijo, puede ser completamente cierto en la medida en que ese hecho haya creado una relación de parentesco que no existía previamente, pero es excesivo extender los términos causa y evento tan lejos, ya que el nuevo acontecimiento no cambia nada objetivo deX ; decir "hijo de la hermana deX " y "sobrino de X " son dos descripciones del mismo hecho y no puede establecerse una relación causal entre ellos. Igual sucede con otro ejemplo Lewis (1986, p. 263): declarar que una manzana está podrida por el hecho de que una parte de ella esté descompuesta, no da cuenta de la relación causal entre dos eventos sino de una relación lógica entre dos descripciones, es contar como si fuesen dos cosas diferentes un objeto y una de sus partes, de lo cual podemos inferir que necesitamos algún criterio que permita diferenciar las relaciones entre enunciados de las relaciones entre objetos.

Hay un punto más a examinar: las diversas teorías sobre la causalidad hablan de la relación entre dos objetos o eventos, aunque se también discute si la relación ocurre entre eventos individuales o entre tipos de eventos; sin embargo, una discusión más amplia debe determinar si la relación causal se da entre los eventos, pues prácticamente no son útiles sin sus descripciones, que como ya mencionábamos, no es un asunto que pueda soslayarse sin consecuencias para la argumentación básica sobre la causación. Los enunciados que buscan expresar relaciones causales pretenden algún grado de extensionalidad, en la medida en que pretenden abarcar tipos de situaciones similares, pese a que los eventos sean complejos, es decir, que se necesita unificar tipos de eventos por encima de sus diferencias. De nuevo, la cuestión está en lograr un equilibrio entre las descripciones singulares, que describen puntualmente pero corren el riesgo de limitarse a señalar la realidad, y los enunciados que aproximan las causas con las leyes.

Recapitulando, lo que se ha buscado defender hasta el momento es que las causas ocurren entre objetos particulares, pero que no es adecuado hablar de estos objetos como causa y efecto. Para que podamos presenciar la acción de una causa tenemos que estar en presencia de una situación 
más compleja, esto es, de las situaciones completas en las que están inmersos los objetos en la realidad. D e ahí que sea más adecuado hablar de la causalidad como cierto tipo de relación entre eventos, que propicia un cambio en una o más propiedades de los objetos implicados. D os elementos son fundamentales en el argumento: que los objetos no son propiamente la causa y el efecto sino los que sufren una alteración o portan las propiedades alteradas, y en segundo lugar que estamos hablando de cambios, es decir, que si ha sido necesario indagar por la causa es porque necesitamos dar cuenta de por qué las cosas cambian y no tanto de por qué las cosas se mantienen como están (que es una percepción errada por la escala corta en la que se observan ciertos cambios, como veremos en el siguiente aparte).

Un evento es un cambio en el estado de un objeto, o en las relaciones que tiene el objeto, sus propiedades y su entorno; esto que cambia o se mantiene es una propiedad del objeto y la causa es la relación que da cuenta de los cambios. Un cambio causal puede ser acompañado de más cambios simultáneos sin papel causal, como el cambio en el entorno de moléculas de aire que acompañan al martillo que rompe el vaso. Algunos de estos cambios son causalmente irrelevantes, a riesgo de caer en una definición circular ya que tendríamos que saber previamente cuáles son los factores relevantes, pero es un riesgo válido en la medida en que la indagación sobre los cambios es provisional y necesita definir entre la infinitud de características en cuestión, cuáles encajan en la explicación buscada, cuáles son los cambios que contribuyen (y en qué medida lo hacen) a la aparición de un efecto.

\subsection{Procesos: otro aspecto del tiempo en la causa}

Si asumimos que el problema de la causa está indisolublemente ligado al cambio, es necesario hacer un examen acerca de cómo entendemos las relaciones entre causa y efecto en referencia a su transcurrir temporal pues si una causa inicia cierto cambio, habrá que determinar si entendemos las relaciones causales como el límite instantáneo que separa la causa del efecto o como procesos más o menos graduales. La noción común de tiempo no permite diferenciar si un suceso es instantáneo, si se prolonga o cuáles son las cotas de la duración de un lapso temporal, cuestión importante en relación con la causa, dado que esta parece suceder de formas variadas, ya sea como una acción puntual, como una acción prolongada, o como el resultado de acciones que se interrumpen cuando logran cierto transición o rebasan algún límite. Es posible hacer una analogía entre la discernibilidad de puntos y de instantes: en la medida en que la ciencia avanza, tenemos 
nociones más precisas de lapsos temporales más pequeños y más grandes, aunque nuestra intuición se aleja de los que se distancian de la escala de lo cotidiano, dificultad que repercute sobre nuestras intuiciones causales.

En el lenguaje, la causa particular suele entenderse de forma análoga a la acción directa de un agente sobre un objeto, por la cual este cambia de posición o estado, de forma que asumimos que un evento es más probablemente la causa en la medida en que sea más cercano en el tiempo a su efecto (un tanto a la manera en que se adjudica la responsabilidad legal, determinada por la cercanía de la acción al fin perseguido). Pese a que el tiempo es una sucesión continua con una dirección que va de lo pasado hacia el futuro, el lenguaje con frecuencia utiliza nociones de proximidad o lejanía que aluden correctamente a nociones espaciales, pero que no son las más adecuadas para la secuencia temporal. Además, con las secuencias de tiempo y de espacio estamos físicamente limitados para percibir su textura debajo de ciertos rangos: así como percibimos como si fuese continua una secuencia de puntos muy pequeños impresos sobre un papel, una sucesión de eventos discontinuos cuyo lapso sea muy corto también la percibimos como si fuese un movimiento continuo. Es lo que sucede con la persistencia retiniana que da origen a la ilusión de movimiento en el cine: en la película hay imágenes fijas, usualmente 24 por cada segundo, cada una de las cuales persiste en la memoria la fracción de tiempo suficiente para que quede superpuesta a la imagen siguiente, que es levemente diferente, de manera tal que se percibe como un movimiento continuo lo que es solamente un conjunto de imágenes fijas. Existe un límite fisiológico, derivado de características como la velocidad de la transmisión de los impulsos nerviosos y de la capacidad de procesamiento de las imágenes en el cerebro, que determina a qué cadencia puede verse una secuencia de imágenes fijas como si fuera continua. Igual ocurre con la percepción del espacio, aunque el caso se diferencia en cuanto contamos con herramientas muy poderosas para extender los alcances de la percepción humana, al punto en que ya nos encontramos no en el límite de lo perceptible sino en el límite de lo posible, pues en este momento se pueden ver (virtualmente) y formar imágenes con átomos individuales, mientras al tiempo no lo podemos ver "de cerca": ahí no valen instrumentos, lo único que se puede hacer para percibir un suceso que ocurre a una alta velocidad es grabar en algún medio las imágenes para luego pasarlas en una secuencia que nos las haga perceptibles, lo cual es, en alguna medida, recurrir a un truco pues requerimos alterar la secuencia real, es decir, crear otra secuencia temporal diferente para poder apreciar lo que ocurre muy rápido. 
Puede negarse que un borde lineal esté compuesto de puntos, pero el cálculo y, por tanto, una gran parte de la física, utiliza tal forma de concebir las curvas. Los infinitesimales riñen con ideas muy arraigadas de sentido común pues tienen implicaciones que parecen contraevidentes, como la existencia de infinitos de diferentes tamaños o que una parte de una secuencia pueda tener tantos miembros como la totalidad, cuestiones identificadas hace tiempo, como en la formulación de Zenón de Elea de las paradojas sobre el movimiento (Ávila, 2004, p. 58). Sin detenernos en ellas, vale la pena examinar algunas de las interpretaciones pertinentes para lo que podríamos llamar la instantaneidad de la acción causal. Las paradojas de Z enón, aparte del problema lógico, implican la dificultad de precisar qué significa la duración de un proceso físico como el movimiento, llegando a cuestionar la capacidad de las matemáticas para describirlo; por eso, Salmon (2001, p. 16) plantea que las paradojas muestran que la visión matemática del continuo es inadecuada para describir procesos temporales. Entendemos los procesos físicos como una sucesión de estados (así como se reconstruye el movimiento en el cine), de ahí que caigamos en una espacialización del tiempo que nos hace confundir los movimientos reales con las trayectorias que describen los objetos: el movimiento es una función que relaciona tiempo y posición, que consiste en la ocupación de una única posición en cada instante dado de tiempo (la teoría at-at del movimiento, que postula Salmon). Bergson (1959, p. 121) niega la posibilidad de que haya una correlación entre el continuo matemático y el tiempo físico; no hay un elemento inextenso - el instanteen la realidad que se corresponda con los elementos que forman el continuo matemático: las aporías de Zenón se derivan de la confusión entre los movimientos reales, que ocurren en conjunto con las secuencias del entorno, con las trayectorias espaciales que pueden representarse, dividirse y medirse con herramientas matemáticas sin ningún problema. A diferencia del espacio, el cambio y el movimiento no se puede reconstruir sin pérdida a partir de estados inmóviles, pues el movimiento requiere de un tiempo que es continuo y no consiste en una secuencia de posiciones. Hay que agregar que el objetivo de la ciencia es crear representaciones cada vez más fieles y útiles de sus objetos de estudio, y así coordinar la teoría con la experiencia. Por esto una línea puede ser tratada como la representación del movimiento de un punto, y no necesariamente como una suma de partes; además los elementos de un conjunto no tienen necesariamente las características de los conjuntos a que pertenecen, tal como ocurre en el caso de la temperatura: es un agregado que carece de sentido en una molécula individual (Salmon, 2001, p. 181). Pero tampoco podemos olvidar que la distancia entre realidad y representación conlleva cierto grado de abstracción. 
Todo lo anterior es muestra del reto que representa para la mente humana el problema de delimitar tipos de causas dependiendo de cómo actúen en el tiempo; en otras palabras de encontrar características comunes a lo que aceptamos como causa, pese a que implica la existencia de eventos diferentes, que actúan en el tiempo de formas diversas. Vale la pena volver a la descripción de Pinker (2007, p. 267-269) acerca de cómo el lenguaje expresa las acciones: los verbos se dividen en clases dependiendo del tipo de acción, de las cuales la principal división es entre estados y sucesos ("saber la respuesta" o "estar en lugar", que son estados, o "ganar una carrera", que expresa un suceso). Los sucesos que tienen un punto final se refieren a un cambio de estado en un objeto, producido por el agente; se extienden en el tiempo pero acaban en un punto. Los verbos también diferencian si el suceso es instantáneo o si se continúa en el tiempo. En unos casos el suceso tiene fronteras indefinidas (un suceso que se puede prolongar más o menos), o definidas (un suceso momentáneo) o si es télico (con una culminación definida); también hay verbos que expresan una acción iterativa (como golpear un clavo) y también están los que designan un inicio (sentarse). También los delitos se expresan con verbos que expresan una actividad o una meta, pues buscan consumarse y si no se hace, quedan en una intención, contrastando una situación que pudo haber ocurrido con otra que ocurrió. En el lenguaje también se expresan las características que aluden a la forma temporal de un suceso y la posición del narrador con respecto a este.

Nuestra forma de comprender los sucesos naturales se enfrenta con situaciones que no siempre parecen corresponder a nuestra experiencia cotidiana; en términos comunes entendemos que la acción causal opera con ciertas características tales como la exterioridad de la causa o la relativa gradualidad de los cambios, pero estas concepciones han tenido una larga evolución en la medida en que se han ido refinando nuestras concepciones científicas. En el espacio absoluto newtoniano se aceptaba la simultaneidad y la acción a distancia instantánea, pero hoy sucede lo contrario, la relatividad excluye por completo la transmisión instantánea de materia o energía. En la teoría relativista ninguna señal supera la velocidad de la luz, de manera tal que la estructura de conos de luz de Minkovsky es también la estructura causal del espacio-tiempo (Hoefer, 2012, p. 694): sólo los eventos que ocurran dentro de los conos de luz pueden tener influencia causal sobre el punto al que confluyen, así como los acontecimientos en este punto influyen solo sobre los acontecimientos que se encuentran en el cono de luz futuro. Esto implica aceptar que existen direcciones permitidas en las cuales opera la influencia causal, que excluyen la acción retroactiva: los efectos no pueden actuar sobre causas que ya no existen. 
De los argumentos relativos a la continuidad o discontinuidad de los sucesos, pueden extraerse algunas ideas relativas a las causas. Cuando intentamos ordenar nuestra percepción del cambio, decíamos, suele manejarse el tiempo por medio de su espacialización, lo cual indica que las secuencias temporales son divididas en fases que nos permiten ordenar nuestras percepciones y entender los procesos. Al parecer, en ocasiones este método excede los límites de lo admisible y crea confusiones innecesarias. Un caso es el de los movimientos periódicos, como en el ejemplo de la rotación mencionado por Mackie (1999, p. 156): la causa del movimiento en un tiempo dado está causada por el movimiento que sucede en el periodo anterior. En principio diríamos que un movimiento rotacional existe precisamente como continuación del movimiento anterior, pero para llegar a esta conclusión hay que asumir algunos presupuestos que pueden ser discutibles. Lo primero es que hay que delimitar es con base en qué criterio se separa un movimiento continuo en fases, pues aún si concordamos en que cada giro es un periodo, no siempre es factible concordar acerca de cuál es el punto de inicio. Con ello nos vemos abocados a incurrir en el error de buscar una discontinuidad que no parece corresponderse con ningún suceso empírico, crear unas fases del movimiento - que pueden ser útiles para comprender la realidad - pero que parecen ser arbitrarias, tal como el mismo Mackie afirma. Lo que hay en la realidad no es un movimiento que ocurre en fases sino un movimiento continuo, lo cual señala una diferencia entre lo que podría ser propiamente una interacción causal entre las fases de un proceso y, por otra parte, la simple continuación de un proceso sin fases naturales que se mantiene por inercia.

Estamos de nuevo ante la dificultad de ver un suceso continuo como un conglomerado de elementos, cuestión que es aplicable también a la noción de cambio y de causa: puede que estemos ante un conjunto de sucesos temporalmente denso, en el que no es lícito señalar un instante primero sobre el cual recae la acción causal, de ahí que analizar un movimiento periódico como producto causal del periodo anterior es también una muestra de nuestra necesidad de jerarquizar los datos. En un movimiento cíclico no se puede alegar ese tipo de causa; si existe la causa de ese movimiento esta se encuentra en el comienzo y no en sus fases, ya que la causa se asocia al cambio, y la perpetuación de un estado de cosas no involucra una relación causal en sentido estricto; esos estados los podemos asociar más con la idea de equilibrio dinámico que con la de cambio propiamente dicho. Ha sido lo usual que la física caracterice los estados momentáneos de un sistema, que busque las regularidades que permitan inferir estados futuros (Sklar, 2012, p. 662). Igual sucede con las situaciones en las que existe un equilibrio: allí se puede acudir a explicaciones no causales, dado que estos son estados a los que se tiende naturalmente en razón 
a que consumen menos energía. Pero si hablamos de causas tenemos que referirnos a los cambios que ocurren en una determinada situación pues estos sucesos son los que requieren de explicación, no así las situaciones estables, de las cuales preguntamos por qué continúan apenas cuando se contrastan con cambios que podrían ocurrir.

Es natural que los cambios presenten rupturas de continuidad pues la materia tampoco es continua, pero en último término la continuidad y la discontinuidad son parciales y complementarias, en la medida en que dependiendo de la escala temporal y espacial en que podamos percibir o estudiar los cambios, estos pueden parecer continuos o discontinuos, y además son parciales pues los cambios están siempre acompañados por permanencias. Con los ejemplos de Hull (2011, p. 271272), un cambio puede ser continuo, como el que ocurre cuando un hierro al rojo pierde calor; periódico, como el que presenta un péndulo oscilando, o aleatorio, como en las formas que adoptan las imágenes de un caleidoscopio. El primero consiste en variaciones que se van acumulando y confluyen hacia una dirección. El periódico presenta una frecuencia de fluctuaciones entre unos valores extremos. El aleatorio puede combinar una impredecibilidad local con distribuciones homogéneas a gran escala, como ocurre en la distribución de las moléculas de un gas. El cambio puede ser considerado el estado más común del universo: bajo la superficie de cualquier fenómeno existen modificaciones o fluctuaciones de algunas propiedades, lo que sugiere que la palabra cambio tiene diversos valores que dependen de las propiedades que estemos tomando en consideración en el momento de evaluar un fenómeno (quizá en el cero absoluto la materia pierda su característica de cambio, pero esta es una noción más teórica que práctica). A sí, la realidad es el resultado de interacciones causales entre eventos, pero hay que tener en cuenta que esos eventos están compuestos de propiedades que se mantienen mientras que en otras sus valores se alteran: lo que llamamos cambio depende de las medidas de propiedades que se alteran y no de las que permanecen constantes (de ahí que un movimiento inercial se pueda considerar como un estado). Además, no hay que olvidar que nuestra apreciación de la realidad depende de la escala en la cual la observamos: la realidad tiene textura muy rugosa a pequeña escala, pero a medida que nos alejamos la apariencia se hace más homogénea. D e manera análoga, la suma de pequeños cambios en direcciones diferentes puede ser considerada como una situación estable, lo cual se confirma con la ausencia de efectos cuánticos a gran escala, ante la virtualmente inexistente posibilidad de que coincidan un conjunto enorme de movimientos diferentes en una sola dirección. 
D esde Hume se ha asumido la contigüidad espaciotemporal como una de las características más aceptables de la causa, sin embargo, la causa y la acción próxima son cuestiones independientes: la causa es compatible con la contigüidad pero no la implica pues existen acciones simultáneas, continuas, retardadas o a distancia (como en el caso de la gravedad, si la entendemos como fuerza y mientras no se tenga una descripción definitiva de la mecánica gravitacional). Además, no siempre puede diferenciarse en qué momento empieza a actuar propiamente una causa, en la medida en que no siempre es evidente lo que diferencia la causa del conjunto de vínculos e influencias que suelen acompañarla. Existen sucesiones de eventos vinculados, llamadas líneas causales, concepto que para Russell reemplaza y explica la noción primitiva de causa, en tanto esta no consista más que de un suceso que precede a otro, en una secuencia en la que se presenta cierta persistencia sin cambios súbitos (lo que llama cuasipermanencia, la cadena de acontecimientos con relaciones causales comunes, en Russell, 2009, p.403). Aunque no hay que olvidar que no todas las secuencias de sucesos son necesariamente causales, tal como ocurre con la dispersión de energía, una tendencia natural de la materia que no requiere de ningún factor ex terno que la cause. En la evaluación de la causalidad de los procesos, en cambio, deben privilegiarse las influencias externas.

Así, estamos debatiendo en qué medida una cadena causal pueda verse más o menos claramente como una secuencia de eslabones, lo que depende del grado de aislamiento que tengan sus factores de influencia con respecto a otras líneas causales, cuestión que no hay manera de delimitar tajantemente; las cadenas causales pueden proveer una explicación adecuada en intervalos cortos, pues mientras más extensa sea empieza a depender de la dudosa transitividad causal. Los vínculos causales son más firmes, esto es, más comprensibles y explicables en intervalos de tiempo cortos, aunque aquí la cuestión parece corresponder más a la cantidad de eslabones causales y no tanto al tiempo: es más firme una explicación causal en que la cadena de acontecimientos presente una menor cantidad de eslabones entre una causa y un efecto remoto; de modo que, pese a la validez limitada de las cadenas causales, constituye una explicación más completa que la búsqueda de un factor causal único. La contigüidad espacial no puede entenderse como un corte en el tiempo ni un punto en el espacio sino más como un segmento de tiempo y de espacio determinado, pues un cambio es un proceso continuo con alguna duración; la adyacencia implica un corte espaciotemporal que separa idealmente el final del proceso de la causa del inicio del proceso del efecto. En términos más adecuados a esta exposición, diríamos que ese punto espaciotemporal 
que está entre la causa y el efecto no es tanto una separación sino el punto o el segmento en que se conectan las propiedades inmersas en el proceso de cambio.

Así como veíamos que un movimiento rotativo inercial requiere de una cierta arbitrariedad para ser dividido en fases, lo propio puede decirse de una cadena causal compuesta de eventos que se prolongan en el tiempo, que son la práctica totalidad. Entonces, lo usual es que los cambios sean graduales, pese a que no siempre podamos notarlo por las limitaciones propias de nuestros sentidos. Podríamos poner como ejemplo la rotura de un vidrio: se puede hacer mediante un golpe 0 aplicando progresivamente una tensión que lo lleve al límite de su resistencia; en el primer caso tenemos la sensación de que el efecto del golpe ocurre de forma instantánea, mientras que en el segundo vemos cómo se va añadiendo tensión que curva la lámina mientras que el material ceda. Los dos casos no son necesariamente diferentes pues, lo percibamos o no, en ambos hay una serie de cambios graduales que concluyen con que en un momento el vidrio pierde su estado y se rompe; más allá de cierta velocidad, el objeto que golpea puede atravesar el vidrio, pero en ningún caso la rotura es del todo instantánea, pese a que así lo percibamos. En el caso de la modificación gradual lo que podemos apreciar es que existe continuidad en un conjunto de propiedades, pero la presión está alterando otras características de forma tal que, si aquella continúa, lleva al material a traspasar el límite de su deformabilidad y hace que se quiebre.

Esa idea sobre estabilidad espacial también es aplicable a la escala temporal, a la dinámica de los objetos ya que, por ejemplo, una oscilación muy rápida es percibida como un fenómeno continuo, tal como ocurre con nuestra percepción de las ondas sonoras o lumínicas: no es individualizable cada oscilación, ni siquiera en las ondas sonoras de baja frecuencia, pero siguen siendo oscilaciones y percibidas como un sonido continuo. De la misma manera podemos entender que la causa opera de forma gradual, y por eso damos valor solo a la primera modificación que percibimos o a la que consideremos relevante; tal como ocurre en el ejemplo de Lewis (1986, p. 174) sobre una depresión en la economía: la serie de bancarrotas empieza por una sola, que junto con las demás conforman el gran evento. No son raros los casos en los cuales el efecto puede verse mucho tiempo después de la acción reputada como su causa: un enfermo tarda tiempo en sanar luego de la toma de los medicamentos, y hay más demora aún en la aparición de efectos en la economía luego de la aplicación de decisiones políticas. Pero también existen procesos que son continuos, cuyas causas pueden ir ejerciendo su influencia de forma acumulativa, de ahí que siempre hay que tener en cuenta las escalas espaciales para contar con los efectos de las causas, pero igual se 
debería hacer con el papel del tiempo en el alcance de ciertos efectos. Hay notorias diferencias entre un análisis causal grueso y uno fino y no es imprescindible que estos coincidan (Woodward, 2007, p. 85), ya que unos factores pueden tener más o menos influencia dependiendo de la escala temporal y espacial que usemos para acotar el fenómeno. Para usar un ejemplo de la fotografía, pese a que la luz es la causa de que se forme una imagen latente (en una película analógica formada por sales de plata), es diferente la perspectiva microscópica que explica por qué determinado grano de plata se ennegrece, que la perspectiva mayor en la que la imagen visible se compone de zonas oscuras y claras. Y esto es así porque las leyes naturales están delimitadas a ciertos rangos dentro de los cuales son aplicables. Podemos ver que una causa (macroscópica) es la que tiene el papel determinante en la escala en la que estamos efectuando su análisis, pero no podemos olvidar que es apenas una de las perspectivas posibles: una piedra rompe un cristal, y no dudamos de que el movimiento de la piedra es el causante, pero las características específicas acerca de cómo ha sucedido el evento dependen por completo de las entidades particulares que estuvieron implicadas en el evento concreto: el movimiento de la piedra puede haber sido causado en circunstancias muy diferentes que implicarían la presencia de un agente, 0 un hecho accidental o incluso un hecho previsto (para eso se fabrican vidrios más resistentes).

Puesto que nos encontramos con la noción de proceso, vale la pena examinar lo que se ha definido al respecto: En la teoría de Salmon y D owe se define un proceso causal como la línea del mundo de un objeto que posee una cantidad conservada, e interacción causal como el intercambio de una cantidad conservada (aporte de D owe, 2012, p. 219) entre dos procesos D owe; lo cual implica seguir la historia de aquel objeto a través del tiempo. En la versión inicial de su teoría Salmon destacaba la transmisión de marca en los procesos, entidades más básicas que los eventos, con una mayor duración y extensión, pues afirma que los eventos son más localizados: el golpe de una pelota contra un vidrio es un evento, mientras que el viaje de la pelota es un proceso. Russell (2009, p. 403) llamó línea causal a la persistencia, a la constancia que presenta un objeto sin cambios súbitos, pero de nuevo hay que insistir en que lo súbito que pueda ser un cambio depende de la escala temporal en que lo midamos, pues, ya está dicho, si pudiéramos ralentizar lo que a simple vista nos parece instantáneo, nos sorprenderíamos de la cantidad de detalles que puede contener.

Puesto que la idea de proceso causal como el capaz de transmitir cantidades conservadas no logra solucionar las múltiples problemas que surgen con respecto a pseudoprocesos, interacciones 
no causales y la posible irrelevancia de cantidades conservadas, habrá que acudir a una idea más intuitiva de proceso, la cual no necesariamente contradice la de Salmon, pero tampoco es muy cercana: para la exposición presente se habla de proceso simplemente en referencia a la gradualidad en la que ocurren los cambios, no tanto a la idea de que la causa está inmersa en una relación unitaria o medianamente indisociable entre la causa y el efecto. Por otra parte lo que se intentaba recalcar es que la noción de causa involucra la idea de cambio, esto es, que pese a que no siempre lo podamos percibir, la acción causal en nuestra escala consiste en cambios más o menos graduales en una o más propiedades de un objeto y es esto lo que podemos llamar proceso, es decir la gradualidad del cambio, en el que es absolutamente esencial la participación del tiempo: el viaje de la recurrida piedra contra el vidrio es un proceso, pero lo entendemos como proceso en la medida en que va cambiando su posición con el paso del tiempo, no tanto por las cantidades que conserve la piedra, pues algunas de ellas se mantienen constantes o son irrelevantes para la rotura del vidrio que la espera en su inmediato futuro. Puede tener una carga eléctrica, un volumen, una forma, que son constantes y que pueden ser modificados, pero para el suceso concreto los factores que importan son la masa y el momento y este se va modificando en la medida en que la piedra describe una parábola como resultado del equilibrio entre el impulso que ha recibido, la fricción con el aire y la atracción gravitacional de la Tierra. En contraste, el momento es el factor causalmente más relevante, pues determina la fuerza que puede ejercer la piedra sobre el vidrio.

\subsection{El papel de las ausencias y omisiones}

A primera vista lo que entendemos por causalidad consiste en la relación que conecta dos objetos que hacen parte de un conjunto de relaciones entre propiedades que se modifican, en otras palabras, la relación ocurre entre dos eventos, de manera que identificamos el evento previo como causa en la medida en que su dinámica ejerce una influencia o acción sobre un evento posterior que consideramos su efecto. Aceptamos que el mundo tiene su actual estado como resultado de la secuencia previa de sucesos, por eso consideramos como una característica indispensable de la naturaleza que nada existe sin una causa previa y que los cambios no aparecen espontáneamente sin que exista una justificación de su existencia. De otra forma nos encontraríamos o en un mundo lleno de milagros o en el reino del azar incognoscible. Existen secuencias de acontecimientos con la suficiente regularidad para conducirnos a dar por sentado que cierto evento ocurrirá y, si no es así, nos preguntamos por la causa de que las cosas no hubieran ocurrido como lo esperábamos; lo propio sucede cuando la presencia de algún factor 
parece obstaculizar la consecución de un resultado que, sin tal perturbación, hubiera ocurrido. De ahí que un problema que enfrentan las diversas teorías sobre la causalidad es el de cómo explicar el papel de las ausencias y omisiones - condiciones cuya falta es necesaria para que ocurra un efecto- y el papel de la prevención - un factor que impide que ocurra el efecto- . Analizar el papel que tiene ausencias y prevenciones en este punto de la exposición obedece a la necesidad de dar respuesta a un problema que ha presentado serias dificultades a algunas de las teorías sobre la causalidad y porque consideramos que desde la perspectiva que se va a defender nos permite dar cuenta de un aspecto fundamental con respecto a la diferenciación entre los aspectos ontológicos y epistémicos de la causa.

\subsubsection{Aspectos pragmáticos}

Aceptamos, por ejemplo, que dejar de suministrar agua a una planta causa su muerte, pero lo que parece tan claro para el sentido común, esto es, que un factor ausente pueda ser causa de un efecto, desde el punto de vista ontológico es problemático: si aceptamos que la ausencia tiene un papel causal estaríamos ascendiendo de alguna forma a existente lo que precisamente es la falta de toda entidad. Convertir esa ausencia en un - si es que se le puede dar un significado a esta expresión - hecho negativo, que puede asumir la forma o bien de una causa faltante que produce un efecto o bien de la ausencia de un efecto que se esperaba si cierto factor no lo hubiera impedido. Vemos así que el punto de vista ontológico es diametralmente opuesto al intuitivo, que no puede ignorarse, dada la importancia que tienen las omisiones en campos tan vastos como el de la responsabilidad moral y legal, entre otros. Por ejemplo, es evidente que no podemos eximir de culpabilidad a quien omite el cuidado de un niño o al responsable de regar la planta, sin cuya acción el niño sufre y la planta perece. En este último caso, se puede pensar que el jardinero encargado del cuidado de la planta es tan causante como cualquiera otra persona, pues ni él ni nadie más realizaron el acto de regarla, de manera que también podríamos culpar al Papa por no haber llevado a cabo la acción. Y sin embargo el grado de responsabilidad de los dos agentes es tan diferente que intuimos de forma fiable cuál es el evento ausente y cuál es el papel del agente cuya ausencia permitió que se diera tal resultado. La intuición acertadamente nos dice que en el conjunto de quienes omitieron el acto hay muchos matices de responsabilidad: hay quienes estaban directamente encargados de ello, otros que no estaban encargados pero que podían haber tomado el relevo, hay quienes podían pero no sabían y hay quienes ni sabían ni podían, a los cuales claramente no se les puede adjudicar ninguna responsabilidad (de ahí que no se pueda decir que 
“todos somos responsables" y que el papel del grupo de agentes factibles no sea interesante para el análisis causal: no tiene sentido detenerse en las infinitas situaciones supuestas que no sucedieron o no podían suceder).

Hay muchos ejemplos en los que se presentan efectos causales que parecen ser consecuencia de las omisiones: alguien altera su comportamiento por un reloj que no suena cuando debería, un médico omite los cuidados que prolongarían la vida de un paciente terminal y, dado que muchos de los casos comunes en la literatura tiene que ver con acciones humanas, habrá que detenerse un momento a examinar qué tienen de particular. Una de las características llamativas es que los casos de omisión o prevención de los actos en ocasiones son evaluados de acuerdo con sus consecuencias legales o morales: a diferencia de la causación en los eventos naturales, en los cuales el efecto ocurre o deja de hacerlo sin más, en la omisión y prevención de los acciones humanas se involucra la idea de la responsabilidad, adjudicable a quien tenía el deber de actuar de cierta manera. También vale la pena anotar que las expresiones dedicadas a la mención de ausencias y prevenciones tienden a usarse más para dar respuestas a porqués o para dar explicaciones, una característica que ofrece un indicio de las posibles respuestas a la cuestión.

Entre las consecuencias morales de un acto, algunas de ellas son físicas y directas, pero también hay otras que son derivadas. Si nos limitamos a la causalidad directa, un asesino que mata a los padres de un niño no causa su orfandad; esta es consecuencia del asesinato, que redefine su situación en el mundo, pero no hay que olvidar las diferencias entre responsabilidad y causalidad: en este caso hay responsabilidad legal y moral porque la orfandad es la consecuencia lógica, no porque sea un efecto secundario de la acción (Sartorio, 2012, p. 576). El consecuencialismo confía en la noción de causa próxima, que se discute en la filosofía del derecho; el resultado debe fluir directamente desde el agente que actúa, como en el caso de dos personas que le disparan alternativamente a su víctima, de forma tal que si el primero yerra el segundo dispara: la causa es la acción que de no haberse presentado no habría ocurrido el efecto, pero en este caso no identifica el papel de la agencia causal individual, ya que si uno no hubiera disparado, lo habría hecho el otro. Sin embargo, hay que insistir en la diferencia entre adjudicar la causa y encontrar la responsabilidad moral: si uno solo de los confabulados disparó, él causó la muerte, pero también el otro tiene responsabilidad por su tentativa. La cuestión es si puede aceptarse cierta forma de transitividad de las causas, pues en el caso del homicidio se podría afirmar que la falta del disparo del primer hombre causó el disparo del segundo. Algunos autores rechazan la transitividad para 
evitar la relación causal de un acto con su larga cadena de consecuencias (Sartorio, 2012, p. 578), pero no puede ignorarse que los actos pueden tener consecuencias no causales, como las consecuencias lógicas con efectos morales (la orfandad del caso mencionado). En la responsabilidad moral o legal se admite cierta transitividad cuando se actúa por interpuesta persona 0 alterando condiciones de manera en que sea inevitable una consecuencia, cuestión que de por sí no valida la transitividad causal pero permite hacer aceptable una explicación. D e todas formas en el caso de las causas alternativas se requiere hacer suposiciones sobre lo que hubiera podido pasar: que el primer agente dejara de actuar no implica necesariamente que el segundo lo haga, ya que puede desistir, errar o su arma puede fallar. Tal vez se podría hablar de una transitividad restringida, en la que el grado de separación aumenta la indeterminación pues en la medida en que se interpongan más eslabones de la cadena causal, es más probable que algo no salga como estaba previsto.

Sin necesidad de abundar en la discusión ética al respecto, es interesante ver cómo desde la perspectiva de la responsabilidad moral hay diferencias claras entre actuar y ser pasivo, con los matices que esto implica: en el caso de la eutanasia, es diferente la responsabilidad de quien actúa para abreviar el sufrimiento, o de quien omite el cuidado para que la naturaleza prosiga su curso, o de quien prodiga un cuidado que conserva la vida pese al dolor que pueda causar, entre otras posibilidades, pese a que desde perspectivas éticas consecuencialistas en principio no existe diferencia pues el resultado es el mismo. Intuitivamente, es evidente que la omisión tiene un papel causal, tal como si fuera una entidad positiva destinada a obtener el fin en cuestión. Físicamente es muy diferente matar que dejar morir: moral y legalmente suele ser más admisible la eutanasia pasiva porque se omite la acción que conduce a la ocurrencia de un fin, dejando que sea la naturaleza (o la enfermedad) la que se encarguen de la situación y, sin embargo, por lo menos en cuanto a la responsabilidad, es necesario considerar la operatividad de las omisiones, dado que algunas parecen ser causas efectivas, aunque lo sean indirectamente. Si se midiera solamente el efecto final no se podría distinguir, en términos causales, entre matar y dejar morir, pero en términos de responsabilidad moral es notoria la diferencia pues las acciones requieren que irrumpa en la realidad un acto que produce un efecto directo, mientras que en la omisión se deja de actuar para que la naturaleza siga su curso. En algunas circunstancias particulares los actos pueden cambiar por completo la valoración que de ellos se haga: un secuestrador, por ejemplo, puede dejar morir de hambre a su víctima al impedirle el acceso a la comida o un médico dejar de suministrar alimento a un paciente en coma. Dado que los seres vivos dependen del suministro 
de alimento para suplir sus necesidades energéticas, si se suspende ese suministro, el gasto de energía determina la muerte del sujeto. Adjudicar la responsabilidad al secuestrador y al médico implica conceder que la omisión tiene poder causal y que la culpa no es de la naturaleza: existen explicaciones válidas dependiendo de cuál es la pregunta que queremos resolver, y si lo que se quiere indagar es el grado de responsabilidad moral, el cuadro es diferente del que da cuenta de las causas fisiológicas. No es lo mismo actuar para conseguir un fin que omitir una acción que permita cumplirlo: suele ser calificado con mayor responsabilidad el actuar que el omitir, pero es una diferencia más bien de grado, pues se acepta que si el acto y la omisión se destinan al cumplimiento de una finalidad es porque ambos son efectivos, es decir, la omisión no se suele considerar neutra pues se la acepta como capaz de posibilitar el cumplimiento de una finalidad causal. D e ahí también se deriva la importancia en detenernos sobre este punto: la dificultad de determinar el estatus ontológico de la omisión es un signo de que algo importante sobre la causación se esconde tras ella, específicamente, detrás de las relaciones entre los factores que hacen posible que un cierto resultado se presente, como se mostrará más adelante.

La relevancia de la omisión es un factor pragmático y no ontológico: en los casos mencionados no se puede alegar que la enfermedad es un factor preexistente si no se acepta que en el caso del secuestro los factores biológicos también lo son. Esto nos devuelve al caso de la responsabilidad del Papa en la muerte de la planta porque tampoco la regó: no hay diferencia entre la falta del jardinero y la del Papa, sino solo en el plano de las obligaciones y las expectativas, como plantea Sartorio (2012, p. 583). Podríamos distinguir entre las condiciones que posibilitan y los factores desencadenantes: las primeras facilitan o hacen posible el evento, son el trasfondo causal sin el cual el efecto no ocurre, conformando el conjunto de condiciones que permiten que cierto factor actúe; en algunos casos no se consideran causas genuinas, pero en otros se las acepta como tales. Los segundos corresponderían a la causa eficiente, pero las omisiones no parecen capaces de desencadenar un efecto, lo cual choca con la intuición común en los casos en que la omisión se aprecia ligada al efecto: se ve como relevante pese a su precariedad ontológica.

Razonamientos similares pueden hacerse alrededor de la prevención: es el caso en que un factor causal interviene impidiendo que el resultado esperado aparezca. En general, podemos decir que un semáforo bien situado impide que los vehículos choquen en una intersección, dadas ciertas condiciones como que su funcionamiento sea correcto, que tenga un suministro de energía y que los conductores lo respeten. Sin embargo, los casos más interesantes de prevención son aquellos 
en que la intervención de un factor sobreviniente es capaz de alterar el curso esperado de los acontecimientos, lo cual nos lleva a otros dos elementos que necesitan definición: la calidad de sobreviniente de un factor y lo que se considera el curso normal de los acontecimientos.

El factor que sobresale o emerge es importante en cuanto no es práctico poner a depender cada efecto de todos los acontecimientos anteriores: la causa de la muerte de César no es su nacimiento (McG rath, 2005, p. 130), pues de esta forma la causa de todo resulta siendo el Big Bang y no habría que buscar ninguna causa particular de todos los acontecimientos del Universo. D e hecho es el origen del Universo, pero esta no es una respuesta que dé cuenta de las causas que estamos buscando, que son el resultado de cierta cadena causal o de una línea de sucesos del mundo; podríamos admitirlo como causa parcial, pero esto implicaría ampliar excesivamente el concepto de condición causal. Hay que considerar, además, que la transitividad de las relaciones causales es limitada como medio explicativo, pues el hecho de que los eventos se encadenen en secuencias no nos permite adjudicar un papel causal a causas remotas, dada la indeterminación creciente que suelen presentar estas cadenas. Nuestra particular sabiduría retrospectiva nos facilita encontrar cualquier explicación aunque no podamos hacer predicciones con ellas y este es un hecho que debería ser suficiente demostración de la debilidad de los argumentos que se apoyan en la transitividad de las causas: es útil para reconstruir la historia de un evento, pero la fiabilidad de las predicciones con causas encadenadas se hace exponencialmente menor con cada uno de los eslabones que nos separan del acontecimiento que queremos prever. Como lo plantea von Wright (1974, p 21), ónticamente el mundo se desenvuelve sobre una línea, sobre la cual no hay modificaciones posibles, pero epistémicamente en un árbol de posibles futuros, una muestra de que es más factible indagar por las causas de un hecho ya ocurrido que por los efectos que habrán de ocurrir.

Ahora, si mencionamos un factor que sobreviene, esto implica que hay un trasfondo de acontecimientos más usual, sobre el que aquel se erige, es decir, sobre lo que llamamos "el curso normal de los acontecimientos". Sin embargo, no parece muy evidente que el sentido común tenga una noción clara de qué es lo normal ni de sus límites precisos. Los estudios sobre causalidad hablan, en su lugar, de las secuencias de acontecimientos que son previsibles por las leyes de la naturaleza. Así, esperamos que los acontecimientos se comporten de una determinada forma de acuerdo con las leyes de la ciencia. Un hecho preventivo sobreviniente no altera las leyes sino que impide que los resultados previsibles se cumplan: si logro atrapar una copa de vidrio que cae 
hacia una superficie sólida prevengo su rotura, pues de otra forma es muy alta la probabilidad de que la aceleración gravitacional termine con ella. En este caso el evento negativo, el no-evento, es el resultado de la intervención de un factor causal o pseudocausal: la intervención de ese factor es la que impide que un cierto estado de cosas llegue a darse. Ahora bien, ese estado de cosas era el previsible de no haberse presentado el factor sobreviniente, lo cual implica que en el análisis de las prevenciones se compara una situación real con una hipotética que pudo haberse presentado en ausencia del factor mencionado. La única guía fiable con la que contamos para diferenciar lo que pueda considerarse como el curso normal de los acontecimientos se encuentra en las leyes formuladas por la ciencia: son ellas las que determinan cuáles son las condiciones para que una cierta transformación ocurra y en qué medida inciden en un resultado.

\subsubsection{Las ausencias frente a los mecanismos causales}

Las ausencias y omisiones ourren si un evento de cierto tipo no sucede, si falta algún factor, pero su dificultad para el análisis conceptual no permite que se las trate como excepciones (Paul, 2012, p. 169); el problema es cómo dar una definición adecuada de los eventos de los cuales hacen parte. Y, como ya se dijo, el análisis sobre las omisiones hace referencia a aspectos pragmáticos en razón a que involucran actos de un agente, pero también hay que contemplar que en la naturaleza ocurren ausencias, fuera de las intervenciones humanas, a las que adjudicamos un papel causal. Ahora bien, debe darse respuesta a la incongruencia entre la equivalencia práctica y la distinción teórica que existe entre causación por ausencia y causación genuina. Entre las dificultades con que se enfrenta el problema de las ausencias está el hecho de que representan formas comunes de encadenar eventos y, sin embargo, como formas causales, se resisten a compaginar con diversas teorías causalistas. Ehring (2012, p. 396) afirma que ante la efectividad causal de las ausencias hay opciones: 0 bien aceptar que son eventos negativos 0 asociados con otros eventos positivos; o bien negar que las ausencias y omisiones constituya casos legítimos de causación, pese a su diferencia intuitiva con los factores reales.

No es del todo claro cuándo una ausencia o una prevención lo son realmente, pues se pueden esgrimir como ejemplos los casos en los que una enfermedad o un accidente impiden el correcto funcionamiento de la fisiología de un ser vivo. D owe (2000, p. 131) cita el ejemplo de sustancias como el opio que causa sopor, o del alcohol, cuyo efecto depresor inhibe la respuesta del cerebro, explicando muchos accidentes de tránsito. En este caso decir que el sopor es causado por el opio 
es aceptar que sus principios activos impiden el estado de completa vigilia, es decir, que un evento con capacidad de transmitir una influencia física, causa una especie de evento negativo, una ausencia. $\mathrm{O}$, en el caso del alcohol, el evento real del accidente es causado por la inhibición de atención, una ausencia, producida por la sustancia. De ahí que las prevenciones y ausencias sean mucho más usuales de lo que quisiéramos: decir que fumar causa enfermedades cardiacas es equivalente a decir que impide el proceso normal de la vida de las células del corazón, así que no es tan fácil diferenciar un hecho positivo de uno negativo. D esde esta perspectiva, las ausencias y omisiones, en tanto involucran casos o eventos negativos, no son causación estricta sino cierta forma de causa posible, una cuasicausación o lo que D owe (2000, p.124) llama "causación*", es decir, no la causa real típica sino combinada con ciertos enunciados contrafácticos, y agrega que a pesar de que se intuya una distinción conceptual sería útil tratar las causas y las omisiones como una sola cosa: cumplen papeles similares, en cuanto al análisis de medios y de fines, además de la explicación y de la responsabilidad (como en el mencionado problema ético de hacer o dejar que pase: la diferencia es epistémica).

Las ausencias y las prevenciones son precisamente rupturas de la continuidad de las cadenas de sucesos que impiden que una influencia causal positiva sea transmitida entre una causa y un efecto. Si se defiende que la relación causal se caracteriza por una interacción física que permita el intercambio de una determinada magnitud, las ausencias deben ser excluidas del campo causal, lo cual va en contra del papel de la omisión en la responsabilidad moral. Pero no solo eso sino que no podrían explicarse relaciones causales cotidianas como la de girar una llave para apagar el motor de un coche, porque no hay ninguna transferencia de cantidad conservada entre el interruptor y el suministro de electricidad o combustible. Ante tal perspectiva las opciones son, o bien que la causación está definida en términos demasiado estrictos, o bien que estos casos no son efectivamente causación sino algo que se le asemeja.

Para la teoría de la cantidad conservada la causa y el efecto están conectados por medio de interacciones físicas; un proceso posee una cantidad conservada y en la interacción se produce un intercambio de esta, cuestión que excluye las prevenciones y las omisiones, pues no permite que exista la conexión física que transmita la cantidad conservada (D owe, 2008); tal cantidad conservada está ligada a eventos positivos aunque no siempre es claro cuándo un evento es positivo o negativo ya que, dice Dowe, una consecuencia positiva produce una infinidad de efectos negativos; sin ir más lejos impide que sucedan muchas otras situaciones, como en el caso 
de la bola de billar que adquiere cierta velocidad a raíz del golpe del taco, excluyendo, a la vez, la multitud de otras velocidades y direcciones posibles. Al parecer no hay evidencia psicológica de que la mente haga una distinción entre eventos positivos y ausencias, aunque sí parece depender del contexto el hecho de que un evento se considere positivo o negativo, lo cual nos devuelve al campo de la búsqueda de la explicación adecuada para el contexto en el que nos encontremos. Menzies y Woodward concuerdan en que la distinción entre eventos positivos y negativos refleja el contraste entre lo que se suele considerar normal y lo que se considera anómalo, contraste que depende del contexto y de las teorías aceptadas, de modo que las ausencias se usan más bien como un recurso lingüístico para contrastar (Menzies, 2012, p. 364). Por ejemplo, en el caso en que un paciente muera por la falta de suministro de un medicamento, es diferente el papel causal y la responsabilidad de la omisión por parte del médico que lo prescribe que la del encargado del suministro, es una cuestión de relevancia de la explicación que estemos buscando: lo normal es que el médico hubiera prescrito y que el enfermero hubiera suministrado el medicamento pero alguno de los dos falla y cuál sea la situación anómala depende de cómo ocurrieron los hechos. Si entendemos que las causas operan por transferencia, como ocurre en el flujo de energía de un objeto a otro, no podríamos dar cuenta de cómo un acto como el de oprimir un interruptor causa que la luz se apague: allí no se transfiere energía pues, por el contrario, el acto determina la eliminación de la transferencia. D owe (2000, p. 126) califica este evento como una prevención, pues el interruptor previene que el circuito quede cerrado, pero la intuición capta allí un acto real en el que se produce una modificación en el estado del mundo. Así que puede haber causas que no transmitan energía (casos de desconexión): una manzana cae si se corta su tallo, pues se produce una transición de energía de potencial a cinética, pero de todas formas no es apreciable que exista un traspaso directo de energía pues, al igual que en el caso del apagado del interruptor, no existe una persistencia espaciotemporal continua de la causa con su efecto. Con una herida en el corazón la ausencia de sangre oxigenada en el cerebro constituye la causa de la muerte, ejemplo que nos muestra cómo una ausencia puede incorporarse entre las condiciones necesarias 0 suficientes para la relación causal, sin que incida en las cantidades transferidas en un proceso.

En el caso de las prevenciones sucede que A causa* no-B, es decir que A impide que B suceda, lo cual no es causación genuina sino un enunciado contrafáctico verdadero sobre la causación genuina (D owe, 2000, p. 132), es decir, que habría que acudir a otra relación posible, esta sí causal pero hipotética, que es la que se ve obstaculizada por la prevención. Además pueden intervenir otros factores, sea como prevención redundante 0 alternativa (preemption). Puede ocurrir una 
interacción entre dos secuencias causales, de manera tal que la prevención actúa solamente en una de las líneas de los sucesos que interactúan, llevando a cabo cierto resultado que impide que en la línea alternativa se produzca alguna diferencia, es decir configurando una secuencia alterna que no habría existido sin la prevención. En el caso de la ausencia el no-evento causa* un efecto pero, pese a lo que afirma D owe, lo que aquí sucede es que realmente se oculta la acción de otra causa, esta sí efectiva, como ocurre en los casos fallidos de prevención: un cortafuegos se pone para evitar que un incendio forestal se expanda, pero si existe una brecha el incendio se propaga; la lectura posible es que la brecha fue la ausencia que produjo la propagación, pero otra lectura más adecuada es decir que esta se debe al comportamiento habitual del fuego; esta es la causa, pero en caso en que el cortafuegos hubiese estado en las condiciones adecuadas la historia hubiera sido diferente.

Menzies (2012, p. 351) afirma que las ausencias son eventos muy misteriosos pues es problemático asumir que las ausencias sean eventos genuinos, dado que se comportan como una especie de evento alterno a otro: por ejemplo, que la ausencia de comida sea un genuino evento positivo del organismo y que su efecto de hambre configure una situación diferente de aquella en que se ha ingerido comida. Son situaciones diferentes: decir que el hambre es causada por ausencia de comida es cierto a nivel explicativo, pero en los hechos hay una serie de eventos positivos en los que los niveles de glucosa en la sangre son interpretados por el cerebro como sensaciones de saciedad o de hambre, que incluso pueden ser falsas, en tanto no se correspondan con la ingesta de comida, pero cuya existencia es real. Beebee agrega una consideración importante: que las proposiciones causales genuinas describen relaciones entre eventos, mientras que se acude a las ausencias en las explicaciones.

Si aceptamos que la prevención y las ausencias son legítimas causas, esto es, que son capaces de alterar la probabilidad de que un efecto ocurra (un signo usual de las causas), nos encontramos con que tendríamos que ignorar la intuición de la diferencia entre causación y pseudocausación, pues comúnmente hay acuerdo en que esos casos no son causación genuina: un descuido en la prevención no es equivalente a causar un accidente. Igual sucede en las teorías de manipulación, en que las causas son definidas como los medios para conseguir algún efecto, y en esa perspectiva la omisión es legítima, pero no es satisfactoria como causa en tanto ignora la diferencia entre acción y omisión, se desentiende del nivel ontológico para centrarse en una posible relación de dependencia, en el campo de la explicación. Dice Woodward (2003, p. 225) quelas teorías causales 
deben aceptar casos en que las ausencias son buenas explicaciones, como en los casos en los que una acción rompe un equilibrio natural entre predadores y presas: por ejemplo, si se extinguen los lobos de una zona, los herbívoros que son su presa pueden llegar a deteriorar la vegetación; así, la ausencia del predador sería la causa de un deterioro de la vegetación, pero no podemos olvidarnos que ese factor intermedio - el papel causal de la abundancia de herbívoros- conforma una secuencia causal alternativa, que tiene continuidad, mientras que la ausencia solo altera las condiciones, es uno más de los factores del entorno causal. El autor da el ejemplo de omisiones explicativas, como en el caso del paciente que muere por falta de un antibiótico, ausencia que se acepta como causal, al punto en que se adjudica la responsabilidad al médico, pero no puede negarse que son los patógenos los que matan al paciente. Habría que comparar el caso con el de otros pacientes que sobrevivieron, pues la teoría de manipulabilidad tiene la virtud de considerar algunas omisiones como explicaciones causales y es en el nivel de las explicaciones donde las omisiones cumplen su mejor papel, así como es factible la búsqueda de regularidades con base en ausencias.

Es necesario entrar a considerar brevemente la noción de permanencia, que nos será útil para construir un argumento alrededor de las ausencias y omisiones. Russell ofrece algunas ideas importantes para configurar lo que entendemos como proceso, definiendo las condiciones de cuasipermanencia, esto es, de la parcialidad de los cambios en el mundo, sobre un fondo de condiciones en las cuales existe algún grado de estabilidad. Para el autor, los eventos pueden estar inmersos en series de acontecimientos en los que hay persistencias, la trayectoria en el tiempo - la historia, diríamos- de un objeto en transformación, es relativa al concepto de la identidad que persiste a pesar del cambio:

A "causal line", as I wish to define the term, is a temporal series of events so related that, given some of them, something can be inferred about the others whatever may be happening elsewhere. A causal line may always be regarded as the persistence of something - a person, a table, a photon, or what not. Throughout a given causal line, there may be constancy of quality, constancy of structure, or gradual change in either, but not sudden change of any considerable magnitude (Russell, 2009, p. 404).

Así, la idea de que los eventos están conectados por líneas causales nos permite llegar a definir un elemento de la causalidad: que los cambios en el mundo son parciales, es decir, que en los cambios que ocurren en la realidad siempre hay características que permanecen, persistencias de cualidades o de estructuras que hacen que los objetos sigan siendo reconocibles a pesar del paso del tiempo 
y que, además, los cambios son graduales en tanto no hay transformaciones que puedan ser consideradas como completas e instantáneas. Este es un marco dentro del que caben las ausencias como parte del panorama causal. Russell menciona la necesidad de aislar el objeto, pero dado que es imposible hacerlo por completo, deberíamos aceptar esta necesidad como el caso límite ideal al que debe tender la indagación causal con el fin de ofrecer la mayor precisión posible y que de esta forma, es decir, por medio de las líneas causales, la ciencia pueda adquirir un mayor conocimiento sobre el mundo.

Pese a las limitaciones que puedan tener las líneas causales, ofrecen algunas ideas útiles para solucionar el problema de las ausencias, siempre que se entiendan como parte de un panorama causal más completo. Hemos defendido la idea de que las causas operan de forma parcial y gradual, lo cual implica que en las concatenaciones de eventos que configuran una causa existen ciertas permanencias que vinculan las causas con sus efectos. En el caso de ausencias, omisiones y prevenciones no se puede defender la idea de que existen ciertas cantidades conservadas como agente de la acción causal pues precisamente esos tipos causales consisten en la falta de continuidad o en la interrupción de una secuencia cuyo efecto sería diferente. Así que, al parecer, la reconstrucción de las líneas de influencia causal, si bien no logra cerrar la brecha ontológica que parece introducirse al aceptar que un no-ente altere una secuencia causal, nos permite, desde una perspectiva epistémica, reconstruir una historia acerca de cómo operan las ausencias. D esde la perspectiva ontológica el factor ausente permite que otros factores operen y desde la perspectiva epistémica ese factor nos permite entender qué secuencias causales pudieron operar y no lo hicieron. Al aceptar que las omisiones y prevenciones son parte del argumentario explicativo, estas cumplen un papel en la indagación experimental y en la predicción científica; en efecto, la ciencia no puede prescindir fácilmente de argumentos tales como que Júpiter defiende a la Tierra de cometas y asteroides, o que los glóbulos blancos retardan el desarrollo de alguna infección, 0 que el viento impide que llueva en algún sitio. Además, el diseño de situaciones experimentales complejas está dirigido con frecuencia a la identificación del factor sin el cual un determinado efecto no se produce: la ausencia de cuál elemento químico es la que retrasa el desarrollo de una planta, por ejemplo. Y así mismo sucede en la predicción utilizada como medio de contrastación empírica de enunciados de la ciencia: si un determinado efecto crucial previsto por la teoría no se produce ya podemos considerar a esa teoría como falsada. El problema es cómo convertimos esa utilidad metodológica de la prevención y de la omisión en un hecho ontológico existente, dado 
que su efecto se deriva precisamente de su ausencia o de los impedimentos que cambiaron la cadena causal. Puestos así, serían no-entes de los que no debería derivarse ningún efecto.

\subsubsection{Ausencias y contrafácticos}

Para Lewis la causación* (causación por ausencia) no es genuina porque involucra eventos negativos y es aceptable solo para elaborar ciertos enunciados; las ausencias no pueden ser genuinos eventos pues implican una disyunción entre causa y efecto, son una ruptura de la secuencia causal. La semejanza entre la causación y la causación* viene de su mencionada correlación contrafáctica, además de la dificultad de su distinción frente al papel que cumplen en la explicación y en la agencia (D owe, 2000, p. 145), datos significativos en cuanto nos permiten entrever que la ausencia debe ser considerada por su papel causal si aceptamos que no se reduce al ámbito ontológico. Algo análogo ocurre en la prevención: cuando se baja una cortina para oscurecer una habitación sucede que una acción real causa una situación que podemos definir como cierto grado de luminosidad o como ausencia total de luz. D e nuevo, resurge el hecho de que la causación real toma una vía y los enunciados otra, lo cual no puede ser de otra manera, dado que pertenecen a ámbitos diferentes. En realidad el acto de bajar la cortina constituye otra secuencia de eventos causales: consiste en interponer una superficie que refleja la luz, luz que en otras circunstancias entraría en la habitación, de modo que lo que calificamos como prevención puede ser visto como un cambio de las condiciones, como una sustitución de una secuencia causal por otra que ya no existirá.

La causación* de D owe, compuesta de causación real y enunciados contrafácticos, se utiliza con fines prácticos, razón que permite a la teoría contrafáctica solucionar un amplio espectro de problemas, conservando la intuición de la diferencia (D owe, 2000, p. 124) entre la causación genuina, por una parte, y la ausencia y la prevención, por la otra. En otro ejemplo de D owe, si un padre descuida a su hijo y este sufre un accidente, no se puede decir que el padre causó el accidente, solo que lo pudo haber prevenido; el padre no tiene una conexión causal - en el sentido físico y directo- con el accidente pero, al actuar como lo hizo, ciertas circunstancias produjeron el accidente, es decir que, ante su falta, fueron otros factores causales los que operaron; la descripción del evento como la falta de cuidado no alude a la causación genuina, y esa es la diferencia que intuimos. Tal intuición se ejemplifica en muchas situaciones, como en la diferencia entre matar y dejar morir o en la responsabilidad que se imputa al negligente. No hay que olvidar 
que el lenguaje puede representar de formas particulares las secuencias causales: así es como usamos hielo para enfriar un líquido; esta es una explicación legítima, pese a que en la naturaleza el calor siempre irradia desde la fuente de calor hacia las zonas con menor temperatura. Lo mismo puede pasar cuando decimos que un poste produce una sombra: allí no hay transmisión de energía entre el poste y la superficie donde se proyecta su sombra; pese a que se puede calificar esta situación como causa por ausencia (Losee, 2011, p. 132): se admite como causación genuina pues la sombra es una causación indirecta, aceptable como causa en el razonamiento contrafáctico. No sobra recordar que la sombra es el ejemplo prototípico de pseudoproceso, por su incapacidad de transmisión de marca: el poste refleja la luz que de otra forma llegaría hasta el suelo, de manera que afirmar que la sombra es causada por el poste es apenas una conveniencia para la economía del lenguaje y para la construcción de la historia causal de un suceso.

Considerar que las ausencias y prevenciones conforman otro tipo de causación o cuasicausación requiere de una especie de hipótesis ad hoc para dar cuenta del procedimiento por el cual actúan, pues se las puede entender como causación posible, en contraste con la situación en la que la omisión no tuvo lugar o la prevención no se llevó a cabo. D owe apela a una teoría contrafáctica de las prevenciones y omisiones, dado que su teoría de las cantidades conservadas no puede dar cuenta de este tipo especial de causación; así es como su definición de la prevención acude a formular que si un evento no se produjo porque fue impedido, esto implica que sin el impedimento habría ocurrido el efecto. En la omisión, el acto omitido permite la consecución del efecto, en caso contrario no se habría producido. Esta es la manera en que una secuencia de eventos que ocurrió se compara con lo usual, con un prototipo o con una ley: se ponen en relación los actos individuales con un tipo colectivo como referencia de lo que suele ocurrir cuando las condiciones son suficientes para que una causa produzca su efecto. En otras palabras, la imposibilidad de encontrar un vínculo causal que opere mediante una cantidad conservada entre un evento que no ocurre, o que impide otro, lo lleva a aceptar una explicación contrafáctica, apelando a lo que habría ocurrido de no ser porque ocurrió otra secuencia de eventos.

D owe (2001, p. 221) propone una teoría contrafáctica de la cuasicausación, para dar cuenta de la omisión y de la prevención: la primera consiste en que no-A cuasicausa B, es decir que la ausencia de A permite la existencia del efecto, de modo que si ocurre A , el efecto no se produce. Y en la prevención sucede que A cuasicausa no-B, es decir, que la acción de $A$ impide $B$, de forma que si A sucede, no ocurre B. Es evidente que se necesita conocer las leyes de sucesión de los fenómenos 
que permitan comparar lo que no ocurrió con lo que hubiera ocurrido. Sin embargo, Dowe concibe que las causas parciales, aunque tengan una débil influencia, también son causas, con lo cual aún las causas remotas son parte de las causas, cuestión que es coherente con una visión irrestricta de la transitividad; sabemos que la causación puede ser parcial o indirecta, y así pasa con la cuasicausación, de modo que el asunto es definir qué tan "parcial e indirecta" puede ser, lo cual implica una respuesta pragmática. La causa genuina ocurre entre eventos positivos y por eso las omisiones y las prevenciones no son verdaderas causas, aunque sí responden a relaciones de dependencia contrafáctica, lo que las dejaría en el papel de causas subsidiarias de otro orden. D owe acepta que la cuasicausación no sea genuina, pues no es literalmente cierto que la omisión opere, dado que interrumpe la secuencia de interacciones de los procesos causales y sin embargo responde a contrafácticos, lo que indica que los enunciados que dan cuenta de la relación pueden ser verdaderos, y que cumplen una indudable función epistémica. El asunto de las omisiones lleva a Paul (2012, p. 168) a decir que el análisis contrafáctico es el más adecuado al respecto pues da cuenta de casos de doble prevención y también de casos en los que no hay transferencia de energía, esto cubre también los casos de causación negativa. En cambio, si limitamos las causas a las genuinas nos quedamos sin una solución frente a los eventos negativos, mientras que la teoría contrafáctica aplicada a la cuasicausación los soluciona. La cuestión sigue siendo la debilidad ontológica de esos contrafácticos.

O tra forma de enfrentarse al problema de las ausencias y prevenciones es aceptar que una ausencia constituye el factor causal genuino que alteran la probabilidad de que un evento suceda, con lo cual si el evento es considerado como positivo o como negativo es secundario, pues lo que importa es que funciona como factor que eleva o disminuye la probabilidad de que un efecto se produzca: un evento sería aquello a lo que puede asignarse un tiempo y una probabilidad. Comenta D owe (2000, p. 124) que el problema de esta concepción es que tropieza con la mencionada intuición de la diferencia, pues para la mente humana hay una diferencia clara entre el hecho de que cierta entidad actúe o que no lo haga. Es común atribuir estatus causal a la prevención y a la ausencia, pero no hay que perder de vista que esa atribución está ligada a comparaciones con las causas reales; la multitud de ejemplos diversos en las que se discute la distinción entre causas y cuasicausas es prueba de la diferencia entre omisiones y actos, entre ausencias y factores reales. Permitir un evento negativo crea problemas también para la teoría contrafáctica de Lewis, como veremos más adelante. 
Q uizás el análisis contrafáctico no enriquece las teorías de los procesos de cantidad conservada de Salmon y D owe sino todo lo contrario; y puede ser así porque tienen que apelar a la historia virtual, construyendo, en lugar de respuestas causales, hipótesis de lo que podría haber ocurrido cambiando un factor y dejando todo lo demás exactamente igual. Tampoco las teorías contrafácticas se escapan del conflicto en tanto las posibles relaciones causales ocurren entre eventos reales, pero lo más difícil es que los efectos no necesariamente se producen de una única forma, pues un efecto suele ser el resultado de una multitud de factores y lo difícil es alterar únicamente uno. De hecho es imposible puesto que la secuencia de eventos del Universo parece no ser cíclica y es por tanto irrepetible, de ahí que cuando se habla de dos situaciones casi idénticas, aparte de la alteración de un solo factor, se habla de situaciones hipotéticas y de condiciones ateris paribus, aplicadas a una situación virtual comparada con la real.

El análisis contrafáctico, pese a su utilidad como medio de determinar ciertas causas y de entender lo que es una condición necesaria, no parece ser el medio más adecuado para elaborar una definición de lo que pueden ser las causas en los hechos, pues da la impresión de ser demasiado amplio como para albergar una definición precisa de las causas y menos aún de los mecanismos causales. Corre también el riesgo permanente de caer en circularidad pues normalmente se necesita conocer con anterioridad cuál es la causa de un determinado tipo de eventos para saber si fue su presencia o ausencia la que produciría el efecto previsto. Dowe (2000, p. 150) afirma que la existencia de una relación de relevancia estadística o una dependencia contrafáctica no constituye la condición necesaria para la producción del efecto; el hecho de que haya un proceso causal es necesario, pero no suficiente para la producción del efecto.

La defensa del análisis contrafáctico de Lewis (1986, pp. 190-193) requiere de una variación para responder a las ausencias: aceptar como excepción un tipo especial de eventos que tienen la característica de ser disyuntos (pueden ocurrir de más de una forma); sabemos que operan pues podemos comparar esas situaciones con otras en las cuales la omisión no se produce, conduciendo a un resultado diferente. La segunda opción que plantea Lewis es la de negar que las ausencias sean eventos, pero si es así, tendría aún que encontrarse una respuesta a cómo es posible que ocurran efectos específicos luego de una desconexión en la cadena de dependencia causal, pues de otra forma habría que admitir que cada ausencia tiene una cantidad infinita de efectos (no es solo ausencia de una factor sino de muchos). La tercera opción es la de aceptarla como causa, una suerte de secuencia causal alternativa que solamente puede ocurrir si se produce la ausencia 
o la omisión; pone el ejemplo de quien omite hacer algo y en lugar de hacerlo toma una siesta: tomar la siesta es un evento que sustituye al acto que debía producirse. Esta alternativa requiere una elaboración contrafáctica diferente, pues el resultado varía si se elabora teniendo en cuenta la ausencia del acto o la presencia del acto sustituto. Esta tercera opción permite mayores posibilidades para dar cuenta de la naturaleza de la ausencia: no es un evento o un acto en sí mismo, dado que implica algo faltante, pero constituye otro acto, un evento sustituto, o un cambio en las condiciones necesarias para la ocurrencia de un efecto: es la ausencia lo que permite que otra secuencias de hechos ocurra.

El caso de la prevención es semejante: el hecho preventivo es la condición suficiente para que el efecto no ocurra, también cumple la condición contrafáctica y es susceptible de manipularse, pero no constituye una condición necesaria, ya que no existió ninguna transmisión de influencia de la causa al efecto. En forma análoga a como ocurre con las omisiones, la dificultad con la prevención radica en que hay que calificar la ausencia de efecto como un evento (o uno de sus elementos), aunque esta situación es común: muchas acciones son ejecutadas con el fin de evitar un efecto, de manera que nos parece normal que se adjudique alguna responsabilidad a quien ejerza el acto preventivo. Intuitivamente las causas se entienden como un factor que interviene en una determinada situación para producir un estado de cosas que no se hubiese dado sin su presencia. Pero las causas también operan de acuerdo con un trasfondo causal, poniendo un estado de cosas diferente con respecto a aquella situación en la que no intervienen. El caso de la prevención es de este último tipo, ya que el acto preventivo configura una situación sin la cual el efecto se habría producido, es una acción que impide un efecto a pesar de la ausencia de conexión física; el efecto se previene, esto es, se evita que suceda, si se ejerce una acción que rompe una cadena causal posible o desconecta las circunstancias que lo harían factible. Como la omisión, la prevención puede entenderse como un estado de cosas que ocurre de una forma diferente a la que hubiera sucedido sin ella. En un mundo hipotético idéntico en el que el factor previsor no intervenga, el efecto esperado se producirá, pero la prevención altera la cadena causal de los eventos reales.

Recapitulando, podemos afirmar que los objetos inmersos en procesos no se transforman completamente, de modo tal que de un objeto no se produce otro completamente diferente, así que es más apropiado hablar de que la causa es lo que transforma una situación, esto es, que en la realidad hay secuencias de cambios graduales en objetos que pueden ser identificados durante 
el paso del tiempo. Sin embargo, la descripción de tales procesos parece insuficiente ante las múltiples dificultades que ofrecen las causas preventivas o por omisión. Habrá que dar un paso más allá y aceptar que la causa es un tipo de interacción que se produce entre situaciones complejas inmersas en el cambio, esto es, entre eventos. Existen situaciones, quizás la mayoría, en las que es necesario contemplar todo el panorama causal, o por lo menos, una mayor cantidad de factores involucrados en la producción de un cambio, ya que la realidad no ofrece una delimitación tajante previa que permita especificar cuáles son los que entrarán en juego: habrá que considerar qué factores son causalmente relevantes y el grado de aislamiento del sistema en cuestión.

Aceptar que las ausencias son causas verdaderas implica aceptar un componente normativo, según plantea McG rath (2005, p. 125), que consiste comparar la situación real con prototipos de relaciones causales. Pese a que los factores negativos desconectan físicamente la causa del efecto, no podemos negar que nos proveen una forma de entender por qué suceden ciertos tipos de sucesiones causales: hay que hacer compatible la desconexión entre la causa y el efecto con nuestra intuición explicativa. No podemos negar que las ausencias cumplen un papel causalmente relevante, por lo menos en la formulación de sentencias: así no cumplan un papel en el estricto sentido de ejercer influencia causal, las ausencias tienen la capacidad de explicar efectos; son parte de la historia causal del efecto, de ahí que la causación sea importante para determinar la responsabilidad y para ofrecer explicaciones. Un evento puede prevenirse y hay muchos factores capaces de prevenirlo, el asunto es descubrir en qué se basa el sentido común para distinguir cuál es la ausencia pertinente. Cuando no se logra dar cuenta de la causa, la autora propone, en el caso de las acciones, el deber moral como indicio: ¿quién debía regar la planta? (McGrath, 2005, p. 134). Esperamos que la causa sea emergente, por eso esperamos que las cosas sucedan de cierta forma y si no lo hacen, podemos buscar el factor que marca la diferencia. Esta no siempre es la condición suficiente, pues no siempre las expectativas se cumplen o tenemos suficiente información para hacer el diagnóstico preciso. La noción que propone McG rath (2005, p. 138) es la de lo normal, es decir, lo regular, que difiere de lo correcto - que es lo regido por normas y parámetros- . Hay que decir que lo normal es muy heterogéneo y vago, a no ser que decidamos llevarlo al campo de las leyes naturales, campo en el cual, en la medida en que ampliamos nuestro conocimiento, tenemos más certeza de cómo han de suceder los acontecimientos, y una mayor seguridad acerca de qué se puede esperar. 
Las normas legales pueden darnos elementos de análisis: ellas están interesadas en identificar el factor involucrado en la existencia de un fenómeno particular, y lo hacen comparando el mundo actual con uno hipotético en el que tal factor esté excluido. Ese factor puede no ser físico, como ocurre en una omisión o en la transmisión de una información, pero se contrasta con los factores considerados normales (Stapleton, 2012, p. 746), condiciones frente a las cuales el factor es necesario, de acuerdo con lo que sabemos sobre el funcionamiento de la realidad. También la norma puede comparar el suceso con otro hipotético aún si es imposible, por medio de una reducción al absurdo. Lo que se intenta determinar en estos casos es el grado de efectividad de un factor en la producción de un resultado: en un asesinato la responsabilidad puede ser por deber, complicidad, coerción, petición, etc., (Stapleton, 2012, p. 749) de manera que es necesario comparar diferentes situaciones para hallar el grado de responsabilidad que puede caber a los agentes, lo cual nos lleva al escenario de la determinación de la relevancia, pues se intenta conocer el factor más influyente en ciertas condiciones. La voluntad constituye la diferencia en la noción de responsabilidad con respecto a la de causa, pero hay elementos comunes valiosos: la intermediación debilita el grado de culpabilidad y así como en una cadena de mando la responsabilidad se va diluyendo de paso a paso, es menos seguro hacer una jugada a varias bandas, en la medida en que interfieren más factores; es más incierto el resultado en la medida en que haya más eslabones en las cadenas causales.

En este panorama, el papel causal de las ausencias, pese a las dificultades que erigen frente a algunas teorías y a su posible estatus ontológico, puede ser entendido como parte de la historia causal de los eventos, pues configuran modos alternativos de propagación de influencia causal. Intuitivamente aceptamos que la ausencia es una causa legítima, pese a que las causas efectivas son otras, con lo cual sería útil considerar que estas causas lo sean de manera indirecta, es decir, que la ausencia permita que otra secuencia causal de sucesos ocurra. Una ausencia desconecta una secuencia de eventos: no necesitamos elevar lo inexistente al papel de causa 0 de factor causal; la ausencia es la característica notable de una secuencia de sucesos que consideramos interrumpida en comparación con otra historia de la cual conocemos su resultado probable. En otras palabras, el papel causal de la ausencia es indirecto pues es el medio por el cual se alteran condiciones necesarias para la producción de un efecto, produciendo una historia diferente y permitiendo que otros factores propaguen la influencia. De modo que la solución a la planta muerta no consiste solamente en que el encargado del riego incumplió con su deber, pues las influencias causales físicas se propagan por otra vía: la planta tiene como condición necesaria 
para su subsistencia el suministro de agua; la falta de riego altera esa condición, con lo cual el efecto se produce. El encargado del riego realiza una actividad cíclica de suministro de agua que es interrumpida, pero la muerte de la planta no es inmediata, lo que es inmediato es la alteración de la condición que propaga la influencia causal, alteración que incrementa progresivamente su efecto a medida que las necesidades de agua de la planta no son satisfechas, causando el progresivo deterioro que lleva a su muerte. Una elipsis en el razonamiento y en el lenguaje nos permite adjudicar la causa y la culpa al jardinero, pero no puede olvidarse que es una elipsis y que la influencia causal requiere de una serie de condiciones sin las cuales la omisión del jardinero no habría sido efectiva: si la planta está en un medio natural tiene mecanismos que no la hacen depender de riego artificial o si se encuentra en un invernadero sus necesidades de líquido son menores, o si entra en un estado de latencia tampoco necesita de agua durante una temporada.

Igual análisis puede hacerse con respecto a la prevención: un agente actúa con el fin de impedir que una condición con influencia causal, una condición necesaria, pueda actuar en una situación, con lo cual el efecto de esta condición no se produce. Puedo detener un balón que va hacia mi ventana. $\mathrm{O}$ puedo poner una reja de metal, con el mismo efecto. En cualquiera de los casos lo que se quiere es impedir la rotura del vidrio, cosa que no sabemos si ha de ocurrir o no, pero para el caso en que un balón se dirija contra mi ventana, con todo el aspecto de condición suficiente para la rotura, la reja hace que el balón rebote y que su impulso no sea descargado en el vidrio; también, como en el caso de la omisión, expresamos lo que sucede en la prevención mediante una elipsis. La prevención no impide directamente la producción del efecto, ya que este puede no producirse por otras causas, sino que altera el conjunto de condiciones de una situación causal, mediante el cambio de uno o más factores; esa alteración lleva a una nueva situación, diferente aunque comparable, a la del mundo en el que el efecto podría producirse: podría incluso haber transmisión de energía, como en el caso del balón que golpea con un obstáculo, pero esa energía disipada ya no puede afectar al vidrio que, de no existir el obstáculo, hubiese sido roto. La comparación es válida con fines heurísticos, científicos o judiciales, pero no hay que olvidar que se compara con una especie de mundo virtual en el que las situaciones son diferentes, no es una situación del mundo real en el que las cosas ocurrieron efectivamente.

En alguna medida ausencias y omisiones son apenas nombres comunes para enunciados contrafácticos que comparan la sucesión ocurrida con la secuencia de eventos esperada porque corresponde a las leyes de la naturaleza, de manera que no son causas en estricto sentido, sino a 
lo sumo causas indirectas, si las consideramos como parte de un evento, compuesto por multitud de factores. Se formula como un contrafáctico porque está hecho a posteriori y en contraste entre por lo menos dos vías alternativas pero, si dejamos de lado nuestro interés epistémico, las influencias causales fluyen como el agua colina abajo: si hay un obstáculo en una vía, hay otras diferentes por las cuales puede seguir su cauce. Así que parece mejor optar, dado que la ausencia impide el contacto, la trasmisión o la influencia física entre objetos, por aceptar que la causa relaciona eventos, es decir, es ese conjunto de factores reunidos lo que constituye la causa. Esta opción parece más factible dado que la relación entre causa y efecto no es una relación binaria entre dos objetos simples sino que depende de un contexto causal de factores más o menos complejo, en el cual la ausencia de cierto factor es significativa si existen otros que toman el papel causal. La existencia de causas por ausencia es un argumento fuerte a favor de la fortaleza de los aspectos pragmáticos de la explicación causal, pese a la dificultad de enmarcarla en el campo de los hechos: que vinculemos una ausencia con ciertos efectos, parece necesario para obtener cierta explicación. Sin embargo, es evidente que las interacciones ocurren entre objetos del mundo, no entre los enunciados con las que los describimos. De ahí la importancia de detenernos tanto tiempo examinando una cuestión que parecía simplemente una particularidad entre las secuencias causales: a pesar de que tienen una extraña ontología, las ausencias y prevenciones tienen una notable importancia epistémica en la medida en que permiten reconstruir la historia causal de los procesos y encontrar explicaciones a ciertas situaciones reales. Además nos permiten entender hasta qué punto puede hacerse una separación entre causas propiamente dichas y condiciones, que es lo que se tratará a continuación.

\subsection{Condiciones o causas}

En las diversas teorías sobre las posibles características de la causa, se considera en qué medida es posible diferenciar un factor como el causante, como el factor que constituye la diferencia frente a la multitud de condiciones que conforman el entorno de una relación causal; el objeto de examinar el problema de las ausencias era precisamente el de trabajar con los límites de lo que se puede denominar relación causal y de sus posibles elementos, a fin de comprender en qué medida se puede hablar de condiciones, o de causas propiamente dichas, lo cual no genera consenso, pero es un problema fundamental para entender y definir qué es la causa. Visto está que se ha intentado hallar una teoría que dé cuenta de qué es aquello que permita unificar las múltiples manifestaciones del vínculo entre la causa y el efecto pero no hay acuerdo pleno en cuanto a si 
estamos hablando de diferentes manifestaciones o de vínculos esencialmente diferentes. Con esa limitación se intentará abordar el problema de hasta qué punto o en qué circunstancia se puede hablar de la diferencia entre condiciones y causas propiamente dichas.

Para que un evento suceda se requiere de un conjunto de factores sin los cuales una relación causal no opera, de modo que aun cuando identifiquemos una causa como eficiente, este factor eficiente puede operar solamente en presencia de otros factores que son necesarios para que el efecto ocurra. Si lo que llamamos causa es una alteración en una sola de las circunstancias previas a la ocurrencia de un evento, de manera tal que sin ella el evento no ocurre, esta alteración sería el factor suficiente. Se suele expresar esta situación en relación a un enunciado contrafáctico: si la condición no se da tampoco el efecto; y esa condición es suficiente si el efecto ocurre siempre que se dé esa causa. Formulado así, lo que se aprecia es que todos los factores previos son condiciones, solo que una de tales condiciones la identificamos como causa en la medida en que se demuestra suficiente. En la práctica, no suele suceder que un factor aislado opere como única causa, salvo en casos muy simples como en las situaciones controladas de los experimentos, pero aun así, para que el factor transmita la influencia causal, son necesarias las condiciones de trasfondo que permiten que la causa opere. Esta consideración sugiere que es necesario examinar con más detalle hasta qué punto puede hacerse una diferenciación entre la causa eficiente y las condiciones de trasfondo.

Las reflexiones sobre las causas han enfatizado las actividades de agentes que producen el efecto y buscando sus análogos en los sucesos naturales; tal sesgo lleva a privilegiar las causas eficientes como los factores legítimamente causales de ciertos resultados. Ese énfasis ha estado presente en una parte importante de la historia de la discusión sobre la causa: para la época del mecanicismo, no era tan interesante la finalidad que puede derivarse del porqué de la relación causal sino más bien el cómo. Esta idea puede encontrarse en varios autores modernos, como Descartes, quien considera que las causas finales no son las que debemos buscar sino las eficientes, las cuales operan por contacto (en oposición a la acción a distancia de la gravedad newtoniana). Hume deriva la conexión necesaria de la unión constante; nuestra mente observa ciertas secuencias de objetos induciendo la existencia de un enlace constante, tomándolo como un indicio de necesidad; por tanto, aquello que consideremos como causa lo debe ser en relación a otras que tienen su misma cualidad, por eso tal cualidad debe ser propiamente considerada la causa. Hoy podríamos hablar de la búsqueda del factor diferencial, dentro del conjunto de factores que preceden al 
evento, factor que es común a diversas situaciones y que nos da la pista de aquello que podemos considerar la causa de un tipo de secuencias.

La octava regla de Hume (1896, p. 95) para la identificación de las causas afirma que si un objeto subsiste sin un efecto, no puede decirse que espontáneamente lo produzca, pues sería necesaria la intervención de algún otro factor (other principle, en sus palabras) para que se diera un cambio: una situación en la que se presenta cierta estabilidad no puede salir de ese estado a menos que algún factor adicional intervenga y produzca un cambio en el estado, factor capaz de influencia y acción, que implica la existencia de causas compuestas. La posición regularista de Hume conlleva que la identificación de una causa implique acudir a las relaciones invariables que se producen entre tipos de eventos, pese a que no siempre es factible la comparación directa, ya sea porque no conocemos más casos o porque el hecho sea accidental, lo cual no indica que carezca de causa. La conexión necesaria no es observable como un color, olor, sonido u otra sensación: de hecho, la conexión causal no es una sensación sino una relación entre eventos concretos, cuya presencia conocemos siempre que percibimos que ha habido un cambio en el entorno espaciotemporal de otro cambio. Pueda que nunca tengamos plena certeza de que ese haya sido el único cambio, pero lo mismo puede decirse con respecto a la regularidad humeana: tampoco podemos estar completamente seguros de que conozcamos un número significativo de casos o de que tal regularidad carezca de excepciones desconocidas; además, atenernos a la conjunción constante no nos da pistas acerca de cómo diferenciar entre los factores presentes cuál sea suficiente para el efecto, o de qué factores podemos prescindir para que el efecto aún se produzca, ya que no hace explícito que pueden existir muchos factores irrelevantes.

Frente a esto, D ucasse (1924, p. 81) afirma que se debe buscar la diferencia particular, el único cambio en el entorno, que en ciertas circunstancias da cuenta de determinado efecto; de manera que la causa es una alteración singular de las circunstancias, y el hecho de que esta sea recurrente es irrelevante para la identificación de la causa, es decir, que no importa si la secuencia de causa a efecto se repita o que no lo haga, esto no hace que una causa sea o deje de serlo: la relación causal existe esencialmente entre eventos concretos y si se elabora una ley es porque existen otros eventos similares, presentan alguna recurrenciay se llega a ella por vías estadísticas. Asociamos la causa a la eficacia o a la suficiencia de alguna característica particular que opere dentro de ciertas condiciones, de forma que si estas se encuentran vinculadas a la causa principal, es como parte del entorno o como causas secundarias. Solo la unión de ese conjunto de factores es lo que 
constituye una causa necesaria y suficiente, aunque seguimos sin encontrar la guía que nos permita diferenciar causas de condiciones, si es que esto es posible.

A diferencia de Hume, D ucasse (1968, p. 11) afirma que las causas pueden ser observables, en la medida en que percibimos una secuencia particular, una relación causal entre eventos, mientras que no es posible observar el conjuntos de ellos: para tener una noción sobre el conjunto acudimos a la abstracción y a la comparación, lo cual implica aislar previamente las secuencias, además de ignorar algunas de sus diferencias, labor común en la elaboración de conceptos. D ucasse parece referirse a una percepción desnuda, esto es, al hecho de que podemos percibir casos concretos en los cuales parece evidente la relación causal, pero la única manera de que esto se convierta en un concepto útil es que podamos ordenar nuestras percepciones inmediatas mediante su puesta en relación con observaciones similares para elaborar así un concepto aplicable de causa a situaciones análogas, o que conozcamos detalladamente los mecanismos causales que inciden sobre la producción del efecto. Además, el autor ve otra confirmación de que nuestra visión es singularista en el hecho de que el lenguaje sustituye el verbo causar por otros más específicos (D ucasse, 1968, p. 8), quedando la palabra causa como el nombre común para aludir al cambio en el entorno, capaz de producir un efecto. D e nuevo, acá podemos ver un signo que apunta hacia la abstracción implicada en el concepto y en el lenguaje, pero que no constriñe a la realidad: aceptamos que los eventos son en algún sentido únicos y que los reunimos bajo un solo concepto para poder encontrar las regularidades que nos permitan entender el mundo.

Para Mill (1973, p. 339) la ley de causalidad es un componente básico de la uniformidad de la realidad; pero, puesto que no toda sucesión es causal, debe existir una conexión necesaria (es decir, incondicional) que, excluya otro tipo de sucesiones. Esto implica contar con el conjunto completo de condiciones para que el efecto ocurra, ya que la incondicionalidad significa que no hay variación bajo cualquier circunstancia. Sin embargo, hay que decir que este tipo de incondicionalidad es un tanto extraño tanto a nivel teórico como práctico, dado que las condiciones suficientes de unos efectos no siempre son sus causas, como se puede ver en el conocido ejemplo del poste: la longitud de la sombra y la posición del Sol permiten determinar la altura del poste, pero esto no quiere decir que la causen, pues está determinada como producto de otra secuencia causal. Mackie elabora una versión modificada de la condición suficiente: un cortocircuito es la causa de un incendio pero no es necesario ni suficiente, sino una condición Inus. En principio, algunas causas se comportan como condiciones necesarias y otras como suficientes, pero hay 
que indagar más al respecto pues determinar qué sea necesario y qué suficiente puede depender del contexto de indagación que se haga sobre la situación particular que se esté estudiando, de la delimitación de los factores pertinentes en el caso, es decir, de aquellos factores que solemos relegar al papel de condiciones necesarias o de trasfondo causal, pero que no tienen la característica eminencia que solemos ver en la causa eficiente.

Ducasse afirma que lo único que puede ser causa o efecto es un evento, es decir, identifica la causa con una relación entre eventos concretos, una relación entre dos cambios o entre ausencias de cambio de un objeto, ya que estos, por sí mismos, solo son agentes o pacientes. Para Mill no hay un clara distinción entre causas y condiciones, pero una cosa es ser suficiente, otra necesario y otra ser ambos; Ducasse (1993, p. 128) califica de absurda la afirmación de Mill de que la diferencia entre causa y condición es arbitraria, pues identifica la causa con un único cambio en el entorno del efecto, en las condiciones pertinentes. Ahora, la cuestión es que lo más común no es que se presente una única alteración en los factores previos a la producción del efecto: lo más usual es que exista una multitud de cambios y no siempre es factible apreciar cuál es el cambio que puede ser considerado como el factor determinante de la aparición del efecto, cuestión que no parece ver D ucasse. De la misma forma, puede que no toda la causa sea observada y que no tengamos datos confiables para delimitar el entorno pertinente; por otra parte, no siempre sucede que haya proporcionalidad entre causa y efecto - un indicio habitual para determinar la incidencia de un cierto factor causal- que permita detectar por el incremento del factor causal si hay o no un correspondiente aumento del efecto.

Mackie (1999, p. 260) busca la suma mínima de factores causalmente relevantes, dada la necesidad de limitar el alcance de las circunstancias y condiciones causales, pues de otra forma todo sería causa de un evento; estas son las características necesarias para la ocurrencia del efecto. Esta suerte de historia causal del efecto pone en relación la conjunción de características de la causa con su consecuencia, de manera que la regularidad nos reporte la necesidad de la causa y aún su suficiencia para el efecto; al reunir todas las características causalmente relevantes, esta regularidad sería un patrón de persistencia. Ahora bien, Mackie (1999, p. 269) reconoce que los enunciados explicativos no implican ni constituyen regularidades, ya que no deben confundirse las causas en tanto explicación de las causas en los hechos. El conocimiento completo es un ideal, como se hace patente cuando se juzgan los actos humanos: puede haber una explicación que apele al conjunto de interacciones físicas o materiales diferente de aquella que atiende a las motivaciones 
de quien realizó el acto. Se ha definido una causa en términos de suficiencia si existe una condición y una ley que dé cuenta de su regularidad (Sosa \& Tooley, 1993, p. 6), pero esto implica que no hay restricción a las condiciones en cuanto a su independencia, lo cual no nos da mucha información acerca de las vías de influencia causal.

Salmon (2002, p. 109), en lugar de centrarse en los factores aislados, cuya consideración está mediada por elementos pragmáticos y de contexto, propone tomar en consideración la estructura causal completa, es decir, la red de procesos e interacciones causales de una región elegida (Salmon, 1993, p. 152), aunque no parece contemplar las enormes dificultades de llevar esto a cabo, pues en múltiples casos la complejidad de los procesos obliga a acudir a modelos estadísticos 0 simplemente a seleccionar los factores que puedan ser puestos en un modelo comprensible: una descripción exhaustiva de las causas suele ser impracticable, pues no siempre se conocen todas las condiciones ni se sabe previamente qué tan relevantes sean. Por otra parte, vivimos en un universo en que no hay discontinuidades abruptas, de manera que los cambios suceden sobre persistencias parciales: un dato más a tomar en cuenta para modificar la imagen del pegamento causal entre la causa y el efecto; es más apropiado hablar de procesos (no en el sentido de Salmon, sino como cambios graduales) que se modifican por medio de interacciones normalmente compuestas por multitud de factores con más o menos capacidad de alterar el proceso. Si no es tan evidente como se pensaba el punto de unión entre la causa y el efecto tampoco será muy claro el papel de un factor como si fuese el único capaz de transmitir su influencia.

Volviendo a Mackie y al problema de las condiciones, este entiende que un evento es la causa de otro si el primero es la condición sin la cual no se presenta el segundo (Mackie, 1999, p. 31), partiendo de que esta condición necesaria opera entre eventos reales e independientes, pero la dificultad consiste en la diferenciación entre condiciones y causas, pues no hay reglas que diferencien qué factores han de ser considerados como causas: en principio, esperamos que los eventos tomen el camino que es más usual, y si este no es el caso, buscamos el factor o factores que presenten una anomalía capaz de alterar la futura secuencia de eventos. De ahí que se aluda a lo normal o a lo usual como las condiciones, es decir, el conjunto de factores que suele estar presente en las situaciones a las que estamos habituados, pero lo que se reputa como causa suele asociarse a lo que se considere en alguna medida como anormal; así, en un incendio se habla más de la chispa que del material inflamable como el factor causal, dado que es la característica que 
emerge sobre un trasfondo de condiciones que podríamos llamar - figuradamente- plano. El efecto no es un objeto simple sino un evento, y si este cambia es por una alteración del conjunto de factores que confluyen a la aparición de un cambio, esto es, de su campo causal2 ${ }^{2}$ D ebe distinguirse entonces entre unos factores que predisponen y aquellos que desencadenan un evento: un conjunto de factores de base que constituirían el conjunto de condiciones necesarias y un factor eficiente dentro de tales condiciones para la aparición del efecto, sin olvidar que todos ellos son causales. Mackie habla de "causa relevante”, pero no logra precisar claramente el alcance de esa relevancia: un factor causal puede ser necesario, pero no suficiente, pese que la noción común de causa busca encontrar el factor que es necesario y suficiente en las circunstancias para producir un efecto; ahora, esta limitación a las circunstancias implica algún grado de insuficiencia, es decir, que el concepto común sería más probabilístico que determinista, como en el caso de la imprudencia que causa un accidente: el descuido que en circunstancias normales es intrascendente, en condiciones de riesgo incrementa la probabilidad de un resultado adverso, así que las causas no son solo necesarias sino también suelen ser suficientes en ciertas circunstancias (Mackie, 1999, p. 50). La cuestión es que lo que sean las circunstancias es propiamente el contexto de la situación y este puede ser ampliamente variado e incluso dependiente de una apreciación contextual, como en el caso de la definición de una situación de riesgo: cuando el invento del automóvil era reciente se consideraba que una velocidad de 30 kilómetros por hora era incluso peligrosa en sí misma.

Se ha definido la causa como necesaria, frente a la contingencia del efecto, en cuanto este depende de que ocurran las condiciones que le dan origen. Mackie define lo necesario y lo suficiente afirmando que una condición es necesaria en relación a un enunciado contrafáctico que vincula la condición con el efecto. Si ocurre un efecto, esto implica que el conjunto de eventos previos es la serie mínima que configura la condición suficiente: si no se da completa el efecto no ocurre, esto es, cada factor es insuficiente, teniendo en cuenta que pueden ocurrir otros conjuntos de condiciones capaces de producir el efecto. Es la mencionada condición Inus, una parte insuficiente pero no redundante de una condición innecesaria pero suficiente (Mackie, 1999, p. 62). También para Mill la causa es el conjunto de condiciones, pese a que en el uso común se busque llegar a un factor único, cuestión importante en experimentación, en la cual se diseñan situaciones controladas que buscan determinar la relevancia que algún factor pueda tener en la aparición de un efecto: de

${ }^{2}$ Mackie (1999, p. 35, nota 3) señala que la idea de "campo causal" fue introducida por John Anderson en "The problems of causality". 
ahí que se proceda a alterar un solo factor cada vez con el fin de descartar la posible influencia causal de otros elementos. La construcción de casos de control en experimentación, en los que se repite una situación para comprobar la relevancia de algún factor es una forma de poner en práctica la búsqueda de tal condición.

Por su parte, Woodward (2003, p. 51) afirma que una condición es suficiente si hay una sola intervención posible en cierto valor que sea capaz de alterar el valor de un efecto, de manera tal que ese valor es su causa; la condición es necesaria si al intervenir sobre la causa se altera el valor del efecto; también habla de causas contributivas y totales, diferenciadas en la medida en que operen con las intervención de otras variables o sin ellas, respectivamente. Woodward, recordemos, define la causa en la medida en que puede identificarse un factor sobre el cual, hipotética 0 realmente, puede intervenirse, es decir, alterarlo con el fin de obtener una variación en el efecto: la relación causal es invariante a algunas intervenciones, de modo que en la relación causal existen algunas variables cuya presencia no es determinante; no son suficientes para producir el efecto, pero son causas contributivas porque son necesarias para la realización del efecto. A hora, lo que no es del todo claro es cómo podríamos difenenciar lo que el autor denomina causas contributivas, frente a lo que otros autores llaman condiciones: en su ejemplo sobre el volumen de un radio (Woodward, 2003, pp. 96-97) afirma que el hecho de que esté encendido es causa contributiva para subir el volumen, pues no puedo hacerlo si el radio está apagado. Pero también se puede decir o bien que para subir el volumen debe cumplirse la condición de que no esté apagado (no causa contributiva sino condición de trasfondo), o bien que el encender el radio es elaborar una secuencia causal diferente. La teoría de manipulación es útil para dar cuenta de causas en muchos casos pero es posible que mejorara haciendo un manejo más adecuado de las condiciones, puesto que no parece aceptable definir como causa contributiva cualquier variable que acompañe al proceso causal, al fin de cuentas muchas de ellas son irrelevantes para el resultado y no siempre es evidente cuáles son.

A hora, la cuestión es que para poder asegurarnos del papel que tiene o puede tener la intervención sobre una situación es necesario comparar una situación real con una virtual, de dos mundos, uno real y otro hipotético, uno con el efecto y otro sin él. Puesto que no podemos tener experiencia de ese mundo hipotético, habrá que apelar a las regularidades de las leyes naturales para prever cómo se habría de comportar con el conjunto de circunstancias del mundo real, salvo un factor. En las teorías contrafácticas la comparación entre mundos alternativos en los que se pueden 
producir o no efectos no siempre es factible y por eso los factores que consideramos las causas totales o suficientes (los que son contrastables con los contributivos) dependen del estado del conocimiento del momento y por tanto de lo que se considere causalmente relevante. D e todas formas Woodward acepta que las teorías van cambiando para hacerse más adecuadas a la realidad, lo cual implica que nuestras interpretaciones sobre cuáles son las causas suficientes también habrán de variar con los alcances del conocimiento, es decir, con la capacidad explicativa de las teorías científicas. Sin embargo, Lewis (1986, p. 163) afirma que la comparación entre mundos posibles de la que depende la visión contrafáctica, conlleva cierta vaguedad, dado que no puede ser completamente resuelta y que además debilita la idea de causación: al final la regularidad puede ser remitida a las leyes de la naturaleza. Lewis afirma que la definición regularista de Hume sigue dominando la filosofía de la causalidad, pues se asume que la relación causal particular es una instancia de una regularidad. Afirma que el regularismo actualmente intenta distinguir las leyes causales de las sucesiones accidentales, apelando a las regularidades relevantes en el caso pues no puede ser tomada en cuenta la totalidad de factores que preceden al efecto, puesto que la causa, en términos generales es "[... ] any member of any minimal set of actual conditions that are jointly sufficient, given the laws, for the existence of the effect" (Lewis, 1986, p. 159; igual definición en Lewis, 1993, p. 193).

Lo que hay que ver es si el análisis regularista logra distinguir la causación genuina de otras relaciones, tales como las prevenciones potenciales alternativas (preemtion). Lewis cree que no, que es mejor una alternativa contrafáctica bien entendida, que se ocupe de relaciones entre eventos particulares y no de generalizaciones; sin preocuparse en la distinción entre causas y condiciones (ni por cuál es la causa principal), ni lo anormal o extraordinario bajo condiciones deterministas, esto es, regidas por leyes pero no por una causalidad ni predictibilidad universales. La cuestión es que al comparar los mundos alternativos habría que precisar qué tan cercanas o lejanas son las divergencias del mundo real con el supuesto y Lewis no ve la posibilidad de que las leyes naturales permitan tal divergencia. De ahí que afirme que bajo el determinismo aualquier divergencia, cualquier comportamiento alternativo requiere de alguna violación de leyes, dado que asumir las leyes de manera rígida implicaría que para cambiar un efecto habría que alterar todo el pasado (Lewis, 1993, p. 203); si tomamos el universo como un único evento, es claro que no puede ser causado por nada distinto de él mismo: no habría más causas y efectos que las interacciones entre sus partes. Pero esto es considerar demasiado estricta la noción de determinismo, ya que el hecho de que existan leyes deterministas no implica que las secuencias causales sean plenamente 
previsibles e infranqueables: las leyes pueden ser rígidas (lo son, pero dentro de campos muy acotados) y sin embargo los comportamientos de los objetos reales no son siempre previsibles 0 lo son apenas en alguna medida. Así sucede con una peonza en movimiento: puede tropezar con una pared o ser empujada y aun así recuperar la perpendicularidad de su eje, mientras su movimiento de giro sea suficientemente rápido; en la medida en que se ralentiza va perdiendo estabilidad. No hay nada de indeterminismo en todo esto y mucho menos violación de leyes, pero esto no implica que los movimientos de la peonza sean predecibles.

Ante la diversidad de este panorama es conveniente dar un paso atrás, para revisar los propósitos del análisis causal. Si lo que queremos hacer es declarar la validez de una situación hipotética contrastada con otra real, la cuestión es que hay una infinidad de mundos factibles en los que muchas cosas podrían ocurrir, aun si nos limitásemos a los casos relativamente sencillos como el de rascar una cerilla: es necesario que esté seca, que no se parta, que haya oxígeno, que no haya viento, etc., solo que estamos acostumbrados a privilegiar el factor de la actividad del agente como el verdadero causante, pero no hay que olvidar que en otras circunstancias cada condición pueden tener un mayor papel causal. La economía del lenguaje hace una comparación tácita con otras situaciones posibles, de manera tal que evita aludir al oxígeno como causa porque siempre estamos en su presencia (Pinker, 2007, p. 287), mientras que rascar la cerilla es un acto que emerge en el mundo. Es evidente que no siempre es posible encontrar un factor privilegiado pues suelen ser múltiples y correlacionados, tal como se ve con los catalizadores en una reacción química: no son los causantes, pero pueden ser indispensables para que otros factores actúen. Y si miramos situaciones menos simples el panorama es más difícil pues, por ejemplo, cómo puede determinarse la causa de un cáncer de pulmón de una persona que respira constantemente el aire contaminado de una ciudad y que también fuma, qué lo diferencia del vecino que respira lo mismo y fuma, pero no tiene cáncer, o cómo actúan esos factores frente a una mayor participación en ejercicio aeróbico, o qué tanto puede influir la alimentación o la vida en un medio rural. Lo que estamos buscando es cierta condición a la que damos el nombre de causa, un factor más eminente o controlable.

De nuevo estamos frente a la pregunta de qué es aquello suficiente para que un evento ocurra, esto es, que si vamos suprimiendo condiciones, cuál es aquella cuya supresión impide que el evento ocurra, o desde otro punto de vista, cuál es el factor común que precede cierto tipo de eventos (Mackie, 1999, p. 137). Hay que tener en cuenta que el orden en que suprimamos los 
diversos factores puede ser crítico y la interpretación de resultados comporta alguna subjetividad, pues incluso lo que podamos entender como un efecto puede ser puntual, pero también puede ser la continuación de un proceso: en un ejemplo de Mackie (1999, p. 142), un cristal se puede romper porque vibra en consonancia con un sonido, caso en el que la rotura es un momento culminante de un proceso progresivo, un tanto diferente a la rotura causada por un golpe, que solemos apreciar como emergente e instantáneo.

Para Mill (1973, p. 329) un efecto se produce por la conjunción de una serie de factores positivos, indispensables, pero privilegiamos uno, el último que incide, y lo llamamos causa; para el autor la causación es más que sucesión regular; la secuencia, aparte de invariable, debe ser incondicional, si es lo suficientemente robusta para que no dependa de otros factores, lo que excluye los eventos que obedecen a una causa común. Mill plantea como vía para identificar la causa los métodos de acuerdo y diferencia: el primero consiste en hallar un factor común a diferentes conjuntos cuando el efecto ocurre, esto es, que hay un conjunto común de condiciones que son seguidas por el efecto. El método de diferencia implica que hay un factor que diferencia el conjunto de condiciones antecedentes con respecto a otros conjuntos de condiciones similares en que el efecto no ocurre, lo cual nos permite identificar la causa (Mill, 1973, p. 392). Conocidas son las limitaciones que los métodos de acuerdo y diferencia de Mill tienen en la identificación de factores causales, pues el número de posibles causas no puede ser muy grande y sería necesario que la relación causal sea invariante, esto es, que las mismas causas tengan los mismos efectos. En realidad, los casos se presentan con mayor complejidad a la de tal esquema, involucrando causas múltiples, correlaciones espurias, apantallamientos, es decir que la utilidad del método está restringida a los casos de causación lineal. Además, como no se diferencia entre causas y condiciones, tampoco se pueden identificar algunos factores irrelevantes.

D ucasse (1924, p 126) también critica los métodos de acuerdo y diferencia de Mill, por limitarse a la causación singular, y los entiende, más que como métodos, como definiciones de necesidad objetiva y suficiencia. D ucasse sostiene que es posible diferenciar la causa de las condiciones, en razón a que la causación concierne a los casos singulares y no a la conjunción constante, sin embargo, su concepción singularista tampoco parece dar plena cuenta de lo que sea la necesidad, que es más una cuestión relativa a la recurrencia de eventos y no es propiamente perceptible. D ucasse (1924, p. 87) entiende que la diferencia entre causa y condición se da en los siguientes términos: la causa es un cambio en las circunstancias antecedentes que es suficiente para producir 
el efecto; mientras que la condición es un cambio, o más frecuentemente un estado, que se revela necesario una vez ocurrido el efecto; es decir que solo a posteriori podemos declarar la necesidad de las condiciones. Mill, en cambio no ve ningún criterio para distinguir la causa de sus condiciones, ya que no hay acuerdo común al determinar entre los diversos factores cuál merece el estatus de causa, pero, señala D ucasse (1968, nota 1, p. 4), Mill incurre en contradicción cuando caracteriza la causa como la única diferencia en las circunstancias y a la vez define la causa como la suma de condiciones. Al parecer, la contradicción radica en que se apunta hacia cosas diferentes, ya que D ucasse hace referencia a los eventos singulares que identifica como los legítimamente causales, puesto que la definición de causa debe orientarse, más que a la universalidad, a la posibilidad de responder a la búsqueda de la causa de eventos concretos; mientras que Mill considera prioritaria la búsqueda de regularidades o de leyes. Para el primero parece evidente que existe un cambio - lo que es propiamente la causa- , una circunstancia situada entre el momento del efecto y el momento que lo antecedió, y los factores que se mantuvieron sin cambio son las condiciones; en su visión, la conjunción constante constituiría un valor añadido, en los casos en que realmente se presente, pero no se la puede considerar como definición de la causa.

La definición de causa no puede implicar que algo sea necesario y suficiente, ya que de esta forma tendríamos que hacer un recuento inagotable de la multitud de circunstancias que hacen posible el efecto; solo se asume que existe un cambio en el conjunto de circunstancias, que es suficiente para la ocurrencia de un evento. D ucasse afirma que si un antecedente es un estado, lo usual es que este sea una condición y no una causa; que la causa deje su estado para producir un efecto es inaceptable si la causa engloba las condiciones: una bola de billar se vuelve causa si choca con otra, es decir, cuando cambian las circunstancias. En la medida en que sumamos factores al entorno de un efecto reducimos la probabilidad de que un evento similar se repita, lo cual priva al conocimiento causal de la capacidad de prever el futuro. Sobre la conexión causal D ucasse (1968, p. 2; también en 1924, pp. 122-123) refiere cuatro posibilidades: 1- el estado 0 cambio de un objeto como la causa que es objetivamente suficiente para el cambio o estado del otro; 2- el estado o cambio de un objeto que haya sido necesitado por el cambio o estado del otro; 3- la condición, es el estado o cambio de un objeto si fue necesario para el cambio o estado del otro, y 4- es resultante si fue contingente con respecto al cambio o estado del otro. En resumen, las situaciones posibles pueden ser causa, efecto, condición o resultante. 
La diferenciación entre estado y cambio, pese a que no sea la respuesta definitiva y concluyente, parece dar un indicio claro de alguna diferencia entre causa y condición: la condición suele ser el estado de un parámetro, normalmente invariable en el lapso entre el inicio y el final del cambio sucedido. Mientras tanto, lo que entendemos como causa suele ser más un cambio, pues lo asociamos a la emergencia o aparición de un hecho en el mundo, con suficiencia para prolongarse en sus efectos. Ducasse limita innecesariamente su tesis al defender que el único cambio en la contigüidad espaciotemporal del efecto es lo que puede ser reputado como causal, pero esto implica dejar sin explicación muchos de las situaciones que son comunes en las relaciones causales, es reducirlas a la visión mecánica de las bolas de billar, en las que claramente se puede ver que un movimiento de una bola está producido por el hecho de que otra la golpea. Lo usual es que existan simultáneamente más de un cambio previo al efecto y si esto es así el criterio diferencial no nos permite separar los cambios relevantes de los irrelevantes para el efecto. Fuera del mundo mecánico hay cantidades de ejemplos en los cuales no es discernible que exista un único cambio en el entorno. El ejemplo típico de las situaciones impredecibles, el de la lluvia, implica un gran conjunto de factores y de cambios cuya discernibilidad dista de ser clara: viento, humedad, temperatura, orografía, radiación solar. Seguramente si pudiese identificarse el papel de cada uno de los factores sería más factible hacer una predicción del tiempo acertada para un lugar determinado, pero lo que vemos es que esa multitud de factores mantienen entre sí relaciones de realimentación que impiden el tipo de predicción o de determinación causal de A a B. Por eso exigen otro tipo de tratamiento, basado más en el comportamiento estadístico del clima que en dilucidar las relaciones causales lineales entre algún factor y la multitud de estados y cambios de la atmósfera.

D ecimos que limitar las condiciones a estados apenas nos da un indicio para diferenciarlas del factor eficiente pues esto depende en gran medida de las características particulares de cada fenómeno a analizar, lo cual indica que no hay una base firme para una separación objetiva entre ambas categorías. Partimos de reconocer que el estado normal del universo y de sus partes es el cambio, pero el cambio sucede con respecto a algunas variables cuyas medidas se alteran mientras que otras permanecen constantes. Por ejemplo, el cuerpo ideal en estado inercial de Newton no recibe el influjo de ninguna fuerza y por eso se mantiene en un estado que se llama movimiento 0 reposo en relación al movimiento o reposo del observador (y descontando la influencia gravitacional del observador). Lo que sucede en la realidad es que un cuerpo se mantiene en movimiento mientras no interactúe con fuerzas capaces de alterar su estado: su masa y velocidad 
se mantienen constantes mientras cambia su posición. Que esto sea un cambio o un estado es indecidible en general y solo puede definirse con respecto a las variables pertinentes: si es un asteroide que se dirige hacia Júpiter o hacia la Tierra, es muy pertinente determinar su velocidad y los cambios de dirección que pueda presentar su trayectoria con respecto a nosotros, pero puede considerarse como un movimiento inercial. Una misma situación puede percibirse como movimiento o como estado de reposo, un ejemplo de que la afirmación de que los estados se comportan más como condiciones es insuficiente para diferenciar si un determinado factor previo al evento es eficiente. Pero no se puede descartar como indicio: si nos remitimos al caso de un incendio forestal, lo usual es que haya un trasfondo causal en el que no se presenten variaciones notorias, tales como la presencia de oxígeno y si es verano la presencia de material combustible seco (y de pirómanos, que al parecer se activan en verano). Pero se necesita un cambio que emerja y desencadene el efecto cuando se presentan las condiciones necesarias: puede ser un pirómano real, que actúa por medio de un mechero; puede ser una descarga eléctrica, puede ser el descuido de un fumador. Todos estos posibles factores emergen sobre un trasfondo causal que vemos como plano, pero que no lo es por completo: si la temperatura es alta, el viento es fuerte y la atmósfera está seca se incrementa la probabilidad de que el factor saliente tenga la posibilidad de que el incendio se produzca, pues en otras condiciones puede apagarse espontáneamente. Entonces se ve que en efecto hay un factor causal emergente, pero que el trasfondo causal no es tan plano, es decir, que no es un único cambio el que produce el incendio, de manera que ese factor emergente actúa como desencadenante pero su operación depende de las demás condiciones causales, sin que exista un límite real y tajante, ni ontológicamente significativo entre causa y condición, de modo que las condiciones tienen tanto papel causal como el factor emergente.

En diversos ejemplos se puede ver que estamos más ante un indicio de lo que se puede considerar el factor más eficiente, la característica que sobresale en un panorama causal, un trasfondo de condiciones más o menos plano, sin olvidar que estos "paisajes causales" tienen muy diversos aspectos, desde las situaciones más evidentes en que el cambio en un solo factor tiene el poder suficiente para causar el efecto, hasta esas situaciones en que los factores causales son un conjunto erizado de "picos" de más o menos relevancia, entre los cuales no siempre es fácil hallar un acuerdo sobre cuál es más prominente y efectivo. En prototipos como el incendio de Mackie, el cortocircuito sobresale con mucho sobre los otros factores; en la rotura del vaso por un martillo, sabemos que el movimiento del martillo lo lleva a estrellarse con el vidrio de manera que su energía es suficiente para producir la rotura y, sin embargo, también habría que preguntarse 
quién mueve el martillo e incluso con qué motivo, lo que es también una causa, así como el grado de fragilidad del vidrio. Pese a que hay ejemplos de más o menos complejidad, la emergencia 0 prominencia de un factor o, más específicamente, el hecho de que un factor presente un cambio, debe ser tomado como indicio de influencia causal. Es indicio útil para determinar un papel causal, un cierto grado de relevancia en la producción del efecto, pero no hay que olvidar que no constituye la diferencia definitiva y concluyente para determinar si el factor es la causa suficiente frente al panorama de las condiciones necesarias. No parece posible que haya una respuesta definitiva ya que el contexto de las preguntas por la causa determina el espacio adecuado de indagación: hay mucha diferencia entre la respuesta que se refiere a las condiciones físicas con respecto a las que responden a la intervención de un agente, tal como se ve en la historia del padre que le pregunta a su hijo por qué la luz de una habitación está encendida, a lo que el hijo responde que porque el circuito eléctrico lleva la corriente hasta la bombilla. La respuesta es causalmente válida pero podemos presumir que el contexto que sugiere la pregunta no indagaba por una respuesta general ni física sino por otra muy diferente referida a los actos humanos, a la razón detrás de una decisión. Si hay más de una respuesta válida es porque los cambios físicos previos al efecto no son los únicos factores a tener en cuenta como eficientes y porque lo que se entiende como condición en un caso puede ser el factor eficiente en otro caso. Valga el ejemplo para reiterar que si un factor es considerado como causa por encima de un paisaje de condiciones que le sirven como panorama necesario es por razones pragmáticas que no pueden encontrarse claramente en las situaciones concretas, de modo que el contexto en el que se indaga por las relaciones causales es el espacio en el que se determina si cierto factor se considera causal 0 eficiente, pero la causa propiamente dicha está en el conjunto de factores que constituyen el evento previo al efecto, y no hay manera de establecer una diferencia ontológica significativa entre causas y condiciones.

Así que la distinción parece depender del contexto y de las teorías implicadas. Para el incendio se requiere la presencia de oxígeno, lo cual se considera normalmente una condición, pero si hablásemos de un experimento controlado el oxígeno podría ser la causa; lo que constituye una muestra de que el contexto de la indagación es determinante de lo que sea causa o condición, aunque no llega a ser arbitraria, pues en muchos casos hay acuerdo en quéfactor es más prominente que los demás: unos factores se consideran como causa principal, otros como secundarias, y otros como condiciones, en respuesta a las necesidades del contexto en que se indaga. El problema para que la causación como relación natural explique los fenómenos es que tendría que dar 
cuenta detallada acerca de la multitud de vías causales específicas, procedimiento que posiblemente tampoco dé cuenta de lo que realmente se busca, que es aquel factor del que pueda ser reputada la principal influencia causal. La teoría naturalista, dice Menzies (2012, p. 364), distingue entre causa y condición afirmando que la primera tiene un valor diferenciado mientras que las otras tienen valores por defecto, sin embargo, esta idea parece remitirse a la de la intervención, pues es esta la que se ve como una variación que sobresale en medio de un trasfondo causal más plano. Similar idea se ve en el análisis acerca de las disposiciones que operan como condiciones de los objetos que participan en la relación causal: la estructura de un objeto determina sus posibilidades y disposiciones, que son incapaces de operar de manera autónoma sin un elemento sobreviviente. Así sucede, por ejemplo con la solubilidad de la sal, que opera si le sumergimos en agua, o con la fragilidad de un cristal, que hace patente su naturaleza inestable cuando recibe un golpe. Sin embargo, ya hemos visto cómo esta separación de causas eficientes con respecto a las características del trasfondo causal, pese a su utilidad epistémica, no ofrece una diferenciación de carácter ontológico, en la medida en que depende de la indagación que estemos realizando. Y, dado que se pretende defender que el aspecto pertinente es el de la búsqueda de explicaciones causales, dedicaremos el capítulo final a indagar al respecto. 


\section{RELEVANCIA CAUSAL Y RELEVANCIA EXPLICATIVA}

The sciences do not try to ex plain, they hardly even try to interpret, they mainly make models. By a model is meant a mathematical construct which, with the addition of certain verbal interpretations, describes observed phenomena. The justification of such a mathematical construct is solely and precisely that it is ex pected to work. ${ }^{1}$

John von Neumann (1903-1957)

En el presente capítulo se hará un acercamiento a las relaciones entre explicación, causa y leyes, temas que, tanto por sí mismos como por las estrechas relaciones que los conectan, han merecido extensos estudios, razón por la cual serán tratados en el presente capítulo solamente en relación a su pertinencia para sustentar las propuestas de solución a los problemas de la causalidad que han venido siendo presentados en los capítulos anteriores. Comenzaremos viendo cómo la explicación es un concepto que puede ser entendido y manejado de formas diferentes, dependiendo del nivel en el cual se enmarquen las preguntas que dan lugar a ella y del propósito particular de comprensión de la realidad que se pretenda. Luego se hará un recuento de los modelos de explicación científica, con sus alcances y limitaciones, que nos conducirá al papel de las leyes en el conocimiento de la realidad, problema que también tiene variadas interpretaciones y límites. El propósito de recorrer todo este panorama es el de enmarcar la cuestión de la relevancia explicativa como articulación entre causa y explicación, como medio de poner en contacto y de delimitar los significados y usos de la relevancia en estos dos espacios. 


\subsection{Explicación y explicación científica}

Explicar los diversos fenómenos que ocurren en la realidad es una necesidad de la mente humana, que no se conforma con la ignorancia o la incertidumbre, ni con respuestas míticas o con trozos de información incoherente, pues sin explicaciones tendríamos en frente un mundo por completo incomprensible. Es, por tanto, un problema fundamental, no sólo para el conocimiento común, sino aún más para la ciencia y para la filosofía pues de las explicaciones se deriva nuestra representación del mundo, además de la posibilidad de prever lo que ocurre y de intervenir en nuestro entorno. A hora, la cuestión es que si este es un problema fundamental, es previsible que habrá discrepancias de fondo acerca de qué entendemos por explicar y, en particular, por los alcances de la noción de explicación científica, cuestión que es necesario tratar a fin de que podamos indagar qué relaciones presenta con la noción de causa. C ausa y ex plicación son términos usuales, tanto en la ciencia como en el habla común que, en principio, parecen relacionados en el intento de dar respuesta a nuestra necesidad de entender cómo y por qué las cosas cambian o han llegado a ser.

O riginalmente explicar significaba desplegar, exponer o desarrollar (Bunge, 1961, p. 301) y, desde el sentido común, se entiende que la explicación consiste en la reducción de lo desconocido a términos familiares, una especie de traducción de lo que no entendemos a lo que conocemos, aunque también se entiende como dar la razón de algo o encontrar su causa. Este significado común no corresponde al de explicación científica, dado que esta construye un conocimiento que no se limita a un estado subjetivo de satisfacción intelectual; de hecho, cuestiones de uso cotidiano pueden requerir de explicaciones científicas complejas (¿por qué caen los cuerpos?, ¿por qué el agua moja?), así como sucede que explicaciones con las que estamos familiarizados carezcan de base cientifica (por ejemplo, que los antibióticos curen la gripe). La ciencia ha tenido posturas muy diversas con respecto a cuál es el objetivo principal que se persigue cuando se quiere entender un fenómeno: hacer descripciones mecánicas, buscar las leyes a las que obedece o encontrar sus causas. En su intento de postular unos criterios aceptables de cientificidad, el positivismo del siglo XIX rechaza que la ciencia tenga por objeto elaborar explicaciones, afirmando que la ciencia no debe buscar una suerte de sentido profundo de por qué ocurren la cosas (Hull, 2011, p. 186); más tarde, el positivismo lógico, en el mismo sentido, cree que la explicación no necesita de la causa, dada la resistencia que esta noción presenta a ser reducida a enunciados contrastables y a que tiene cierto sesgo metafísico. Se afirma la idea de que la explicación hace 
parte de la ciencia solamente si posee la seguridad del análisis deductivo, dado que la ciencia tiene entre sus objetos describir los fenómenos, predecir con base en leyes naturales y controlar la naturaleza, pero esto deja a la explicación causal por fuera del interés de la ciencia y también de sus alcances, dado que la ciencia se caracteriza por apoyar sus enunciados en datos empíricos y el vínculo causal general se resiste a la observación.

Sin embargo, reducir el papel de la ciencia al de elaborar descripciones no ofrece el panorama completo de lo que hace esta forma de conocimiento: la descripción en principio parece dirigirse a dar cuenta de los mecanismos del evento pero no de las razones por las que ocurre, por eso puede darse el caso de que sucesos cuya mecánica es conocida y predecible, generen inquietudes porque aún no han sido explicados. D e ahí que se pueda afirmar que la descripción nos ofrece un retrato incompleto de la realidad y que la ciencia también tiene por objeto dar explicaciones que nos permitan hacer comprensible el mundo. Pese a que la discusión no termina, algunos autores aceptan que la búsqueda de las causas también puede ser considerada uno de los objetivos legítimos de la ciencia, entre otras formas de explicación posible. En esta dirección fue de crucial importancia que la concepción heredada aceptara la posibilidad de que la ciencia ofrezca explicaciones de los hechos: en el trabajo "Studies in the Logic of Explanation", publicado por Hempel y O ppenheim en 1948 (p. 137), se sostiene que una explicación consiste en un argumento deductivo válido que da cuenta de la ocurrencia de un evento particular a partir de las leyes que regulan el tipo de fenómenos del que haga parte el evento (cuestión que veremos más adelante). Los autores reconocen que no todas las explicaciones científicas son de esta variedad nomológico-deductiva, pues también hay explicaciones probabilísticas y estadísticas, en las que la ocurrencia del evento no es completamente predecible.

El empirismo lógico intentó encontrar una formalización general de la explicación científica por medio de las leyes pertinentes y las condiciones iniciales, que superara esa especie de sentido profundo en torno al cual gravitaba la explicación. D e esta forma se pretendía superar la teleología, acudiendo a enunciados con contenido empírico y relaciones lógicas entre ellos: sospechan de las causas teleológicas porque dependen de mecanismos oscuros y parecen poner la dirección causal en contravía de la dirección temporal. Pese a que esta noción es un innegable paso en el tratamiento científico de la explicación, existen muchos hechos que se resisten a ser sometidos a su esquema. No todos los fenómenos de la naturaleza pueden ser comprendidos con este procedimiento, entre ellos los actos humanos, en los cuales es usual es indagar por sus fines: 
entre los seres vivos y otros sistemas autoregulados, existen mecanismos que se comportan como si cumplieran finalidades o funciones, cuyas explicaciones en principio parecen fuera del alcance de los modelos propuestos por la visión heredada. Nagel (1974, pp. 34-35), por su parte, agrega que hay otros tipos de explicación, como la funcional o la genética: la primera es de mayor aplicación en biología y ciencias humanas, al implicar funciones e intenciones, y la segunda alude a la evolución histórica de sucesos. O tras explicaciones describen a nivel funcional o estructural, o proceden por reducción a un nivel diferente o por medio de la búsqueda de correlaciones estadísticas. D e ahí que tengamos que explorar otras de las características de la explicación que nos permitan tener más elementos de análisis sobre sus posibles relaciones con otras de las actividades de la ciencia.

\subsubsection{La posible simetría entre predicción y explicación}

Hempel y O ppenheim (1948, p. 138) defienden la existencia de una simetría entre explicación y predicción pues, asumiendo que las leyes que regulan el comportamiento de la naturaleza son constantes, una explicación nos provee de una deducción válida que da cuenta de un evento pasado, mientras que su proyección hacia el futuro nos brinda la posibilidad de prever nuevos acontecimientos. Así, a la explicación y a la predicción se les puede aplicar el mismo análisis formal, pues su diferencia es apenas pragmática: si el evento ya ocurrió el argumento da cuenta de por qué lo hizo, y si no ha ocurrido pero conocemos las leyes y los antecedentes, el argumento nos permite prever que el evento ha de ocurrir. Sin embargo, no parece ni evidente ni necesario que esto sea así, dado que no todas las explicaciones legítimas permiten hacer predicciones, como sucede en casos complejos o en situaciones gobernadas por leyes indeterministas, en los cuales las predicciones, cuando son posibles, tienen una fiabilidad restringida. Si bien las explicaciones probabilistas son útiles como indicio de la correlación entre factores, no sucede lo mismo con las predicciones que, en el sentido estricto planteado por Rescher (1998, p. 42-45) no pueden ser dadas en términos probabilísticos: la probabilidad apenas provee el alcance de una predicción, pero una predicción genuina requiere de precisión y compromiso con el hecho que va a suceder, ya que adjudicar una probabilidad (aun alta) no es equivalente a decir que el evento ocurrirá, pues se adjudicaría un estatus ontológico a una consideración epistémica. Sin embargo, de esta consideración epistémica de las probabilidades como indicio de la causa y guía para la predicción no puede prescindirse, pese a lo que afirma el autor: son elementos necesarios para nuestro conocimiento. Por otra parte, y en la misma dirección de la asimetría con respecto a la 
explicación, existen predicciones basadas en correlaciones conocidas que, pese a no estar explicadas, permiten hacer predicciones, tal como ocurre con el conocimiento precientífico de las mareas (Salmon \& Kitcher, 1989, p. 49): antes de conocerse su causa, ya se contaba con el conocimiento suficiente para saber que estaban asociadas al movimiento de la Luna. A hora, si se tuviese una descripción completa del mundo, de todas las fuerzas, mecanismos e interacciones que ocurren (tal como la del demonio de Laplace), no se necesitaría ninguna explicación - y, comenta Salmon $(2006,127)$, tampoco habría preguntas, pues estas requieren de cierta perplejidad- : las preguntas surgen precisamente porque tenemos un conocimiento incompleto de algún fenómeno o inquietudes con respecto a cómo se han de comportar los fenómenos en el futuro. Desde esa perspectiva ideal la explicación perfecta es una descripción completa; sin embargo, podemos presumir que nuestro conocimiento siempre será parcial, lo cual implica que quizás nunca contemos con tal descripción completa que nos devele hasta el más mínimo detalle de los mecanismos.

A parte de la diferencia con respecto al tiempo, hay otra diferencia entre predicción y explicación, con respecto a su función, que determina su estructura: una explicación suele buscar la respuesta a un porqué, mientras que la predicción hace un enunciado acerca de cómo han de ocurrir determinadas interacciones, de modo que en principio sus funciones son diferentes. No hay que perder de vista que las predicciones están limitadas por el grado del conocimiento que poseamos de la multitud de factores que inciden en que un evento se produzca o deje de hacerlo: las predicciones no son completamente exactas, aun en el caso de relaciones mecánicas, de ahí que una predicción imprecisa no siempre invalida una teoría o aminora se capacidad explicativa. La predicción es un objetivo legítimo de la ciencia, e incluso puede servir como test de cientificidad, en la medida en que las teorías científicas aceptadas suelen tener mayor capacidad predictiva. Ahora, este no es un test definitivo, pues la predicción no es el único criterio, como ocurría con los modelos de Ptolomeo y de Copérnico: eran capaces de hacer similares predicciones, pero el segundo ofrecía una visión más coherente y completa de los movimientos planetarios. El modelo geocéntrico de epiciclos era en realidad un conjunto de modelos del movimiento de cada uno de los planetas con respecto a la Tierra, pero el mismo Ptolomeo elabora otro modelo capaz de las mismas predicciones (el modelo de órbitas excéntricas); sus modelos son geométricamente equivalentes, pero en el siglo II no existía aun información suficiente como para saber cuál de ellos se correspondía con el comportamiento real de los planetas. El modelo heliocéntrico de Copérnico, en cambio, integraba todos los movimientos planetarios en un modelo único del 
conjunto de planetas orbitando alrededor del Sol. Ambos hacían predicciones similares porque estaban limitados a observaciones poco precisas y porque utilizaban órbitas circulares y, pese a que muchas de sus predicciones podían coincidir, hay una clara ventaja en un modelo unitario que nos permite eliminar supuestos independientes e hipótesis erradas. Esta es una prueba de que la predicción y la explicación pueden tener estructuras muy diferentes: apoyar una teoría en sus predicciones puede consistir más en un procedimiento argumental que en un análisis de las causas en los hechos: es posible hacer una asociación entre las predicciones de las que es capaz una teoría y su adecuación a los hechos, pero no es completamente certera (Lipton, 2012, p. 630), no nos ofrece un criterio definitivo de la validez de la teoría, sino más de su capacidad pragmática.

Contrario a lo que plantea la visión heredada, la asimetría entre predicción y explicación es notoria en virtud a que la primera en principio no requiere que entendamos los mecanismos que llevan a cierto resultado: bastaría con constatar cierta regularidad en los comportamientos de la naturaleza, pero para poder dar una explicación necesitamos de un procedimiento por lo menos más completo, más informativo que la simple regularidad. Y el anterior ejemplo es prueba de ello: los eclipses pueden ser predichos por los modelos ptolemaico y copernicano (así como los predecían astrónomos precolombinos en América), y sin embargo ambos eran errados e incapaces de dar una explicación apropiada del movimiento planetario. Además, puesto que las causas preceden a los efectos, es más factible determinar la historia de un evento - que es una vía posible para elaborar una explicación- que predecir que el evento se produzca, lo cual entraña no solamente conocer los mecanismos causales sino descontar algún grado de incertidumbre que suele interferir en los acontecimientos. Las predicciones por eso no ofrecen una certeza completa, pues siempre hay un margen de error, que se hace mayor en la medida en que involucre más factores, que la predicción sea más acotada y que se aleje en el tiempo. Baste mencionar como ilustración que las predicciones sobre el movimiento de los cuerpos del sistema solar son fiables en el corto plazo (por el relativo aislamiento del sistema), pero aún aquí, en plazos mayores se incrementa la incertidumbre. Así, la predicción mejora en la medida en que se conozca las leyes y haya más información disponible pero, como se mencionó previamente, conocer la causa no necesariamente hace más exacta la predicción, ni la explicación se reduce a encontrar la causa de un fenómeno. Las causas operan en la realidad en tanto que las predicciones dependen de nuestro conocimiento de las condiciones que rigen en una situación determinada. 


\subsubsection{Las preguntas tras la explicación}

La ciencia busca comprender la realidad y para lograrlo intenta, entre otras cosas, dar respuesta a interrogantes concretos sobre los eventos y sus relaciones. Esto implica que su objeto inicial es el de hacer descripciones de los objetos y de sus mecanismos. Ciertas concepciones afirman que el objetivo de la ciencia no es el de dar respuesta al porqué de los fenómenos, dado que la realidad es contingente, de manera que no existe una necesidad lógica tras en la ocurrencia de los fenómenos (Nagel, 1974, p. 37). Otros autores, en cambio, afirman que la explicación científica se ocupa principalmente de dar respuesta a los porqués, además de otros tipos de explicaciones admisibles. Conocer puede consistir en describir o en explicar: una cosa es constatar, saber que algo existe y cómo opera, y otra es saber por qué existe o entender el mecanismo de sus cambios; es diferente, por ejemplo, saber que las células están rodeadas por una membrana que entender la razón por la cual este hecho es necesario o qué funciones cumple. En términos más generales, se suele asociar la explicación con la noción de causa y con las preguntas tipo “¿por qué... ?”, pero no hay que olvidar que esta pregunta tiene pluralidad de usos y de significados y que la respuesta a esa pregunta no es la única forma de explicar; baste recordar cómo Newton al formular la ley de la gravitación universal se niega a ofrecer alguna hipótesis especulativa sobre por qué caen los cuerpos o se mueven los planetas; su objeto es demostrar que ambos fenómenos son manifestaciones diferentes de una sola regularidad, que describe las interacciones gravitacionales entre dos cuerpos, lo cual era suficiente para el momento. En cierta medida, esa descripción nos permite entender el fenómeno, aunque una explicación completa requiere del conocimiento sobre los mecanismos que propagan la influencia, si es el caso, o dar cuenta de cómo se producen los movimientos en un espacio moldeado por la masa.

En el uso común del lenguaje se suele preguntar ¿por qué? con el objetivo de pedir una explicación, pero esta no es la única posibilidad: hay peticiones de explicación que pueden acudir al ómo y preguntas tipo ¿por qué? que indagan por mecanismos: “¿cómo funciona una caja de cambios?” puede ser una petición de explicación; “¿por qué esta planta está seca?” puede apuntar no a la explicación del hecho referido directamente sino a la diferencia entre esta planta en particular y la verde que se encuentra al lado. En ocasiones la distancia entre un cómo y un porqué no es tan clara. Muchas veces la pregunta ¿por qué? es una petición de una causa, pero la pregunta también puede estar indagando por las condiciones, esto es, por una descripción del mecanismo por el cual un sistema opera, lo cual apunta más a un cómo: en un ejemplo de D ucasse (1924, p. 183), la 
respuesta a por qué al pulsar un botón suena un timbre, es la descripción de cómo el botón activa el paso de la electricidad que mueve un dispositivo que golpea una campana. Así que estas ilustraciones son una muestra de que así como las preguntas pueden dirigirse hacia niveles diferentes con respecto al conocimiento por el que se indaga, de la misma forma sucede que las respuestas también se dirigen a niveles de explicación que pueden ser muy diversos.

O tro ejemplo, de O kasha (2012, p. 717), es la comparación que se puede hacer entre las explicaciones que elaboran la biología funcional y la evolucionista: la primera se dedica a indagar cómo funciona un organismo y sus partes, mientras que la segunda indaga por quélos organismos exhiben ciertas características, es decir, qué ventajas les dan estas a los organismos y por qué han llegado a tenerlas en vez de otras, o por qué la selección natural permitió que se perpetuaran mientras otras desaparecían. En el ejemplo se hace patente que las preguntas pueden ser formuladas de diferentes maneras y también es cierto que en estos casos no es del todo discernible la noción de causa de la de mecanismo (el porqué del cómo): podríamos entender que la biología funcional se ocupa de las causas próximas y la evolucionista de causas más remotas o incluso finales, haciendo de paso más difícil una descripción detallada de los medios de influencia; pero no sobra reiterar que no quedan excluidas los porqués ni las explicaciones causales. Pese a la importancia que tienen las explicaciones causales, en efecto no todas lo son, como lo plantea Lipton (2012, p. 621): hay muchas explicaciones válidas que apelan a deducciones a partir de leyes 0 a otras regularidades. El autor ilustra este caso con el efecto que tienen los premios y los castigos a los pilotos por su desempeño: se ha creído habitualmente que los castigos son más efectivos para mejorarlo y que los premios son inútiles, pero lo que parece haber detrás es una regresión al comportamiento promedio, es decir, una explicación estadística que permite hacer predicciones, que no riñe con el hecho de que cada comportamiento individual tiene sus causas particulares.

No puede negarse que asociar las preguntas tipo ¿por qué? a la explicación lega a esta cierta vaguedad y un sesgo antrópico, que lo remite a los intereses y conocimiento de quienes piden y elaboran las explicaciones; el sentido de esta variedad de preguntas y de sus respuestas es muy dependiente del contexto, de manera que las respuesta pueden ser más o menos válidas en relación a las condiciones de las preguntas. Puede ocurrir que indaguemos por el detalle de las conexiones causales, pero que muchas de estas involucren mecanismos desconocidos, lo cual haría incompleta la respuesta mientras no se responda al cómo. Pero, si lo que se busca es una explicación más general que dé cuenta de la regularidad y de la correspondencia con leyes naturales, una explicación 
descriptiva incompleta puede ser satisfactoria; es decir, que podemos conocer la razón por la cual ocurre un fenómeno sin que tengamos por completo resuelto el problema de los mecanismos por los cuales la cuestión ha llegado a ser así: si ponemos el caso del evolucionismo, vemos que es una teoría-marco que provee las explicaciones generales de los cambios de las especies, pero aún falta conocer mucho sobre los mecanismos por medio de los que opera. Hay que tener en cuenta que elucidar los mecanismos es una labor progresiva de la ciencia y pese a que hoy no tengamos respuestas de ciertas formas de operación, cada vez la ciencia ofrece más conocimiento al respecto. Por eso un porqué también se puede interpretar lícitamente con respecto a la necesidad que relaciona un hecho con alguno de los factores que lo anteceden, es decir se puede preguntar por el factor que tenga más relevancia en el panorama causal o mayor relevancia para la sustentar una explicación; en otras palabras, que si bien la explicación causal no es la única posible, defendemos que sigue siendo necesaria en la comprensión de muchos fenómenos, en especial en la indagación de hechos particulares y en la reconstrucción de la historia de los fenómenos. No pretendemos reducir la explicación a la explicación causal ni que la explicación causal responda exclusivamente a las preguntas del tipo ¿por qué?, sino que una parte importante de las explicaciones tanto en la ciencia como en el conocimiento general pueden ser comprendidas por esta vía y que, por otra parte, la relación entre este tipo de preguntas y ese tipo de explicaciones tiene una marca fundamental para entender una característica de la relación causal, que es la de la contextualidad: el por qué es siempre dependiente de las condiciones de contexto de quien indaga, de quien responde y de la información posible y pertinente, de ahí que, como se planeó en aparte anterior, lo que se considere como causa o condición obedece más a consideraciones epistémicas que ontológicas. Para continuar, es necesario hacer un recorrido por la evolución que han tenido los modelos de elaboración de explicaciones.

\subsection{Modelos de explicación científica}

Nos apoyaremos para este aparte principalmente en los trabajos sobre explicación de Wesley C. Salmon, en la medida en que sus nociones sobre causalidad son cercanas a la posición que se ha buscado sostener en el presente trabajo. Seguiremos al autor en su recuento de la evolución de los modelos de explicación científica, que nos permitirán acercarnos a entender cómo se han estructurado algunas de las formas de explicación más aceptadas, lo cual nos dará un marco general con el cual delimitar los espacios adecuados a la indagación sobre las causas y su conocimiento. Salmon, en Scientific E x planation and the Causal Structure of the W orld (1984, p. 16), 
divide la explicación en tres tipos: epistémica, que responde a la búsqueda del incremento de información sobre los fenómenos a explicar, a las conexiones con otros hechos por medio de leyes; modal, cuyo objetivo es mostrar que el evento a explicar tenía que suceder, como resultado de la necesidad que lo liga a sus antecedentes, y la óntica, que pretende explicaciones objetivas, vinculadas a la identificación de las causas. Nos ocuparemos de las explicaciones epistémica y (más adelante) de la óntica, que son las que ofrecen su sustento a la presente sección.

\subsubsection{Modelos de ley de cobertura}

Salmon narra cómo a mediados del siglo XX se retoma la idea de que la ciencia tiene entre sus objetivos el de explicar, pues previamente lo usual era aceptar que sus funciones son más las de describir la naturaleza con el fin de ejercer control, pues se creía que la explicación correspondía a otro ámbito, más allá de la observación empírica, campo que el empirismo lógico considera cuanto menos oscuro y ajeno a la ciencia. La concepción heredada adquiere su forma madura por medio de los trabajos de Hempel y O ppenheim, entre otros; su formalización requiere que la explicación científica se exprese como un argumento: a un ex planandum, una sentencia que describe un hecho del mundo físico (que también pueden ser eventos, cosas, procesos o regularidades) se le provee de un explanans, la clase de sentencias que dan cuenta del fenómeno (Hempel \& Oppenheim, 1948, p. 137). Las condiciones generales que se piden a una explicación es que sea un argumento deductivo, que el explanans contenga una ley general que subsuma el hecho a explicar (por eso se llama el modelo de ley de cobertura) y que tenga contenido empírico: la condición empírica es que las sentencias que constituyen el ex planans deben ser verdaderas. En los términos mencionados, la explicación es principalmente una cuestión epistémica, que consiste en mostrar que el evento era esperable: dadas las premisas del argumento (compuestas por las leyes que rigen este tipo de eventos y por las condiciones iniciales) el evento es la conclusión; tales elementos constituyen el modelo nomológico-deductivo, una explicación con la forma de una argumento lógico basado en leyes. En esta concepción, como se mencionó, la distinción entre explicación y predicción es apenas temporal, referida al momento en que nos encontramos: se reduce a la cuestión pragmática de si el acontecimiento ocurrió u ocurrirá, dado que ambas son apenas dos instancias de la misma ley. De esta manera, los hechos quedan subsumidos bajo leyes de cobertura pues se demuestra que los hechos que se quiere explicar corresponden a los casos definidos por la ley, cuestión que requiere de alguna definición previa. 
Hay que tener en cuenta que existe una distancia considerable entre concebir la ley como una generalización sobre el comportamiento de la naturaleza y entenderla como una noción de comportamiento idealizado pero, en todo caso, no siempre el comportamiento de la naturaleza corresponde puntualmente a la universalidad de las leyes. Hempel, inicialmente, asume que fuera de las condiciones lógicas de la explicación científica se necesita una condición empírica de adecuación, que consiste en la verdad de las premisas, pero dado que esta plena seguridad no siempre existe, hay que contar con un grado alto de confirmación de las evidencias relevantes (Hempel \& Oppenheim, 1948, p. 137). Idealmente, si se cuenta con la ley de cobertura y las condiciones iniciales, la conclusión es la ocurrencia del evento a explicar pero, si no tenemos tal certeza, hemos de contar con la alta probabilidad de que el evento ocurra, posición que reduce la confiabilidad de la explicación y además impide explicar un evento de baja probabilidad. Así, el modelo tiene un mayor poder explicativo en la medida en que las probabilidades sean más altas, pues de esta forma es evidente que el caso corresponde a la ley (o que puede ser excluido de ella si la probabilidad es muy baja): el modelo nomológico-deductivo puede, de tal manera, verse como el caso límite de relevancia estadística, es la explicación de los casos en que la probabilidad de que ocurra cierto evento es igual a 1. Cuando no se dispone de una ley universal que implique la presencia del efecto a partir de una causa, sino cierta probabilidad de que aparezca, se induce de los resultados observados su probabilidad: dadas estas premisas se espera con más o menos confianza que el efecto ocurra, de modo que la explicación se convierte en la posibilidad de anticipación nómica (nomic ex pectability) (Psillos, 2007, p. 153), en otras palabras, qué tan seguro es que un evento haya de suceder con respecto a la ley que lo cubre.

Ahora bien, en los casos en que no tenemos tal certeza, hay que determinar por medio de la observación cuál es la probabilidad de que un efecto se produzca, dada la existencia de la ley y de las condiciones iniciales. Con los datos estadísticos sobre la presencia de una cierta propiedad en la situación causal podemos determinar la frecuencia con que tal propiedad incide en un efecto, de modo que podemos contar con otro modelo de explicación, el estadístico-inductivo, en el cual la explicación de un hecho particular es un argumento inductivo que confiere al hecho a explicar una alta probabilidad. Los modelos de ley de cobertura requieren que los hechos a explicar se subsuman bajo leyes, pero no siempre se cuenta con la certeza de que los casos correspondan a una ley determinista, lo cual implica que hay que aceptar no solo leyes universales sino también leyes estadísticas, método que permite formalizar muchas explicaciones científicas 
plenamente válidas, pero que implica asumir condiciones diferentes a las necesarias para construir un argumento deductivo basado en leyes de cobertura.

La situación se complica para la aplicación del modelo nomológico-deductivo en dos aspectos: por una parte el modelo requiere que se hayan identificado leyes universales, cuestión que en la práctica tiene que resolverse estadísticamente, determinando el grado de pertenencia de un evento a los casos definidos por una ley. Y esto conduce al otro aspecto: ese uso de la estadística no solo se debe a las limitaciones del conocimiento, sino a que en el mundo también existen acontecimientos y relaciones que siguen siendo imprevisibles independientemente de la información que poseamos, de manera que es necesario incorporar a la explicación científica la estructura básica de aquellos acontecimientos con comportamientos indeterministas. Ahora, limitar las explicaciones legítimas a argumentos nomológico-deductivos implicaría desconocer que también existen correlaciones que no obedecen a leyes y aun así son capaces de sustentar predicciones, como en el caso de correlaciones accidentales: todos los primates tienen extremidades con cinco dedos y podemos predecir que la aplastante mayoría de los que nazcan las tendrán, lo cual es una predicción fiable que no explica.

Aquí nos encontramos con un problema notable para los modelos de ley de cobertura y es que no ofrecen herramientas para distinguir entre las leyes y las generalizaciones accidentales, y estas últimas, por sus propias características, no permiten elaborar explicaciones válidas. Podemos encontrar argumentos formalmente correctos que se basan en generalizaciones accidentales e irrelevantes, factores espurios en la medida en que no pueden sustentar una explicación adecuada, como en el mencionado caso de los anticonceptivos que el señor Jones consumió para evitar su embarazo (Salmon, 2006, p. 50): no podemos adjudicar el efecto a una ley que lo asocie con el consumo del medicamento, pues es un caso típico de un factor regular que carece de relevancia para producir el efecto. También podemos confundir correlaciones con relaciones causales, como en el caso de la caída de la lectura de un barómetro en relación a la presencia de mal tiempo: están relacionados por una generalización que se cumple, pero en virtud a que obedecen a una causa común, el cambio en la presión atmosférica. Para Salmon la solución a estas limitaciones es asumir que el problema de la explicación no es solo epistémico, por eso defiende su concepción óntica según la cual la explicación y la causalidad necesitan de una base objetiva, y reconoce que, si bien no todas las explicaciones son causales, estas dan cuenta de multitud de fenómenos, pues no todos los sucesos pueden ser regularizables y deducidos a partir de leyes. Esta propuesta de 
una teoría causal de la explicación la contrasta con la de la concepción heredada, aunque también con el modelo de relevancia estadística que el mismo Salmon había propuesto, así como de la explicación pragmática de van Fraassen (González, 2010, p. 211).

\subsubsection{La concepción óntica de Salmon}

The time has come, it seems to me, to put the "cause" back into "because"

W. Salmon

La concepción óntica de la explicación apunta hacia las relaciones entre los hechos, a diferencia de las concepciones epistémicas que buscan la corrección lógica de los argumentos y de los enunciados que los describen; Salmon (2006, p. 121) considera que la descripción del hecho no basta para su explicación sino que para dar cuenta de él se requiere apelar a conocimientos causales, tales como las diferencias entre leyes causales y no causales, entre procesos causales y pseudoprocesos, entre causas y coincidencias; en resumen, conocer los mecanismos que inciden en que una interacción ocurra. A esto se refiere cuando llama a poner la palabra cause en el término because, que se utiliza en inglés como respuesta a las preguntas tipo ¿por qué?, una forma de enfatizar que la influencia causal es una característica que permite la modificación de una estructura entre dos procesos que son causa y efecto, definidos como las secuencias capaces de transmitir una marca y que además hace posible una variedad de explicaciones.

La teoría de Salmon es una herramienta muy útil para entender que la interacción entre las historias causales de dos entidades se caracteriza por el intercambio de magnitudes de las propiedades relevantes para la causa: es claro que en un choque entre dos objetos, magnitudes como el momento o la dirección sufren intercambios, cesiones de un objeto sobre el otro. Pero no pueden desconocerse las objeciones que ya se han hecho acerca de las limitaciones de tal concepción (D owe, 2008), como la dificultad de definir los procesos por la permanencia y uniformidad: se requiere de un cierto grado de idealización en la medida en que los procesos suelen sufrir transformaciones en cantidades que la teoría requiere se conserven, así como presenta dificultades para excluir pseudoprocesos y para definir cuáles son las cantidades relevantes en la interacción. La cuestión aquí es que si bien la teoría es aplicable a ciertos tipos de interacción física, nuestras necesidades de explicación causal son mayores que las que abarcan tales 
interacciones: muchos campos, y no solo de las ciencias sociales, quedan fuera de esta concepción de la causa.

La subsunción bajo leyes puede ser insuficiente para dar cuenta de la ocurrencia de muchos eventos así como lo puede ser para proveer una explicación que nos permita entenderlos, dada la aplicación limitada de las leyes; pero aun aceptando la perspectiva más amplia de la relevancia estadística, una explicación necesita complementarse con información causal y teorética, como lo afirma Salmon (1984, p. 100), ya que el estado de nuestro conocimiento también limita los alcances explicativos de las leyes. Como se ve en los problemas mencionados, el modelo nomológico-deductivo debe ser complementado con otras formas de explicación que se ocupen de los casos en que la certeza no es completa - posiblemente, la mayoría - o de aquellos en que se presenten relaciones espurias: hay una diferencia entre los casos que corresponden claramente a una ley que relaciona factores o causas con sus efectos (es decir, cuando la presencia de un factor es seguida por el efecto) y los casos en los que la presencia de un factor tiene una relevancia más o menos alta para la producción de un efecto. Necesitamos separar las relaciones genuinamente causales de las irrelevantes o de las correlaciones producidas por una causa común desconocida.

El modelo de relevancia estadística de Salmon busca solucionar problemas del modelo inductivoestadístico de Hempel, al costo de alejarse de la explicación como argumento y de asumir que la relevancia estadística no explica por sí sola, sin información adicional, el papel de las causas: que haya una correlación estadística no implica la presencia de relaciones causales. Este es el caso en que se espera un resultado altamente probable: en el caso de un plaguicida, si fuera 100\% efectivo podríamos explicar su acción como el cumplimiento de una ley que determina un resultado a partir de una condición inicial, la aplicación del plaguicida; pero si la efectividad de la sustancia es más baja, no tenemos una certeza inicial sobre qué otros factores inciden en la producción de su resultado. La ley de cobertura nos da cuenta de los casos positivos, pero los negativos se quedan sin explicación: pueden existir factores protectores o de resistencia de la plaga que enmascaran los resultados, alterando las vías de influencia causal. El modelo parte de cierta información acerca de las posibles relaciones entre causas y efectos para poder adjudicar una probabilidad de que cierto factor se relacione con la ocurrencia del evento, pues de otra forma no se pueden excluir las correlaciones de dos eventos que semejan una relación causal pero que son en realidad efectos de una causa común o que puedan obedecer a correlaciones sin papel causal. En otras 
palabras, aún en los casos de alta probabilidad, el modelo por sí solo no ofrece herramientas para excluir las relaciones espurias, pues incluso cuando el argumento es formalmente correcto no garantiza que provea una explicación satisfactoria.

La vía para dar respuesta a aquellos casos en los que la subsunción a una ley no ofrece total certeza, sino apenas cierta probabilidad de su inclusión, es el modelo inductivo-estadístico, en el que se llega a una conclusión a partir de la observación de casos similares: dadas las premisas se tiene cierta probabilidad de que el efecto ocurra; se compara el caso a explicar con una ley estadística que cubre tal tipo de fenómenos. Al igual que en el modelo nomológico-deductivo, el modelo inductivo-estadístico no ofrece herramientas para diferenciar las correlaciones espurias o irrelevantes, y además se sigue necesitando una alta probabilidad, esto es, que las probabilidades bajas no permiten dar una explicación adecuada del fenómeno. Para solucionar este problema en el modelo de Hempel (2005, p. 517), se apela al requisito de máxima especificación (RMS) con el fin de que el tipo de hechos del que se ocupe la explicación sea lo más acotado posible, y que en la explicación se incluyan todos los hechos relevantes, pero esto no asegura que sean incluidos solo ellos dado que la clasificación se hace con base en el conocimiento previo que se tenga sobre el tipo de caso: si el conocimiento fuera completo se podría hacer un argumento nomológicodeductivo. Esto implica una concesión que no acepta el modelo: que hay factores más o menos relevantes en la explicación del fenómeno. Una probabilidad alta no garantiza que la explicación sea adecuada, como en el caso de los síntomas de una enfermedad: son comunes a la enfermedad, así que permiten determinar qué enfermedad es la que afecta a los pacientes que los presentan, pero también puede haber pacientes asintomáticos, en los que la enfermedad está presente. La cuestión, afirma Salmon, es que: "What is crucial for statistical explanation [... ] is not how probable the explanans renders the explanandum, but rather, whether the facts cited in the explanans make a difference to the probability of the explanandum" (Salmon, 2006, p. 59).

Así que lo que importa determinar, más que la relación de probabilidad, es si entre los factores causales y su posible efecto hay relaciones de influencia que puedan ser confirmadas o descartadas comparándolas con otras. Lo que se necesita, según el autor, es relevancia estadística, elementos capaces de sustentar una correlación genuina; una razón de peso que lo aleja del modelo inductivoestadístico pues, en última instancia, este es un modelo que sólo pretende ser una extensión del modelo nomológico-deductivo, aplicada a ciertos casos, sin que logre solucionar sus limitaciones. 
La explicación probabilista parece más ligada a los indicios de relación que se muestran por medio de correlaciones que a los mecanismos causales y ya hemos visto cómo, ante la complejidad de las relaciones posibles entre eventos, no es fácil distinguir las relaciones genuinas de las espurias, como en el conocido caso de la asociación entra delincuencia y origen racial en Estados Unidos: a partir de la abundancia de afroamericanos en las cárceles se podría establecer una asociación entre delincuencia y origen étnico, pero si no se tienen en cuenta factores como los de acceso a educación y trabajo, parcialmente dependientes del ingreso per capita, se podría considerar como genuina una relación entre delitos y "raza", simplificando un caso mucho más complejo. Es un ejemplo de asociaciones indirectas entre factores que ponen dificultades al uso de la relevancia estadística. Cuando buscamos dar una explicación a un evento ya ocurrido, la escogencia de la clase correcta de referencia se hace para determinar cuál es el factor que determinó el hecho y para excluir falsas relaciones. Se puede apelar a la explicación inductivo-estadística, observar la frecuencia que presentan las relaciones entre un factory el efecto, complementada con el requisito de máxima especificidad, con el fin de diferenciar los factores que deben ser tenidos en cuenta para elaborar la explicación: por esto la explicación óptima nomológico-deductiva se refiere a una clase epistémicamente homogénea. En una explicación deductiva el evento a explicar depende de las premisas, hay una correspondencia determinista entre unas características y otras, que no depende de lo que sepamos ni de cómo hagamos las descripciones. Por eso la explicación inductivoestadística busca segmentar el conjunto de casos estudiados hasta obtener un grupo homogéneo frente al factor relevante, momento en que la explicación deja de ser inductiva y se vuelve deductiva, pues se aplica a toda la subclase, satisfaciendo el criterio de máxima especificidad (Salmon, 2006, p. 74).

Para Salmon el modelo inductivo-estadístico de Hempel no permite construir argumentos como el modelo nomológico-deductivo, es más, considera que, más que un argumento que basa la explicación en datos estadísticos, es apenas un ensamblaje de información relevante (Salmon, 1984, p. 88), pues no siempre las explicaciones se pueden basar en que haya una alta probabilidad de que el evento ocurra; en otras palabras, la regularidad que se busca no puede depender de un enunciado y de sus relaciones lógicas, ya que la regularidad se encuentra en los hechos, que son independientes de quien elabore el enunciado y de si se ha hecho con corrección formal. Además, los argumentos inductivos presentan otra debilidad y es que la introducción de premisas adicionales baja la probabilidad de que el evento se presente; no se puede pedir que conozcamos todas los casos, pues el argumento dejaría de ser inductivo: todos los cisnes eran blancos hasta que no se 
descubrieron los australianos, una sola observación con la capacidad de refutar el enunciado. Lo que observa Salmon es que existe información irrelevante que invalida las explicaciones, pero que parece respetar los argumentos; así que no importa si existen premisas de más en los argumentos, pero para las explicaciones se requiere de toda la evidencia relevante. Aunque las probabilidades apunten a una dirección un factor improbable puede ser la clave de la explicación: es más probable que una turbulencia derribe un avión, pero un improbable tornillo defectuoso también lo puede hacer, de modo que los argumentos inductivos son incapaces de explicar hechos particulares. Si nos atenemos a la alta probabilidad podría adjudicarse un papel causal al consumo de vitamina $\mathrm{C}$ como tratamiento contra la gripe o a la psicoterapia como cura de la neurosis: no es posible distinguir estadísticamente si hay efectividad genuina o remisión espontánea, en estos ejemplos de Salmon; dado que existe la cura espontánea, no es estadísticamente significativo el posible efecto de tales tratamientos.

Por consideraciones como estas Hempel concede que la explicación estadística conlleva cierta "ambigüedad epistémica", cuestión que no se contemplaba en el modelo nomológico-deductivo: es necesario especificar si la clase de eventos a los que se aplica el argumento es homogénea o si puede subdividirse de manera significativo. Entonces el argumento no puede girar en torno a que las premisas garanticen una probabilidad más alta para que se produzca el evento a explicar, sino qué factores entre las premisas constituyen los diferenciales para la probabilidad de que el evento se produzca, esto es, introducir una condición de relevancia: el mencionado requisito de máxima especificidad (Salmon, 2006, p. 57). Se necesita conocer la relevancia estadística de un factor para elaborar la explicación, de ahí que sea necesario diseñar mecanismos de control experimental que permitan demostrar si el factor en cuestión es capaz de producir un resultado diferente con respecto a las situaciones en las que este no se presenta, una idea muy valiosa sobre la que volveremos más adelante.

Existen factores estadísticamente relevantes que también son causalmente relevantes y esto implica que la relevancia estadística positiva o negativa se puede traducir a contribución causal o prevención, de forma que una explicación de un fenómeno aleatorio adjudica la producción del evento a los factores positivos y a pesar de los negativos (no es simplemente la ausencia de un factor sino un factor que baja la probabilidad), pues no puede hacerse una explicación compuesta solamente de ausencias; además en los modelos estadísticos la ausencia de un factor relevante hace incorrecta la explicación mientras que el modelo causal puede proveer explicaciones válidas en que falten 
factores relevantes, como sostiene Humphreys (1981, p. 229). Por ello la explicación no puede limitarse a la información estadística sino que debe hacer referencia a lo que es causalmente relevante: no puede identificarse la relevancia estadística con relevancia explicativa, pues la primera puede referirse a correlaciones sin papel causal.

A diferencia de las formas de explicación que intentan unificar en el menor número de leyes y asunciones sobre la naturaleza, para la concepción óntica que defiende Salmon el conocimiento busca explicar los mecanismos por medio de los cuales opera la naturaleza, trasciende el aspecto descriptivo y busca dar cuenta de cómo las cosas llegan a ser; la unificación emprende su tarea de arriba hacia abajo, mientras que la explicación causal de la visión óntica lo hace de abajo hacia arriba (Salmon, 2006, p. 182). Sin embargo, dado que esta labor es tan compleja, no puede afirmarse que ambas visiones sean incompatibles, sino que se las puede observar como dos aspectos de la explicación: mientras que la visión causal óntica ofrece una explicación local de cómo cierto hecho ocurrió (mediante procesos e interacciones causales o no causales) la otra visión da cuenta de las leyes tras de los hechos concretos, buscando una unificación global que permita entender la estructura del universo, que dé cuenta de las regularidades; de modo que cada una de estas visiones puede ser más adecuada que la otra en determinados contextos.

\subsubsection{Probabilidades y relación causal}

En la naturaleza encontramos situaciones en las que podemos estar casi completamente seguros de que un efecto ha de producirse, pero también puede ocurrir que se conjuguen las circunstancias que consideramos como causales sin que sean seguidas por los efectos esperados: no siempre el vaso que cae se rompe o el fósforo que se frota se enciende. En estas situaciones los análisis de probabilidad son una herramienta fundamental para encontrar las causas, pues permiten manejar múltiples factores y por esta razón logran dar cuenta de las relaciones de influencia causal entre características de diferentes eventos; en palabras de Cartwright (1999, p. 126), las probabilidades son una sombra de la máquina subyacente. Suppes (1970, p. 7), referente imprescindible de la probabilidad causal, afirma que la noción actual de causalidad no es estrictamente determinista, en el sentido en que incluso en el lenguaje común se asocia cierto factor causal con la posibilidad incierta de que se produzca un resultado: se asigna una tendencia a que ese factor tenga una mayor o menor influencia sobre cierto efecto. Utiliza como ejemplo el de una vacuna: su aplicación baja sensiblemente el riesgo de que se contraiga la enfermedad, pero no excluye que esto pueda 
suceder. D e todas formas, dependiendo del tipo de investigación y de la información disponible, la ciencia puede encontrar la relación entre propiedades concretas y las características de su naturaleza, pero, agrega Suppes (1970, p. 60) que en las ciencias biológicas y sociales prevalece el análisis probabilista, seguramente por la ausencia de teonías y leyes que permitan hacer predicciones exactas. El análisis probabilístico de la causa se basa en que la presencia de una característica 0 factor causal no implica necesariamente que el efecto ocurra, sino que lo hace más probable. Tiene ventajas notorias, tales como que permite comparar casos cuya probabilidad es muy baja: por ejemplo, la conjunción de eventos improbables puede ser considerada como indicio de una causa común, ya que considerarlos separados haría mucho más baja su probabilidad, de modo que en casos como este encontramos una herramienta útil para aproximarnos a la identificación de la relaciones causales. En condiciones deterministas regulares la causa es la condición suficiente para la producción del efecto pero, puesto que no siempre el efecto sigue a lo que aceptamos usualmente como causa, la probabilidad nos provee de medios para identificar los factores que pueden tener una influencia causal, cuando desconocemos los mecanismos causales o cuando existe algún grado de indeterminación entre la causa y el efecto, de modo que, como lo plantea Sebastían Álvarez (1998, p. 522), el análisis probabilístico “[... ] permite rescatar a la causalidad de la concepción determinista en que surgió y la hace aplicable a contextos probabilistas 0 indeterministas".

Un aspecto a considerar es que las teorías probabilistas de la causa han desarrollado medios para responder a las iniciales limitaciones, como en ciertos casos de relaciones espurias, en los que hay una correlación entre efectos colaterales; pero lo que la hace más atractiva es que permite trabajar con casos en que el factor causal tiene grados (es decir, en que sus valores no se limitan a 0 y 1 ), así como permite determinar no solo la influencia positiva sino también la capacidad inhibitoria que puede tener un factor de la relación causal (Hitchcock, 1997). El análisis probabilístico ha añadido formas de identificar factores intermedios y horquillas causales que dificultaban la identificación de las causas, pero sigue habiendo algunos problemas con respecto a la asimetría causal, dado que las relaciones probabilísticas son simétricas: la causa incrementa la posibilidad del efecto, como este lo hace con la causa. No sucede así con las relaciones causales, en las que el efecto siempre es posterior o cuando mucho simultánea con la causa, determinando una dirección asimétrica. 
Cuando la información es incompleta, existen vías de análisis para estructurar la correcta delimitación de las clases de eventos en los que se intenta entender las interacciones causales. Esta es una forma de complementar el modelo de explicación nomológico-deductivo con el inductivo-estadístico, un medio de tratar con grupos heterogéneos. Si no puede hacerse una partición relevante con respecto a que los individuos posean o no un atributo, la clase es homogénea, pero si encontramos atributos de una subclase que pueden influir sobre un efecto, hemos de buscar si tal atributo permite constituir una subclase exclusiva. Para que se pueda elaborar una explicación a partir de tal procedimiento deben tenerse en cuenta todos los factores relevantes, pero solo ellos, dado que hay muchas clasificaciones posibles. D e esta forma se pueden solucionar algunos de los problemas esgrimidos en contra del modelo inductivo-estadístico: el descenso en la lectura del barómetro hace más probable la tormenta, pero no la explica, y esto es debido a que la probabilidad de que se presente una tormenta, dada la baja del barómetro y la caída en la presión atmosférica, es igual a la probabilidad de la tormenta dada la caída en la presión atmosférica, lo cual convierte en irrelevante causalmente la lectura del barómetro, pues no puede afectar de ninguna forma a la tormenta. Este modelo, de relevancia estadística, concibe la explicación de un hecho particular en la relación de los factores que son estadísticamente relevantes para el hecho a explicar, con independencia del grado de probabilidad resultante, pero no hay que olvidar que no implican necesariamente una relación causal (Psillos, 2007, p 159).

Sin embargo, el hecho de que cierta propiedad de la causa esté relacionada estadísticamente con un efecto no implica que sea una condición suficiente para su producción. Salmon (1993, p. 147) cree que la relevancia estadística es un ingrediente necesario en la causación, pero agrega que la causa va más allá, de modo que las relaciones probabilísticas entre eventos deben tener en cuenta las conexiones físicas que transmiten la influencia causal, pues en los casos en que hay eslabones intermedios en la cadena causal la probabilidad no nos provee de una respuesta clara que permita desentrañar los mecanismos. Además hay que agregar que la probabilidad se suele aplicar más a la determinación de expectativas acerca de cómo puedan ocurrir determinadas relaciones entre eventos, mientras que el tratamiento estadístico corresponde a los datos disponibles, es decir, a la información con la que ya se cuenta. Existen algunos ejemplos problemáticos, como el caso de la relación entre trombosis y píldoras anticonceptivas: tanto las píldoras como el embarazo aumentan la probabilidad de trombosis pero, puesto que las píldoras previenen el embarazo, actúan previniendo la trombosis. También en el conocido ejemplo de Rosen citado por Suppes (1970, p. 41): el mal golfista cuya probabilidad de acertar es baja, en teoría, pero cuando lanza en la dirección 
equivocada la bola, un árbol la reconduce en la dirección correcta, produciendo el mismo efecto que el de un lanzamiento certero, cuya probabilidad de éxito habría sido mucho más alta. Es una consecuencia muy improbable, pero no imposible y es una muestra de cómo puede actuar la relevancia estadística negativa: existen factores capaces de alterar la probabilidad de que ocurra cierto resultado, cambiando el valor de la probabilidad inicial. Razones para no olvidar los medios por los que se propaga la influencia causal, es decir, los mecanismos por medio de los cuales interactúan los procesos, de forma que la relevancia causal debe primar sobre la correlación estadística, sin desconocer que esta última es muy útil para detectar causas que en principio está ocultas.

El modelo inductivo-estadístico apela a la homogeneidad epistémica pero la cuestión es que no siempre es posible hacer una partición relevante satisfactoria; el requisito de máxima especificidad de Hempel intentaba solucionar el problema de la relevancia de un factor para la explicación; esto implica que el evento a explicar ya sucedió y que la partición relevante de la clase ya ha ocurrido: la partición se hace para buscar evidencias, esto es, para comprobar si corresponde a cierta ley. Álvarez (1998, p. 525-6) también menciona la necesidad de una contexto causal homogéneo, que permita evitar la paradoja de Simpson, según la cual subgrupos de datos pueden exhibir una correlación estadística contraria a la totalidad, como en el caso de los fumadores que hacen ejercicio, cuya frecuencia de infartos es menor que la del grupo total de fumadores. Por su parte, el modelo de relevancia estadística de Salmon (2006, p. 80), intenta encontrar un concepto de homogeneidad objetiva, de modo que en condiciones de determinismo estricto las explicaciones de hechos particulares no son irreductiblemente estadísticas (si se consigue la información faltante se convierten en explicaciones deductivas), pero si el indeterminismo es verdadero, si en el mundo hay aleatoriedad real, hay que aceptar explicaciones estadísticas, pues esto implica que el comportamiento de algunas entidades no depende de las particiones que podamos realizar: en tales casos no existe ninguna forma de identificar un antecedente que sea necesario para la ocurrencia del evento. En cierta medida los modelos estadísticos implican una búsqueda de las condiciones de determinismo estricto, en la medida en que apuntan a la clase más homogénea posible en que las probabilidades sean máximas, es decir, se aspira que el incremento del conocimiento lleve la explicación hacia el campo deductivo, que el evento obedezca a una certeza deductiva con respecto a los hechos explicativos. Sin embargo, abundan los casos más complejos que, independientemente de que obedezcan leyes deterministas, no ofrecen suficientes datos para hacer predicciones ni para determinar cuáles son las vías de influencia causal; lo mismo 
sucede en presencia de factores aleatorios, que hacen incierta la partición en subclases de acuerdo con los atributos relevantes. En esta dirección apunta Cartwright:

The macroscopic world is to all appearances neither deterministic nor probabilistic. It is for the most part an unruly mess. O ur job is to find methods of modelling the phenomena of immediate concern that will provide us with as much predictive power as possible. Just as with social statistics, where we realise that if we want to model the associations of quantities of interest we will have more success with probabilistic models than with deterministic ones, so too with causality: models of probabilistic causality have a far greater representational range than those restricted to deterministic causality Cartwright (1999, p. 110).

De modo que la tarea a realizar es la de encontrar las herramientas correctas para cada caso. El problema de delimitar la clase de referencia tiene que ver con la interpretación de la probabilidad y con la concepción que se tenga sobre las leyes. Las leyes son aplicables dentro de ciertos límites, lo cual implica que exijan cláusulas, solo que mientras más clausulas tengan se convierten en más particulares, lo cual, dice Salmon (2006, p 84), puede privar la ley de contenido, corriendo el riesgo de que las cláusulas œeteris paribus se usen para proteger los argumentos de la refutación; pero no se puede desconocer su importancia en la explicación inductivo-estadística, pues cumple el rol del requisito de máxima especificidad de Hempel. Las explicaciones de sesgo óntico ponen a los hechos como explicaciones, por eso se dice que la gravedad de la Luna explica las mareas, por ejemplo. Ahora, esto implica la existencia de una cierta indefinición de los límites entre causa y explicación: la explicación podría ser o no un argumento, pero que la Luna cause las mareas es un hecho independiente de si se expresa de una u otra forma. Además, no hay que olvidar que esta es una elipsis de todos los hechos y eslabones causales implicados. D e acuerdo con Hempel y la ley de cobertura, podemos explicar por qué un gas tiene cierta temperatura especificando su volumen y su presión, pero esto no nos dice cómo se produce la temperatura: en realidad esto parece más una descripción de un conjunto de factores cuya interrelación determina el estado y propiedades del gas, es decir, la coexistencia de relaciones entre factores, pero no parece una explicación adecuada de los mecanismos que llevan a cabo la producción de cambios.

Para concluir este aparte podemos decir que el análisis probabilístico de la causalidad apunta hacia la búsqueda de las relaciones entre la presencia de ciertos factores o propiedades de una causa y su efecto, pero existen dificultades insalvables en el intento de reducir la causa a la probabilidad, si aceptamos que las causas ocurren de forma singular. Esto no implica que estas herramientas dejen de ser útiles en el análisis causal: en situaciones deterministas nos permiten 
establecer correlaciones correctas entre factores causales y efectos, siempre y cuando se complementen con información que permita excluir correlaciones espurias e irrelevantes. La existencia de relaciones estadísticamente relevantes es un signo claro (aunque no absolutamente confiable) de la existencia de relaciones causales entre los factores o propiedades relacionados: actúa como un medio para determinar la relevancia causal, esto es, como un indicio de los mecanismos que operan en la producción de un efecto y de la magnitud de su incidencia sobre tal efecto. Pero la mayor utilidad de la información estadística y probabilística está en procesos indeterministas y en contextos de predicción bajo condiciones de incertidumbre, en los que se constituye en la herramienta propia del análisis causal; en ausencia de información sobre los mecanismos se constituye en la explicación genuina para estos casos.

\subsection{Las leyes y las relaciones causales}

Es indudable que para tener una idea más clara de los problemas que gravitan en torno a los modelos de explicación hemos de referirnos al problema del papel de las leyes, que repercuten en la identificación de lo que sea la causa, en el análisis probabilista de la causa y de la explicación y en la tensión entre visiones singularistas y regularistas de la causalidad. Pese a que las relaciones causales tienen una ocurrencia singular, la necesidad de encontrar explicaciones comunes a tipos de fenómenos nos lleva a buscar patrones de regularidad en la naturaleza, aunque también en este caso se puede apreciar la diferencia entre entender las leyes como descubrimientos y entenderlas como estructuras que la mente crea para ordenar los datos de la naturaleza. El problema es que no está suficientemente delimitada la noción de ley, pues no siempre se la puede diferenciar de una generalización accidental. Mackie (1999, p. 206) considera que el regularismo tiende a considerar la ley como derivable de otras regularidades más fundamentales, dado que las accidentales, en cambio, se limitan a casos particulares, como en el ejemplo de "todas la monedas de mi bolsillo son brillantes". Pero aún las regularidades accidentales pueden derivarse de otras, así que parece más adecuada la afirmación de que las leyes deben apoyarse en evidencia inductiva, que garantiza que otros casos del mismo tipo las cumplan. Además, una generalización accidental, pese a que sea verdadera no sustenta los enunciados contrafácticos (unidos a la evidencia) que permiten la aplicación de una ley.

Se aspira a que una ley de la naturaleza sea el caso extremo de una ley estadística, es decir, que dados ciertos antecedentes, cuando la probabilidad de que ocurra cierto evento es 1, el enunciado 
tendría la fuerza de una necesidad lógica (Mackie, 1999, p. 232). Tooley (1987, p. 5) identifica las leyes con una relación contingente, irreducible y teorética entre universales, concepción que permite que una ley pueda seguir siéndolo aún sin tener alguna instancia en la cual esta se presente. Por ejemplo, la primera ley de Newton requiere que sobre un cuerpo no se ejerza ninguna fuerza para que mantenga su estado inercial y esto no ocurre nunca: un ejemplo de lo que sería una ley teorética. Si la condición de ausencia de fuerzas no se presenta, es decir, si alguna fuerza incide sobre el movimiento del cuerpo, se altera el movimiento inercial, con un cambio proporcional a la fuerza, que es lo que define la segunda ley; así, podríamos decir que el requerimiento de ausencia de fuerzas es más una condición que define el comportamiento de un cuerpo, esto es, su tendencia a permanecer en un estado inercial; si lo vemos de esta manera, como condición para adquirir cierto estado, se debilita la posición de Tooley.

Para diferenciar entre ley y regularidades accidentales Woodward $(2003,167)$ acude a la noción de ley aceptada en filosofía de la ciencia: enunciados condicionales cuantificados universalmente; que describan regularidades sin excepción (no se refieren a casos o localizaciones particulares), que puedan ser contrastados con las observaciones y que sean capaces de soportar condicionales contrafácticos; además de esto las leyes suelen integrarse en cuerpos teóricos mayores y ofrecen ejemplos paradigmáticos. Aunque, desde su punto de vista, el mejor criterio para identificar a las leyes es que ante intervenciones y otros cambios tal generalización se conserve invariante. Sin embargo, también las generalizaciones accidentales pueden ser verdaderas, y no por eso son leyes: pese a su naturaleza regular no sustentan una explicación científica. Es por ello que las leyes se deben poner en el contexto de un sistema de generalizaciones, con lo cual el enunciado con forma de ley puede hacer parte de un sistema deductivo que garantice una jerarquía que excluya lo accidental y posibilite hacer deducciones.

Así que lo que consideramos más adecuado con respecto a la diferenciación entre las leyes y las regularidades accidentales está en consonancia con una concepción de las leyes correspondiente a la búsqueda de los patrones de regularidad que existen en la naturaleza y la diferencia con las regularidades accidentales se encuentra en que estas son localizables, en el sentido en que no pueden extenderse a la generalidad de los casos ni a la vez ser puestas en relación con un cuerpo más general de leyes. Sin embargo, hay que tener en cuenta que las leyes sirven como un principio de análisis de casos particulares, pero son más adecuadas para los modelos teóricos, en los cuales se cumplen las condiciones estrictas que permiten su cumplimiento con la precisión necesaria. 
Tampoco hay que olvidar que hay leyes de coexistencia y leyes causales, que no son siempre diferenciables con claridad, pero ya hemos insistido en que nuestra búsqueda de la razón de los cambios en la naturaleza nos hace inclinar a la indagación por las regularidades causales.

Puesto que el objeto del presente estudio es la indagación por la causa, comentaremos algunos de los aspectos de la relación que existe entre causa y ley causal. Tooley $(2003,167)$ considera que hay tres alternativas posibles al considerar tal relación: la primera afirma que las leyes causales son primarias y las relaciones causales secundarias, las leyes causales determinan a las causas, como corresponde a la visión regularista, de manera tal que los hechos concretos son la manifestación de una relación universal. A esta opción se opone la visión singularista, que afirma que lo primario son las relaciones causales que ocurren entre los estados de cosas concretos mientras que las leyes son secundarias, esto es, que se derivan o se construyen a partir de nuestro conocimiento de los hechos. La tercera alternativa (con pocos partidarios, según comenta el autor), desecha las dos posibilidades anteriores al negar que los hechos causales singulares estén lógicamente determinados por las leyes y afirmando que pueden existir causas singulares para los que no haya una ley causal correspondiente; lo cual es una versión del singularismo, que niega de forma más extrema el papel de la regularidad y dejaría en duda nuestra posibilidad de prever el comportamiento natural.

La primera opción, que da prioridad a las leyes causales, encuentra dificultad en compatibilizarse con la existencia de leyes indeterministas, capaces de producir resultados imprevisibles; pero aún dentro del campo determinista no es muy aceptable que las leyes ocupen un lugar más básico que sus manifestaciones causales, pues estas se encuentran en los hechos, mientras que las leyes hacen parte de nuestros sistemas de conocimiento del mundo. D ucasse (1968, p. 6), defensor del singularismo, afirma que la causa ocurre entre eventos concretos, de modo que la recurrencia es irrelevante para la noción de causa, y que tampoco constituye el sentido de la relación causal, mientras que si se elabora una ley es porque existen relaciones similares susceptibles de generalización: si existe sucesión constante es apenas una evidencia de que en la serie de eventos hay alguna conexión causal. El riesgo que corre la visión singularista es que una posición extrema al respecto conduciría a entender la causación como la relación que ocurre entre dos eventos concretos, relación única e irrepetible que, por lo tanto, no obedece a leyes, ni permite diferenciar las relaciones causales de las no causales: en la tercera alternativa la relación causal sería el resultado de unir leyes causales con hechos no causales, lo cual puede dejar hechos singulares sin una ley 
que los cubra, y esto no parece aceptable, pues oscurece las relaciones entre causa y ley, creando además otras relaciones con hechos no causales que requerirían de una definición adicional. La alternativa para Tooley (1987, p. 251) es aceptar una visión que él denomina realista, que defina la relación causal como una relación teorética entre estados de cosas, que determine la dirección de la transmisión lógica de probabilidades.

Sobre esta cuestión es pertinente la lectura que Cartwright hace sobre el problema de las leyes, que divide entre fenomenológicas y teoréticas, las primeras encargadas de las descripciones de los sucesos y las segundas inferidas a partir de las primeras. La autora adopta una posición un tanto radical, que deja patente desde el mismo título de su libro $\mathrm{H}$ ow the $\mathrm{L}$ aws of Physic $\mathrm{L}$ ie; en el que compara la física con una especie de simulación que ofrece conclusiones correctas sobre algunos fenómenos y sobre sus causas, pero que no se corresponden necesariamente con la realidad (Cartwright, 1991, p. 156). Así, la física trabaja con modelos idealizados en la medida en que a las propiedades genuinas de los objetos se les suman otras no porque sean reales sino por su conveniencia al modelo. Entre estas se crean algunas propiedades tan ideales que llegan a lo ficticio, pues carecen de sentido fuera de las condiciones controladas de los experimentos, en las que, en lugar de indagar por el comportamiento real, se busca que la realidad imite a los modelos. De esta forma las leyes fundamentales son generales apenas aparentemente, puesto que las ecuaciones se cumplen en los objetos que fueron construidos para que se comporten de acuerdo con las leyes, es decir, en los modelos:

In general, nature does not prepare situations to fit the kinds of mathematical theories we hanker for. We construct both the theories and the objects to which they apply, then match them piecemeal onto real situations, deriving - sometimes with great precision - a bit of what happens, but generally not getting all the facts straight at once. The fundamental laws do not govern reality. What they govern has only the appearance of reality and the appearance is far tidier and more readily regimented than reality itself (Cartwright, 1991, p. 162).

La parte de razón que asiste a Cartwright consiste en que, en efecto, la ciencia busca unas leyes generales que permitan determinar cómo operan las relaciones entre los eventos reales, pero estos siempre tiene un comportamiento más complejo del que es expresado por medio de las leyes fundamentales y en ese sentido se aproximan más a las idealizaciones de los modelos que al comportamiento real de los objetos. Como muestra podemos poner el funcionamiento de las palancas, en las cuales se establece una relación inversamente proporcional entre las fuerzas que están en los extremos y las distancias con respecto al punto de apoyo; el asunto es que requieren 
de condiciones ideales que se aproximan a la realidad pero que no se cumplen estrictamente, salvo en un modelo idealizado en el que la palanca no debe tener masa, pues el peso correspondiente a esa masa habría necesario recalcular la proporción, ni debe presentar ninguna torsión ni fricción pues perdería eficiencia: total, se trata de una palanca infinitamente rígida y sin masa, a todas luces ficticia. Y el otro caso es el de la ley de gravedad que define la atracción entre dos masas con respecto a su distancia, situación ideal que no se cumple en el universo: la sola presencia de un tercer cuerpo con masa hace que las ecuaciones de Newton carezcan de la capacidad de predecir el comportamiento de forma exacta. Si esto es así, el ámbito estricto de aplicación de las leyes es el de los modelos idealizados. Ahora, es justo decir que la ciencia progresa hacia la elaboración de leyes más precisas, y que pese a que las leyes definan un comportamiento ideal, esto no implica que estas leyes carezcan de poder explicativo; sería más acertado entender que los modelos son abstracciones necesarias para entender la complejidad del mundo, como lo plantean Bertuglia y Vaio (2005, p. 12): los mecanismos por los cuales ocurre el cambio no son evidentes, y se apela a crear representaciones que se centran en aspectos que son primarios en una situación, dejando de lado otros que no se consideran relevantes.

Para Cartwright (1991, p. 11) la explicación busca tanto las leyes que gobiernan el tipo de eventos como determinar cuáles son sus causas. Lo primero consiste en encuadrar el hecho en el marco de leyes teoréticas abstractas (que no describen hechos particulares), pero este camino, como veíamos, no conduce hacia la verdad de los hechos, ya que los mismos hechos pueden caber en diferentes modelos. D eterminar las causas implica la búsqueda de las leyes fenomenológicas que rigen las situaciones concretas, así que no son admisibles dos historias causales del mismo hecho. Los modelos de leyes de cobertura tratan de hacer las dos tareas simultáneamente, cosa que no es posible ya que las causas se excluyen en su acción real, mientras que las descripciones teóricas provistas por los modelos pueden ser compatibles. Cartwright dice que, contra lo que se suele creer, las leyes de cobertura incluyen muy poco, dada su escasez, pues el tipo más usual de regularidad no son las leyes sino las generalizaciones ceteris paribus. Puesto que las leyes requieren de unas condiciones que muchas veces son ideales, su aplicación se limita a casos particulares, a los pocos casos en que las condiciones son las correctas. La ciencia necesita leyes de cobertura, que permitan unificar las explicaciones pero, agrega: "There is no reason to think that the principles that best organize will be true, nor that the principles that are true will organize much" (Cartwright, 1991, p. 53), de modo que hay que seguir contando con la tensión entre los modelos comprensibles 
y la realidad que se resiste a ser organizada y comprendida; no hay leyes sin excepciones ni es claro cuánto tenga que ceder la exactitud en pro de la capacidad de explicar.

La autora sostiene que la explicación no es la guía hacia la verdad (Cartwright, 1991, p. 4), como lo sostienen las concepciones pragmáticas de la explicación, salvo que estemos hablando de una explicación causal. Así, lo que se debe hacer no es buscar la mejor explicación sino la causa más probable, que es lo que buscan los experimentos: especificar los factores explicativay causalmente relevantes. En última instancia lo que hace Cartwright no es negar que existan leyes de cobertura - aunque no siempre están disponibles- , lo que afirma es que las explicaciones preceden al conocimiento de las leyes y, mientras estas no se hayan formulado, la ciencia debe decir qué tipo de explicaciones son admisibles. Puede ser fructífera la vía de determinar estadísticamente los factores que tengan la mayor incidencia causal sobre los efectos, como base para elaborar explicaciones de situaciones causalmente problemáticas, aunque Cartwright cree que aun así queda un remanente de casos sin explicar: si atribuimos la causa al factor que ofrezca la correlación estadística más significativa pueden quedar casos que no pueden adjudicarse a esa causa, como sucede con el uso de los plaguicidas: nos queda por explicar y encontrar la causa de que unos especímenes sobrevivan, pues evidentemente no la podemos atribuir a la sustancia aplicada y no es una respuesta satisfactoria acudir a la existencia de influencias ocultas. Es cierto que la ciencia busca principios y leyes unificadoras, pero no al punto en que se tengan que aceptar los que se alejen significativamente de los hechos reales (Cartwright, 1991, p. 53). Una idea similar fue expresada por Einstein (2011, p. 232): “En la medida en que se refieren a la realidad, las proposiciones de la matemática no son seguras y, viceversa, en la medida en que son seguras, no se refieren a la realidad", frase que alude a las aplicaciones de las matemáticas, pero es extensible a las limitaciones esenciales a todo modelo: el grado de abstracción necesario para que abarque un conjunto de fenómenos lo hace más comprensible y armónico con sistemas de representación basados en leyes, pero a la vez lo aleja de su aplicación a entidades particulares, normalmente más complejas. Es un hecho que la matematización de la física ha permitido su gran desarrollo actual, y que la matematización también es una forma de explicación, pero no se puede desconocer cierta tensión entre este procedimiento y la búsqueda de explicación de los eventos particulares.

Las teorías y los modelos buscan la generalidad necesaria para extender su aplicación y por eso se resisten a especificar casos, lo cual se constituye en un límite a su validez en procesos irreversibles, que tienen un comportamiento único y por eso deben ser descritos individualmente, pues las 
ecuaciones no pueden predecir la evolución futura general de los procesos (Cartwright, 1991, p. 64). Otras de las observaciones acertadas que hace Cartwright es que en ocasiones conocemos las causas de un fenómeno y las leyes de cobertura que se aplican en el caso, pero esto no equivale a tener una buena explicación: si la explicación no puede describir el proceso completo seremos incapaces de comprender por qué el evento sucede, ya que en el efecto pueden incidir leyes de un dominio diferente a la ley de cobertura que generaliza estos casos (Cartwright, 1991, p. 71). Así, no basta con que las leyes naturales describan adecuadamente el comportamiento de los sistemas físicos o permitan unificarlos en una jerarquía; según la autora, se necesita un acuerdo entre el contenido fáctico y la capacidad explicativa: no basta con tener una buena descripción 0 leyes de cobertura. Las leyes, aun cuando sean verdaderas, no explican mucho, si no es en conjunción con información acerca de las causas: la vía más adecuada para explicar es buscar la causa más probable. Cuando los resultados de diversos experimentos u observaciones son congruentes no es porque confluyan hacia una explicación privilegiada sino que su coherencia se debe a que son efecto de una sola causa, elemento que debe ser tomado en cuenta si se quiere hacer el tránsito entre explicación y causa.

Salmon (1984, p. 239) defiende la idea de que son las causas las que estructuran el mundo; defiende una visión de la explicación científica que consiste en encontrar las regularidades estructurales del mundo a las que corresponden los fenómenos, regularidades basadas en las relaciones causales, por lo cual su concepción óntica es una concepción causal de la explicación científica. Salmon no llega a afirmar que la explicación causal sea universal, pues admite que posiblemente las causas tienen diferentes formas, pero defiende que su objeto es entender cómo operan las cosas. El autor se queda corto en su afirmación pues parece evidente que las causas tienen formas diferentes de operación, esto es, que existen muchos mecanismos diferentes por medio de los cuales en la naturaleza pude propagarse la influencia causal; también es cierto que lo que aceptamos como explicación tampoco se limita a dar cuenta de las causas: un marco general de leyes es un procedimiento válido para dar cuenta de diversos fenómenos de forma coherente. Hay, por ejemplo, un evidente progreso científico en el hecho de poder aplicar una sola ley a eventos aparentemente inconexos como la caída de los cuerpos y las órbitas elípticas de los planetas: el relato está incompleto mientras no tengamos una descripción susceptible de tratamiento experimental de las posibles ondas que trasmitan la influencia gravitatoria, pero hay explicación, en la medida en que contamos con descripciones adecuadas de muchas interacciones, que estas interacciones se comportan de manera previsible dentro de los límites de la teoría y que 
hay leyes generales coherentes con las regularidades de la naturaleza. No conocemos la explicación definitiva, pero una explicación incompleta también es una explicación. Podemos ver las leyes de Newton como las regularidades del comportamiento localizado de eventos en una escala intermedia, en que no están involucrados cuerpos muy masivos (ni muy pequeños) ni velocidades muy altas, es decir, como una aproximación a la relatividad, que comprende fenómenos a escalas mayores, pues no es factible ni tiene mucho sentido calcular los efectos relativistas de los eventos de nuestra escala intermedia (como tampoco suele tenerlo el cálculo de los efectos cuánticos). Las leyes tienen un ámbito de aplicación que no es general y, por otro lado, la ciencia progresa descubriendo que las regularidades locales pueden tener concordancias con campos mayores, por eso deberíamos aceptar lo provisorio de las explicaciones y su perenne incompletud. Además de esto no hay que olvidar que hay campos más susceptibles de tratamiento por leyes, como la física, mientras que en biología o aún más en ciencias sociales las posibles leyes son de aplicación más local y por eso están llenas de excepciones.

Tras esta exposición parece oportuno recordar que sigue habiendo discusiones acerca de si las leyes son necesarias o contingentes, y si en últimas la noción de ley abarca todo lo que incluimos en ella. No hay que olvidar que las leyes no se limitan a las causales, por ejemplo hay leyes taxonómicas, que clasifican, cinemáticas, que describen movimientos, y estadísticas, como la cinética del calor (Bunge, 1961, p. 270). Son leyes que unifican comportamientos bajo una proporción regular que en alguna medida también explican o permiten construir explicaciones. Por su parte, Lewis, con respecto a la importancia de las leyes en la explicación sostiene:

[... ] I would never deny the relevance of laws to causation, and therefore to explanation; for when we ask what would have happened in the absence of a supposed cause, a first thing to say is that the world would then have evolved lawfully.

[... ] It can be agreed that information about the prevailing laws is at least highly relevant to causal information, and vie versa; so that the pursuit of explanation and the investigation of laws are inseparable in practice (Lewis, 1986, p. 239).

Y, en efecto, cuando se indaga por las causas hay que suponer que la realidad, pese a tener una ocurrencia singular, cumple con ciertos parámetros regulares de comportamiento: los fenómenos tienen rasgos particulares, pero eso no significa que su comportamiento sea único, dado que la naturaleza es más o menos predecible. Ese grado de predicción está determinado por qué tanto conozcamos las leyes que rigen un tipo de casos y qué tan precisa es la información que tenemos sobre el caso en particular. Q ue no conozcamos la causa no implica que podamos calificar como 
arbitrario el comportamiento de la naturaleza, pues en ese caso es más sensato suponer nuestra ignorancia que la ausencia de leyes. Algunas de las regularidades que observamos son accidentales, pero son las leyes las regularidades relevantes para la explicación de un efecto: podemos dar cuenta de una causa conociendo el conjunto de condiciones que concurre para la existencia del efecto, junto con las leyes correspondientes. Los argumentos nomológico-deductivos pueden ser buenas explicaciones, pero esto no nos puede llevar a negar que es en el mundo donde ocurren las relaciones causales singulares y que estas no siempre son manifestaciones de las leyes conocidas por la ciencia, ya sea porque no han sido formuladas o porque son hechos accidentales, que de todas maneras son causales. Las explicaciones pueden acudir a leyes, pero ya hemos visto que existen otras formas de explicación y, en cuanto tiene que ver con la preeminencia entre causa y leyes naturales, optamos por la defensa de una estructura causal del mundo, en que las leyes permitan unificar manifestaciones diversas de los acontecimientos. Como lo plantea GarcíaEncinas (1998, p. 17), la dependencia causal ocurre en el nivel ontológico, así que puede haber leyes para todas las relaciones singulares pero las relaciones causales no dependen de ellas, pues están en la realidad y no en nuestros enunciados.

Woodward (2003, p. 23) considera acertadamente que una teoría de la causalidad y de la explicación debe tener algunas características como las siguientes: ser descriptivamente adecuada, de manera que capte las características principales de las explicaciones paradigmáticas y las estructuras de los sucesos; debe mostrar lo que tienen en común las variedades de explicación causal; debe permitirnos evaluar explicaciones y diferenciar enunciados explicativos de los solo descriptivos; debe elucidar los éxitos y fracasos de las anteriores teorías, y debe tener un soporte epistemológico adecuado, que posibilite examinar la corrección de las explicaciones. Esto implica que lo más adecuado es que una teoría de la causa y de la explicación se desarrolle de manera conjunta, una forma de dar cuenta de las explicaciones causales de los eventos concretos.

Recapitulando, podemos decir que esa base ontológica y singular en que operan las causas es el punto de partida para elaborar las leyes y las teorías causales. La observación y el experimento nos permiten descubrir por vía inductiva los patrones que cumple la naturaleza, pero de la misma forma tales procedimientos nos han mostrado que las leyes son expresiones formalizadas de un comportamiento idealizado de los fenómenos, son expresiones de cómo se comportaría la naturaleza en condiciones ideales, pero como estas rara vez se cumplen es inútil pedir necesidad (o una probabilidad de 1); desde esta idea no parece aceptable la universalidad de las leyes, dado 
que los fenómenos presentan variaciones y así, lo más adecuado es aceptar que hay cierto componente estadístico en toda ley, en su aplicación a conjuntos de casos y que, además, las leyes cada vez son más locales. La utilidad de las leyes o de la regularidad causal consiste en que permiten modelar comportamientos ideales, de manera tal que si el evento particular se aparta de este comportamiento es porque existe una interferencia que es necesario buscar, algo que hemos aprendido en nuestra búsqueda de estrategias efectivas para incidir sobre la naturaleza.

No podemos medir la verdad de las leyes y de las teorías en la medida en que sean capaces de dar explicaciones satisfactorias o que salven los fenómenos, pues en esta medida podríamos construir una estructura científica sin pretensiones de universalidad y con una capacidad explicativa limitada. Pero tampoco es aceptable asumir que las leyes se ocupan más de los modelos que de la realidad y que por tal razón sean falsas las leyes fundamentales. Es más adecuado entender que hay leyes más o menos particulares y que, en la medida en que una ley pretenda abarcar una gama mayor de fenómenos lo hará a costa de ignorar ciertas diferencias. Q ue las leyes sean limitadas porque se basan en condiciones ideales no nos puede llevar a desecharlas porque en efecto, en situaciones experimentales el comportamiento de los objetos cumple las leyes en el sentido en que su comportamiento se acerca más a un modelo, en la medida en que las perturbaciones pueden ser controladas; no puede declararse la falsedad de la ley pues esta puede, en principio, prever el papel que puedan tener otros factores adicionales. En el epígrafe de von Neumann con el que se empezó este capítulo el autor afirma que la ciencia, más que explicar, elabora modelos descriptivos de la realidad y que la aspiración es modesta: solo se espera que los modelos funcionen. No hay que olvidar que en muchos campos de la ciencia no se han logrado formular leyes aceptables, ya sea porque no se han podido matematizar o porque sencillamente no se han descubierto regularidades tan poderosas como las de la física.

\subsection{Contextualidad de la explicación}

Buscar la causa de un evento equivale a indagar por los factores particulares que permitieron que este ocurriera; sin embargo, indagar si el evento pertenece a una tipología de casos similares, es decir, comparar si presenta factores comunes con otros casos permite conocer otras dimensiones del evento y prever el efecto que podría ocurrir. Así es que nuestro interés abarca tanto la relación entre causas y efectos concretos, como el conocimiento de los elementos que concurren en una relación ideal, sin interferencias, entre los factores presentes en una situación y sus cambios, de 
manera tal que la ocurrencia de cierto cambio en un evento permita predecir que ocurrirá otro cambio en otro evento como su consecuencia. Como se ha insistido hasta el momento, esto señala la tensión que existe entre la constatación del evento individual frente a la necesidad de encontrar regularidades que nos permitan explicar y prever el comportamiento de la naturaleza. Lo usual es que el cambio sea un proceso más complejo de lo que se aprecia a simple vista, pero esto no implica que todos los elementos del cambio sean necesarios para la producción del efecto; la única manera de saber si uno de los elementos del cambio es suficiente es comparándolo con otro estado de cosas en que este factor esté ausente; esto implica depender en alguna medida de las descripciones de los sucesos. Existe un posible contraste, por lo menos cierta diferencia, entre una descripción de un evento concreto y otra que idealiza en alguna medida cuáles son los factores necesarios para que el evento se produzca o para que podamos adjudicar la misma causa a efectos diferentes. Como ya mencionábamos, el énfasis en las características peculiares del cambio concreto nos pone en riesgo de ignorar que necesitamos hallar las regularidades en el cambio que nos permitan entender cómo opera la naturaleza. Pero tampoco es necesario ir hasta un regularismo extremo que adjudique las causas solamente a la conjunción constante, por todas las consecuencias que trae tal posición: necesitamos crear una visión del mundo que sea capaz de describir lo concreto sin olvidar la búsqueda de explicaciones más generales.

Esto nos devuelve a la consideración de los eventos frágiles, que no pueden ocurrir sino de una determinada forma y en determinado tiempo, una cuestión que nos remite a si las causas se reputan de los eventos individuales o de tipos de eventos, en lo cual nos encontramos con el problema de si se buscan leyes o descripciones. Esa fragilidad puede abrir las puertas a causas espurias, como al atribuir un papel causal a factores irrelevantes por el hecho de ser únicos: si los eventos son irrepetibles siempre serán la conjunción de una serie de factores única, y si no podemos comparar el evento con otros similares, tampoco se pueden diferenciar los factores que tienen un papel causal de aquellos que no lo tienen. Menzies (2012, p. 350) menciona como ejemplo el caso del fusilado cuya muerte es causada por el pelotón, como un todo único, es decir, incluyendo a algún soldado que no disparó, que para el caso es tan causante como los demás. Así, se pone a depender altamente la causa del contexto, pero deberíamos tener información suficiente como para que la causa se mantenga independiente de la forma en que son descritos los eventos, a fin de evitar que la indagación por la causa se confunda con la búsqueda de una explicación convincente; no hay que olvidar que consideramos la causa como un problema eminentemente ontológico. La cuestión consiste en la virtual imposibilidad de describir una relación causal sin 
hacer una elipsis de toda la situación, de ahí que un solo evento puede ser descrito de muchas formas: "moví el interruptor", "encendíla luz", "iluminélahabitación", "alertéal ladrón” (Menzies, 2012, p. 347): en cada descripción se enfatiza un determinado aspecto que se considera esencial, lo cual puede ser interpretado como una muestra de que se denotan eventos diferentes. Esta es una forma de entenderlo, pero es pertinente limitar el planteamiento de Menzies acerca de este ejemplo, haciendo la observación de que en últimas la realidad es una sola, a pesar de que las descripciones sean múltiples: el hecho es uno solo, independientemente de las fórmulas verbales que utilicemos para describirlo (y de las deducciones que se puedan hacer con tales expresiones), dado que siempre tenemos un interés en resaltar el aspecto que se considera relevante para la explicación, no tanto para la causa o para la historia causal, que incluso puede ser parcialmente desconocida.

Una explicación puede ser más o menos insatisfactoria, en la medida en que se basa en información falsa o insuficiente, pero también si hace un uso incorrecto de relaciones de inferencia. Pero, aparte de estos elementos epistémicos y lógicos, la explicación también debe atender a una cuestión pragmática: la relevancia de la información que provee puede hacer que sea satisfactoria o no. Idealmente la explicación debería tender hacia una situación en que el evento consecuente tenía que ocurrir o su probabilidad debía ser muy alta, en obediencia clara a las leyes estipuladas para el tipo de casos pertinente. Pero no hay que olvidar que en la práctica las probabilidades de ocurrencia de un evento no son necesariamente altas y existe aún menor seguridad sobre la predicción detallada de eventos. Y, fuera de excepcionales casos con aislamiento completo o en situaciones controladas de laboratorio, no existe la posibilidad de hacer la descripción total de una situación, razón por la cual también las explicaciones son en alguna medida parciales y provisionales: siempre hay un gran número de factores capaces de intervenir en mayor o menor medida en el curso causal y de esta forma proveen explicaciones diferentes aunque compatibles. La provisionalidad de la explicación es una cuestión que evoluciona en la medida en que la ciencia elabora teorías capaces de dar respuesta a más preguntas, de modo que toda teoría puede ser complementaria (o superior) a aquella que remplaza.

Así como veíamos que la diferenciación entre lo que se considera como el factor causal eficiente frente a las condiciones de trasfondo depende del contexto de indagación, esta indefinición es más patente en el caso de la explicación. La parcialidad de las explicaciones es una cuestión que se enfrenta a unos límites concretos: no hay manera de dar una explicación total de algún fenómeno, 
puesto que la realidad es compleja, cada evento está inmerso en una red de relaciones causales y no causales que hacen inagotable (e incluso inútil) una descripción y una explicación total. Esto no impide que se puedan hacer explicaciones satisfactorias, siempre que tengamos en cuenta que son parciales y que en ellas se privilegian algunas características que se consideran más relevantes que otras frente al contexto de la pregunta que se intenta responder, lo cual no implica que haya causas particulares correspondientes a cada una de las explicaciones posibles. Lo que parece claro en la búsqueda de las causas es que contamos con una serie de indicios acerca de cuáles pueden ser los factores relevantes en una determinada situación y que las historias se reconstruyen explicativamente en dependencia de ciertas necesidades pragmáticas. Por esto, diferentes descripciones no implican diferentes eventos pero dan base a explicaciones diferentes, lo que de nuevo nos lleva a preguntarnos por el papel de la relevancia de ciertos factores causales en la explicación, que es el problema que se tratará a continuación.

De la pluralidad de explicaciones no se puede concluir que las causas no existan objetivamente (tal como lo han sostenido autores que privilegian las explicaciones funcionales), o que cumplan simplemente la función de dar una explicación que salve los fenómenos, independientemente de si se corresponde con la realidad. En este sentido, van Fraassen (1996, p. 97) afirma que las teorías se pueden elegir por su capacidad de explicación, esto es, más por su adecuación empírica que por ser verdaderas, y más por su capacidad de enmarcarse dentro de estructuras que por dar explicaciones. Lo que podemos deducir al respecto es la importancia del contexto: tanto el lenguaje de las teorías, como su evaluación y las explicaciones que provean atiende a intereses humanos, de modo que una parte de la explicación se ocupa más de los componentes pragmáticos que de la búsqueda de la verdad. En cierta medida es razonable esta afirmación, pero se podría objetar que esto implicaría una marcada subjetividad en la explicación, que no parece el caso, dado que la ciencia ofrece con el paso del tiempo más respuestas, más acertadas y con un más amplio consenso; la ciencia elabora nuevos enunciados sobre la realidad y complementa y corrige los anteriores. La ciencia no se limita a salvar los fenómenos sino que aspira a dar cuenta de cómo estos ocurren realmente, así que la idea de salvar los fenómenos es una respuesta provisional mientras no tengamos hipótesis más adecuadas para responder a cómo los eventos se modifican causalmente, idea que, pese a no dar cuenta de todas las alternativas de explicación, sigue siendo el medio de más alcance para comprender cómo operan las cosas en el mundo. 


\subsection{Relevancia en la historia causal y el contexto explicativo}

Este último aparte está dedicado a mostrar algunas de las consecuencias que las reflexiones hechas hasta el momento han tenido para la defensa de la concepción sobre causa y explicación que se ha intentado estructurar en el presente escrito. La intención que se tiene es la de mostrar que en la indagación sobre las causas es necesario contar con el concepto de relevancia, como una fuente de indicios útiles para desentrañar el papel que cumplen los factores causales en la producción de un efecto. Esa utilidad se puede ver tanto en la ontología causal como en la búsqueda de explicaciones, pues este último espacio debe estar ligado a la construcción de las historias causales, el espacio adecuado dentro de una concepción óntica de la explicación.

\subsubsection{Los ámbitos de la explicación y de la causa}

La idea de que en cada una de las situaciones que ocurre entre la causa y el efecto existe un cierto tipo de conexión, con características comunes, no es más que un intento de sintetizar un panorama que es mucho más complejo, dado que no ha sido posible encontrar una característica, una noción o una propiedad que sea común a todo tipo de causas. Varios autores han defendido la naturaleza contextual de la causa e incluso su inexistencia dentro de las ciencia, pero Hitchcock (2003, p 4) afirma que el problema está más en creer que la relación causal es una sola; para el autor la causa tiene su papel en la distinción entre estrategias efectivas y no efectivas (en lo cual coincide con Cartwright): acertadamente afirma que pese a no existir una relación causal única, podemos dar cuenta de que ciertos factores tienen una incidencia real que nos posibilita obtener algunas consecuencias. Muchos factores y condiciones tienen incidencia causal, son causas genuinas de la ocurrencia de un efecto, pero cuál de los múltiples factores incidentes aceptemos como causa depende de los intereses de quienes indaguen sobre el suceso: un accidente de coche puede ser causado por una imprudencia, pero no toda imprudencia causa un accidente, si a él sumamos el desgaste de los neumáticos o el agua sobre el pavimento, la falta de visibilidad, etc., veremos que cada uno de los factores puede ser considerado como genuinamente causal y es posible que si se presentase apenas uno de los factores en lugar del conjunto, el accidente podría no haber ocurrido. Cada uno de los factores que se reste de la situación global haría menos probable el accidente y cuál sea considerado el principal depende de la perspectiva desde la que se esté considerando la situación: sea esta la de mejorar el diseño de la carretera o de los neumáticos, 0 la preparación previa de los conductores. 
Ahora, desde la perspectiva del análisis de los factores causales como necesarios o suficientes, entran en juego otras consideraciones sobre cómo hemos de entender las tipologías de causas, dado que la sola observación singular no nos da suficiente información como para entender y menos aún, para prever cómo han de ocurrir los sucesos. Sobre este punto Hitchcock afirma que se ha de acudir a las leyes de la naturaleza, y llama la atención sobre la necesidad de diferenciar las leyes de sucesión de las leyes de coexistencia, pues estas apuntan a las correlaciones entre propiedades, como las que se dan entre presión, temperatura y volumen en un gas. Cada teoría científica está hecha para dar cuenta de cierto rango de problemas: ya que se parte de diversidad de preguntas, no existe una teoría única que dé cuenta de los fenómenos y, de la misma manera, tampoco puede esperarse que exista una única forma de causa ni un mecanismo único de influencia causal. En esto consiste la cuestión del contexto como definidor de causas y condiciones: lo que se acepta como condición de fondo para una determinada teoría puede ser un factor determinante si la pregunta varía, tal como se veía en el ejemplo del párrafo anterior, pues factores como el del asfalto mojado o el del desgaste de los neumáticos pueden ser considerados parte del trasfondo causal, en la medida en que los fabricantes del coche deben prever que se habrán de presentar eventualmente, pero también puede ser los factores más sobresalientes para dar una solución adecuada a determinadas preguntas.

En definitiva, las respuestas que encontremos al buscar las causas siguen correspondiendo al problema con el que se encontró Hume al intentar su definición: tenemos ciertas percepciones de la realidad, pero en ellas no encontramos el elemento clave de la causa - la necesidad de la conexión- , y sin él nos encontramos apenas con una sucesión de eventos de la que no tenemos otra impresión diferente de la contigüidad espaciotemporal. La cuestión es que Hume sustenta la verdad en las impresiones que los sentidos tienen de la realidad, lo que impide desentrañar la forma de reducir el vínculo causal a elementos perceptibles en la realidad, más allá del hecho de que inferimos que siempre que cierta causa ocurre, le sucede cierto efecto. Y además, no tener certeza sobre en qué consiste la unión causal nos dejaría sin los elementos para distinguir una conjunción constante de una relación causal, o incluso de una coincidencia. De ahí que Hume tenga que dar el mencionado giro (D uque, 2005, p 234) desde su intento de definición de la causa a partir de la observación de las secuencias reales a la impresión que estas causan en nuestra mente, de la causa en los objetos pasa a sustentar la necesidad en una idea, en una inferencia que no puede percibirse en la realidad, pues no se encuentra un vínculo común perceptible en todas las relaciones entre causa y efecto. Este giro va desde lo ontológico a lo epistémico pues, en el 
primer plano, no se puede poner a depender una secuencia concreta de otros acontecimientos similares con los cuales no hay vínculo real; la mente compara nuestras experiencias con la presencia de un objeto que suele cumplir un papel causal y de ahí derivamos que ha de presentarse su efecto.

En la prosecución de nociones adecuadas de explicación se ha intentado poner las bases más firmes posibles por medio de la elaboración de argumentos con la seguridad lógica en la forma y con contrastabilidad empírica. Si no logramos esta seguridad podemos acudir al modelo inductivoestadístico, que nos ofrece la información necesaria, si no para que el fenómeno ocurra, por lo menos para dar cuenta del incremento en su probabilidad. Sin embargo Mackie (1999, p. x) acertadamente afirma que la causalidad es más que regularidad pero no tanto como necesidad lógica, ya que no se ha encontrado que la causa pueda ser traducible a una relación lógica entre premisas, pues siempre conlleva contingencias, en la misma forma que las leyes.

Nuestra posición como agentes capaces de intervenir en el mundo nos hace proyectar en la naturaleza la semejanza con nuestros actos para interpretar como causas las sucesiones que se presentan entre eventos (Álvarez, 2014, p. 137). Es indudable que nuestro análisis de las causas está mediado por nuestras proyecciones interpretativas sobre la realidad, que nos hacen ver como causales incluso las relaciones que se reducen a simples sucesiones, pero de ahí no podemos deducir que las causas no tengan una existencia objetiva, es decir, que independientemente de si conocemos o no cierta realidad, existen propiedades de los objetos capaces de establecer relaciones de transformación que obedecen a regularidades 0 a tendencias. Y si bien la explicación responde a nuestros intereses, estos no se limitan alo práctico, también queremos elaborar una representación lo más completa posible del mundo y esto implica buscar las explicaciones que sean válidas dentro de un esquema general coherente. Las teorías de manipulación, que ven la causa como una noción que proyectamos en el mundo, parecen olvidar que incluso nuestras proyecciones se hacen sobre elementos objetivos de la realidad, no son arbitrarias. Es posible que el análisis causal haya incurrido en una confusión con respecto al papel del contexto para la causa: cuando se busca una causa apelamos al factor que sobresalga dentro de lo que solemos considerar como normal, cuestión que depende de lo que aceptemos previamente como una situación usual. Tal factor es el que tiene un valor más significativo para la explicación que se esté buscando en un determinado contexto, pero en principio no sabemos si de esa forma llegamos a la respuesta más adecuada para una descripción de los mecanismos. Puede entenderse la búsqueda de causas 
como una forma de hacer más comprensible el mundo, es decir, que contribuya a crear una visión objetiva que corresponda de forma más certera a los acontecimientos de la realidad, que contribuye a formar un cuadro coherente compuesto por las indagaciones de las diferentes ciencias en su intento de comprender cómo operan los mecanismos por los cuales la realidad se transforma. Este contexto es el que nos permite entender que las dos vertientes de la causalidad siguen siendo necesarias y por eso en el presente trabajo se hace una defensa de la concepción óntica de la causa que da base a la búsqueda de una de las formas de explicación científica.

\subsubsection{Los aspectos ónticos de la relevancia}

Como hemos visto, el término explicar es polisémico, pero lo que se ha intentado defender en este trabajo es que la explicación causal tiene un papel fundamental en la construcción del conocimiento y en nuestra comprensión del mundo, pues asumimos que una explicación no se puede reducir a un argumento sino que debe más bien dar cuenta de cada relación en la que un cambio depende de un estado previo, esto es, de los mecanismos (en sentido amplio) que permiten que un estado sufra una alteración. No se pretende desconocer que los argumentos basados en leyes dan cuenta de cierto tipo de eventos y que además existen explicaciones no causales, solo que la explicación causal es una de las herramientas más importantes para dar cuenta de acontecimientos individuales. Hasta cierto punto esta posición va en sintonía con la concepción óntica de Salmon (1984, p. 121), que propone que la explicación de un evento consiste en hallar su correspondencia con un patrón de regularidades naturales (sean universales o estadísticas); sin embargo, las leyes no son suficientes para dar fortaleza a la explicación, algunas de estas regularidades, las causales, tienen un indudable poder explicativo pues permiten entender una amplia variedad de fenómenos. Salmon señala como insuficientes las concepciones que asimilan la explicación a una inferencia (mientras esta no dé cuenta de los procesos de transmisión de influencia causal) y la tesis pragmática, que juzga las teorías por su adecuación, poniendo a la explicación a cumplir funciones particulares del contexto, lo que la hace epistémicamente relativa. El modelo causal da cuenta de la diferencia entre conocer y entender: lo primero es necesario pero no suficiente para lo segundo, en tanto hay cosas que se saben o incluso se pueden predecir, pero no explicar y, en la medida en que se reconstruye la historia causal, se incrementa progresivamente la información sobre el suceso. 
Un evento puede ser el resultado de una variedad de condiciones causales, pero el hecho de que se dé más o menos relevancia a un factor no implica que obedezca a diferentes causas, sino que pueden existir diferentes explicaciones. Para llegar a este punto es necesario aclarar los diversos sentidos en que es utilizado el término relevancia, pues en medio de la discusión se habla de relevancia estadística, de relevancia causal y de relevancia explicativa. Retomemos este punto en cuanto a la diferencias entre Hempel y Salmon. Este critica el modelo de Hempel porque no logra desentrañar que entre las premisas y la conclusión del argumento nomológico-deductivo debe haber relaciones de relevancia explicativa, pues de otra forma serían aceptables argumentos con premisas irrelevantes simplemente por el hecho de que tienen la forma y la regularidad de una ley, como en los casos mencionados de la sal que se disuelve en el agua porque ha recibido un hechizo (Salmon, 1984, p. 31) o del hombre que no queda embarazado porque toma píldoras anticonceptivas. En efecto, si enunciamos que, por ejemplo, "todo hombre que toma anticonceptivos evita su embarazo" y constatamos que el sujeto es hombre y que toma píldoras anticonceptivas, la conclusión es que "el señor Jones no queda embarazado por tomar píldoras anticonceptivas". Evidentemente esta explicación no es válida porque conocemos que ningún varón puede embarazarse naturalmente, independientemente de si toma o no píldoras anticonceptivas: no hay diferencia estadística entre uno y otro caso. Necesitamos determinar qué hace que un argumento de este tipo sea inválido pues corremos el riesgo de aplicarlo en casos en los que existen mecanismos desconocidos. El modelo nomológico-deductivo no da cuenta de la relevancia causal: si sus argumentos son formalmente correctos tendríamos la impresión de tener una explicación válida y no sabríamos si la relación entre las premisas y la conclusión se corresponde con los hechos. Es una vieja objeción a los argumentos de la que ya tenía noción Aristóteles (A nalítioos Segundos, Libro I.2. 71b 30) cuando señala que los silogismos construidos a partir de relaciones causales son más apropiados demostrativamente que los que se relacionan características accidentales, aunque estos también sean formalmente correctos.

Salmon (1984, p. 45) inicialmente analiza la noción de relevancia explicativa en términos de relevancia estadística: no se puede reducir la explicación a la relevancia estadística, de ahí que Salmon continúe con la búsqueda de los mecanismos de la causa, y aduce que la explicación debe incluir los factores estadísticamente relevantes; es necesario que los procesos causales y la relevancia estadística se complementan para proveer una explicación satisfactoria. Para solucionar los problemas en que intervienen factores irrelevantes Hitchcock sugiere una relación entre los juicios intuitivos de relevancia explicativa con respecto a los contrafácticos, dado que no parece haber una forma clara de excluir los factores irrelevantes diferente a la de preguntarnos ¿se disolvería la 
sal de no haber sido hechizada? Puesto que no hubiera ocurrido nada diferente, los enunciados contrafácticos nos llevan a afirmar que el factor en cuestión es irrelevante:

If one adheres to a counterfactual or probabilistic theory of causation, the coincidence of our judgments of explanatory relevance with those of counterfactual dependence or statistical relevance strongly suggests that explanatory relevance just is causal relevance (Hitchcock, 1995, p. 312).

Más atrás había afirmado:

[... ] it is hard to resist the conclusion that our intuitive judgments of explanatory relevance correspond closely to our judgments about the truth of counterfactuals [... ] (p. 311).

Es razonable la afirmación, dada la utilidad de los enunciados contrafácticos para la elaboración de explicaciones pero, de la misma forma que no es posible hacer una reducción completa de la causación a la probabilidad, tampoco parece posible hacerlo a términos contrafácticos, así como tampoco se puede dejar de lado el hecho de que las explicaciones son muy dependientes del tipo de indagación. En cambio lo que puede apreciarse es cierta confluencia de estrategias de análisis causal a partir de sus indicios. Salmon negaría que la relevancia estadística sea constitutiva de la relevancia causal pues no acepta las teorías probabilísticas de la causación ni que los argumentos contrafácticos sustituyan la causa. Hitchcock (1995, p. 316), por su parte, considera que la teoría de la cantidad conservada, pese a que no logra hacer un análisis reductivo de los conceptos de procesos e interacciones causales ni da reglas infalibles para detectarlos, da guías para reconocer procesos e interacciones y es un medio útil para reconocer este tipo de entidades en la ciencia física, pero tampoco provee los medios para solucionar los problemas de la noción de relevancia explicativa.

Sin embargo, no está definido dentro de la teoría de Salmon en qué medida entra la relevancia estadística dentro de las explicaciones causales genuinas. Se ha insistido en que la conexión causal implica un proceso que no se agota en la regularidad de la conexión constante, pues esta no es necesariamente causal. A hora, no es menos cierto que la explicación de un evento puede acudir a su historia o a los mecanismos subyacentes, explicaciones que pueden ser plenamente compatibles. Parece extraño que la vía que sugiere Salmon para solucionar el problema no fuese más desarrollada, pues apenas sugiere que las relaciones de probabilidad son un medio para buscar evidencia de las relaciones causales genuinamente explicativas. En Scientific E x planation 
(1984, p. 34, nota 10), por ejemplo, afirma que las probabilidades, a pesar de que no son explicaciones en sí mismas, son herramientas importantes para la construirlas, pues permiten dar salida a los requerimientos de homogeneidad y de máxima especificidad de las explicaciones estadísticas o probabilísticas: si un factor no ayuda a favorecer 0 a impedir un efecto será causalmente irrelevante, pese a que estadísticamente lo sea. En otro aparte de la misma obra, Salmon (1984, pp. 190-192) afirma que si tenemos un sector homogéneo de la clase de referencia la probabilidad del efecto es igual a 1, en términos de relevancia estadística, pero si este no es el caso, la explicación es más completa en la medida en que se ocupe tanto de los factores que propician como de los que previenen un hecho. Las diferencias entre los autores giran en torno al papel de la causa con respecto a la explicación: Hempel rechaza la idea de que la explicación deba ser causal y también que la relevancia estadística tenga poder explicativo, ya que no reconoce (por lo menos inicialmente) cómo puedan encajar los eventos poco probables dentro de su concepción de la explicación. Tampoco Salmon la hacía, pero finalmente declara: "The explanatory significance of statistical relations is indirect. Their fundamental import lies in the fact [... ] that they constitute evidence for causal relations" (Salmon, 1984, p. 192). Y agrega que esto no importa si se niega el papel esencial de la causa en la explicación, como hace Hempel, mientras que para los defensores de la concepción óntica de la explicación, como Salmon, la relación entre relevancia estadística y causalidad da mucha importancia a los factores que resultan de los análisis estadísticos.

Considerar la relevancia estadística como indicio de la relevancia causal parece una buena vía para solucionar varios de los problemas relacionados con la causa. Pero hay que tener en cuenta que es un indicio y no una evidencia, como cree Salmon: constituye un signo y no una prueba de que detrás de una relación estadística se esconde algún factor capaz de ejercer influencia causal. La relación no es tan fuerte como para que permita unificar la relevancia explicativa con la relevancia causal en las teorías probabilísticas y contrafácticas de la causación: la relevancia explicativa es muy dependiente del contexto, pues este delimita el alcance de una explicación. Sin embargo, tras el conjunto de factores causales y sus posibles relaciones hay una base objetiva: los hechos y sus relaciones son lo que determina qué es relevante causalmente, qué factores tienen una mayor o menor incidencia causando o previniendo cierto efecto. Muchas veces los factores pueden ser u operar de formas desconocidas y por eso se averigua si hay una asociación estadística (positiva o negativa) entre factor y efecto. Estos datos de relevancia estadística son los indicios de que el factor puede ser relevante causalmente (propiciando o impidiendo) determinado efecto. En condiciones ideales, esta base permite elaborar una explicación que describa el papel que ha 
tenido el factor en la producción del evento; la cuestión es que las condiciones ideales lo son porque usualmente no ocurren en la realidad. Lo usual es que tengamos que conformarnos con dar cuenta solamente de los pocos factores que conocemos y elaborar una elipsis de toda la situación causal para hacerla comprensible por medio de una explicación más o menos cercana a la propuesta por el modelo nomológico-deductivo. No es poco, pues por esa vía las ciencias han hecho progresos indudables, pero no hay que olvidar que cada ciencia da cuenta de las causas correspondientes a su objeto de estudio, cuya delimitación establece los factores y condiciones que se consideran normales para una situación o para el contexto de la pregunta que se pretende responder. La relevancia explicativa seguramente es una característica de cómo un factor causal es capturado por una explicación: dice en qué medida una proposición da cuenta de la razón por la cual ocurre un determinado fenómeno, cuestión que, como hemos visto en capítulos anteriores, es altamente dependiente del contexto, dado que no es factible separar una causa en estricto sentido de las condiciones del trasfondo causal. Entretanto, la relevancia estadística depende de las correlaciones entre factores determinados y la presencia o ausencia de un efecto, es decir, de cómo cada uno de los factores causales incide en los hechos concretos; tal información puede ser más o menos desconocida y en la medida en que mayor sea el conocimiento de los eventos las tres instancias de relevancia deben confluir.

\subsection{Conclusión: relevancia causal y explicativa}

Tras el largo trascurso que ha hecho el problema de la causalidad hay que devolverse a las preguntas que han sido el acicate de la especulación filosófica en la modernidad, es decir a la inquietud de Hume sobre qué es lo que hay tras las conexiones causales, tras esas sucesiones que esconden una conexión que intuimos pero que se resiste a dar una evidencia cierta de su existencia, con el fin de analizarla y de entender cómo opera. No podemos conformarnos con que tras ese vínculo se esconda algo incognoscible, aunque la idea de necesidad tiene un acento metafísico que se resiste a su reducción a los mecanismos usuales de la realidad. Por eso se ha hablado de poderes causales, pero cuando Hume (2004, p. 179) intenta definir en qué consisten se encuentra con que ni siquiera se puede confiar en que siempre que se presente la causa le siga el efecto, por lo menos mientras no conozcamos por qué su conexión puede ser necesaria.

Esa necesidad creó la ilusión de que el problema de las causas podía resolverse por medio de una inferencia, pero la implicación lógica no es equivalente a la relación causal, de ahí que las ciencias 
continúen indagando los mecanismos por los cuales ocurre el cambio en las cosas: la naturaleza es independiente del pensamiento y así mismo las causas. Sin embargo, no podemos olvidar que las relaciones causales son fuentes de explicación de cambios particulares que ocurren en la realidad, aunque no sean las únicas posibles. No hay que perder de vista que esta cuestión tiene matices: si bien las causas están en los hechos reales, es cierto que la única forma que tenemos de elaborar un conocimiento útil sobre ellos es la de elaborar proposiciones que los describan y ponerlos en sistemas coherentes que operen con herramientas lógicas. Las causas son objetivas, pero nuestro conocimiento tiene un grado de convencionalidad innegable, que se encuentra ligado a nuestras preguntas e intereses: un mismo sistema es susceptible de múltiples descripciones, que pueden ser más o menos objetivas pero, aparte de esto, también son diferentes. Sin embargo, su componente objetivo, dependiente de las relaciones singulares que transforman la realidad, impide que entendamos la causación como una categoría relacional.

Se ha afirmado que las ciencias maduras no necesitan la noción de causa, más allá de la heurística, para lo cual Norton (2007, p. 30) utiliza el ejemplo de la gravitación: donde Newton habla de gravedad, Einstein habla de deformación del espacio-tiempo; Newton nos permite entender de manera más familiar como operan las cosas a nuestra escala, mientras que la concepción de Einstein es más compleja y abarca una escala más amplia. Para los efectos prácticos inmediatos entender la gravedad como una fuerza es adecuado; de lo cual Norton deduce que las causas son tan reales como la fuerza gravitacional, en cuanto no son inventadas arbitrariamente, pero tienen una realidad derivada; subsisten en algunos conceptos de la ciencia, pero más en el nivel de la ciencia popular que en los enunciados propios de la ciencia. Ahora bien, si entendemos que la ciencia pretende conocer y entender la realidad este planteamiento de nuevo reduciría el alcance del conocimiento científico a la descripción de la realidad, pero la ciencia no se detiene en ello; la ciencia necesita elaborar las explicaciones que permitan entender las dinámicas de lo real. Hay que insistir en que las causas están ligadas a los cambios y que la búsqueda de explicaciones causales es una parte legítima y necesaria del conocimiento científico, pese a que este no suela emplear explícitamente el término.

Nuestra búsqueda de explicaciones comprensibles de lo que acontece en el mundo nos ha llevado en alguna medida a confundir el mapa con el territorio, nuestras representaciones con la realidad: al parecer nuestra búsqueda de un orden subyacente nos lleva a privilegiar ciertos factores que nos ofrecen una explicación comprensibley los ponemos en la posición de factores con relevancia 
causal. Pero no es igual la relevancia causal que la relevancia explicativa. El mundo sucede de cierta manera y lo usual es que cada evento obedezca a una multitud de factores, pero saber qué factores tienen una mayor incidencia en la producción de un efecto no es lo mismo que determinar qué factores nos permiten elaborar una explicación más adecuada. Esta depende claramente del contexto, pues las ciencias delimitan los problemas de los cuales se ocupan y dejan de lado aquello para la cual sus herramientas conceptuales no son adecuadas; un mismo fenómeno puede ser analizado desde perspectivas diferentes. Además, cuando se indaga por una causa se busca un factor que sobresalga sobre las secuencias usuales y esto depende de qué se considera normal en cada contexto. D eterminar el grado de influencia causal implica el uso de múltiples herramientas que nos ayuden a armar el paisaje causal con sus grados de relevancia objetiva. Seguramente las correlaciones estadísticas estén entre las mejores herramientas para determinar el grado de influencia causal: son una vía necesaria para buscar las vías de influencia y por este medio, para indagar los mecanismos que, estos sí, son la respuesta definitiva a la indagación por las causas. Igual se podría decir de la elaboración de estrategias efectivas: la posibilidad de diseñar situaciones en las que puede producirse un efecto a partir de ciertas intervenciones constituye una fuente de indicios de los mecanismos causales.

Pero también los condicionales contrafácticos son útiles como medio paraindagar por las relaciones causales: preguntarse por los posibles cambios que habrían de ocurrir con la alteración de algún factor en una secuencia causal nos permite también llegar a indicios de cuáles son los factores efectivos para producir el cambio. D e esta manera se puede intuir si el cambio corresponde a una ley o a una generalización accidental y en qué caso puede hacerse una intervención que permita llegar a cierto resultado. Al igual que las herramientas estadísticas, los enunciados contrafácticos causales permiten acceder a los elementos cuyo papel causal es más determinante, independientemente de si hablamos de causas mecánicas o de otro tipo; podemos hacer el ejercicio virtual de comparar dos mundos paralelos para poner a prueba los posibles cambios que ocurren alterando un factor; no tendremos certeza de si el mundo virtual con el cambio seguiría una ruta paralela al mundo real, pero el ejercicio es capaz de darnos indicios fiables de lo que podría suceder.

Ahora, hay que tener en cuenta que no se ha logrado elaborar ninguna teoría sobre la causa que sea capaz de dar cuenta de las diferentes vías de influencia causal, pero lo que parece más factible es delimitar causa y explicación como pertenecientes a instancias diferentes. Pese a que causas y 
explicación son dos nociones fuertemente vinculadas, no podemos olvidar que pertenecen a dos ámbitos diferentes, lo óntico y lo epistémico, respectivamente. Esto se puede ver claro en el papel de la relevancia y del contexto. Una cosa es la relevancia dentro de las causas y otra en las explicaciones; por ejemplo, por qué un vidrio se rompe es una pregunta que pide respuestas diferentes si nos encontramos en el marco de una investigación que busca incrementar la resistencia del vidrio o si se están diseñando ampolletas que midan impactos, o si se estudia el fenómeno de la resonancia, pero un vidrio concreto se rompe una sola vez por un mecanismo causal concreto. Un factor es relevante con respecto a las causas cuando es capaz de determinar la presencia de un efecto, su presencia lo hace mayor o más probable (y hablamos de efecto más probable porque estamos tratando de causas medianamente desconocidas). Si no conocemos qué factor produce cierto efecto se acude a métodos para acceder o elaborar un conocimiento que nos permita entender el fenómeno.

En muchas ocasiones no es posible determinar de manera definitiva y aceptable si uno de los variados factores que inciden en un efecto cumple el papel suficiente para la producción de un efecto. Pero esto no indica que la causa dependa del contexto, si asumimos que los hechos son lo que son, independientemente de nuestra descripción. Ahora bien, las explicaciones son dependientes del contexto, incluso la explicación causal, pues la relevancia de un factor para la explicación no implica que el factor sea más relevante para la producción de un evento: para cada explicación existen condiciones que determinan a qué pregunta se quiere responder, qué problemas son los que se quieren resolver y en qué descripción de la realidad pueden encajar ciertas respuestas a las preguntas. La explicación, causal o no, es un asunto con un notorio cariz pragmático, relativo a nuestro nivel de conocimiento de la realidad y a nuestros intereses. D e ahí que sean explicaciones válidas cuestiones tan extrañas a nivel óntico como las ausencias, que no existen en la realidad y por tanto no pueden ser actores de influencia causal, una muestra de que no es completamente posible separar la explicación de la causa, como tampoco los aspectos epistémicos y ónticos de la cuestión, solo que es algo que se debe tener en cuenta para que dejemos de considerar cuestiones genuinamente relevantes en la explicación como si fueran relevantes causalmente.

Pongamos por caso un grupo de eventos que se reputa como consecuencia de un posible factor causal. Si conocemos por completo las causas hablaríamos simplemente de que algo causa su efecto, esto es, que si hay una ley y están determinadas las condiciones iniciales podemos separar claramente del grupo de eventos cuáles corresponden al accionar de un factor causal. Esto no es 
lo usual, pues las situaciones reales suelen ser más complejas y ocurre que los efectos genuinos se mezclan con falsos y los factores causales con los irrelevantes. Entonces hay que hacer divisiones del grupo inicial en subgrupos, de acuerdo con características que puedan ser relevantes en la presencia del efecto: si la división no muestra diferencias estadísticas es porque tal característica es irrelevante, pero si las hay, podemos trabajar con la subclase de eventos en la que sea relevante. Este procedimiento se replica hasta que sea posible aislar el subgrupo más pequeño posible de eventos relacionados con el factor causal en estudio, siempre teniendo en cuenta que se deben comparar muestras de control con el fin de que no haya equivocaciones con falsas subdivisiones ni con características con relevancia negativa (preventores). Lo que se obtiene como resultado es el grupo de eventos que más probablemente está relacionado con la presencia de un factor causal. Hay que tener en cuenta que esta es una forma de trabajar con los indicios de las causas, pero las causas están en los diversos mecanismos por medio de los cuales se propaga una influencia. Tales mecanismos son en principio ocultos, y el propósito de la ciencia es elucidarlos pero, mientras no se conozcan, lo que hacemos es buscar explicaciones que serán más o menos adecuadas en la medida en que correspondan al contexto de una determinada pregunta. De esta manera existen factores que pueden ser más o menos relevantes para construir un explicación que nos permita entender cierto fenómeno, explicaciones que son adecuadas a un contexto en el que se formula una pregunta, pero que pueden ser inadecuadas o irrelevantes dentro de otro contexto. O tra cosa sucede con la relevancia causal: que una condición sea más o menos relevante para la producción de un efecto es algo que está estrictamente en los hechos, pero esto no tiene ningún halo de conexión oculta, es un conocimiento que se va elaborando en la medida en que la ciencia sea más capaz de dar cuenta de los fenómenos, por eso aquí lo que se llama contexto es completamente diferente y no hace alusión a preguntas sino a las condiciones habituales de una situación. Conocer los mecanismos consiste en saber cuál es el grado de influencia de una condición sobre un efecto y saber cómo opera.

Es justo recordar que este procedimiento ha venido siendo elaborado lentamente a lo largo de la historia para solucionar los problemas de la inducción aristotélica, que toma forma en los métodos de acuerdo y diferencia de Mill: comparar situaciones en las que se produce un efecto con el fin de detectar si existe un factor en común en todas ellas, lo cual eleva la probabilidad de que sea condición suficiente para la aparición del efecto. Y comparar un conjunto de situaciones para constatar si cierto factor está presente siempre que el efecto ocurra y ausente cuando este no se presente, un indicio de que el factor es condición necesaria para el efecto. Tales métodos contaban 
con el determinismo aceptado en su momento; pero hoy es más usual contar con que las situaciones son más complejas, dificultando tal inferencia causal (Kincaid, 2012, p. 740). Actualizando el método podemos decir que la conclusión no es segura sino probable en la medida en que puedan existir factores desconocidos o efectos de una causa común. Pero, dada la complejidad de las relaciones causales, es decir, dado que lo usual es la presencia de múltiples mecanismos que operan de formas diferentes, lo más posible es que existan factores adicionales que no se hayan tomado en cuenta o que simplemente no se conozcan.

Este punto es muy importante porque el asunto de la relevancia explicativa se puede aplicar aquí: los cambios se componen de permanencias y alteraciones, y lo que se busca cuando se quiere dar una explicación es detectar cuáles son los factores que influyen en la modificación de las propiedades en cuestión. Algunas explicaciones corresponden a la relación física entre el factor y las propiedades del objeto sobre el cual recae el efecto (información que no siempre está disponible o que no siempre es discernible de los datos irrelevantes) pero otras dependerán de factores que tienen una relevancia limitada a las condiciones específicas de la situación; lo cual implica que algunas explicaciones pueden ser válidas dentro del contexto de alguna ciencia 0 como respuesta a cierta pregunta. El diseño de experimentos busca identificar al factor determinante dentro de las circunstancias, es decir, el factor que es capaz de conjugarse con el conjunto de las demás condiciones del trasfondo para la producción de un efecto, pero también puede orientarse a detectar la relevancia causal de un factor dentro de condiciones controladas con el fin de elaborar una explicación: puestas las condiciones $\{x, y, z\}$ se busca determinar si otro factorn altera un determinado efecto. Tales condiciones pueden corresponder a una situación real, pero también pueden ser condiciones de aislamiento artificial, modelado con el fin de establecer un contexto dentro del que sea posible hacer la indagación. En ese sentido, pese a que la causa es particular, las relaciones causales se pueden corresponder a leyes 0 a regularidades que permiten unificar parcialmente la operatividad de ciertos factores en ciertas condiciones. También, en la medida en que podamos ir haciendo particiones de la clase de referencia en subclases más homogéneas, es posible elaborar un cuadro cada vez más completo de los grados de influencia causal de cada factor dentro del paisaje causal que produce un efecto, lo que equivale a hacer modelos menos abstractos y más precisos que permitan descripciones más adecuadas a los sucesos, reconstrucciones más veraces y completas de su historia causal. 
La cuestión es que los mecanismos causales son muy complejos. Cada evento se produce como resultado de un conjunto de factores que propician o dificultan su ocurrencia y así, para elaborar una explicación completa del evento se necesitaría reconstruir su historia causal, labor que podría ser inagotable. Ante tal reto, la única posibilidad es construir historias coherentes que respondan a preguntas concretas, por lo cual las explicaciones causales son elipsis que resumen lo que se considera el mínimo para que una historia causal sea coherente. Puesto que al efecto suelen confluir múltiples factores causales, es previsible que no haya acuerdo acerca de cuál es más relevante, dado que algunos son más relevantes en unos contextos que en otros (Lewis, 1986, p. 215), pese a ser parte de la misma historia causal. Si no hay una sola forma de reconstruir las historias causales no es solo porque la historia causal sea múltiple sino porque también necesitamos dar relevancia a unas explicaciones sobre otras: no existe una única forma correcta de hacerlo, no existe una forma de referir la multitud de condiciones que conforman la historia causal, diferente de resumirla a los factores relevantes dentro de un contexto determinado, sin perder el objetivo de que, por lo menos idealmente, existe un historia causal única, que es lo que se aspira construir como resultado final del proceso de conocimiento. 



\section{CONCLUSIONES: LA PERTINENCIA DE LA EXPLICACIÓN CAUSAL}

Luego de hacer una revisión detallada por las diversas exploraciones teóricas sobre la causa, es claro que no se ha llegado a un acuerdo acerca de qué pueda cumplir el papel de un cemento causal que una los diversos acontecimientos del mundo, otra forma de decir que no se ha podido demostrar que exista un vínculo objetivo (Hitchcock, 2003, p. 4) que cumpla de forma universal las funciones de transmisor de influencia o de vehículo del cambio. Esto indica que por ahora toda teoría causal está limitada a dar cuenta de solo una parte de los vínculos existentes entre los sucesos, lo que nos remitió a la pregunta por el interés que reside tras la búsqueda de las causas y a su incidencia en nuestras representaciones del mundo.

Si tenemos interés por buscar las causas es porque la realidad se compone de objetos (que definimos como tales en cuanto ofrecen cierta permanencia) que sufren transformaciones, es decir, alteraciones de algunas de sus propiedades. La indagación acerca de cómo y por qué se producen estos cambios busca reconstruir su historia causal y acercarse a la posibilidad de predecir cambios futuros, que son algunas de las finalidades posibles de la explicación. Tanto la ciencia como la filosofía han elaborado diversas herramientas para explicar la realidad, por medio de la búsqueda de algún orden tras las múltiples manifestaciones de los sucesos, o haciendo una traducción de lo incomprensible a lo ya conocido. Las vías para dar cuenta de la realidad también son múltiples y, pese a los intentos para omitir la idea de la causa en la explicación científica, esta sigue prestando una valiosa guía heurística a la investigación. No toda explicación apela a la búsqueda de causas, pero la explicación causal sigue ocupando un lugar importante en toda forma de conocimiento. Con este panorama, en esta sección final se busca exponer los elementos que se han considerado valiosos para delimitar los ámbitos apropiados de la explicación causal, una perspectiva que posibilita otra forma de entender la solución del problema de las causas. 


\subsection{Las caracteństicas de la relación causal}

El supuesto inicial que se asumió en esta exposición es que la pregunta por la causa se genera cuando encontramos un cambio en objetos o en eventos, una ruptura frente a lo que puede ser considerado el estado usual de los acontecimientos: de aquello que cambia nos preguntamos cuál es o cuáles son los factores capaces de determinar tal acontecimiento. Podemos hablar de causa solamente cuando hay un nuevo estado o una modificación en las características de un objeto que, sin la participación de los mencionados factores, continuaría inalterado. Sin embargo los cambios no son instantáneos, pues implican una secuencia de alteraciones graduales. Ni totales: en los cambios hay propiedades que alteran sus magnitudes, mientras que otras permanecen constantes. Lo que interesa a la indagación causal es la razón de los cambios, pues asumimos que todo cambio tiene una causa, por el principio de uniformidad de la naturaleza. La mente humana no se conforma con la descripción de los hechos sin conocer sus causas, es decir, las secuencias de cambios y las conjunciones de influencias nos posibilitan conocer su origen y prever su comportamiento futuro.

El conocimiento causal, como todo conocimiento, es un ideal perseguido; no poseemos más que estructuras de conceptos que nos permiten dar cuenta de los acontecimientos de la realidad y aspiramos a que lo hagan cada vez mejor: el avance de nuestro conocimiento está determinado por la adecuación más precisa de nuestros conceptos con respecto a los fenómenos, a la vez que con la construcción de una estructura coherente de conceptos. Así, nuestro conocimiento sobre las causas pasa por descripciones gruesas del factor o de los factores que se consideran principales en la ocurrencia de un determinado evento pero, en la medida en que se recopile una mayor cantidad de información, se crea una historia causal más llena de relieves y matices que puede dar cuenta de la multitud de vías de influencia que son relevantes para la aparición del efecto. Así, el límite cognoscitivo ideal de una relación causal está en la descripción de todo el panorama causal que existe previamente al efecto: existen simultáneamente multitud de factores con algún papel causal ya sea como factores condicionantes o como los factores eficientes para la presencia de unos determinados efectos, así como existen factores que impiden o retardan el efecto.

No hay pleno acuerdo en torno a cuáles han de ser las rasgos comunes a las relaciones causales: en alguna medida persisten las características del vínculo humeano, pero también es cierto que no agotan la variedad de formas que pueden presentar las causas. Las causas son, desde la 
perspectiva ontológica, singulares y únicas: cada vez que aparece un nuevo acontecimiento en la realidad lo hace por sus propias causas, por la alteración de condiciones previas a la existencia de ese efecto concreto, pues cada cambio tiene una situación espaciotemporal única en el universo. Sin embargo, constatar esto no nos permitiría elaborar un conocimiento sobre el mundo, así que es necesario ir más allá en la búsqueda de los patrones comunes en los cambios; la falta de acuerdo teórico sobre el tema es un indicio de que la causa tiene múltiples formas de manifestarse, múltiples formas de relación que se emparentan con la necesidad de buscar explicaciones.

Es posible que no pueda llegarse a un acuerdo sobre los mecanismos de influencia causal, pues parece imposible encontrar rasgos universales en la operación de las causas. Pero no solo existe una pluralidad de mecanismos, sino una pluralidad de factores que confluyen en la aparición de los efectos, esto es, que también es común la multicausalidad o por lo menos, la existencia de cambios concomitantes que concurren simultáneamente con los factores propiamente causales: existen efectos que se siguen directamente de las causas y es evidente su relación, pero en otros casos, particularmente en los de mayor complejidad, con multiplicidad de causas y de efectos, la relación puede no ser evidente, ya sea porque no se puede identificar claramente la confluencia de los factores necesarios o porque los efectos sean de ocurrencia mediata o acumulativa. Más adecuado que hablar de causa sería hablar de trasfondo causal o de situación causal, dado que la causa comprende el conjunto de las condiciones necesarias para que ocurra un efecto. Este puede ocurrir por diversidad de circunstancias, cada una de las cuales está compuesta de factores necesarios, pues sin ellos el efecto no puede ocurrir, y algún factor o factores suficientes para desencadenar el evento. Sin embargo, en las situaciones concretas no suele haber acuerdo acerca de si puede diferenciarse un factor como propiamente causal frente a las condiciones del trasfondo, dado que no siempre es cuantificable la incidencia de un factor o su calidad de eminente frente a los demás; por eso, el ideal de conocimiento total de una relación causal es inagotable. Aquí encontramos otra razón para la identificación de regularidades en los comportamientos naturales, suficientes para el establecimiento de leyes y modelos de operación, cuya aplicación está limitada a condiciones predeterminadas y al aislamiento de los sistemas; habremos de acudir a la comparación con otras situaciones similares que nos den una idea de en qué consiste la trayectoria usual o normal de los acontecimientos, o cuál es el factor más importante en el contexto de indagación, lo cual enfatiza los aspectos epistémicos del problema de la causalidad. 


\subsection{Causas y explicación}

Las expectativas racionales, más exactamente la predicción científica, dependen de la observación continuada de secuencias de eventos en que la ocurrencia de cierto antecedente lleve a su consecuencia, o a que se incremente la probabilidad de que esta ocurra. Sin embargo la repetición de similares condiciones no garantiza que los eventos se repitan exactamente, pero esto no impide aislar los factores relevantes para replicar una situación, de manera tal que puedan determinarse los que tengan una repercusión en el efecto, como se hace en la ciencia, en el conocimiento común y en la elaboración de estrategias de acción. Por esta vía accedemos al conocimiento de regularidades y leyes naturales, así como a la posibilidad de hacer predicciones: la regularidad, aunque sea ideal, es lo que le permite a la ciencia elaborar hipótesis y teorías acerca de la naturaleza.

No obstante, conocer secuencias causales habituales no garantiza la exactitud de las predicciones, dado que conocer las causas no implica que necesariamente se conozca cómo actúen o cómo se relacionen estas con la multiplicidad de factores que suelen estar presentes en las circunstancias normales. Pero se obtiene un mayor grado de fiabilidad en la medida en que el conocimiento sobre los mecanismos y las vías de influencia causal sea mayor. Casos complejos como el de la predicción del clima se conocen hoy lo suficiente como para que se hayan identificado los diversos factores que inciden para que, por ejemplo, se presente una lluvia, sin que eso implique una fiabilidad absoluta de las predicciones, pues es necesario tener en cuenta que estas dependen de una precisión sobre condiciones iniciales que requiere una enorme cantidad de datos. Y aún con ellos, sus interrelaciones son de tal complejidad que no puede preverse más que a corto plazo y con mediana precisión espacial cómo van a presentarse los resultados de su conjunción.

Entonces, hay que preguntarse si la causación puede reducirse a definir las relaciones funcionales entre diversas entidades, ya que las leyes naturales dan cuenta de cómo operan relaciones entre ciertas propiedades de objetos, y no todas involucran causas, sino que también definen relaciones de coexistencia, como las que ocurren en situaciones de equilibrio que no son necesariamente causales. El hecho de que se exprese matemáticamente la descripción de esos casos no excluye la licitud de la pregunta sobre el porqué causal, e igual ocurre con los diversos intentos de reducir la causa a diferentes elementos: se obtienen teorías que se ocupan de algunos fenómenos pero quedan por fuera casos sin explicación. Además, se dirigen hacia dos objetos diferenciables aunque relacionados: la idea de causa cumple el papel ontológico de relacionar entidades en proceso de 
cambio y apunta a la búsqueda de una comprensión sobre la estructura del mundo, mientras que las funciones nos develan el cómo, esto es, la mecánica de operación de la forma en la que se relacionan la materia y la energía. En la medida en que buscamos dar una explicación a la historia causal de un suceso, encontramos tipologías de secuencias que nos permiten explicar y entender la razón por la cual ocurren ciertos sucesos.

El propósito de la ciencia es hallar los mecanismos que encajen mejor con los datos a fin de desechar las interpretaciones que escapen a ellos. Pero no puede olvidarse que existen ámbitos en los cuales los posibles mecanismos o aquello que cumple su función son, por ejemplo, las motivaciones de los actos humanos o las interacciones químicas entre un organismo y su entorno. La multitud de factores y las diversas preguntas posibles por la explicación permiten que existan respuestas diferentes a un mismo suceso, por tanto el asunto, como diría Popper (1994, p 64-65), consiste en tejer redes cada vez más finas de teorías que permitan conocer de forma más detallada los sucesos: en esa medida podemos dar cuenta con más seguridad de la historia causal de un evento y de hacer predicciones más fiables acerca de cómo ha de evolucionar.

Pero entonces hay que definir si el problema de la causa es ontológico o epistémico. Estudiar los usos del término causa, en el lenguaje común o en la ciencia, puede ser una vía para descubrir las intuiciones comunes del concepto. El uso común parece más claro, dado que preguntar el porqué de una determinada situación se asocia normalmente con la causa, abarcando desde los acontecimientos naturales más usuales hasta las motivaciones humanas, y englobando las respuestas a la búsqueda de cierto tipo de explicaciones. La ciencia es un tanto cautelosa en el uso explícito del término, pero utiliza muchos términos que le permiten describir de forma más específica las vías de influencia causal. Los enunciados que describen las situaciones causales son sujetos de inferencias lógicas, con lo cual se constituyen en una herramienta de los razonamientos deductivos en la ciencia, poniéndolos en relación con la aplicación de leyes. Ahora, este uso de la ciencia no implica que las relaciones causales dejen de ser asuntos de facto, relaciones entre hechos reales y concretos, que no solamente están en nuestro conocimiento y en nuestras descripciones, de ahí que la necesidad de la relación causal no se reduzca a una necesidad lógica sino que depende de las relaciones observadas en la realidad, pues en el estudio de las causas nos enfrentamos a relaciones contingentes. 
Lo que se ha buscado mostrar es que la razón de que no haya una teoría unificada de la causa está vinculada a la idea de que también existen múltiples teorías sobre la explicación: podemos entender los fenómenos enmarcándolos en nuestras estructuras de conceptos y leyes, pero este proceso se hace por diferentes vías, de manera que no toda explicación es causal. En cierta forma la idea de explicación es más amplia que la de causa, pues aparte de la búsqueda de causas se entiende por explicación de un hecho ya sea su adecuación a una ley o el estableciendo de conexiones inferenciales con enunciados generales (Salmon, 1984, p. 16). La búsqueda de explicaciones es un propósito que subyace a la creación de nuevo conocimiento, razón por la cual aceptamos como explicación una multitud de posibilidades que pueden ser más o menos satisfactorias dependiendo del contexto. La explicación causal puede estar ligada a leyes o expresarse como un argumento, pero también como la reconstrucción de una historia causal; la explicación causal es una de las posibles formas de dar respuesta a ciertas inquietudes, las preguntas tipo ¿por qué? que se formulan para indagar por las transformaciones que ocurren en la realidad y, de modo que la diversidad de mecanismos de acción de las causas y diversidad de posibles preguntas implica que aquello que se entienda como la causa estará determinado por el contexto de indagación, por la información disponible y por el interés con el que cada especialidad científica delimita los problemas que le son propios.

\subsection{Los mecanismos}

Necesitamos conocer las causas para predecir y explicar los cambios que ocurren a los objetos, pero tales cambios suceden en ciertas propiedades tanto de los propios objetos como del conjunto de factores en medio de los que se encuentran, que juntos forman un evento localizado espaciotemporalmente. Para que un evento suceda se requiere que confluyan las condiciones sin las cuales una acción causal no puede ser efectiva. En otras palabras, lo que podamos llamar causa es una modificación en cierto factor previo a la ocurrencia de un evento que concurre con un conjunto de condiciones necesarias, pues sin ellas el evento no ocurre. De manera que la efectividad de la causa depende de la conjunción de un trasfondo de circunstancias que habitualmente no comportan la ocurrencia de cambio alguno, sea en la emergencia de un nuevo estado 0 en la alteración de una secuencia; un factor o más que emergen sobre ese panorama de circunstancias o condiciones es una causa si su presencia da paso a un nuevo estado, una nueva situación o una alteración notoria en un proceso y este elemento es lo que habitualmente se ha llamado causa eficiente. Las causas y los efectos son las modificaciones que se erigen sobre 
persistencias parciales, pues el cambio nunca es total: no hay un pegamento causal entre dos objetos sino procesos que son modificados parcial y gradualmente. Así, hablamos de que los objetos sufren esos cambios, pero el panorama es mucho más complejo: lo usual es que paralelo al cambio que consideramos como causal existan cambios en otras propiedades, algunos de los cuales acompañan el cambio, pero son irrelevantes para el efecto, tal como una marca de tiza en el movimiento de una bola de billar, y algunas permanencias, que como la cantidad de oxígeno en un incendio, son indispensables para que el efecto se produzca. D e ahí que todas las condiciones relevantes - no solo el factor eficiente- sean también causas. El problema es que los acontecimientos del mundo están ligados en una red ilimitada de causas y efectos y ante la imposibilidad práctica de conocer todo el trasfondo causal es necesario entender que no todos los factores en juego son relevantes sino que lo que se identifica como la causa depende del contexto de indagación en el que nos encontremos. Esto conlleva el riesgo de elaborar historias causales y explicaciones que pueden ser insatisfactorias fuera de su debido contexto, pero hay que tener en cuenta que una descripción más detallada es más exacta pero más compleja y en las descripciones sucintas se pueden dejar de lado factores que pueden ser fundamentales pero se llega a una explicación más comprensible. Además a esto hay que añadirle que las historias causales, en la medida en que involucren un lapso de tiempo mayor, se hacen menos seguras, ya que una mayor cantidad de eslabones hace menos confiable la historia y menos precisa la predicción.

Si el sistema está razonablemente aislado (es decir, si las interferencias que recibe no alteran el efecto), si su comportamiento se analiza dentro de un plazo relativamente corto y si sus descripciones son matemáticamente lineales, podemos tener mayor seguridad en la indagación de una causa pues estas situaciones poco comunes garantizan la proporcionalidad entre la causa y el efecto (Bertuglia \& Vaio, 2005, p. 39). Con todo, idealmente se busca ir más allá de la aproximación para hallar una respuesta única, un único factor al que se pueda adjudicar el efecto, pero esto no siempre es posible, razón poderosa a favor de no reducir la causa a la eficiencia y para tener en cuenta el contexto de indagación: el mismo fenómeno estudiado por dos ciencias puede tener causas en alguna medida diferentes. Además, el análisis de los factores causales implica tener en cuenta cómo se suelen desenvolver acontecimientos similares, es decir, hay que determinar cuál es el curso habitual de los acontecimientos para poder diferenciar qué ha cambiado. Esto también depende del conocimiento previo que se tenga sobre cada situación, de ahí que se da el caso en que la ciencia logre identificar causas nuevas en hechos que se consideraban resueltos: 
los hechos pasados no han variado, pero el conocimiento que se tiene sobre las cosas cambia en la medida en que la ciencia adquiere nuevos datos. El límite de la comparación entre secuencias causales es que muchas son más impredecibles en la medida en que se incrementa el plazo, haciendo la transitividad incierta: puede conocerse a posteriori la historia que han tenido concatenaciones de factores para llegar a una situación, pero de este no se deriva necesariamente que se pueda conocer con antelación la secuencia futura de acontecimientos.

Las relaciones causales pueden ser complejas y sus casos no son necesariamente extrapolables a otros similares, ofrecen un conocimiento matizado por alguna incertidumbre, lo que nos lleva al campo de las probabilidades y, así, la importancia relativa de los diversos factores depende de qué tanto eleven la probabilidad del efecto, cuando hay suficiente información como para calcularlas. Por tal razón la relevancia de los diversos factores es necesaria para dar con la explicación causal pertinente, lo que es más notorio en la medida en que sean más complejos los hechos a explicar: de esta forma la correlación de probabilidad entre factores y efectos constituye un índice confiable de qué tan efectivo y necesario sea el factor.

Algunas causas son más perceptibles que otras o encajan más fácilmente con nuestros mecanismos de inferencia causal: algunas secuencias causales son directas y lineales, replicables experimentalmente, pero otras son condicionadas a factores con los que entran en juego, otras son inciertas pues dependen de secuencias únicas con presencia de factores que pueden ser aleatorios o, si no lo son, también pueden obedecer a una dinámica compleja. En este punto, en efecto, puede afirmarse que desconocemos la conexión necesaria, pero no podemos concluir por tal razón que el mundo sea arbitrario, pues en la medida en que aumenta nuestro conocimiento es más predecible; cada vez más se conocen los mecanismos por medio de los cuales operan las relaciones causales. Pero, ¿esta búsqueda de los mecanismos disuelve el por qué en el ómo? En alguna medida sí, pero hay algunas consideraciones finales que hacer al respecto.

\subsection{Coda}

En el análisis que se ha hecho acerca de las causas y condiciones se ha podido observar que no hay un criterio de aplicación absoluta destinado a diferenciar lo que podríamos llamar las causas propiamente dichas de las condiciones. Los diversos criterios empleados para hacer esa diferenciación se han revelado insuficientes para dar cuenta de algo más que determinadas 
tipologías de vínculo causal, dejando por fuera una cantidad de excepciones tan grande como para sospechar de no hay teoría capaz de dar cuenta cabal del fenómeno. D ada la complejidad que suelen tener las relaciones causales reales y la dificultad de diferenciar los factores suficientes para el efecto, frente a los factores del trasfondo, no suele ser fácil predecir si un factor será capaz de producir un efecto. A posteriori, en cambio, es relativamente más factible saber cuáles de las condiciones tuvieron algún papel causal, precisamente porque son los factores que encajan mejor dentro de la explicación, pero con anterioridad a los acontecimientos lo que podemos hacer es elaborar una especie de paisaje causal en el que las condiciones tengan una mayor o menor prominencia en razón a lo que pueda indicarnos el conocimiento previo sobre cómo se comportan cierto tipo de acontecimientos.

Por eso, lo que se intentó hacer en el presente trabajo era un rastreo de diferentes indicios causales que son muestra de la variedad de facetas que ofrecen las relaciones causales. Puesto que diferentes teorías ofrecen campos en los que pueden ofrecer herramientas para la indagación causal, la opción que parece más factible por el momento es apreciar tales teorías como herramientas para la indagación por campos particulares de relación entre los fenómenos, dependiendo ya sea del tipo de eventos de los que se ocupen o de las formas específicas de relación. Se espera que la ciencia progresivamente siga elaborando las respuestas más satisfactorias, que consisten en la descripción de los mecanismos y en la reconstrucción de la historia causal de los cambios, pero esta es una consideración ideal, la del conocimiento pleno y, mientras no exista, es necesario seguir trabajando con los indicios que nos proveen diferentes teorías, una consecuencia práctica del pluralismo causal. D e todas formas, algunos aspectos de la indagación por las causas seguirán dominados por la necesidad de explicaciones y de intervenciones sobre la realidad, que también son instancias válidas de las indagaciones causales, dado que los contextos dentro de los que se encuentran nuestros intereses también son marco de las posibles historias causales de los sucesos. Esto no implica que cualquier explicación sea posible ni que la pregunta por la causa lleve a respuestas subjetivas; lo que implica es que las respuestas son parciales y provisionales, pero también adecuadas a nuestras necesidades explicativas: cuál sea el factor que aceptamos como causa de un suceso determinado depende de las condiciones que sean consideradas como las usuales dentro de un cierto contexto y esto es así porque en el efecto confluyen una multitud enorme de factores cuya enumeración es inagotable. 
Así, parece que somos regularistas de la explicación y singularistas de las causas: desde la perspectiva ontológica las causas son singulares y los eventos frágiles, pero desde la perspectiva epistémica tenemos que trabajar con leyes, probabilidades y tipologías de mecanismos. Los campos epistémico y ontológico no son separables del todo, pero se debe intentar una situación más precisa de los problemas y de las preguntas. Sirva lo anterior para afirmar, en otras palabras, que tanto la explicación como la causalidad están ligadas a los aspectos pragmáticos del contexto. La causa es una lícita inquietud ontológica ligada a la inquietud epistémica por su papel dentro de cierto tipo de explicaciones; lo que sería más conveniente es tener más en cuenta que pese a que sus miras apuntan en direcciones diferentes los conocimientos de los dos ámbitos pueden colaborar en la creación de una representación más fiel y completa de la realidad. No hay una posición preponderante del por quésobre el cómo, simplemente hay que intentar hacer claridad con respecto a la licitud de ambas preguntas y a sus propósitos divergentes: los mecanismos no sustituyen por completo a la historia causal. 


\section{BIBLIOGRAFÍA}

Álvarez, Sebastián (1998). La causalidad probabilista y las dificultades del enfoque humeano. Theoria, (V ol 13/3), pp. 521-542.

Álvarez Toledo, Sebastián (2014). Causation and the agent's point of view. Theoria, (79). San Sebastián: Universidad del País Vasco, pp.133-147.

Anscombe, G.E.M. (1993). Causality and D etermination. En Sosa y Tooley (Eds.), Causation (pp. 88-104), O xford: O xford University Press.

Aristóteles (1988). A nalítioss Segundos. Madrid: G redos

Aristóteles (1995). Física. Madrid: G redos.

A ristóteles (1998). M etafísica (2 ed.). Madrid: G redos.

Armstrong, D.M. (1993). A World of States of Affairs. Philosophical Perspectives, 7, p. 429-440.

Ávila, Roberto (2004). Un pedacito de tiniebla griega-Acerca del problema del movimiento en Zenón de Elea. Cuestiones de Filosofía, (6), pp. 49-66.

Beebee, Helen (2007). Hume on Causation: The Projectivist Interpretation. En H. Price \& R. Corry (Eds.), Causation, Physics, and the constitution of reality (pp. 224-249). Norfolk: O xford University Press.

Beebee, Helen; Hitchcock, Christopher, \& Menzies, Peter (Eds.) (2012). The 0 x ford H andbook of Causation. Oxford: Oxford University Press

Bergson, Henri (1959). E nsayo sobre los datos inmediatos de la conciencia. En 0 bras esogidas. México: Aguilar (trabajo original publicado en 1889).

Bertuglia, Sergio \& Vaio, Franco (2005). N onlinearity, Chaos \& Complexity. The D ynamics of N atural and Social Systems. New York: Oxford University Press.

Broadie, Sarah (2012). The Ancient G reeks. En H. Beebee et al. (Eds.), The 0 x ford H andbook of Causation (pp. 21-39). Oxford: O xford University Press.

Bunge, Mario. (1961). Causalidad: El principio de causalidad dela ciencia moderna. Buenos Aires: Eudeba. Carnap, Rudolf (1995). A n Introduction to the Philosophy of Scienœ. New York: D over. 
Carroll, John W. (2012) Anti-reductionism. En H. Beebee et al. (Eds.), The 0 x ford H andbook of Causation (pp. 279-298). O xford: Oxford University Press.

Cartwright, Nancy (1991). H ow the laws of Physics L ie. New York: Oxford University Press.

Cartwright, N. (1999). The D appled W orld. New York: Cambridge University Press.

Cartwright, Nancy (2000). An empiricist defense of singular causes. En R. Teichmann (Ed.), L ogic, Cause \& A ction (pp: 47-58). Cambridge: Cambridge University Press.

Cartwright, Nancy (2004). Causation: O ne Word, Many Things. Philosophy of Scienœ, V ol. 71, (5), pp. 805-820.

Cartwright, Nancy (2007). H unting causes and uses them. A pproaches in Philosophy and E onomics. Cambridge: Cambridge University Press.

Casini, Lorenzo (2012). Causation: Many Words, One Thing? Theoria, (74), pp. 203-219.

Chaparro, G raciela \& Ávila, Roberto (2005). La presencia del caos en un mundo determinista. Cuestiones de Filosofía, (7), pp. 58-68.

Clatterbaugh, Kenneth (2012). The early moderns. En H. Beebee et al. (E ds.), The O x ford H andbook of Causation (pp. 55-72). Oxford: Oxford University Press.

Cohen, S. Marc, (2015, otoño), "Aristotle's Metaphysics". The Stanford E ncyclopedia of Philosophy. Edward N. Zalta (ed.), URL = <http:/ / plato.stanford.edu/ archives/ fall2015/ entries/ aristotle-metaphysics/ > . Consultada 20/ 11/ 2015.

Cohen, Martin (2010). E l escarabajo de W ittgenstein. Madrid: Alianza Editorial.

Collingwood, R.G. (1940). An Essay on Metaphysics. Oxford: Clarendon Press.

De Pierris, Graciela \& Friedman, Michael (2013, diciembre) K ant and Hume on causality. The Stanford Encyclopedia of Philosophy. Edward N. Zalta (ed.), URL = <http:/ / plato.stanford.edu/ archives/ win2013/ entries/ kant-hume-causality/ > . Consultado 12/ $07 / 2015$.

Dicker, G eorge (2001). H ume's E pistemology and M etaphisics, A n introduction. Londres: Routledge.

D owe, Phil (2000). Physical causation. New York: Cambridge University Press.

D owe, Phil (2001, junio). A Counterfactual Theory of Prevention and 'Causation' by O mission. A ustralasian Journal of Philosophy. V ol. 79, (2), pp 216-226.

D owe, Phil, (2008). Causal Processes. The Stanford E ncydopedia of Philosophy (E dición de verano de 2008), Zalta, Edward N. (ed.), URL = <http:/ / plato.stanford.edu/ archives / fall2008/ entries/ causation-process/ >. Consultada 4/ 10/ 2011.

D owe, Phil (2012). Causal Process Theories. En H. Beebee et al. (Eds.), The Ox ford H andbook of Causation (pp. 213-233). Oxford: Oxford University Press. 
D ucasse, Curt John. (1924, febrero) Causation and the types of necessity. U niversity of Washington Publications in the Social Scienoes V ol. $1 \mathrm{~N}^{\circ}$ 2, pp. 69-200.

D ucasse, Curt John (1968). Truth, Knowledge and Causation. London, Routledge.

D ucasse, Curt John (1993). On the Nature and the O bservability of the Causal Relation. En E. Sosa \& M. Tooley (Eds.), Causation (pp. 125-136). Oxford: Oxford University Press.

Duque, Felix (2005). E studio preliminar. En D. Hume, Tratado de la naturaleza humana. (4 ed.). Madrid: Tecnos.

Eagle, Antony (2007). Pragmatic Causation. En Price \& Corry (Eds.), Causation, Physics, and the Constitution of Reality. Norfolk: Oxford University Press, pp. 156-190.

Ehring, D ouglas (2012). Causal relata. En H. Beebee et al. (Eds.). The Ox ford $\mathrm{H}$ andbook of Causation (pp. 387-413). Oxford: Oxford University Press.

Einstein, Albert (2011). Mis ideas y opiniones. Barcelona: Bosch.

Elga, Adam (2007). Isolation and Folk Physics. En H. Price \& R. Corry (Eds.), Causation, Physic, and the constitution of reality (pp. 106-119). Norfolk: Oxford University Press.

García-Encinas, María José (1998). Análisis de la causalidad desde una aproximación singularista. Memoria para optar al grado de D octor en Filosofía. Universidad del País Vasco. San Sebastián.

García-Encinas, María José (2004). Transference, or identity theories of causation. Theoría 49, pp. 31-47.

García-Encinas, María José (2011). Singular Causation without D ispositions. Theoría 70 , pp. 3550.

Gasking, D ouglas (1955, octubre). Causation and recipes. M ind, V ol 64, 256, pp. 479-487.

G odfrey-Smith, Peter (2012). Causal Pluralism. En H. Beebee et al. (Eds.), The 0 x ford H andbook of Causation (pp. 326-337). Oxford: Oxford University Press.

G onzález, Wenceslao J. (Coord.) (2002). D iversidad de la ex plicación científica. Barcelona: Ariel.

González, Wenceslao J. (2003). From E rk lären-V erstehen to Prediction-U nderstanding: The Methodological Framework in Economics. En M. Sintonen, P. Ylikoski \& K. Miller(Eds.), Realism in A ction: E ssays in the Philosophy of Social Sciences, D ordrecht, pp. 33-50.

González, Wenceslao J. (2010). L a predioción científica: Concepciones filosófico-metodológicas desde H . Reichenbach a N . Rescher. Barcelona: Montesinos.

Harré, Rom (1986). G randes ex perimentos científicos. Barcelona: Labor.

Hempel, Carl G. \& O ppenheim, Paul (1948, abril). Studies in the Logic of Explanation. Philosophy of Scienœ, V ol. 15, (2), pp. 135-175. 
Hempel, Carl G. (2005). L a ex plicación científica-E studios sobrehistoria dela filosofía dela ciencia. Barcelona: Paidós. (Trabajo original publicado en 1965).

Hitchcock, Christopher (1995, junio). Discussion: Salmon on explanatory relevance. Philosophy of science. $\mathrm{V}$ ol. 62 , (2), pp. 304-320

Hitchcock, Christopher (1997). Probabilistic Causation. En: http:/ / plato.stanford.edu/ entries/ causation-probabilistic/ \#Pot. Publicado en Jul 11, 1997; revisado en Sep 6, 2002. Consultado 7/ 09/ 2009.

Hitchcock, Christopher (2003). Of Humean Bondage. British Journal for the Philosophy of Science, (54), pp 1-25.

Hitchcock, Chistopher (2007). What Russell G ot Right. En H. Price \& R. Corry (Eds.). Causation, Physics, and the constitution of reality (pp. 45-65). Norfolk: Oxford University Press.

Hocutt, Max. (1974, octubre). Aristotle’s Fuor Becauses. Philosophy, V olume 49 (190), pp 385-399.

Hoefer, Carl (2012). Causation in Spacetime Theories. En H. Beebee et al. (Eds.), The 0 xford $\mathrm{H}$ andbook of Causation (pp. 687-706). Oxford: Oxford University Press.

Hull, L.W.H. (2011). H istoria y filosofía de la ciencia. Barcelona: Crítica. (Trabajo original publicado en 1959).

Hume, D avid (1896). A Treatise of H uman N ature. Oxford Clarendon Press (Trabajo original publicado en 1739).

Hume, D avid (2004). Investigación sobre el entendimiento humano. (Sanfélix, Vicente y O rs, Carmen, traductores. Edición bilingüe.). Madrid: Istmo. (Trabajo original publicado en 1748).

Humphreys, Paul (1981, agosto). Aleatory explanations. Synthese, 48, pp. 225-232.

Kant, M. (1982). Crítica de la razón pura. México: Porrúa, (Trabajo original publicado en 1781).

Kim, Jaegwon (1993). Causes and Events: Mackie on Causation. En E. Sosa \& M. Tooley (Eds.), Causation (pp. 60-74). Oxford: Oxford University Press.

Kincaid, Harold. (2012). Causation in the Social Sciences. En H. Beebee et al. (Eds.), The $0 \mathrm{x}$ ford H andbook of Causation (pp. 726-743). Oxford: Oxford University Press.

Kutach, D ouglas (2007). The Physical Foundations of Causation. En H. Price \& R. Corry (Eds.), Causacion, Physics, and the constitution of reality (pp. 327-350). Norfolk: Oxford University Press.

Lewis, D avid. (1986). Philosophical Papers, vol. II. O xford: Oxford University Press.

Lewis, D avid (1993). Causation. En E. Sosa \& M. Tooley (Eds.), Causation (pp. 193-204).Oxford: Oxford University Press.

Lipton, Peter (2012). Causation and E x planation. En H. Beebee et al. (Eds.), The 0 x ford H andbook of Causation (pp. 619.631). Oxford: Oxford University Press. 
Losee, John (2011). Theories of Causality-From A ntiquity to the Present. New Jersey: Transaction Publishers.

Mackie, John L. (1993). Causes and Conditions. En E. Sosa. \& M. Tooley (Eds.), Causation (pp. 33-55). Oxford: Oxford University Press.

Mackie, John L. (1999). TheC ement of theU niverse. A study of Causation. New York: Oxford University Press.

McG rath, Sarah (2005). “Causation by omission: A dilemma”. Philosophical Studies, (123), pp. 125-148.

Menzies (1989). A unified account of causal relata. A ustralasian Journal of Philosophy, (67:1), pp. 59-83.

Menzies, Peter (2012). Platitudes and Counterexamples. En H. Beebee et al. (Eds.), The 0x ford H andbook of Causation (pp. 341-367). O xford: O xford University Press.

Mill, John Stuart (1973). A System of L ogic. Toronto: Robson. (Trabajo original publicado en 1865).

Miller, D avid (Comp.) (1995). Popper-E scritos selectos. Mexico: Fondo de Cultura Económica.

Nagel, Ernest (1974). L a estructura de la ciencia (2 Ed.). Barcelona: Paidós.

Norton, John D. (2007). Causation as Folk Science. En H. Price y R. Corry (Eds.), Causation, Physics, and the constitution of reality. (pp. 11-44). Norfolk: Oxford University Press.

O kasha, Samir (2012). Causation in Biology. En H. Beebee et al. (Eds.). The Ox ford H andbook of Causation (pp. 707-725). Oxford: Oxford University Press.

O wens, D avid (1992). Causes and C oincidences. Cambridge: Cambridge University Press

Paul, L.A. (2012). Counterfactual Theories. En H. Beebee et al. (Eds.). The $0 \mathrm{x}$ ford H andbook of Causation (pp. 158-184). Oxford: Oxford University Press.

Pinker, Steven (2007). E l mundo de las palabras: U na introducción a la naturaleza humana. Barcelona: Paidós.

Popper, Karl R. (1994). E 1 U niverso abierto-U n argumento a favor del indeterminismo (2 ${ }^{\mathrm{a}}$ ed). Madrid: Tecnos.

Popper, Karl R. (1995). El problema de la inducción (1953, 1974). En D. Miller (Comp.), PopperE scritos selectos. México: Fondo de Cultura E conómica.

Price, Huw y Corry, Richard (Eds.) (2007). Causation, Physics, and the constitution of reality. Russell's Republic Revisited. Norfolk: Oxford University Press.

Psillos, Stathis (2002). Causation and ex planation. Montreal: McG ill-Queen University Press.

Psillos, Stathis (2007). Past and Contemporary Perspectives on Explanation. En T. Kuipers (Ed.), $\mathrm{H}$ andbook of the Philosophy of ScienceFocal Issues (pp. 97-173). Amsterdam: Elsevier. 
Psillos, Stathis (2008, enero). Causal Pluralism. En: http:/ / users.uoa.gr/ psillos/ PapersI/ 26Causal\%20Pluralism.pdf. Consultado 17/ 04/ 2013.

Psillos, Stathis (2012). Regularity Theories. En H. Beebee et al. (Eds.). The Ox ford H andbook of Causation (pp. 131-157). Oxford: Oxford University Press.

Rescher, Nicholas (1998). Predicting the futureA n Introduction to the Theory of Forecasting. Albany: State University of New York.

Riedl, Rupert (1983). Biología del conocimiento-L os fundamentos filogenéticos dela razón. Barcelona: Labor.

Russell, Bertrand (1953). On the Notion of Cause, with Applications to the Free-Will Problem. En H. Feigl y M. Brodbeck (Eds.), Readings in the Philosophy of Science, (pp. 387-407). New York: Appleton-Century-Crofts. (Trabajo original publicado en 1912).

Russell, Bertrand (2009). H uman Knowledge, Londres: Routledge. (Trabajo original publicado en 1948).

Salmon, Wesley C. (1984). Scientific E x planation and the Causal Structure of the W orld. New Jersey: Princeton University Press.

Salmon, Wesley C. (1993). Probabilistic Causality. En E. Sosa y M. Tooley (Eds.). Causation. (pp. 137-153). Oxford: Oxford University Press

Salmon, Wesley C. (Ed.) (2001). Z eno's Paradox es. Indianapolis: Hackett Publishing Company.

Salmon, Wesley C. (2002). Explicación causal frente a no causal. En González, Wenceslao J. (Coord.) D iversidad de la ex plicación científica. Barcelona: Ariel.

Salmon, Wesley C. (2006). Four decades of ScientificE x planation. Pittsburgh: University of Pittsburgh Press. (Trabajo original publicado en 1989)

Salmon, W. y Kitcher, P. (Eds.) (1989). M innesota Studies in the Philosophy of Scienœ. Vol. XIII, Scientific E x planation. Minneapolis: University of Minnesota Press.

Sartorio, Carolina (2012). Causation and E thics. En H. Beebee et al. (Eds.), The 0 x ford H andbook of Causation (pp. 575-591). Oxford: Oxford University Press.

Schaffer, J. (2000). Causation and Laws of Nature: Reductionism. En T. Sider et al. (Eds.), Contemporary D ebates in M etaphysics. Oxford: Blackwell.

Sklar, Lawrence (2012). Causation in Statistical Mechanics. En Beebee et al. (Eds.). The 0x ford H andbook of Causation (pp. 661-672). Oxford: Oxford University Press.

Stapleton, Jane (2012). Causation in the Law. En H. Beebee, et al. (Eds.). The $0 \mathrm{x}$ ford H andbook of Causation (pp. 744-769). Oxford: O xford University Press, pp. 744-769.

Sosa, Ernst \& Tooley, Michael (Eds.) (1993). Causation. Oxford: Oxford University Press.

Suppes, Patrick (1970). A Probabilistic Theory of Causality. Helsinki: North-Holland Publishing Company. 
Tooley, Michael. (1987). Causation: A realist approach. Oxford: Clarendom Press.

van Fraassen, Bas (1996). L a imagen científic. México: Paidós.

von Wright, G eorg Henrik (1971). E x planation and understanding. London: Routledge \& Kegan Paul.

von Wright, Georg Henrik (1974). Causality and D eterminism. New York: Columbia University Press.

Williamson, Jon (2012). Probabilistic Theories. En H. Beebee, et al. (Eds.). The $0 \mathrm{x}$ ford H andbook of Causation (pp. 185-212). Oxford: Oxford University Press.

Woodward, James (2003). Making Things H appen. A Theory of Causal Explanation. New York: Oxford University Press.

Woodward, James (2007). Causation with a Human Face. En H. Price \& R. Corry (Eds.). Causacion, Physics, and the constitution of reality. Norfolk: Oxford University Press, pp. 66-105. 